\title{
Propiedades Físico-Mecánicas y Durables de Hormigones Reciclados
}

Claudio Javier ZEGA

Tesis presentada para el grado de

DOCTOR EN INGENIERÍA

Área Departamental Construcciones, Facultad de Ingeniería, U.N.L.P.

septiembre, 2010. 

Universidad Nacional de La Plata

Facultad de Ingeniería

\section{Propiedades Físico-Mecánicas y Durables de Hormigones Reciclados}

Claudio Javier ZEGA

Director: Ing. Ángel A. Di Maio

Co-Director: Dr. Ing. Raúl L. Zerbino

Tesis presentada para el grado de

DOCTOR EN INGENIERÍA

Área Departamental Construcciones, Facultad de Ingeniería, U.N.L.P.

septiembre, 2010. 



\section{Agradecimientos}

Quiero expresar mi más sincero agradecimiento al Ing. Ángel Di Maio, por la colaboración brindada durante la realización de las investigaciones, y por su dedicación en la dirección del presente trabajo. También quiero agradecer al Dr. Ing. Raúl Zerbino, por la dedicación en la co-dirección y por el aporte realizado al trabajo de tesis.

Al Ing. Luis Traversa, director del LEMIT (Laboratorio de Entrenamiento Multidisciplinario para la Investigación Tecnológica), por permitir la realización de los trabajos experimentales en dicho laboratorio.

A los compañeros del LEMIT, por la colaboración brindada de manera desinteresada en la realización de los ensayos y por el aporte realizado a la interpretación de algunos resultados obtenidos, los cuales contribuyeron al desarrollo de la tesis.

También quiero manifestar mi reconocimiento al personal del LEMIT, particularmente al del Área Tecnología del Hormigón, por la colaboración brindada durante la realización de las experiencias.

Por último, quiero agradecer muy especialmente a quien fue uno de los pilares de sustento al momento de encarar este desafío, Luciana, por su comprensión, compañía y apoyo incondicionales, que hicieron más amena la realización de este proyecto. 



\section{Resumen}

El reciclado de los residuos de construcción y demolición para ser empleados en la producción de hormigones, principalmente aquellos que provienen de la trituración de hormigones de desecho, se ha convertido en una alternativa de gran importancia respecto a la disminución de la contaminación ambiental, permitiendo además una reducción en la explotación de recursos naturales no renovales.

Las propiedades que presentan los agregados reciclados se ven modificadas con relación a las que poseen los agregados naturales de densidad normal, principalmente su porosidad, densidad y resistencia. Estas diferencias son atribuidas al mortero de cemento que se encuentra adherido a las partículas de agregado natural, o bien constituyendo una partícula por sí mismo. Respecto al comportamiento resistente, los hormigones reciclados pueden presentar resistencias similares a las del hormigón de origen, dependiendo de la calidad y porcentaje de agregado reciclado utilizado. Sin embargo, el desempeño durable que presentan los hormigones reciclados podrá variar en función de las características de los hormigones, del porcentaje de agregado reciclado utilizado y de las condiciones a las cuales son expuestos.

El objetivo principal del presente trabajo de Tesis consiste en determinar la influencia que tiene el nivel de resistencia y el tipo de agregado grueso natural (AGN) del hormigón de origen sobre las propiedades de los agregados gruesos reciclados (AGR). A tal fin, se elaboraron hormigones de razones a/c 0,45 y 0,65 empleando AGN de uso habitual en diferentes regiones del país, tales como piedra partida granítica, cuarcítica y basáltica, y canto rodado silíceo. Los AGR se obtuvieron de la trituración de dichos hormigones, analizándose diferentes propiedades físico-mecánicas de los mismos, como granulometría, densidad, absorción, desgaste "Los Ángeles", pasa tamiz de $75 \mu \mathrm{m}$, peso por unidad de volumen, porcentaje de vacíos, índices de lajosidad y elongación, y contenido de mortero, comparativamente con las correspondientes a los AGN.

El comportamiento mecánico de los hormigones elaborados con 25 y 75 \% de AGR se compara con el de los hormigones con $100 \%$ de AGN. Para ello se realizaron evaluaciones de las resistencias a compresión, tracción por compresión diametral y módulo de rotura en flexión, determinándose también el módulo de elasticidad estático. Además, se realizaron valoraciones con ensayos semi-destructivos (Break-Off) y no destructivos 
(ultrasonido y frecuencia de resonancia) a fin de determinar las posibles modificaciones que pueden producirse debido a las características que poseen los AGR.

Con el fin de adquirir un mayor conocimiento sobre la durabilidad de los hormigones reciclados, se analizan distintas propiedades de transporte comparándolas con las de hormigones de igual nivel resistente elaborados con agregados naturales. Se realizaron determinaciones de absorción de agua por inmersión, succión capilar, penetración de agua a presión y difusión de cloruro en inmersión. Además, se presentan los resultados obtenidos en experiencias de campo sobre hormigones expuestos en suelo con sulfato.

De los resultados obtenidos surge que el tipo de AGN del hormigón de origen puede tener mayor influencia que la razón a/c sobre algunas propiedades de los AGR, como la densidad, la absorción de agua, la resistencia a la abrasión y el contenido de mortero.

En cuanto a la resistencia a compresión, en los hormigones con $75 \%$ de AGR se alcanzaron los mismos niveles resistentes que en los hormigones originales, mientras que en los elaborados con $25 \%$ de AGR la resistencia se incrementó en aproximadamente $15 \%$.

Con relación al comportamiento durable, en los hormigones con $75 \%$ de AGR de granito y basalto los parámetros de transporte por capilaridad y permeabilidad duplican a los determinados en los hormigones originales, mientras que en los elaborados con $25 \%$ de AGR de canto rodado se produce una disminución del orden del $25 \%$. Respecto a la difusión de cloruro, los hormigones con AGR de cuarcita y canto rodado muestran una mayor capacidad de retención de cloruro con relación a los hormigones originales, la cual se incrementa con el contenido de AGR.

En base a los resultados obtenidos surge que, al igual que lo que sucede en los hormigones convencionales, la razón a/c es el principal factor que condiciona el desempeño durable de los hormigones reciclados, debiéndose considerar en segundo término el tipo de AGN empleado. Al incrementarse la razón a/c, el tipo y porcentaje de AGR utilizado se constituye en un factor de mayor importancia. 


\begin{abstract}
The recycling of construction and demolition waste in concrete production, particularly the obtained from the crushing of waste concrete, is an important alternative from ecological point of view. This fact is related to less quantity of waste materials and with a decrease in the use of non-renewable natural resources.

The properties of the recycled aggregates are different from those of natural aggregates, mainly their porosity, density, and strength. These differences are attributed to the cement mortar that remains attached to the natural aggregate particles or being a particle itself. Regarding the resistance behaviour, recycled concretes can have strengths similar to that of the original concrete, depending on the recycled aggregate quality and the percentage of employment. However, durable performance of recycled concrete may vary depending on the characteristics of the concretes, the percentage of recycled aggregate used, and the conditions to which they are exposed.
\end{abstract}

The main objective of this Thesis is to determine the influence of strength level and type of natural coarse aggregate (NCA), in the original concrete, on the properties of recycled coarse aggregate (RCA). Concretes of water/cement ratio of 0.45 and 0.65 were made with different NCA (granite, quartzite, and basalt crushed stone, and siliceous gravel). The RCA were obtained from the crushing of concretes. Different properties of RCA, such as sieve analysis, specific gravity, water absorption, abrasion resistance, material finer than $75 \mu \mathrm{m}$, unit weigh, voids, flakiness index, and mortar content, were determined and compared to those of the NCA.

The mechanical behaviour of concretes made with 25 and $75 \%$ of RCA are compared to those of the concretes made with $100 \%$ of NCA. The compressive strength, splitting tensile strength, flexural strength, and static modulus of elasticity of recycled were determined. Also, semi-destructive (Break-Off) and non-destructive (ultrasound and resonant frequency) tests were applied.

In order to have greater knowledge about the durability of recycled concrete, transport properties of concretes made with 25 and $75 \%$ of RCA are compared to those of concretes with the same strength level made with $100 \%$ of NCA. The water absorption, capillarity water absorption, water penetration under pressure, and chloride diffusion 
tests were carried out. Also, the results obtained from field experience on concretes exposed to sulphate soils are presented.

According to the obtained results, the NCA in original concrete may have greater influence than the water/cement ratio on some RCA properties, such as specific gravity, water absorption, abrasion resistance, and mortar content.

In respect to the compressive strength, concretes made with $75 \%$ of RCA present the same strength levels that those of original concretes, while concretes made with $25 \%$ of RCA present strength levels $15 \%$ higher.

With respect to the durable behaviour, the capillarity and permeability transport parameters of concrete made with $75 \%$ of RCA of granite and basalt were twice those obtained in the original concretes, while these parameters of concrete with $25 \%$ of RCA of siliceous gravel were $25 \%$ lower. On the chloride diffusion test, the concretes made with RCA of quartzite and siliceous gravel present higher binding capacity than original concretes, which increases with the RCA content.

According to the obtained results, it appears that, like what happens in conventional concretes, the water/cement ratio is the main factor influencing the durable behaviour of recycled concretes, and the type of NCA used should be considered secondarily. By increasing the $\mathrm{w} / \mathrm{c}$ ratio, type and percentage of RCA used becomes more important. 


\section{Índice}

Agradecimientos

Resumen

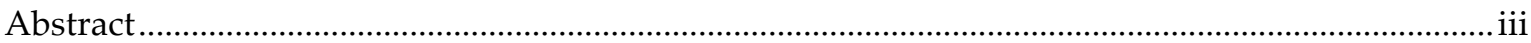

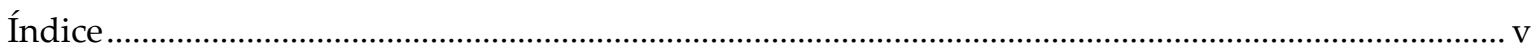

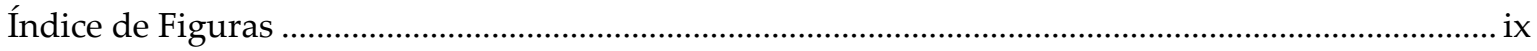

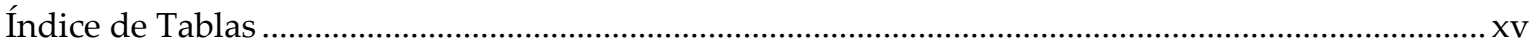

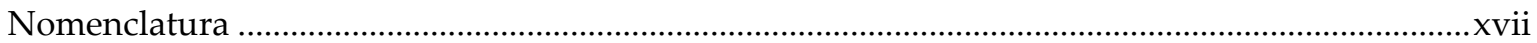

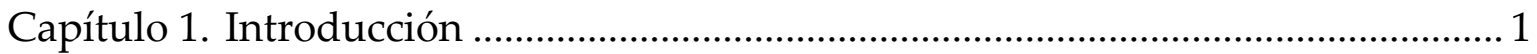

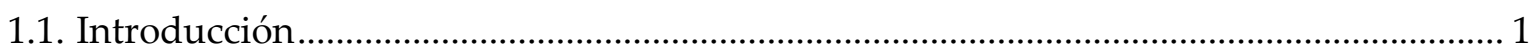

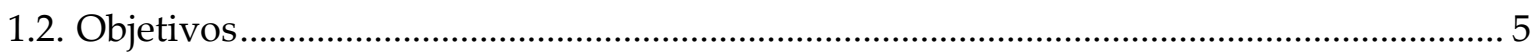

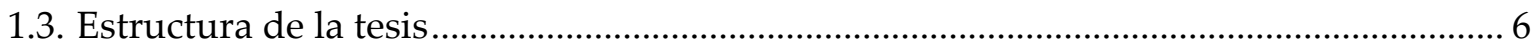

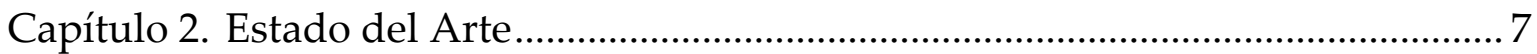

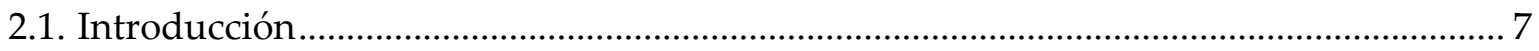

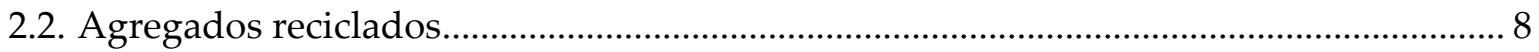

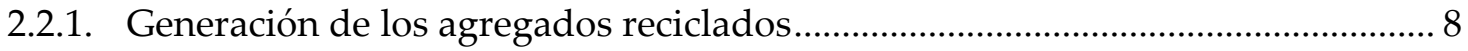

2.2.2. Composición y características visuales................................................................... 11

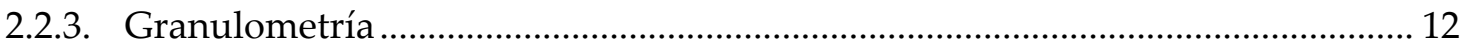

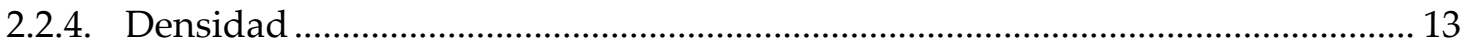

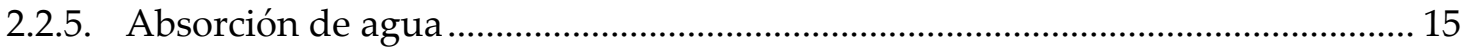

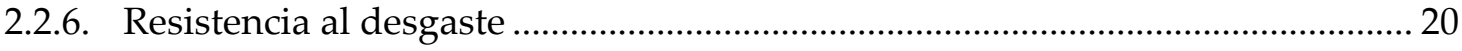

2.2.7. Contenido de mortero adherido a los agregados.................................................. 23

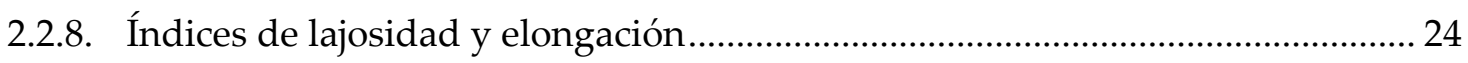

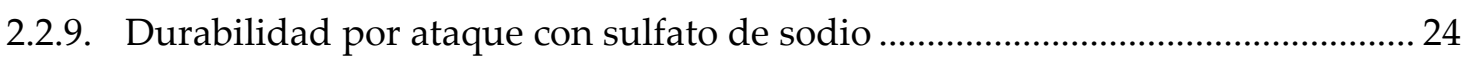

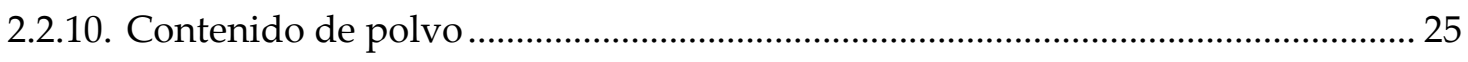

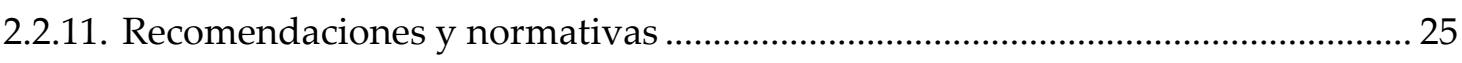

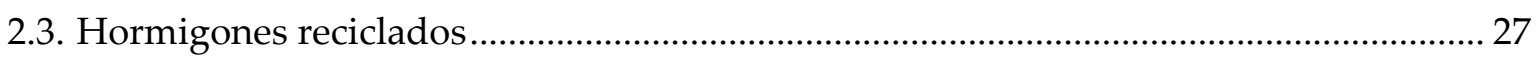

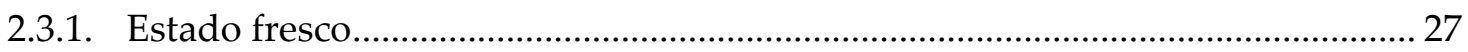

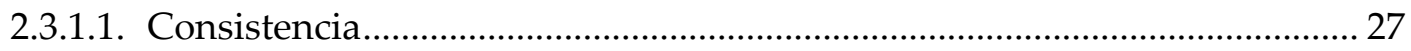

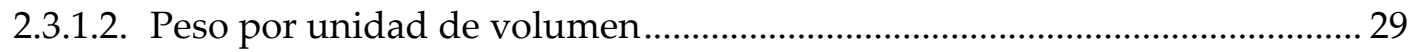

2.3.1.3. Aire naturalmente incorporado....................................................................... 29

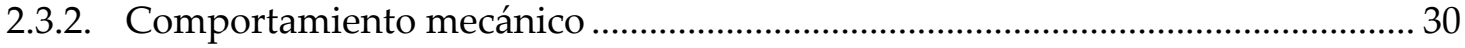

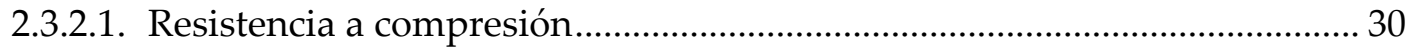

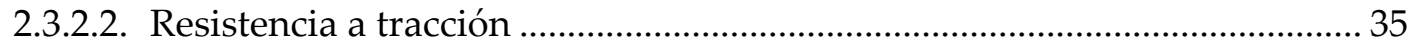

2.3.2.3. Módulo de elasticidad estático ........................................................................ 36

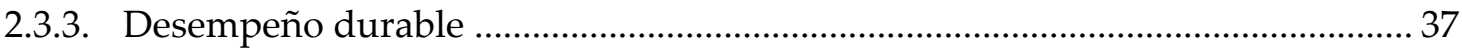

2.3.3.1. Absorción de agua............................................................................................... 37 
2.3.3.2. Permeabilidad al aire

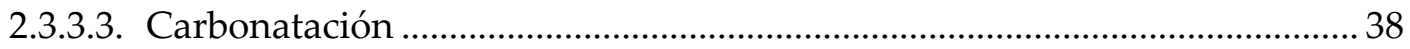

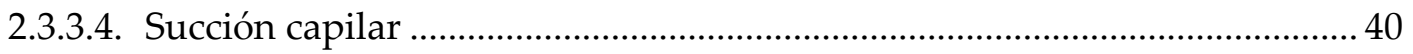

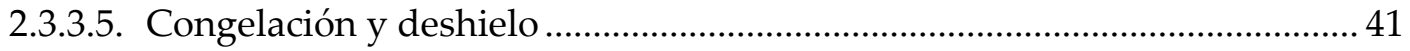

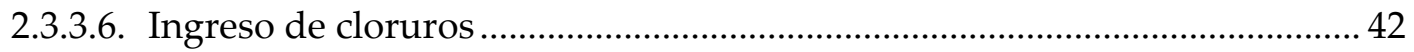

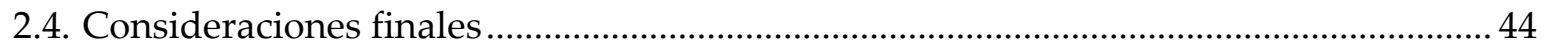

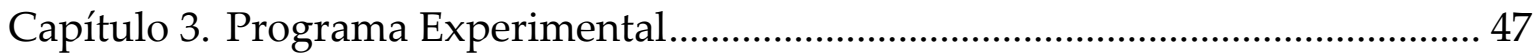

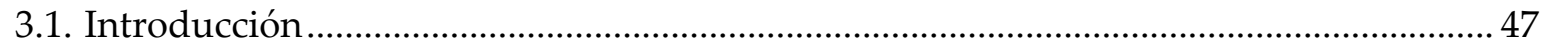

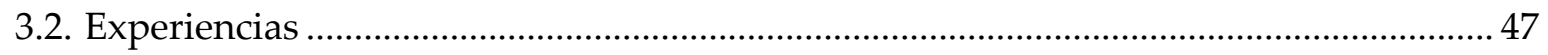

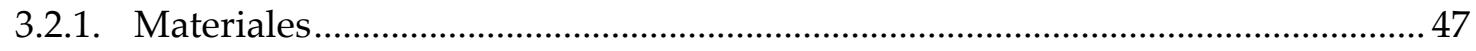

3.2.1.1. Agregados gruesos naturales.......................................................................... 47

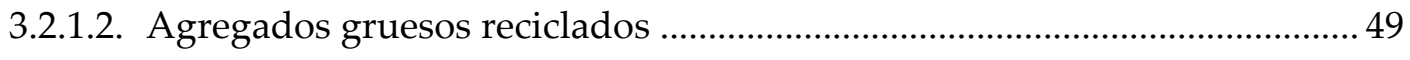

3.2.1.3. Otros materiales componentes..................................................................... 51

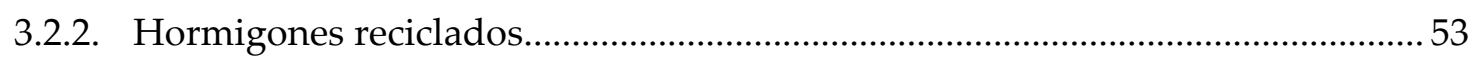

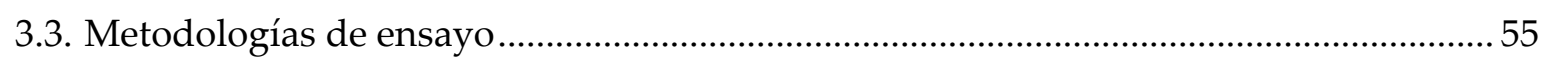

3.3.1. Evaluación de los agregados gruesos naturales .................................................. 55

3.3.2. Evaluación de los agregados gruesos reciclados.................................................... 57

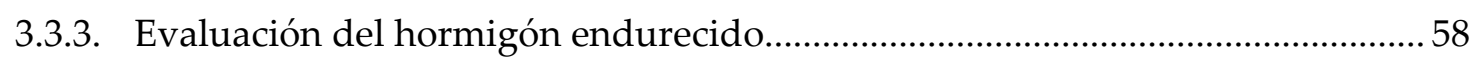

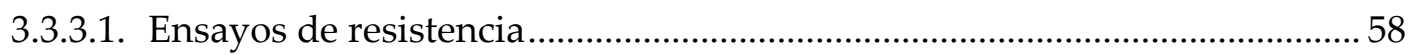

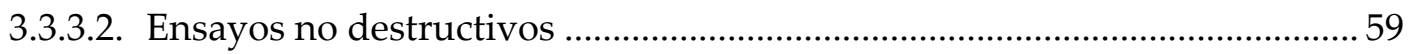

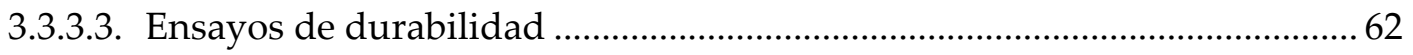

Capítulo 4. Caracterización de Agregados Gruesos Reciclados ............................... 71

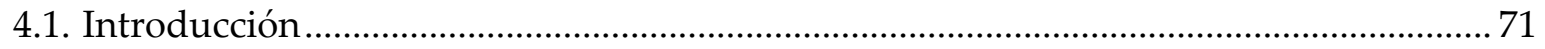

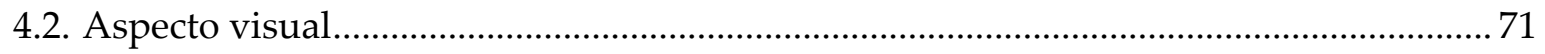

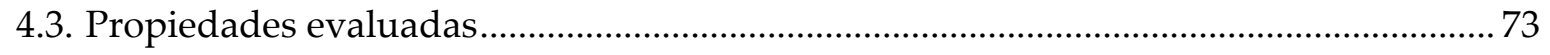

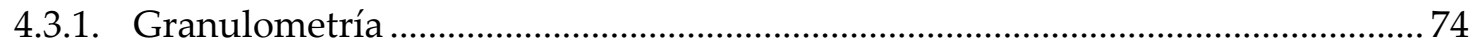

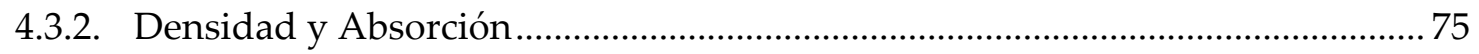

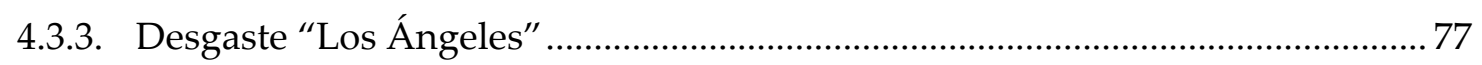

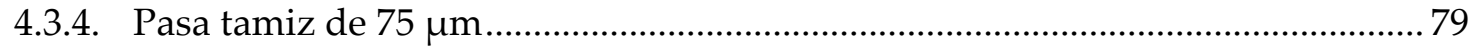

4.3.5. Peso por unidad de volumen y porcentaje de vacíos ............................................ 80

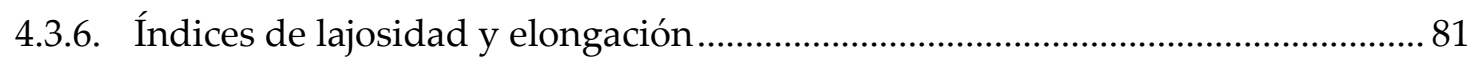

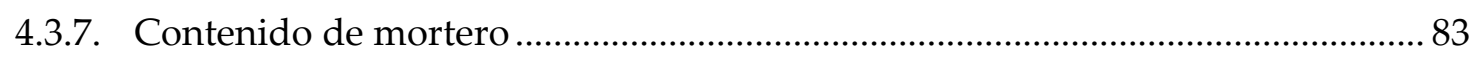

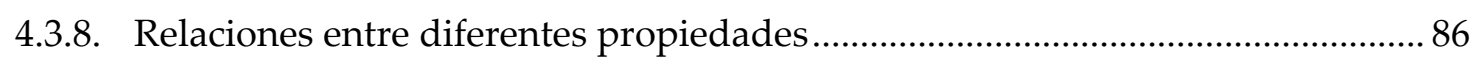

4.4. Conclusiones sobre las propiedades de los agregados gruesos reciclados..................... 88 


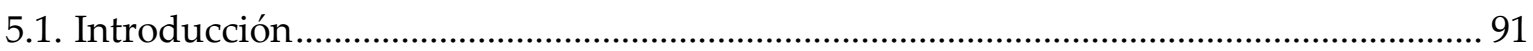

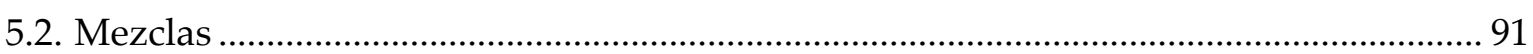

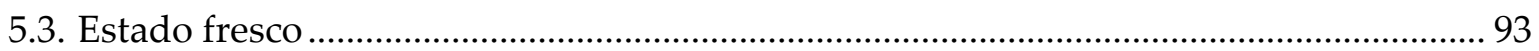

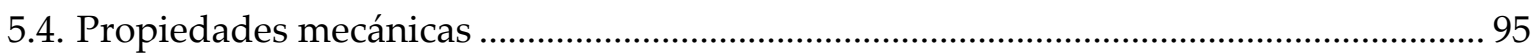

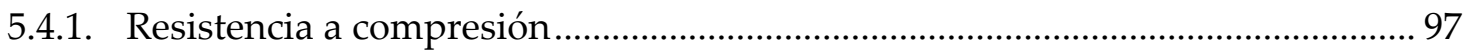

5.4.2. Resistencia a tracción por compresión diametral.................................................. 100

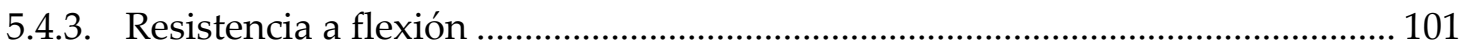

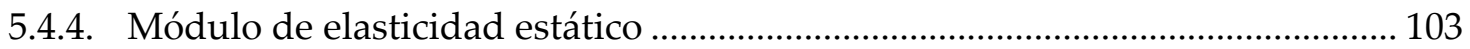

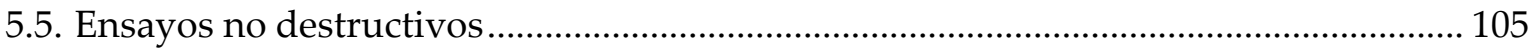

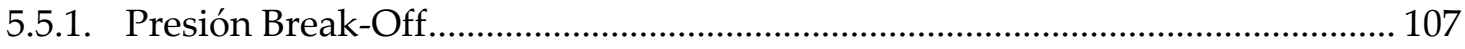

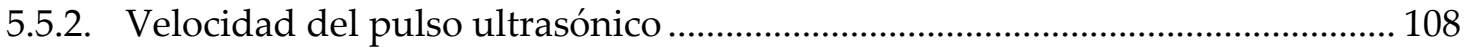

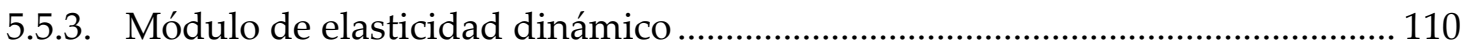

5.6. Relaciones entre parámetros mecánicos y END ........................................................... 112

5.7. Conclusiones sobre el comportamiento mecánico de los hormigones reciclados ...... 117

Capítulo 6. Durabilidad de Hormigones Reciclados ............................................... 121

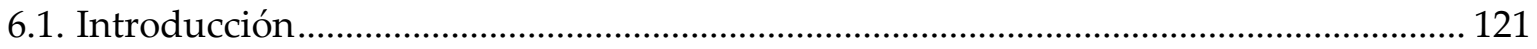

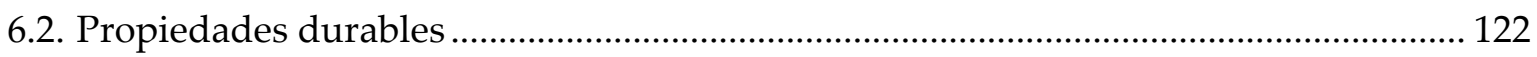

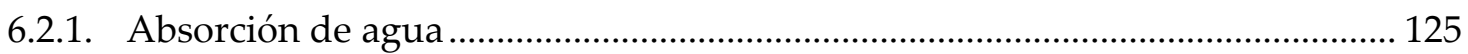

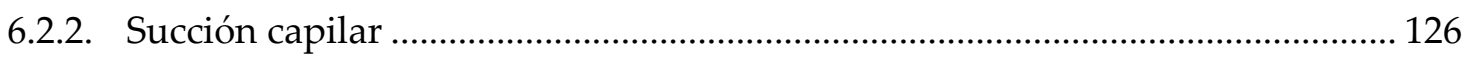

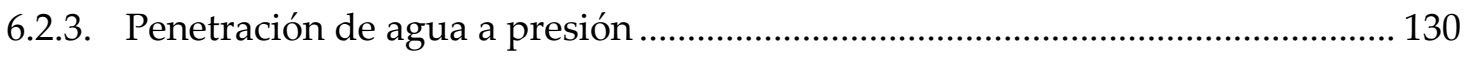

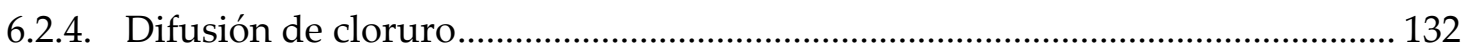

6.3. Relaciones entre la absorción de agua de los agregados y parámetros durables ........ 140

6.4. Relaciones entre la resistencia a compresión y parámetros durables............................ 143

6.5. Conclusiones sobre la durabilidad de los hormigones reciclados ................................. 147

6.6. Experiencia de campo: exposición en suelo con sulfato .................................................. 148

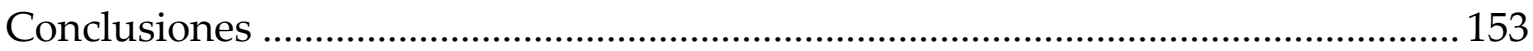

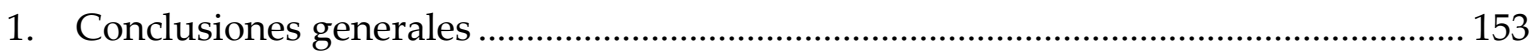

a) Propiedades de los agregados gruesos reciclados .................................................... 153

b) Comportamiento mecánico de los hormigones reciclados ........................................ 154

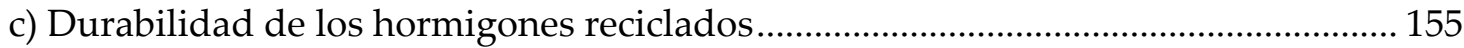

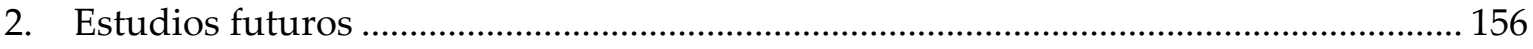

Referencias Bibliográficas................................................................................. 159 


\section{Índice de Figuras}

Figura 2.1. Esquema de funcionamiento de una planta de producción de agregados reciclados mediante sistema abierto.

Figura 2.2. Esquema de funcionamiento de una planta de producción de agregados reciclados mediante sistema cerrado.

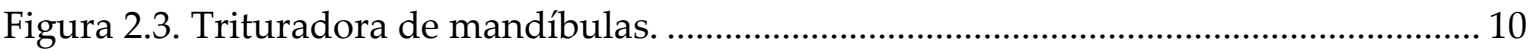

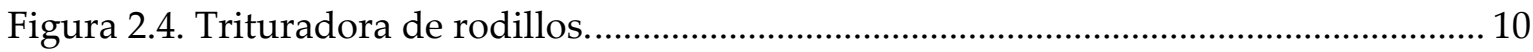

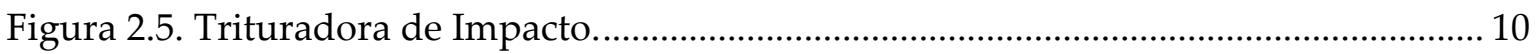

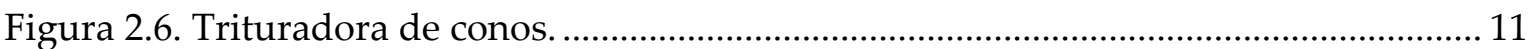

Figura 2.7. Características de las partículas que componen el AGR...................................... 12

Figura 2.8. Variación de la resistencia a compresión con la razón a/c para hormigones reciclados y convencionales. …………………....................................................... 33

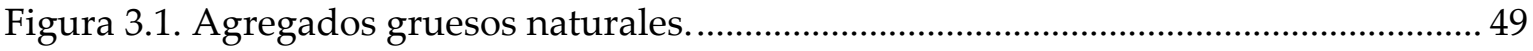

Figura 3.2. Trituradoras de mandíbulas utilizadas para generar los AGR........................... 50

Figura 3.3. Procedimiento para la generación del agregado reciclado................................... 50

Figura 3.4. Granulometrías de las arenas naturales. ............................................................... 52

Figura 3.5. Granulometría de los agregados gruesos naturales.............................................. 56

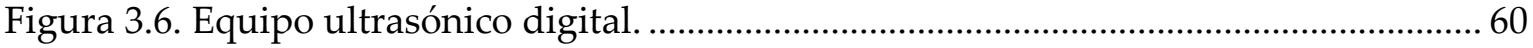

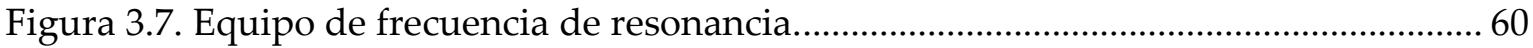

Figura 3.8. Molde plástico y broca diamantada para generar los testigos del ensayo

Break-Off

Figura 3.9. Testigo y base de apoyo de la celda de carga del ensayo Break-Off. 61

Figura 3.10. Celda de carga, válvula de presión y manómetro del equipo Break-Off. 62

Figura 3.11. Probeta para el ensayo de succión capilar. 63

Figura 3.12. Esquema del ensayo de succión capilar. 64

Figura 3.13. Curvas individuales, promedio y curvas límite obtenidas en el ensayo de succión capilar.

Figura 3.14. Gráfico de velocidad de succión capilar. 65

Figura 3.15. Equipo para evaluar la penetración de agua a presión. 66 
Figura 3.16. Perfil de penetración marcado sobre cada mitad de una probeta. .66

Figura 3.17. Esquema de la probeta y determinación del perfil de cloruros. .68

Figura 3.18. Ubicación de las probetas en el campo experimental.

Figura 4.1. AGR obtenido de un hormigón con: a) granito; b) cuarcita; c) basalto; d) canto rodado silíceo.

Figura 4.2. Partícula de AGR obtenido de un hormigón con: a) cuarcita; b) canto rodado silíceo. .73

Figura 4.3. Curvas granulométricas de los agregados gruesos reciclados. 75

Figura 4.4. Densidad de los agregados gruesos naturales y reciclados. 75

Figura 4.5. Absorción de los agregados gruesos naturales y reciclados................................ 77

Figura 4.6. Desgaste “Los Ángeles” de los agregados gruesos naturales y reciclados........ 78

Figura 4.7. Desgaste de los AGR relativos a los del AGN. 79

Figura 4.8. Pasa tamiz de $75 \mu \mathrm{m}$ de los agregados gruesos naturales y reciclados. 79

Figura 4.9. PUVs de los agregados gruesos naturales y reciclados. 80

Figura 4.10. Porcentaje de vacíos de los agregados gruesos naturales y reciclados. 81

Figura 4.11. Índice de lajosidad de los agregados gruesos naturales y reciclados. .82

Figura 4.12. Índice de elongación de los agregados gruesos naturales y reciclados. 83

Figura 4.13. Contenido de mortero de los agregados gruesos reciclados. 83

Figura 4.14. Gradación de los agregados naturales luego del ataque ácido realizado sobre los AGR: a) Granito; b) Cuarcita; c) Basalto; d) Rodado silíceo. 85

Figura 4.15. Relación absorción-densidad para los AGN y AGR. .86

Figura 5.1. Resistencia a compresión relativa de hormigones de razón a/c 0,45. .97

Figura 5.2. Resistencia a compresión relativa de hormigones de razón a/c 0,65. 98

Figura 5.3. Interfaces AGN-mortero. .99

Figura 5.4. Interfaz mortero viejo-mortero nuevo. 100

Figura 5.5. Resistencia a tracción por compresión diametral relativa de hormigones de razón a/c 0,45. 101 
Figura 5.6. Resistencia a tracción por compresión diametral relativa de hormigones de razón a/c 0,65. 101

Figura 5.7. Módulo de rotura relativo de hormigones de razón a/c 0,45. 102

Figura 5.8. Módulo de rotura relativo de hormigones de razón a/c 0,65. 102

Figura 5.9. Módulo de elasticidad estático relativo de hormigones de razón a/c 0,45..... 103

Figura 5.10. Módulo de elasticidad estático relativo de hormigones de razón a/c 0,65... 104

Figura 5.11. Módulo de elasticidad estático de hormigones de razón a/c 0,45 105

Figura 5.12. Módulos de elasticidad estático de hormigones de razón a/c 0,65. 105

Figura 5.13. Presión Break-Off relativa de hormigones de razón a/c 0,45. 107

Figura 5.14. Presión Break-Off relativa de hormigones de razón a/c 0,65. 108

Figura 5.15. Velocidad del pulso ultrasónico relativa de hormigones de razón a/c 0,45. 108

Figura 5.16. Velocidad del pulso ultrasónico relativa de hormigones de razón a/c 0,65. . 109

Figura 5.17. Velocidad ultrasónica vs. densidad de los hormigones.

Figura 5.18. Módulo de elasticidad dinámico relativo de hormigones de razón a/c 0,45. 110

Figura 5.19. Módulo de elasticidad dinámico relativo de hormigones de razón a/c 0,65. 111

Figura 5.20. Módulo de elasticidad dinámico vs. densidad de los hormigones.

Figura 5.21. Relación entre la resistencia a tracción por compresión diametral y la resistencia a compresión. 112

Figura 5.22. Relación entre el módulo de rotura a flexión y la resistencia a compresión. 113

Figura 5.23. Relación entre el módulo de elasticidad y la resistencia a compresión.

Figura 5.24. Relación entre la velocidad del pulso ultrasónico y la resistencia a compresión, para los hormigones originales y reciclados. 116

Figura 5.25. Relación entre los módulos de elasticidad estático y dinámico. 117

Figura 6.1. Absorción de agua en hormigones de razón a/c 0,45. 125

Figura 6.2. Absorción de agua en hormigones de razón a/c 0,65. 125

Figura 6.3. Succión capilar en hormigones de razón a/c 0,45 elaborados con: a) granito;

b) cuarcita; c) basalto; d) canto rodado silíceo. 127 
Figura 6.4. Succión capilar en hormigones de razón a/c 0,65 con: a) granito; b) cuarcita;

c) basalto; d) canto rodado silíceo.

Figura 6.5. Velocidad de succión capilar en hormigones de razón a/c 0,45...................... 129

Figura 6.6. Velocidad de succión capilar en hormigones de razón a/c 0,65....................... 129

Figura 6.7. Penetración media de agua en hormigones de razón a/c 0,45.......................... 130

Figura 6.8. Penetración media de agua en hormigones de razón a/c 0,65.......................... 131

Figura 6.9. Perfiles de cloruro en hormigones de razón a/c 0,45....................................... 133

Figura 6.10. Perfiles de cloruro en hormigones de razón a/c 0,65....................................... 134

Figura 6.11. Coeficientes de difusión de cloruro soluble en agua de hormigones de razón a/c 0,45.

Figura 6.12. Coeficientes de difusión de cloruro soluble en agua de hormigones de razón a/c 0,65 .

Figura 6.13. Relación cloruro soluble en agua - cloruro retenido para hormigones de razón a/c 0,45.

Figura 6.14. Relación cloruro soluble en agua - cloruro retenido para hormigones de razón a/c 0,65.

Figura 6.15. Relación cloruro soluble en agua - cloruro retenido en función del contenido de AGR, en hormigones de razón a/c 0,45.

Figura 6.16. Relación cloruro soluble en agua - cloruro retenido en función del tipo de AGN, en hormigones de razón a/c 0,45.

Figura 6.17. Relación cloruro soluble en agua - cloruro retenido en función del contenido de AGR, en hormigones de razón a/c 0,65.

Figura 6.18. Relación cloruro soluble en agua - cloruro retenido en función del tipo de AGN, en hormigones de razón a/c 0,65.

Figura 6.19. Relación entre la absorción de agua AGN-AGR y la velocidad de succión capilar.

Figura 6.20. Relación entre la absorción de agua AGN-AGR y la capacidad de succión capilar.

Figura 6.21. Relación entre la absorción de agua AGN-AGR y el coeficiente de difusión de cloruro soluble en agua. 
Figura 6.22. Relación entre la absorción de agua AGN-AGR y la penetración media de agua a presión.

Figura 6.23. Relación entre la resistencia a compresión y la velocidad de succión capilar.

Figura 6.24. Relación entre la resistencia a compresión y el coeficiente de difusión de cloruro soluble en agua.

Figura 6.25. Relación entre la resistencia a compresión y la penetración media de agua a presión.

Figura 6.26. Aspecto visual de las probetas expuestas en suelo con sulfato.

Figura 6.27. Variación relativa del módulo de elasticidad dinámico en el tiempo para hormigones expuestos en suelo con sulfato

Figura 6.28. Variación relativa del peso de las probetas en el tiempo para hormigones expuestos en suelo con sulfato.

Figura 6.29. Variación relativa de la velocidad del pulso ultrasónico en el tiempo para hormigones expuestos en suelo con sulfato 


\section{Índice de Tablas}

Tabla 2.1. Densidad de los AGR en función de la calidad del hormigón original y el tamaño de partículas.

Tabla 2.2. Absorción de los AGR en función de la calidad del hormigón original y el tamaño de partículas.

Tabla 2.3. Absorción de agua del AGR en función del tiempo de inmersión y la edad de trituración.

Tabla 2.4. Desgaste “Los Ángeles” de los AGR en función de la calidad del hormigón original y el tamaño de partículas.

Tabla 2.5. Contenido de mortero de los AGR en función de la calidad del hormigón original y el tamaño de partículas.

Tabla 2.6. Requisitos para los agregados reciclados según distintas recomendaciones internacionales.

Tabla 2.7. Resistencia a compresión de hormigones reciclados en función de la calidad del agregado grueso reciclado.

Tabla 2.8. Resistencia a compresión en función de la calidad del agregado reciclado 32

Tabla 3.1. Características de los agregados gruesos naturales. 48

Tabla 3.2. Denominación de los agregados gruesos reciclados 51

Tabla 3.3. Propiedades del cemento. 52

Tabla 3.4. Propiedades de las arenas naturales. 52

Tabla 3.5. Hormigones originales y reciclados. 54

Tabla 3.6. Síntesis del programa experimental. 55

Tabla 3.7. Normas de ensayo utilizadas. 56

Tabla 3.8. Propiedades de los agregados gruesos naturales. 57

Tabla 4.1. Propiedades de los agregados gruesos reciclados. 74

Tabla 4.2. Granulometría de los agregados gruesos reciclados... 74

Tabla 4.3. Valores del contenido de mortero, absorción de agua y desgaste "Los Ángeles" de los AGR. 87

Tabla 5.1. Proporciones de las mezclas de razón a/c 0,45. 92 
Tabla 5.2. Proporciones de las mezclas de razón a/c 0,65.

Tabla 5.3. Propiedades en estado fresco de hormigones de razón a/c 0,45 .......................... 94

Tabla 5.4. Propiedades en estado fresco de hormigones de razón a/c 0,65......................... 94

Tabla 5.5. Propiedades mecánicas de hormigones de razón a/c 0,45...................................96

Tabla 5.6. Propiedades mecánicas de hormigones de razón a/c 0,65 ................................. 97

Tabla 5.7. Parámetros de END de hormigones de razón a/c 0,45....................................... 106

Tabla 5.8. Parámetros de END de hormigones de razón a/c 0,65...................................... 106

Tabla 5.9. Módulo de elasticidad estático estimado para hormigones de razón a/c 0,45.. 114

Tabla 5.10. Módulo de elasticidad estático estimado para hormigones de razón a/c 0,65 .

Tabla 6.1-a). Propiedades de transporte de hormigones de razón a/c 0,45

Tabla 6.1-b). Coeficientes de difusión de cloruro en hormigones de razón a/c 0,45.

Tabla 6.2-a). Propiedades de transporte de hormigones de razón a/c 0,65.

Tabla 6.2-b). Coeficientes de difusión de cloruro en hormigones de razón a/c 0,65 124 


\section{Nomenclatura}

RCD: residuos de construcción y demolición

AGN: agregado grueso natural

AR: agregado reciclado

AGR: agregado grueso reciclado

AFR: agregado fino reciclado

$D_{\text {sss: }}$ densidad en condición de saturado y superficie seca

Ds: densidad en condición seca

Ab: absorción de agua

PUVs: peso por unidad de volumen del agregado en estado suelto

a/c: razón agua/cemento (en peso)

$\mathrm{HC}$ : hormigón convencional

HR: hormigón reciclado

As: asentamiento

PUV fr: peso por unidad de volumen del hormigón en estado fresco

PUV: peso por unidad de volumen del hormigón en estado endurecido

T: temperatura

hr: humedad relativa

$\mathrm{f}^{\prime}$ c: resistencia a compresión

ftc: resistencia a tracción por compresión diametral

MR: módulo de rotura en flexión

E: módulo de elasticidad estático

END: ensayos no destructivos

BO: presión Break-Off

V: velocidad del pulso ultrasónico

Ed: módulo de elasticidad dinámico

s: desvío estándar

$\mathrm{CO}_{2}$ : dióxido de carbono

$\mathrm{V}_{\text {sc: }}$ velocidad de succión capilar

Csc: capacidad de succión capilar

Dap: coeficiente de difusión de cloruro

$P_{\text {med: }}$ penetración media de agua a presión

Pmáx: penetración máxima de agua a presión 



\section{Capítulo 1}

Introducción

\subsection{Introducción}

El reciclado de los materiales permite que su ciclo de vida sea más eficiente y coherente con las tendencias de protección del medio ambiente. Luego de agotada la vida útil de un producto, este se convierte en un residuo, el cual mediante algún proceso logra transformarse en un nuevo material, pudiendo ser utilizado para la elaboración de un nuevo equipo o componente. El caso ideal sería utilizar para la manufactura del nuevo producto el mismo insumo del que proviene, logrando de este modo una mayor eficiencia de vida del material.

El proceso de reciclar materiales de desecho, aunque ello no se conocía como tal, se ha realizado desde la antigüedad aprovechando los elementos y estructuras en desuso originadas durante la ejecución de las estructuras principales como fuente de materiales fácilmente disponibles para su uso en la construcción de nuevas estructuras, obteniendo como resultado indirecto una reducción en la cantidad de materiales desechados. Luego, la denominada "revolución industrial" y más tarde el avance tecnológico en materia de equipos permitieron que los diferentes productos pudieran ser generados y procesados de manera rápida y eficiente, dando lugar a la idea que todo lo viejo era obsoleto y debía descartarse para dar paso a los nuevos materiales. Como consecuencia de ello, la cantidad de materiales desechados ha experimentado un continuo crecimiento.

Durante las últimas décadas se ha producido una toma de conciencia por parte de la población en general, debido a diversos factores, que han llevado a replantear la situación actual y retornar a las antiguas costumbres, incentivando el reciclado de materiales de desecho.

En tal sentido, la industria de la construcción se ha caracterizado, a través de los años, por emplear los desechos generados por otras industrias, ya sea con el fin de dar una deposición final a los mismos, o también a partir de su utilización como nuevos materiales para la elaboración de hormigones, dando un valor agregado al desecho. El ejemplo más común y de mayor trascendencia lo constituyen las adiciones minerales activas, cons- 
tituidas por cenizas volantes, humo de sílice, cenizas de cáscara de arroz, escorias granuladas de alto horno, entre otras, las cuales constituyen subproductos industriales.

El empleo de los residuos de construcción y demolición (RCD) como reemplazo parcial o total del agregado natural, fino o grueso, principalmente aquellos que provienen de la trituración de hormigones viejos, tiene su justificación en motivos relacionados fundamentalmente con la preservación del medioambiente, la conservación de los recursos naturales, una reducción de los costos, y un aprovechamiento racional de la energía.

La industria del hormigón emplea a nivel mundial aproximadamente 10 billones de toneladas de arena y roca natural, a la vez que genera más de 1 billón de toneladas en residuos de construcción y demolición cada año [Mehta, 2002]. En tal sentido, en Estados Unidos se estima que dichos residuos alcanzan valores del orden de 250 a 300 millones de toneladas/año. Por su parte, en Japón se generan 85 millones de toneladas/año de residuos de construcción, de los cuales un 40 \% corresponde a desechos de hormigón [Kasai, 2004]. En la Comunidad Europea se estima que la generación de RCD es del orden de los 200 a 300 millones de toneladas anuales, lo cual equivale entre 0,5 a 1 tonelada per capita por año. Asimismo, aproximadamente el $28 \%$ de estos desechos fueron reciclados hacia fines de la década del '90 [Lauritzen, 2004]. En el caso de Alemania, los RCD ascienden a 88,6 millones de toneladas anuales de los cuales el $69 \%$ es reciclado y utilizado para la elaboración de materiales de construcción, y de ello, sólo 1,9 millones de toneladas (aproximadamente 3,1\%) es empleado como agregado para hormigón [Müller, 2005]. Holanda, genera anualmente 20 millones de toneladas/año de RCD, equivalente a 1,25 toneladas por habitante, de los cuales más del $95 \%$ es reutilizado, mayormente para sub-bases de caminos y sólo un 3,3\% en hormigón [Janssen y Put, 2005]. En España, la generación de residuos es de 38,5 millones de toneladas, y un $20 \%$ constituye desechos de hormigón [Vázquez, 2005]. Por otra parte, en Israel, la cantidad de residuos de construcción es del orden de 7,5 millones de toneladas anuales, equivalente a 1,1 tonelada per capita por año; siendo la mayoría de ellos depositados como relleno en sitios tanto legales como ilegales [Katz et al, 2005].

Los residuos de construcción y demolición procesados mediante una simple trituración dan lugar a un material granular con una buena aptitud para su empleo como material de relleno o para la construcción de bases y sub-bases de caminos. Pero sin lugar a dudas, el reciclado de los mismos para su uso como agregados en la producción de nuevos hormigones constituye una alternativa relevante y a la vez deseable tanto desde el punto de vista ecológico como económico. Para que esto sea posible, se debe efectuar una 
primera clasificación del material de desecho, previo al proceso de trituración, de manera de eliminar aquellos materiales indeseables como metales, madera, asfalto, yeso, vidrio, cerámica, suelo, etc. Luego de la trituración se efectúa una clasificación final y lavado del material granular resultante, de manera de eliminar la mayor cantidad posible del polvo adherido, obteniéndose así lo que se denomina Agregado Reciclado.

Los primeros estudios documentados en la bibliografía sobre la caracterización de materiales provenientes de la demolición de edificios, para su empleo como agregados en hormigón, datan de mediados de la década del '40, hecho que se encuentra directamente vinculado con el período de postguerra y cuya finalidad era la búsqueda de una aplicación para estos materiales de desecho. De este modo, ello permitiría reducir las grandes cantidades de desechos originados por la destrucción de las ciudades, lo cual requeriría una menor necesidad de terrenos para su disposición, a la vez que disminuiría la demanda de materiales vírgenes necesarios para la reconstrucción de los centros urbanos [Nixon, 1978; Olorunsogo y Padayachee, 2002].

Cuando dichos agregados reciclados provienen de la trituración de hormigones de desecho, la característica más distintiva que presentan en comparación con algunos agregados naturales se centra en su elevada absorción de agua, motivada por la presencia de mortero y/o pasta de cemento adherida al agregado original. Esta situación diferencia las propiedades de los agregados reciclados respecto a sus pares naturales, a la vez que provoca modificaciones en las características de las mezclas con ellos elaboradas, ya sea en estado fresco como así también en las propiedades del hormigón endurecido. Según se indica en la bibliografía, las exigencias que debe cumplir un hormigón elaborado con agregados reciclados procedentes de la trituración de hormigones son las mismas que para un hormigón con agregados naturales [Grübl y Rühl, 1998]. Sin embargo, dichas exigencias dependerán de la estructura de destino del hormigón reciclado como así también del ambiente de exposición de la misma.

En un agregado natural las propiedades dependen de las características de la roca a partir de la cual fue obtenido, mientras que en los agregados reciclados sus propiedades dependerán de las características de la roca natural y de la calidad del mortero del hormigón original que forma parte de este nuevo agregado [Hansen y Narud, 1983].

De manera similar a lo que sucede con los agregados naturales obtenidos por trituración, conocidos habitualmente como piedra partida, en los cuales al efectuar la clasificación por tamaños se genera un desecho o sobrante con partículas de tamaño inferior a los 
$6 \mathrm{~mm}$ (denominado material 0-6), y el cual es empleado en muchos casos como arena de trituración, durante la trituración de hormigones también se genera un material que puede asemejarse al mencionado pudiendo, a partir de efectuar su separación por medio de una malla de abertura $4,75 \mathrm{~mm}$, clasificar a los agregados reciclados en gruesos (AGR) y finos (AFR) según queden retenidos o pasen dicha malla respectivamente.

Considerando la importancia que en la actualidad adquiere el impacto medioambiental, el empleo de los agregados reciclados presenta dos beneficios: por un lado se utiliza un material de desecho, permitiendo disminuir las cantidades que se depositan, mientras que por otro lado se reduce la cantidad de agregados naturales a extraer, los cuales constituyen una fuente de recursos no renovable. En lo que se refiere a la explotación de canteras a cielo abierto, se produce una situación particular ya que en muchos casos se origina un gran impacto sobre el paisaje del lugar modificándolo, hecho que también perjudica en cierta forma a la industria del turismo.

Los beneficios relacionados con cuestiones de costos están, en nuestro país, fuertemente asociados con el transporte de los agregados naturales desde las fuentes de extracción hasta los centros urbanos donde se los emplea, ya que, en el caso de los agregados reciclados el lugar de generación es el mismo en el cual se dan las posibilidades de su empleo. A ello debe sumarse un beneficio económico, y en definitiva de conservación de energía, relacionado con la trituración de los hormigones, ya que la energía consumida podría resultar menor que cuando se tritura piedra natural, debido a una menor resistencia por parte de los mismos.

La importancia de la temática ha llevado a países desarrollados como Alemania, Japón, EE.UU., Bélgica, Holanda, Reino Unido, entre otros, a redactar reglamentos o recomendaciones para el empleo de los RCD como agregados para la producción de hormigones estructurales, o bien incluyen a los agregados reciclados en las normas y reglamentos para los hormigones convencionales. En algunos casos, dichos documentos datan de aproximadamente dos décadas [Grúbl y Rühl, 1998; Hansen, 1986; RILEM, 1994; Balázs et al, 2008; Kasai, 1994; Vyncke y Rousseau, 1994; Janssen y Put, 2005; Poon, 2005]. Un claro ejemplo a nivel internacional lo constituye España, quien en el año 2001 comenzó a llevar a cabo el Plan Nacional de Residuos de Construcción y Demolición (PNRCD 20012006), cuyo fin es alcanzar un porcentaje de empleo del material reciclado en la elaboración de hormigones cercano al 60\%. Actualmente, se encuentra en desarrollo el II Plan Nacional de Residuos de Construcción y Demolición (II PNRCD 2007-2015), el cual forma parte del Plan Nacional Integrado de Residuos (PNIR 2008-2015), dentro del cual algunos 
de los objetivos planteados incluyen la reducción de los $\mathrm{RCD}$, la clausura de vertederos inadecuados, la recolección controlada y correcta gestión de los RCD en un 95\%, y el reciclaje del $40 \%$ de los RCD a partir de 2011. Debe mencionarse que España ya posee una recomendación para el uso de los agregados gruesos reciclados en hormigones con requerimientos resistentes de tipo estructural, admitiendo su empleo hasta un máximo del $20 \%$ en reemplazo del agregado grueso natural [EHE, 2008].

Por los motivos señalados, y con el fin de incentivar el empleo de los residuos de construcción y demolición, resulta indispensable en primera instancia tomar conocimiento en laboratorio sobre las características físico-mecánicas que poseen los agregados reciclados, como así también de la influencia que tienen sobre las propiedades de los hormigones con ellos elaborados, haciendo hincapié en el comportamiento durable de los mismos.

\subsection{Objetivos}

De los antecedentes recopilados surge que las características distintivas que presentan los agregados reciclados respecto a los naturales se centran en la calidad del mortero del hormigón original. Sin embargo, no se han encontrado antecedentes respecto a la influencia que podría tener el tipo de agregado grueso natural (AGN) que contiene el hormigón original sobre las propiedades de los agregados gruesos reciclados (AGR), como así tampoco sobre el comportamiento de los hormigones con ellos elaborados.

Además, se ha observado que el comportamiento durable de los hormigones reciclados puede ser muy variado según sean las características de los hormigones, el porcentaje de AGR utilizado y el mecanismo de transporte de fluidos al cual son expuestos.

Por lo indicado anteriormente, el objetivo del presente trabajo es determinar la influencia que tiene el nivel de resistencia y el tipo de agregado grueso natural del hormigón de origen, sobre las propiedades físico-mecánicas de los AGR y el comportamiento de los hormigones reciclados en estado endurecido. Para ello se estudiaron hormigones de dos niveles resistentes (razones a/c 0,45 y 0,65) empleando cuatro tipos de AGN de uso habitual en Argentina (granito, cuarcita, basalto y canto rodado silíceo).

El objetivo específico consiste en evaluar el comportamiento durable de hormigones elaborados con distintos porcentajes de AGR ( 25 y $75 \%$ ), de niveles resistentes similares a los de los hormigones de origen, frente a distintos mecanismos de transporte, tales como capilaridad, permeabilidad y difusión. 


\subsection{Estructura de la tesis}

El presente trabajo de tesis se encuentra organizado en diferentes capítulos, avocados cada uno de ellos a un tema en particular, según se describe a continuación:

Este Capítulo sirve de introducción a la temática del reciclado de los residuos de construcción y demolición, en especial los obtenidos a partir de la trituración de hormigones de desecho, indicándose también los objetivos planteados. En el Capítulo 2 se presenta una revisión bibliográfica de los conocimientos alcanzados durante las últimas tres décadas, fundamentalmente a nivel internacional, sobre las propiedades de los agregados gruesos reciclados, como así también respecto a los comportamientos mecánico y durable de los hormigones con ellos elaborados.

La parte central de la tesis se encuentra avocada al desarrollo de los estudios realizados con el fin de dar cumplimiento a los objetivos planteados en el punto anterior. De este modo, en el Capítulo 3 se resumen las experiencias llevadas a cabo y las metodologías implementadas en las diferentes evaluaciones. En el Capítulo 4 se analizan las propiedades físico-mecánicas evaluadas sobre los AGR obtenidos a partir de la trituración de hormigones de distintos niveles resistentes y elaborados con diferentes tipos de agregados gruesos naturales, respecto a las mismas propiedades determinadas sobre estos últimos agregados. En el Capítulo 5 se presentan y analizan los resultados obtenidos con relación al comportamiento mecánico y al módulo de elasticidad estático de los hormigones reciclados, conteniendo distintos porcentajes de los AGR, comparativamente con los alcanzados en los hormigones originales que contienen el mismo tipo de AGN. En el Capítulo 6 se presentan los resultados del desempeño durable de los hormigones reciclados en estudio, determinado mediante la evaluación de diferentes propiedades de transporte, haciendo un análisis comparativo con el comportamiento que presentaron los hormigones de igual nivel resistente elaborados con los diferentes AGN. Además, se presenta y analizan los resultados obtenidos en una experiencia de campo realizada sobre hormigones con distintos porcentajes de AGR expuestos en suelo con sulfato.

Finalmente, se presentan las Conclusiones más relevantes que surgieron de estas experiencias, y se sugieren posibles lineamientos para estudios futuros.

Además, se presenta de manera detallada y unificada las Referencias Bibliográficas citadas durante el desarrollo del trabajo de tesis. 


\section{Capítulo 2}

\section{Estado del Arte}

\subsection{Introducción}

Las consecuencias ocasionadas por la Segunda Guerra Mundial han sido devastadoras desde todo punto de vista, incluyendo aspectos sociales, humanos y económicos, como así también a nivel de infraestructuras edilicias. La destrucción masiva de las ciudades produjo grandes cantidades de desechos de demolición que debieron ser retirados, inutilizando los terrenos destinados a su depósito, a la vez que la demanda de materiales vírgenes para la reconstrucción de los centros urbanos creció vertiginosamente. Ambos hechos han motivado la necesidad de estudiar las propiedades que presentaban estos materiales desechados con el fin de emplearlos para la elaboración de nuevos materiales, fundamentalmente en reemplazo del agregado natural en los hormigones.

Los primeros estudios documentados hacen referencia al uso de residuos de mampostería, ya que era el material de construcción más predominante en la época [Nixon, 1978]. Sin embargo, los materiales recuperados constituían pequeñas cantidades las cuales eran destinadas a la estabilización de bases o sub-bases de autopistas, o eran utilizadas como relleno de terrenos. Debido a razones medioambientales, relacionadas con la disminución de los sitios disponibles para la deposición y la escasez de agregados naturales de buena calidad, sumado a cuestiones de costos, los volúmenes de residuos a ser depositados fueron restringidos [Hansen, 1986]. A partir de ellos, el estudio de las propiedades que poseen los agregados reciclados obtenidos a partir de la trituración de los residuos de construcción y demolición adquiere una mayor relevancia, ya sea que los mismos provinieran de restos de mampostería u hormigón. Los obtenidos a partir de estos últimos son los que presentan mayores posibilidades de uso en la industria de la construcción como agregados para la elaboración de nuevos hormigones, en reemplazo de los agregados naturales. En este capítulo se presenta una revisión bibliográfica de los estudios más importantes realizados sobre la temática como así también sobre las propiedades físico-mecánicas y durables que presentan los hormigones con ellos elaborados. 


\subsection{Agregados reciclados}

\subsubsection{Generación de los agregados reciclados}

Los denominados residuos de construcción y demolición (RCD) dan lugar a la generación de una gran variedad de materiales granulares los cuales se pueden dividir en dos grandes grupos, los provenientes de los desechos de mampostería y los obtenidos a partir de la trituración de hormigones.

El origen de estos hormigones de desechos puede ser muy variado, desde los resultantes de la demolición parcial o total de estructuras de hormigón armado y pavimentos hasta los originados a partir de los restos de hormigones que retornan en los mixers y son depositados en sitios inapropiados. Indistintamente de la procedencia del hormigón, su trituración permite generar materiales granulares cuya distribución de tamaño de partículas se ajusta, totalmente o en parte, a la distribución de tamaños que se exigen a los agregados naturales utilizados para la elaboración de hormigones. Estos materiales granulares son conocidos como agregados reciclados de hormigón, o simplemente agregados reciclados.

Los métodos y sistemas para la remoción del hormigón de las estructuras a reparar o demoler incluyen desde equipos de alto rendimiento montados sobre vehículos (martillos de impacto neumático o hidráulico, bolas de demolición, cabezales cortadores rotativos, distintos tipos de sierras diamantadas, etc.), hasta diferentes tipos de herramientas de mano (neumática, hidráulica, eléctrica, a combustible) utilizadas para trabajos menores de remoción [ACI, 2002]. Cualquiera de estos métodos tiene por finalidad reducir el tamaño de los bloques de hormigón de manera de lograr un tamaño acorde con el medio de transporte disponible y/o con las características de la trituradora empleada para la generación de los agregados reciclados.

Las plantas de producción de agregados reciclados presentan características muy semejantes a las empleadas para la producción de agregados naturales, con la incorporación de equipos para la eliminación de los contaminantes que no suelen estar presentes en estos últimos. Estas plantas de procesamiento de agregados pueden operar mediante sistemas abiertos o cerrados, siendo de preferencia los segundos ya que permiten tener un mayor control sobre el tamaño máximo de partícula obtenido [ACI, 2002]. En las Figuras 2.1 y 2.2 se presentan esquemas de funcionamiento de plantas de producción de agregados con sistemas abierto y cerrado respectivamente. 


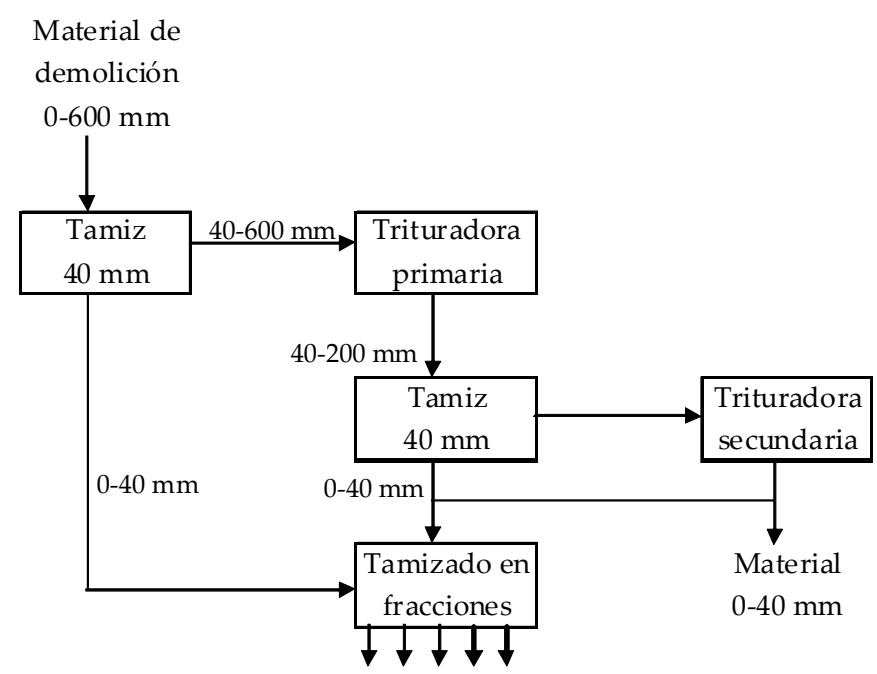

Figura 2.1. Esquema de funcionamiento de una planta de producción de agregados reciclados mediante sistema abierto.

(Adaptado de ACI, 2002)

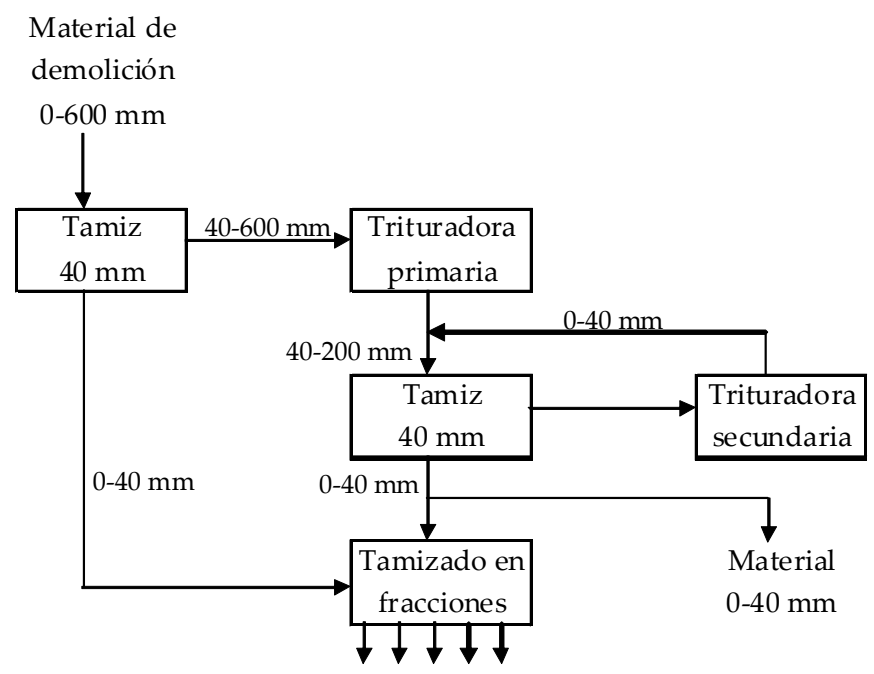

Figura 2.2. Esquema de funcionamiento de una planta de producción de agregados reciclados mediante sistema cerrado.

(Adaptado de ACI, 2002)

Ambos métodos de producción de agregados permiten obtener agregados reciclados que pueden ser clasificados de manera general en agregado grueso reciclado (AGR) y agregado fino reciclado (AFR), a partir de realizar su separación en el tamiz cuya abertura de malla es 4,75 mm, tal como sucede con los agregados naturales obtenidos por los mismos métodos. En estos últimos, la fracción fina es conocida como arena de trituración o descarte (0-6 mm).

La mayoría de las trituradoras utilizadas en los sistemas de producción de agregados emplean una combinación de cuatro mecanismos básicos (impacto, fricción, corte y 
compresión) para producir la fractura del material [www.penncrusher.com]. Dentro de los diferentes tipos de trituradoras existentes, se pueden mencionar las de mandíbulas (Figura 2.3), de rodillos (Figura 2.4), de impacto (Figura 2.5) y de conos (Figura 2.6), entre otras.
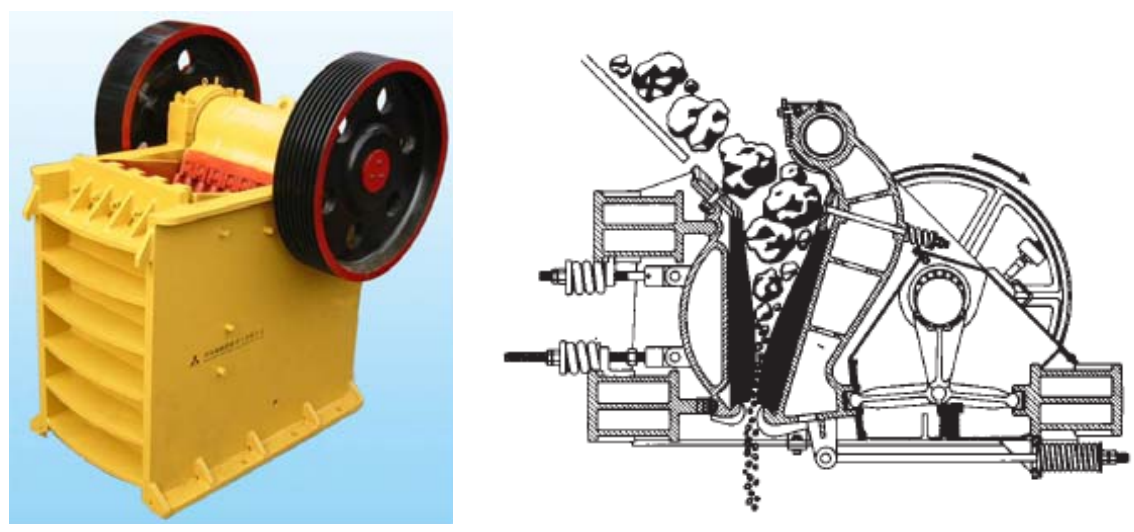

Figura 2.3. Trituradora de mandíbulas.

(Fuentes: www.stone-crusher.cn; www.penncrusher.com)
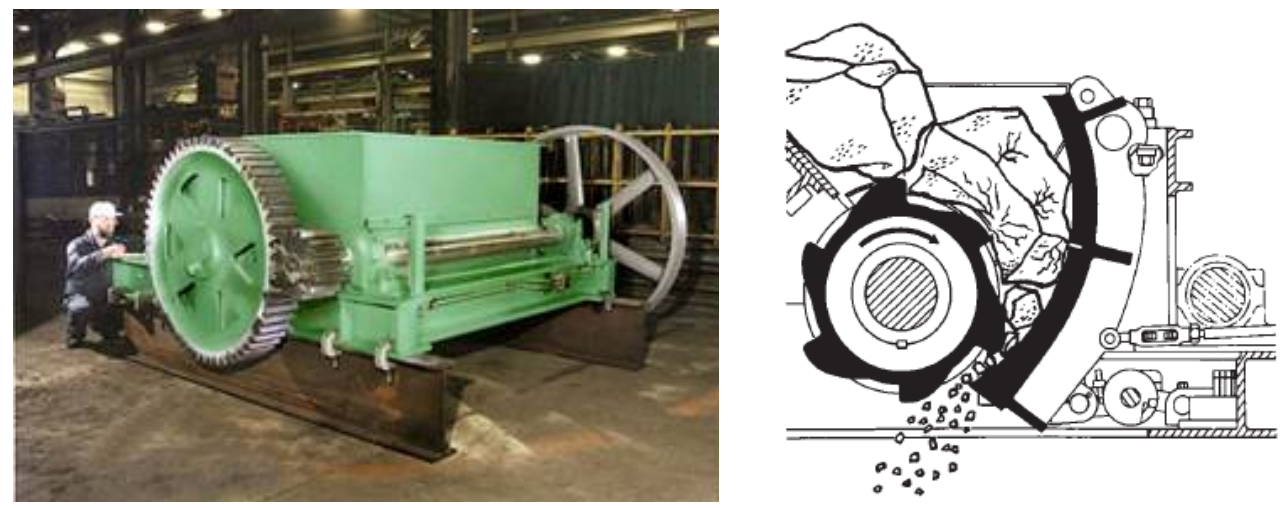

Figura 2.4. Trituradora de rodillos.

(Fuente: www.penncrusher.com)
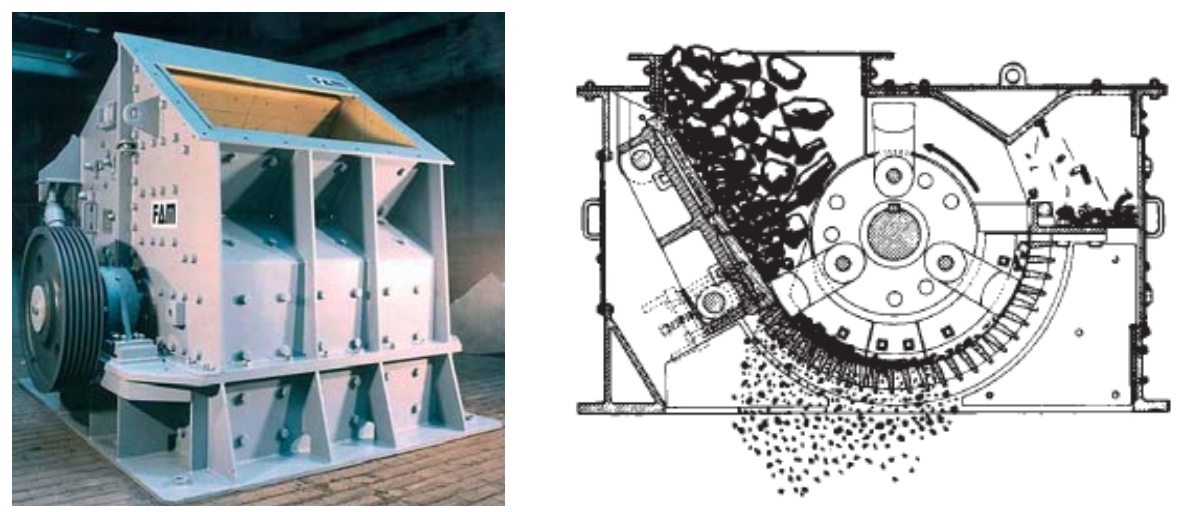

Figura 2.5. Trituradora de Impacto.

(Fuentes: www.fam.de; www.penncrusher.com) 

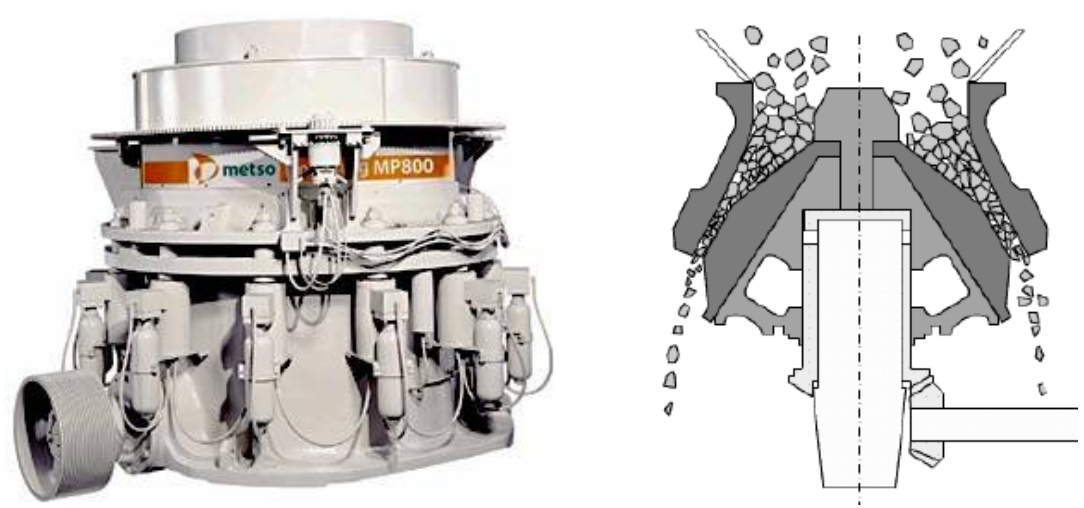

Figura 2.6. Trituradora de conos.

(Fuentes: www.metsominerals.com; www.break-day.com)

Las características de los agregados que resulten de triturar hormigones con las trituradoras mencionadas serán diferentes debido a que los mecanismos que utilizan para moler el hormigón difieren entre sí. En tal sentido, se indica que los agregados reciclados obtenidos por medio de una trituradora de mandíbulas presentan una distribución granulométrica que los hace más aptos para su empleo en la elaboración de hormigones [Hansen y Narud, 1983], mientras que los generados a partir de una trituradora de impacto resultaran con una mejor gradación para su empleo en la construcción de caminos [ACI, 2002].

\subsubsection{Composición y características visuales}

Los agregados reciclados presentan un aspecto visual diferente al de un agregado natural, debido a la presencia de mortero de cemento en su composición. En tal sentido, las partículas que lo componen podrán estar formadas por roca natural o mortero en distintas proporciones. Este hecho da lugar a partículas de una variada proporción entre ambos materiales, conforme se esquematiza en la Figura 2.7. Puede observarse que es posible hallar partículas compuestas por roca natural que presentan adherido mortero, otras en las cuales la roca se encuentra inmersa en una matriz de mortero, rodeándola completamente, y otras en las cuales el mortero aparece constituyendo partículas por sí solo. Las cantidades relativas de cada una de ellas estará en función de las características del hormigón que se tritura, como resistencia, tamaño máximo del agregado, características de la roca natural, etc., y del método de procesamiento utilizado para la obtención de los agregados reciclados, incluyendo el tipo y la cantidad de trituradoras empleadas [Hansen y Narud, 1983; Limbachiya et al, 2000; Sánchez de Juan y Alaejos Gutiérrez, 2009]. 


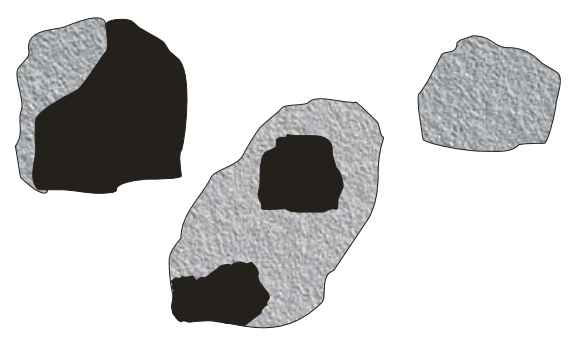

Figura 2.7. Características de las partículas que componen el AGR.

Teniendo presente la composición que poseen los agregados reciclados como así también la mayor porosidad que presenta el mortero de cemento, puede esperarse, en principio, que las propiedades físico-mecánicas y durables de los agregados reciclados se modifiquen, en mayor o menor medida, con relación a las de los agregados naturales.

\subsubsection{Granulometría}

Como se mencionó anteriormente, la distribución granulométrica de los agregados reciclados se encuentra fuertemente influenciada por el método de procesamiento empleado, sin embargo, para un dado tipo de trituradora la granulometría de los mismos resulta independiente del nivel resistente del hormigón a partir del cual son obtenidos [Hansen y Narud, 1983; Sri Ravindrarajah y Tam, 1985]. Tal como fuera indicado, durante la trituración de los hormigones se generan partículas con una gran variedad de tamaños, las cuales es necesario separar en las fracciones gruesa y fina.

Se indica que la granulometría del AGR se ubica casi en su totalidad dentro de los límites establecidos para los AGN [Hansen, 1986]. Otros autores llegaron a las mismas conclusiones luego de triturar hormigones a distintas edades comprendidas entre 1 y 28 días [Katz, 2003; Buttler, 2003].

Con relación al AFR, sus características resultan muy semejantes a las de una arena de trituración, con partículas angulosas y un elevado contenido de polvo. En consecuencia, su módulo de finura resulta muy superior al de la mayoría de los agregados naturales de río, siendo incluso mayor que el valor máximo admitido para la elaboración de hormigones estructurales [Hansen y Narud, 1983; Buyle-Bodin y Hadjieva-Zaharieva, 2002; Khatib, 2005]. Tales características ocasionan que la granulometría del AFR, al igual que sucede con la arena de trituración, se encuentre en su mayor parte fuera de los límites establecidos por las normas para las arenas naturales. 
Si bien existen estudios que evalúan las propiedades del AFR y su influencia en la elaboración de hormigones [Khatib, 2005; Evangelista y Brito, 2007], en general se desaconseja su utilización para la elaboración de hormigones estructurales [Hansen, 1986; Grübl y Rühl, 1998; Buyle-Bodin y Hadjieva-Zaharieva, 2002]. En cuanto a la cantidad de AGR disponible del total de agregados obtenidos en la trituración, algunas investigaciones concluyen que la cantidad de material fino reciclado $(<4,75 \mathrm{~mm})$ es mayor a medida que la resistencia del hormigón que se tritura disminuye [Sri Ravindrarajah y Tam, 1985], debido al menor contenido de cemento y mayor cuantía de arena que presentan los hormigones más pobres. En otro estudio, en cambio, se ha encontrado que la cantidad de fracción fina generada está comprendida entre 25 y $30 \%$, independientemente de la resistencia del hormigón [Buttler, 2003].

\subsubsection{Densidad}

La presencia de mortero como parte constituyente de los AGR, el cual posee una mayor porosidad que la roca natural, produce una disminución de la densidad de dichos agregados con relación a la de los naturales. El efecto es más notorio cuanto mayor es el contenido de mortero de los AGR [Zega et al, 2005a); Sánchez de Juan y Alaejos Gutiérrez, 2009]. La Tabla 2.1 resume algunos de los valores de densidad informados para los agregados reciclados y los agregados naturales originales. Puede observarse que la calidad de los hormigones originales no tiene una marcada influencia sobre la densidad de los agregados reciclados generados a partir de su trituración [Hansen y Narud, 1983; Sri Ravindrarajah y Tam, 1985; Katz, 2003]. Sin embargo, se ha observado una menor densidad en los agregados reciclados provenientes de un hormigón de pavimento de baja calidad [Tavakoli y Soroushian, 1996]. Este hecho se correspondió con una mayor cantidad de mortero adherido a las partículas de dicho agregado, atribuyéndoselo a que el hormigón que dio lugar a ese agregado presentaba una menor relación agregado grueso/agregado fino y un mayor contenido unitario de cemento. La disminución producida en la densidad de los agregados reciclados con relación a la de los naturales es del orden del 5 al $15 \%$.

Contrariamente a lo señalado, en un estudio reciente se indica una disminución de la densidad de los AGR a medida que se incrementa la resistencia del hormigón de origen [Padmini et al, 2009]. Estos resultados fueron confirmados por los obtenidos en el ensayo de peso por unidad de volumen. Este hecho es atribuido a que durante el proceso de trituración, el mortero se desprende con mayor facilidad de los hormigones con menor resistencia, siendo luego eliminadas en el proceso de tamizado. En consecuencia, los AGR que provienen de hormigones con menor resistencia presentan menor contenido de mortero 
que los originados de hormigones con resistencias más elevadas, dando como resultado una mayor densidad en el primero de los casos.

Tabla 2.1. Densidad de los AGR en función de la calidad del hormigón original y el tamaño de partículas.

\begin{tabular}{|c|c|c|c|c|c|}
\hline Referencia & $\begin{array}{c}\text { Fracción } \\
(\mathrm{mm})\end{array}$ & $\begin{array}{c}\text { Densidad } \\
\text { AGR }\end{array}$ & $\begin{array}{c}\text { Densidad } \\
\text { AGN }\end{array}$ & $\begin{array}{l}\text { Tipo de } \\
\text { AGN }\end{array}$ & Observaciones \\
\hline \multirow{3}{*}{$\begin{array}{c}\text { Hansen y Narud, } \\
1983\end{array}$} & $4-8$ & 2,$34 ; 2,35 ; 2,34$ & 2,50 & \multirow{3}{*}{ Calizo } & \multirow{3}{*}{$\begin{array}{c}\text { Razón a/c } \\
0,40 ; 0,70 ; 1,20, \\
\text { respectivamente }\end{array}$} \\
\hline & $8-16$ & 2,$45 ; 2,44 ; 2,42$ & 2,62 & & \\
\hline & $16-32$ & 2,$49 ; 2,48 ; 2,49$ & 2,61 & & \\
\hline $\begin{array}{c}\text { Sri Ravindrarajah } \\
\text { y Tam, } 1985\end{array}$ & $5-37,5$ & 2,$44 ; 2,46 ; 2,44$ & 2,67 & Granítico & $\begin{array}{c}\text { Razón a/c } \\
0,51 ; 0,60 ; 0,73, \\
\text { respectivamente }\end{array}$ \\
\hline \multirow{4}{*}{$\begin{array}{c}\text { Sri Ravindrarajah } \\
\text { et al, } 1988\end{array}$} & $4,75-9,5$ & 2,54 & \multirow{4}{*}{2,67} & \multirow{4}{*}{ Granítico } & \multirow{4}{*}{$\mathrm{f}^{\prime} \mathrm{c}: 60 \mathrm{MPa}$} \\
\hline & $9,5-13,2$ & 2,52 & & & \\
\hline & $13,2-19$ & 2,46 & & & \\
\hline & $>19$ & 2,47 & & & \\
\hline \multirow{2}{*}{$\begin{array}{c}\text { Tavakoli y } \\
\text { Soroushian, } 1996\end{array}$} & $4,75-19$ & 2,$41 ; 2,26$ & 2,63 & \multirow{2}{*}{ Calizo } & \multirow{2}{*}{$\begin{array}{l}\text { f'c: } 54 ; 44 \mathrm{MPa} \text {, } \\
\text { respectivamente }\end{array}$} \\
\hline & $4,75-25$ & 2,$45 ; 2,37$ & 2,69 & & \\
\hline \multirow{2}{*}{ Poon et al, 2004} & $4,75-10$ & 2,33 & \multirow{2}{*}{2,62} & \multirow{2}{*}{ Granítico } & \multirow{2}{*}{---} \\
\hline & $10-20$ & 2,37 & & & \\
\hline $\begin{array}{c}\text { Machado y } \\
\text { Latterza, } 1997\end{array}$ & $4,75-9,5$ & 2,45 & 2,88 & Basáltico & $\begin{array}{c}\text { f'c: } 22 \mathrm{MPa} ; \\
\text { a/c: } 0,68\end{array}$ \\
\hline \multirow{2}{*}{$\begin{array}{l}\text { Hernández y } \\
\text { Fornasier, } 2005\end{array}$} & $4,75-20$ & 2,49 & \multirow{2}{*}{2,72} & \multirow{2}{*}{ Granítico } & Laboratorio \\
\hline & $6-20$ & 2,41 & & & Planta \\
\hline \multirow{3}{*}{$\begin{array}{l}\text { Cúneo Simian y } \\
\text { Durán, } 1995\end{array}$} & $4,75-19$ & 2,55 & 2,75 & Granítico & \multirow{3}{*}{$\mathrm{a} / \mathrm{c}: 0,56$} \\
\hline & $4,75-19$ & 2,45 & 2,65 & $\begin{array}{c}\text { Silíceo } \\
\text { triturado }\end{array}$ & \\
\hline & $4,75-19$ & 2,66 & 2,98 & Basáltico & \\
\hline \multirow{2}{*}{ Katz, 2003} & $2,36-9,5$ & 2,$35 ; 2,38 ; 2,32$ & --- & \multirow{2}{*}{--- } & \multirow{2}{*}{$\begin{array}{l}\text { AGR a edades } \\
\text { de } 1,3 \text { y } 28 \text { días }\end{array}$} \\
\hline & $9,5-25$ & 2,$59 ; 2,60 ; 2,55$ & --- & & \\
\hline
\end{tabular}


En los primeros estudios desarrollados sobre la temática en el LEMIT, los valores de densidad obtenidos en AGR generados a partir de la trituración de hormigones convencionales de dos niveles resistentes diferentes (distinta razón a/c), resultaron similares entre sí [Di Maio et al, 2001]. Dichas densidades fueron 8 \% inferiores a la del agregado natural granítico.

Otro hecho significativo que se desprende de la Tabla 2.1 está relacionado con el tamaño de partícula considerada. Para agregados reciclados obtenidos de hormigones de una misma calidad, la densidad disminuye levemente a medida que el tamaño de la fracción involucrada se reduce [Hansen y Narud, 1983; Poon et al, 2004; Katz, 2003]. Contrariamente, otros autores obtuvieron incrementos en los valores de densidad al reducirse la fracción de agregado reciclado [Sri Ravindrarajah et al, 1988].

Además de los estudios mencionados, en Tabla 2.1 se presentan otros [Machado y Latterza, 1997; Hernández y Fornasier, 2005; Cúneo Simian y Durán, 1995] que también concluyen que la densidad de los agregados reciclados se ve reducida con relación a la de los agregados naturales originales.

De los antecedentes recopilados surge que los AGR presentan una menor densidad en comparación con la de los AGN del mismo tipo. Esto es atribuido, en todos los casos, a la composición que posee el material reciclado, con partículas constituidas por roca natural y mortero de cemento en proporciones variables. La mayor porosidad que presenta el mortero de cemento provoca la reducción en la densidad de los AGR, que puede alcanzar el $15 \%$; dicha disminución es mayor cuanto más alta es la densidad del agregado grueso natural.

\subsubsection{Absorción de agua}

La cantidad de agua que el agregado reciclado puede absorber depende de que el mismo se ponga en contacto directo con el agua de mezclado, con la pasta de cemento o con el mortero del hormigón. Asimismo, dicha propiedad también dependerá de la condición inicial de humedad en que se halle el agregado y del tiempo en que el mismo permanece en contacto con el agua.

En la Tabla 2.2 se presentan valores de absorción de agua de los AGR indicados en la bibliografía. 
Tabla 2.2. Absorción de los AGR en función de la calidad del hormigón original y el tamaño de partículas.

\begin{tabular}{|c|c|c|c|c|c|}
\hline Referencia & $\begin{array}{l}\text { Fracción } \\
\text { (mm) }\end{array}$ & $\begin{array}{l}\text { Absorción } \\
\text { AGR (\%) }\end{array}$ & $\begin{array}{l}\text { Absorción } \\
\text { AGN (\%) }\end{array}$ & $\begin{array}{l}\text { Tipo de } \\
\text { AGN }\end{array}$ & Observaciones \\
\hline \multirow{3}{*}{$\begin{array}{c}\text { Hansen y Narud, } \\
1983\end{array}$} & $4-8$ & 8,$5 ; 8,7 ; 8,7$ & 3,7 & \multirow{3}{*}{ Calizo } & \multirow{3}{*}{$\begin{array}{c}\text { Razón a/c } \\
0,40 ; 0,70 ; 1,20, \\
\text { respectivamente }\end{array}$} \\
\hline & $8-16$ & 5,$0 ; 5,4 ; 5,7$ & 1,8 & & \\
\hline & $16-32$ & 3,$8 ; 4,0 ; 3,7$ & 0,8 & & \\
\hline $\begin{array}{c}\text { Sri Ravindrarajah } \\
\text { y Tam, } 1985\end{array}$ & $5-37,5$ & 5,$4 ; 4,5 ; 4,7$ & 0,3 & Granítico & $\begin{array}{c}\text { Razón a/c } \\
\text { 0,51;0,60;0,73, } \\
\text { respectivamente }\end{array}$ \\
\hline \multirow{4}{*}{$\begin{array}{c}\text { Sri Ravindrarajah } \\
\text { et al, } 1988\end{array}$} & $4,75-9,5$ & 6,4 & \multirow{4}{*}{0,35} & \multirow{4}{*}{ Granítico } & \multirow{4}{*}{$\mathrm{f}_{c}^{\prime}: 60 \mathrm{MPa}$} \\
\hline & $9,5-13,2$ & 5,5 & & & \\
\hline & $13,2-19$ & 5,4 & & & \\
\hline & $>19$ & 5,4 & & & \\
\hline \multirow{2}{*}{$\begin{array}{c}\text { Tavakoli y } \\
\text { Soroushian, } 1996\end{array}$} & $4,75-19$ & 4,$5 ; 8,1$ & 2,0 & \multirow{2}{*}{ Calizo } & \multirow{2}{*}{$\begin{array}{l}\mathrm{f}^{\prime} \mathrm{c}: 54 ; 44 \mathrm{MPa} \text {, } \\
\text { respectivamente }\end{array}$} \\
\hline & $4,75-25$ & 3,$6 ; 6,6$ & 1,1 & & \\
\hline \multirow{2}{*}{ Poon et al, 2004} & $4,75-10$ & 7,6 & \multirow{2}{*}{1,2} & \multirow{2}{*}{ Granítico } & \multirow{2}{*}{---} \\
\hline & $10-20$ & 6,3 & & & \\
\hline \multirow{2}{*}{$\begin{array}{l}\text { Hernández y } \\
\text { Fornasier, } 2005\end{array}$} & $4,75-20$ & 5,0 & \multirow{2}{*}{0,5} & \multirow{2}{*}{ Granítico } & Laboratorio \\
\hline & $6-20$ & 5,1 & & & Planta \\
\hline \multirow{3}{*}{$\begin{array}{c}\text { Cúneo Simian y } \\
\text { Durán, } 1995\end{array}$} & $4,75-19$ & 5,5 & 0,2 & Granítico & \multirow{3}{*}{$\mathrm{a} / \mathrm{c}: 0,56$} \\
\hline & $4,75-19$ & 6,8 & 0,8 & $\begin{array}{c}\text { Silíceo } \\
\text { triturado }\end{array}$ & \\
\hline & $4,75-19$ & 5,8 & 0,6 & Basáltico & \\
\hline \multirow{2}{*}{ Gómez et al, 2001} & $5-10$ & 7,0 & 1,1 & \multirow{2}{*}{ Calizo } & \multirow{2}{*}{---} \\
\hline & $10-20$ & 6,0 & 0,9 & & \\
\hline $\begin{array}{c}\text { Buyle-B. y } \\
\text { Hadjieva-Z., } 2002\end{array}$ & $6-20$ & 6,0 & 0,2 & $\begin{array}{c}\text { Silíceo } \\
\text { triturado }\end{array}$ & --- \\
\hline \multirow{2}{*}{ Katz, 2003} & $2,36-9,5$ & 9,$7 ; 8,1 ; 8,0$ & --- & --- & \multirow{2}{*}{$\begin{array}{l}\text { AGR a edades } \\
\text { de } 1,3 \text { y } 28 \text { días }\end{array}$} \\
\hline & $9,5-25$ & 3,$2 ; 3,4 ; 3,3$ & --- & --- & \\
\hline \multirow{3}{*}{$\begin{array}{l}\text { Padmini et al, } \\
2009\end{array}$} & $4,75-10$ & 4,$6 ; 4,8 ; 5,0$ & 0,3 & \multirow{3}{*}{ Granítico } & \multirow{3}{*}{$\begin{array}{l}\mathrm{f}^{\prime} \mathrm{c}: 34 ; 48 ; 55 \mathrm{MPa} \text {, } \\
\text { respectivamente }\end{array}$} \\
\hline & $4,75-20$ & 3,$7 ; 4,1 ; 4,9$ & 0,3 & & \\
\hline & $4,75-40$ & 2,$2 ; 2,5 ; 2,8$ & 0,3 & & \\
\hline
\end{tabular}


En la Tabla 2.2 puede observarse que los AGR presentan absorciones variables entre 3,5 y $9 \%$, las cuales resultan muy superiores a las de los AGN, que en general son inferiores al $2 \%$. Las absorciones de los AGR, para una misma fracción de agregado, resultan muy similares entre sí independientemente de la calidad del hormigón de origen (distinta razón a/c). Al igual que en el caso de la densidad, este comportamiento es atribuido al mortero del hormigón original presente en las partículas que componen el agregado reciclado [Hansen y Narud, 1983; Sri Ravindrarajah y Tam, 1985]. Sin embargo, Tavakoli y Soroushian (1996) indican mayor absorción en los agregados reciclados obtenidos de hormigones de inferior calidad, hecho que se produjo para dos tamaños máximos diferentes de dichos agregados. Por otro lado, Padmini et al (2009) indican mayores absorciones en los AGR al incrementarse la resistencia de los hormigones de origen, verificado para tres tamaños máximos diferentes, hecho atribuido a un menor contenido de mortero de los AGR que provienen de los hormigones con menor resistencia debido a su eliminación durante el proceso de triturado.

En estudios realizados en el LEMIT se encontró que el agregado grueso reciclado presentaba absorciones de agua de 5,4 \%, independientemente de la calidad del hormigón de origen, mientras que la del agregado natural fue de 0,5 \% [Di Maio et al, 2001].

Otra particularidad que surge de observar los valores de la Tabla 2.2 es que, para una misma calidad de hormigón, las absorciones de los agregados reciclados aumentan al disminuir el tamaño de partícula evaluado [Hansen y Narud, 1983; Sri Ravindrarajah et al, 1988; Tavakoli y Soroushian, 1996; Gómez et al, 2001; Katz, 2003; Padmini et al, 2009].

Si bien la edad a la cual se tritura el hormigón (entre 1 y 28 días) parece no influir sobre la distribución granulométrica ni la densidad del agregado reciclado, dicha conclusión no se aplica a la capacidad de absorción de agua, para la cual una menor edad del hormigón se traduce en una menor absorción del AGR. Este hecho fue atribuido al menor contenido de mortero que presentó dicho agregado, el cual se pudo haber separado durante el proceso de trituración como consecuencia de un bajo grado de hidratación del cemento [Buttler, 2003]. Este comportamiento se repitió para la absorción a 10 minutos, 30 minutos y 24 horas, cuyos valores se presentan en la Tabla 2.3. Los valores de absorción de agua a 30 minutos representan aproximadamente el $90 \%$ de la absorción total a 24 horas, para las tres edades de trituración. 
Tabla 2.3. Absorción de agua del AGR en función del tiempo de inmersión y la edad de trituración.

[Buttler, 2003]

\begin{tabular}{|c|c|c|c|c|}
\hline \multirow{2}{*}{$\begin{array}{c}\text { Tiempo de } \\
\text { inmersión }\end{array}$} & \multicolumn{4}{|c|}{ Absorción de agua (\%) } \\
\cline { 2 - 5 } & \multirow{2}{*}{ AGN } & \multicolumn{3}{|c|}{ AGR } \\
\cline { 3 - 5 } & & 1 día & 7 días & 28 días \\
\hline $10 \mathrm{~min}$ & 1,24 & 4,74 & 5,67 & 5,51 \\
\hline $30 \mathrm{~min}$ & 1,37 & 4,84 & 5,81 & 5,68 \\
\hline 24 horas & 1,96 & 5,48 & 6,41 & 6,16 \\
\hline
\end{tabular}

Debido a la elevada absorción de agua que presentan los agregados reciclados, su empleo junto con los agregados naturales permitirá que la absorción del conjunto granular sea inferior al límite máximo establecido por algunos reglamentos. En tal sentido, un estudio realizado sobre diferentes muestras de agregados reciclados indica que la absorción de los AGR es muy superior al 5 \% -límite establecido por la Instrucción de Hormigón Estructural (EHE)- estableciendo que, para AGN con absorciones entre 1 y 3,75 \%, los porcentajes de utilización de los AGR que cumplirían con el límite antes mencionado se encuentra en el rango 20-45 \% [Sánchez de Juan y Alaejos Gutiérrez, 2003].

Los valores de absorción presentados corresponden, en todos los casos, a determinaciones realizadas en base a las normas vigentes para agregados naturales. Una de las cuestiones sobre las cuales se ha explorado se refiere al método de ensayo empleado para la determinación de la absorción de agua del agregado reciclado. La alta porosidad del material reciclado, la tendencia a su disgregación y la gran cantidad de material fino presente en los mismos, son consideradas como posibles causas de distorsión en la determinación de la absorción del agregado reciclado por medio de los métodos que se aplican a los agregados naturales. Por tal motivo, se han propuesto algunos métodos alternativos para la determinación de la absorción en los agregados reciclados.

Uno de los métodos propuestos [Leite et al, 2000] consiste en secar la muestra a $100^{\circ} \mathrm{C}$ hasta masa constante, registrándose este valor. Luego se coloca la muestra, seca y fría, en un recipiente, se tapa y se sumerge en agua de modo que pueda registrarse el peso sumergido. Se registra el incremento de peso de la misma al estar sumergida en agua a distintos intervalos de tiempo hasta 24 horas de iniciado el ensayo, determinándose las absorciones en condición seca y en condición sumergida, adoptando como absorción del 
material reciclado la resultante del promedio de las dos anteriores. Las respectivas absorciones, seca y sumergida, se obtienen a partir de las siguientes expresiones:

$$
\begin{aligned}
& A_{\text {seca }}(\%)=\frac{M_{\text {sum }-\mathrm{f}}-M_{\text {sum }-0}}{M_{\text {seca }}} \\
& A_{\text {sum }}(\%)=\frac{M_{\text {sum }-\mathrm{f}}-M_{\text {sum }-0}}{M_{\text {sum }-0}}
\end{aligned}
$$

Donde:

$$
\begin{aligned}
& \text { Aseca: absorción del material seco (\%) } \\
& \text { Asum: absorción del material sumergido (\%) } \\
& \text { Msum-f: masa de material sumergido en el instante final (g) } \\
& \text { Msum-0: masa de material sumergido en el instante inicial (g) } \\
& \text { Mseca: masa de material seco en estufa (g) }
\end{aligned}
$$

Por medio de este método han encontrado que la absorción del AGR a 30 minutos de iniciado el ensayo es del $57 \%$ de la correspondiente a 24 horas (4,95\%). Esto no condice con lo hallado por otros autores como fue mencionado anteriormente [Buttler, 2003]. Asimismo, Leite et al (2000) indican que cuanto menor es el tamaño máximo de la muestra a ensayar mayor será la absorción, obteniendo para el AFR una absorción a 30 minutos del $66 \%$ de la correspondiente a 24 horas $(8,6 \%)$.

Otro de los métodos propuestos para evaluar la absorción de agua de los agregados reciclados [Tam et al, 2008] radica en la medición en tiempo real de la absorción de agua. El método consiste en colocar una muestra de agregado reciclado, seco a $75^{\circ} \mathrm{C}$ hasta peso constante, en un picnómetro el cual es enrasado con agua y pesado en el tiempo $\mathrm{T}_{0}$. Luego, se registran los descensos en el nivel del agua a diferentes intervalos de tiempo. Transcurrido un tiempo $\mathrm{T}_{\mathrm{i}}$, se restituye el nivel de agua enrasando el picnómetro y se pesa nuevamente. La cantidad de agua adicionada representa la cantidad de agua absorbida por el agregado reciclado, la cual puede obtenerse por la diferencia de pesadas a los tiempos $\mathrm{T}_{0}$ y $\mathrm{T}_{\mathrm{i}}$ dividido la masa seca del agregado.

Mediante el método descripto en el párrafo anterior los autores concluyen, de modo semejante a la mayoría de los estudios mencionados, que el agregado reciclado presenta una mayor absorción de agua que el agregado natural. Aunque el método en cuestión 
es propuesto para mejorar la determinación de dicha propiedad en el caso de los agregados reciclados, no se realizaron determinaciones mediante los ensayos utilizados habitualmente de manera de poder comparar con la técnica propuesta.

De lo indicado en la bibliografía sobre la capacidad de absorción de agua que presentan los AGR, surge que la presencia de mortero origina una gran variación en los valores de absorción, pudiendo ser desde 2 hasta 30 veces superior a la correspondiente al agregado grueso natural. En este sentido, se observa que para rocas naturales con absorciones inferiores al $1 \%$ la correspondiente a los agregados reciclados se encuentra, en general, por debajo del $5 \%$; en tanto que cuando el agregado natural tiene absorciones del 2 al $3 \%$, el agregado reciclado puede presentar valores del orden del $10 \%$, hecho que estaría indicando que la capacidad total de absorción de agua de los AGR está influenciada tanto por el mortero que forma parte de los agregados reciclados como por la calidad de la roca a partir de la cual se obtuvo el agregado natural.

Esta mayor absorción de agua que presentan los agregados reciclados deberá ser tenida en cuenta al momento de definir las proporciones de los materiales en la elaboración de los mezclas, resultando también de vital importancia en el comportamiento durable de los hormigones elaborados con agregados reciclados.

Diferentes autores han evaluado la porosidad sobre distintas muestras de AGR, obteniendo valores comprendidos entre 12,5 y $16 \%$, presentando los AGN porosidades de entre 0,3 y 3 \% [Gómez et al, 2001; Buyle-Bodin y Hadjieva-Zaharieva, 2002; Vázquez y Barra, 2002]. Esta diferencia entre la porosidad del agregado natural y la del reciclado es siempre atribuida al mortero de cemento que se encuentra presente en los agregados reciclados.

\subsubsection{Resistencia al desgaste}

El ensayo de desgaste por abrasión “Los Ángeles” constituye un método de caracterización de los agregados gruesos que se encuentra fuertemente arraigado, al punto tal que el conocimiento de un determinado valor de pérdida por parte de un agregado nos proporciona una idea de la resistencia y tenacidad de la roca que compone dicho agregado. Sin embargo, el mismo representa una gran exigencia para el material que se encuentra sometido a acciones conjuntas de abrasión e impacto, no sólo entre las partículas que componen el agregado sino también por parte de las bolas de acero que se adicionan. 
Debido a la presencia de interfaces entre los agregados y la pasta de cemento, en general, la resistencia del hormigón resulta inferior a la de la roca que compone el agregado [Ziegeldorf, 1983] y a la del propio mortero [Giaccio y Zerbino, 1997]. Llevado esto a los agregados reciclados obtenidos de la trituración de hormigones, es de esperar que la resistencia de los AGR sea inferior a la de los AGN, debido a la existencia de dichas interfaces en las partículas que componen los agregados reciclados (ver Figura 2.7).

En la Tabla 2.4 se presentan valores de pérdida por desgaste "Los Ángeles" de los AGR y AGN indicados en la bibliografía. Puede observarse un mayor valor de desgaste cuanto menor es la calidad del agregado reciclado (mayor razón a/c del hormigón de origen) [Hansen y Narud, 1983; Tavakoli y Soroushian, 1996; Hernández y Fornasier, 2005; Tabsh y Abdelfatah, 2009]. Este comportamiento fue atribuido a la presencia del mortero que se encontraba adherido a las partículas de los agregados reciclados. Contrariamente, en otro estudio, indican pérdidas de peso por desgaste que fueron independientes de la calidad del hormigón original, con valores del orden del 40 \% [Sri Ravindrarajah y Tam, 1985].

Otro hecho significativo que puede observarse en la Tabla 2.4 es una modificación en los valores de desgaste “Los Ángeles" según sea el tamaño de partícula de agregado considerada, aunque este comportamiento difiere de un autor a otro. Mientras que en algunos casos se verifica una disminución del desgaste al incrementarse la fracción de agregado evaluada [Hansen y Narud, 1983; Sri Ravindrarajah et al, 1988], en otros se indica un comportamiento opuesto, obteniéndose mayores pérdidas al aumentar el tamaño nominal del agregado [Tavakoli y Soroushian, 1996; Gómez et al, 2001].

Según se mencionó anteriormente, una menor edad del hormigón al momento de su trituración produciría un mayor desprendimiento del mortero adherido, hecho al cual se le atribuyó la menor absorción que presentaron los agregados reciclados obtenidos de triturar hormigón a edad temprana (1 día) con relación a los de edades más avanzadas (ver Tabla 2.3). Los resultados obtenidos por el mismo autor en el ensayo de desgaste “Los Ángeles" parecen contradecir lo antedicho. En la misma experiencia, el agregado generado a 1 día presentó una pérdida superior al $40 \%$, mientras que los obtenidos a edades de 7 y 28 días presentaron valores de desgaste menores, del orden del $30 \%$. El AGN tenía un desgaste del 20,5\%. Sin embargo, una menor edad del hormigón al momento de su trituración implica una menor resistencia, con lo cual, el resultado obtenido sigue la misma tendencia mencionada anteriormente mostrada para otros autores. 
Tabla 2.4. Desgaste “Los Ángeles" de los AGR en función de la calidad del hormigón original y el tamaño de partículas.

\begin{tabular}{|c|c|c|c|c|c|}
\hline Referencia & $\begin{array}{c}\text { Fracción } \\
(\mathrm{mm})\end{array}$ & $\begin{array}{c}\text { Desgaste AGR } \\
(\%)\end{array}$ & $\begin{array}{l}\text { Desgaste } \\
\text { AGN (\%) }\end{array}$ & $\begin{array}{l}\text { Tipo de } \\
\text { AGN }\end{array}$ & $\begin{array}{l}\text { Características } \\
\text { Ho de origen }\end{array}$ \\
\hline \multirow{3}{*}{$\begin{array}{c}\text { Hansen y Narud, } \\
1983\end{array}$} & $4-8$ & 30,$1 ; 32,6 ; 41,4$ & 25,9 & \multirow{3}{*}{ Calizo } & \multirow{3}{*}{$\begin{array}{c}\text { Razón a/c } \\
0,40 ; 0,70 ; 1,20, \\
\text { respectivamente }\end{array}$} \\
\hline & $8-16$ & 26,$7 ; 29,2 ; 37,0$ & 22,7 & & \\
\hline & $16-32$ & 22,$4 ; 25,4 ; 31,5$ & 18,8 & & \\
\hline $\begin{array}{c}\text { Sri Ravindrarajah } \\
\text { y Tam, } 1985\end{array}$ & $5-37,5$ & 37,$2 ; 40,8 ; 40,8$ & 18,1 & Granítico & $\begin{array}{c}\text { Razón a/c } \\
0,51 ; 0,60 ; 0,73, \\
\text { respectivamente }\end{array}$ \\
\hline \multirow{4}{*}{$\begin{array}{c}\text { Sri Ravindrarajah } \\
\text { et al, } 1988\end{array}$} & $4,75-9,5$ & 36,2 & \multirow{4}{*}{18,5} & \multirow{4}{*}{ Granítico } & \multirow{4}{*}{$\mathrm{f}^{\prime} \mathrm{c}: 60 \mathrm{MPa}$} \\
\hline & $9,5-13,2$ & 31,6 & & & \\
\hline & $13,2-19$ & 27,7 & & & \\
\hline & $>19$ & 28,8 & & & \\
\hline \multirow{2}{*}{$\begin{array}{c}\text { Tavakoli y } \\
\text { Soroushian, } 1996\end{array}$} & $4,75-19$ & 26,$4 ; 41,7$ & 22,9 & \multirow{2}{*}{ Calizo } & \multirow{2}{*}{$\begin{array}{l}\text { f'c: } 54 ; 44 \mathrm{MPa} \text {, } \\
\text { respectivamente }\end{array}$} \\
\hline & $4,75-25$ & 28,$7 ; 42,7$ & 22,9 & & \\
\hline \multirow{2}{*}{$\begin{array}{l}\text { Hernández y } \\
\text { Fornasier, } 2005\end{array}$} & $4,75-20$ & 32,0 & \multirow{2}{*}{19,0} & \multirow{2}{*}{ Granítico } & Laboratorio \\
\hline & $6-20$ & 40,0 & & & Planta \\
\hline \multirow{3}{*}{$\begin{array}{c}\text { Cúneo Simian y } \\
\text { Durán, } 1995\end{array}$} & $4,75-19$ & 29,2 & 22,0 & Granítico & \multirow{3}{*}{$\mathrm{a} / \mathrm{c}: 0,56$} \\
\hline & $4,75-19$ & 42,5 & 37,0 & $\begin{array}{c}\text { Silíceo } \\
\text { triturado }\end{array}$ & \\
\hline & $4,75-19$ & 31,9 & 21,6 & Basáltico & \\
\hline \multirow{2}{*}{ Gómez et al, 2001} & $5-10$ & 29,9 & 21,2 & \multirow{2}{*}{ Calizo } & \multirow{2}{*}{--- } \\
\hline & $10-20$ & 33,4 & 21,6 & & \\
\hline $\begin{array}{c}\text { Tabsh y } \\
\text { Abdelfatah, } 2009\end{array}$ & $4,75-25$ & $28 ; 33$ & 24,0 & --- & $\begin{array}{l}\mathrm{f}^{\prime} \mathrm{c}: 50 ; 30 \mathrm{MPa}, \\
\text { respectivamente }\end{array}$ \\
\hline
\end{tabular}

En el caso de agregados reciclados obtenidos de un centro de reciclaje, en donde se desconoce la calidad de los hormigones triturados, se indican pérdidas superiores al $40 \%$, con una variación del 5,1 \% [Sánchez de Juan y Alaejos Gutiérrez, 2003].

Como conclusión de lo expuesto en diversos trabajos de investigación en lo que se refiere a la pérdida de peso que sufre el AGR al ser evaluado por medio del ensayo "Los Ángeles" surge que, al igual que en el caso de la absorción, en la determinación de éste 
parámetro también tiene una gran influencia tanto la calidad de la roca natural como la del mortero que forma parte de los agregados reciclados, presentando el ensayo de desgaste una gran variación entre diferentes muestras de AGR.

\subsubsection{Contenido de mortero adherido a los agregados}

La presencia de mortero, como ya se mencionó, es la causante de las mayores diferencias existentes entre las propiedades de los agregados reciclados respecto a los naturales. Algunos autores han encontrado que el contenido de mortero presente en los agregados reciclados se incrementa a medida que el tamaño nominal disminuye [Hansen y Narud, 1983; Limbachiya et al, 2000; Katz, 2003; Sánchez de Juan y Alaejos Gutiérrez, 2009; Tanaka et al, 2004]. Sin embargo, en la Tabla 2.5 puede observarse que los contenidos resultan muy diferentes de un autor a otro, siendo en algunos casos superiores al $30 \%$ y en otros del orden del $10 \%$. Estas diferencias pueden ser atribuidas al método de procesamiento utilizado, ya que cuando el AGR fue obtenido mediante una trituradora de mandíbulas, en una sola pasada, los contenidos de mortero resultaron muy superiores a los obtenidos en AGR generados en una planta productora de agregados, que incluía una trituradora primaria de mandíbulas y una secundaria de conos, lo cual permitió disminuir el contenido de mortero adherido a los agregados reciclados.

Tabla 2.5. Contenido de mortero de los AGR en función de la calidad del hormigón original y el tamaño de partículas.

\begin{tabular}{|c|c|c|c|}
\hline Referencia & $\begin{array}{c}\text { Fracción } \\
(\mathrm{mm})\end{array}$ & $\begin{array}{c}\text { Mortero adherido } \\
\text { en los AGR (\%) }\end{array}$ & $\begin{array}{l}\text { Características del } \\
\text { hormigón de origen }\end{array}$ \\
\hline \multirow{3}{*}{$\begin{array}{c}\text { Hansen y Narud, } \\
1983\end{array}$} & $4-8$ & $58 ; 64 ; 61$ & \multirow{3}{*}{$\begin{array}{c}\text { Razón a/c } \\
0,40 ; 0,70 ; 1,20 \text {, res- } \\
\text { pectivamente }\end{array}$} \\
\hline & $8-16$ & $38 ; 39 ; 39$ & \\
\hline & $16-32$ & $35 ; 28 ; 25$ & \\
\hline \multirow{2}{*}{$\begin{array}{c}\text { Limbachiya et al, } \\
2000\end{array}$} & 5-10 & 11,5 & \multirow{2}{*}{ Planta de reciclados } \\
\hline & $10-20$ & 9,3 & \\
\hline \multirow{2}{*}{ Katz, 2003} & $2,36-9,5$ & $16 ; 15 ; 13$ & \multirow{2}{*}{$\begin{array}{c}\text { AGR a edades de } 1, \\
3 \text { y } 28 \text { días }\end{array}$} \\
\hline & $9.5-25$ & $7 ; 6,7$ & \\
\hline \multirow{2}{*}{$\begin{array}{c}\text { Sánchez de Juan y } \\
\text { Alaejos Gutiérrez, } \\
2009\end{array}$} & $4-8$ & $33-55$ & \multirow{2}{*}{$\begin{array}{l}15 \text { muestras de una } \\
\text { planta de reciclados }\end{array}$} \\
\hline & $8-16$ & $23-44$ & \\
\hline
\end{tabular}


Asimismo, en la Tabla 2.5 también puede observarse que, para una misma fracción de agregados reciclados, los contenidos de mortero no presentan diferencias significativas, ya sea que los mismos hayan sido obtenidos de hormigones de diferentes calidades o de hormigones triturados a distintas edades. Sin embargo, Sánchez de Juan y Alaejos Gutiérrez (2009), al evaluar muestras de AGR de origen variado y desconocido obtuvieron que los contenidos de mortero adherido se encontraban en un amplio rango de valores, indicándose que aquellos agregados cuyo contenido de mortero sea inferior al $44 \%$ pueden ser considerados de buena calidad para la elaboración de hormigones estructurales.

Se podría pensar que al disminuir la calidad del hormigón que se tritura, la cantidad de mortero adherido a los agregados reciclados será menor, aunque ello no se traduzca necesariamente en una mejora de sus propiedades, estando las mismas influenciadas por factores propios de las mezclas como contenido unitario de cemento, relación agregado grueso/agregado fino, tipo de agregado natural, tamaño máximo, etc.

\subsection{8. Índices de lajosidad y elongación}

En algunas rocas naturales, la existencia de planos de fractura orientados puede hacer que el proceso de trituración produzca una importante cantidad de partículas lajosas en los AGN [Poole y Sims, 2003; Czarnecka y Gillott, 1982]. En el caso de los hormigones que se trituran, los planos de debilidad (interfaces) se encuentran distribuidos sin una orientación definida, provocando que los AGR presenten bajos porcentajes de partículas lajosas.

En general, se ha encontrado que la presencia del mortero adherido a las partículas de roca natural produce una modificación en la forma de las partículas de los agregados reciclados, resultando menores valores para el índice de lajas [Gómez et al, 2001; Hernández y Fornasier, 2005]; estos últimos autores indican índices de elongación en los AGR similares o superiores al del AGN.

\subsubsection{Durabilidad por ataque con sulfato de sodio}

No es frecuente encontrar en la bibliografía determinaciones sobre la durabilidad de los agregados reciclados frente al ataque por sulfato. El método que habitualmente se aplica es el especificado en la Norma ASTM C 88 para agregados naturales, ataque físico por precipitación de sales de sulfato. Como es de esperar, las pérdidas obtenidas en los AGR resultan, en todos los casos, superiores a las determinadas sobre los agregados natu- 
rales aunque, de igual modo que sucede con otros ensayos, se encontraron diferencias en los resultados indicados por diferentes autores. Mientras que en algún caso indican pérdidas que rondan el $26 \%$ [Buyle-Bodin y Hadjieva-Zaharieva, 2002], en otro resultan del orden del $11 \%$ [Tabsh y Abdelfatah, 2009], con un leve incremento al disminuir la resistencia del hormigón que dio origen a los AGR.

En estudios realizados en el LEMIT sobre AGR obtenidos a partir de la trituración de hormigones de origen desconocido y variado, conteniendo piedra partida granítica como AGN, los valores medios de pérdida por ataque físico con sulfato de sodio fueron del $44 \%$, con una variación del $17 \%$ [Zega, 2008].

\subsubsection{Contenido de polvo}

Si bien el contenido de polvo $(<75 \mu \mathrm{m})$ presente en el AGR es superior al del AGN, en la mayoría de los casos este valor ha estado por debajo del límite $(1 \%)$ admitido por la Instrucción de Hormigón Estructural (EHE) [Sánchez de Juan y Alaejos Gutiérrez, 2003].

En estudios previos realizados en el LEMIT, se encontró que la cantidad de polvo presente en los AGR puede ser similar al del agregado natural granítico [Zega, 2008], obteniéndose en la mayoría de los casos porcentajes inferiores al límite $(1,5 \%)$ indicado en el Proyecto de Reglamento Argentino [CIRSOC 201:2005] para AGN de trituración.

Otros autores hallaron que uno de los agregados reciclados presentaba un porcentaje de material fino similar al del agregado natural granítico mientras que en el otro agregado dicho porcentaje era levemente superior [Hernández y Fornasier, 2005]. Por lo tanto, dicho comportamiento dependerá de la limpieza que tenga el material, pudiendo en algunos casos presentar cantidades de polvo semejantes al del agregado natural.

\subsubsection{Recomendaciones y normativas}

En la Tabla 2.6 se presentan las especificaciones más importantes consideradas en algunas de las recomendaciones o normativas existentes a nivel internacional para el uso de los agregados reciclados de hormigón.

Debe mencionarse que la mayoría de estas recomendaciones limita el uso los agregados reciclados a la fracción gruesa, descartando los AFR o, en el mejor de los casos, la fracción con tamaño de partículas inferior a $2 \mathrm{~mm}$. 
Tabla 2.6. Requisitos para los agregados reciclados según distintas recomendaciones internacionales.

\begin{tabular}{|c|c|c|c|c|c|c|}
\hline Fuente & Densidad & Absorción & $\begin{array}{c}\text { Desgaste } \\
\text { "Los Ángeles" }\end{array}$ & $\begin{array}{c}\text { Pasa tamiz } \\
75 \mu \mathrm{m}\end{array}$ & $\begin{array}{c}\text { Pasa tamiz } \\
4,75 \mathrm{~mm}\end{array}$ & $\begin{array}{l}\text { Contenido } \\
\text { cloruro }^{1)}\end{array}$ \\
\hline $\begin{array}{c}\text { Alemania } \\
\text { [Grübl y Rühl, } \\
\text { 1998] }\end{array}$ & $>2000$ & $<10 \%$ & --- & --- & $<5 \%$ & $<0,04 \%$ \\
\hline $\begin{array}{c}\text { RILEM } \\
\text { [121-DRG, 1994] }\end{array}$ & $>2000$ & $<10 \%$ & --- & $<2 \%$ & $<5 \%$ & $=\mathrm{AN}$ \\
\hline $\begin{array}{c}\text { Hungría } \\
\text { [Balázs et al, 2008] }\end{array}$ & $2000-3000$ & --- & --- & --- & --- & --- \\
\hline $\begin{array}{c}\text { Japón } \\
\text { [Kasai, 1994] }\end{array}$ & $>2200$ & $<7 \%$ & $<35 \%$ & $<1 \%$ & --- & $<0,04 \%$ \\
\hline $\begin{array}{c}\text { Australia } \\
\text { [Sagoe-Crentsil y } \\
\text { Brown, 1998] }\end{array}$ & $>2100$ & $<6 \%$ & $<30 \%$ & $<1 \%$ & --- & $=\mathrm{AN}$ \\
\hline $\begin{array}{c}\text { España } \\
\text { [EHE, 2008] }\end{array}$ & --- & $<7 \%$ & $<40 \%$ & $<2 \%$ & $<5 \%$ & $=\mathrm{AN}$ \\
\hline $\begin{array}{c}\text { Bélgica } \\
\text { [Vyncke y Rous- } \\
\text { seau, 1994] }\end{array}$ & $>2100$ & $<9 \%$ & --- & $<3 \%$ & $<5 \%$ & $<0,06 \%$ \\
\hline $\begin{array}{c}\text { Holanda } \\
\text { [Janssen y Put, } \\
\text { 2005] }\end{array}$ & $>2100$ & $<6 \%$ & $<40 \%$ & --- & --- & --- \\
\hline $\begin{array}{c}\text { Hong Kong } \\
\text { [Poon, 2005] }\end{array}$ & $>2000$ & $<10 \%$ & --- & $<4 \%$ & $<5 \%$ & $<0,05 \%$ \\
\hline
\end{tabular}

1) Contenido de cloruro expresado en $\%$ del peso del agregado.

Con relación a la densidad de los agregados reciclados, considerándolos en la condición de seco a peso constante, las diferentes recomendaciones establecen un valor mínimo que, en general, se encuentra entre 2000 y $2200 \mathrm{~kg} / \mathrm{m}^{3}$. Estos valores son acorde con la densidad que pueden presentar los hormigones elaborados con agregados naturales de densidad normal.

En lo que respecta a la absorción de agua, la cual constituye uno de los puntos críticos que presentan los agregados reciclados dada la gran diferencia que tienen con los agregados naturales, las distintas recomendaciones indican diferentes porcentajes límites. Algunas establecen exigencias mayores limitando la absorción de los agregados reciclados a un máximo de $6 \%$, mientras que otras permiten hasta un $10 \%$. Dichos valores se co- 
rresponden con las diferentes calidades de los agregados naturales, de acuerdo a la disponibilidad en cada país.

Otra de las propiedades que se exigen a los agregados reciclados está relacionada con su resistencia, aunque no todas las recomendaciones consultadas hacen referencia a ello. Algunas indican evaluar los agregados reciclados mediante el ensayo de desgaste “Los Ángeles”, estableciendo límites máximos de pérdida variables entre 30 y 40 \%.

En cuanto al contenido de polvo, que de acuerdo a la recomendación que se utilice puede considerar como tal al material que pasa por lavado el tamiz de abertura de malla de 75 o $63 \mu \mathrm{m}$, en general los límites resultan similares a los del agregado natural, con valores del 1 al $2 \%$, aunque en algunos casos se permite hasta un $4 \%$ de pérdida. El contenido de material fino (partículas $<4,75 \mathrm{~mm}$ ) que pueden presentar los AGR se encuentra limitado en todos los casos al $5 \%$.

Si bien algunas recomendaciones son más exigentes que otras en cuanto a la presencia de contaminantes, como sulfato, arsénico, cromo, mercurio, etc. [Grübl y Rühl, 1998], en la mayoría de ellas se hace referencia al contenido máximo admisible de cloruro. En general, debe estar por debajo del 0,05\%.

\subsection{Hormigones reciclados}

Las características distintivas que presentan los AGR obtenidos a partir de la trituración de hormigones, respecto a las que poseen los AGN, producen modificaciones en sus propiedades físico-mecánicas y durables debido a la presencia del mortero del hormigón original en la composición de sus partículas. Por tal motivo, la composición de los AGR puede provocar modificaciones en las propiedades de las mezclas que se elaboren, tanto en estado fresco como así también sobre el comportamiento mecánico y durable de los hormigones reciclados.

\subsubsection{Estado fresco}

\subsubsection{Consistencia}

La mayoría de los AGN habitualmente utilizados en la región central de Argentina poseen un bajo coeficiente de absorción efectivo, por lo que las modificaciones que se producen en el contenido de agua de mezclado de los hormigones con ellos elaborados son despreciables. Sin embargo, si la absorción es elevada, debe ser tenida en cuenta al 
momento de elaborar las mezclas. Esta situación se produce cuando se emplean AGR. La desatención de este aspecto puede producir modificaciones importantes en la trabajabilidad de las mezclas.

En la bibliografía se hace referencia a tres metodologías de trabajo adoptadas para la elaboración de hormigones reciclados. Una de ellas consiste en utilizar los AGR en estado de humedad natural al igual que los agregados naturales, es decir, secos al aire. Otra metodología se basa en considerar la absorción efectiva del agregado reciclado, o sea la cantidad de agua que es capaz de absorber desde el estado de humedad natural hasta el de saturado y superficie seca, adicionando dicha cantidad como agua adicional de mezclado. Si bien al utilizar esta metodología se puede diferenciar entre razones a/c total y efectiva, según se considere o no el agua extra adicionada, no sería posible asegurar la cantidad de agua que el agregado haya absorbido, debido a que, como ya se mencionó, la misma dependerá de que el agregado entre en contacto directo sólo con el agua de mezclado, con la pasta de cemento o con el mortero del hormigón [Vázquez y Barra, 2002]. Sin embargo, este método sería efectivo si el agregado se mantuviera durante al menos 30 minutos sumergido en el agua total de mezclado, ya que durante dicho tiempo estaría absorbiendo alrededor del $90 \%$ de su capacidad [Buttler, 2003]. Un tercer procedimiento adoptado en varios estudios consiste en saturar los agregados reciclados durante 24 horas previo a su empleo, evitando de esta forma que absorban parte del agua de mezclado [Di Maio et al, 2002].

Cuando los agregados reciclados fueron empleados en la condición de humedad natural, es decir, secos al aire, fue necesario adicionar un contenido de agua extra a las mezclas, del orden de 10 a $15 \mathrm{l} / \mathrm{m}^{3}$, para obtener asentamientos semejantes a los de mezclas de similares características elaboradas con agregados naturales [Hansen y Narud, 1983; Sri Ravindrarajah y Tam, 1985]. Además, los asentamientos medidos resultaron independientes de la calidad del agregado reciclado como así también de la matriz de los hormigones reciclados. Cuando el procedimiento adoptado consistió en emplear los agregados reciclados en estado de humedad natural y ajustar la cantidad de agua de mezclado en función de la absorción efectiva de los AGR, no se encontraron diferencias entre los asentamientos medidos en las mezclas con respecto a las producidas con $100 \%$ de agregados naturales [Sri Ravindrarajah et al, 1987]. Por el contrario, otro estudio concluyó que para un mismo tipo de mezcla, la elaborada con agregado reciclado presentó un asentamiento muy superior al correspondiente a la mezcla con agregado natural [Rasheeduzzafar y Khan, 1984]. 
Se evidencia que el estado de humedad inicial en que se hallen los AGR al momento de utilizarlos influirá sobre el asentamiento de los hormigones con ellos elaborados. A partir de variar dicho estado de humedad (seco al aire, seco a peso constante y saturado a superficie seca) Poon et al (2004) indican que cuando los agregados fueron empleados en estado saturado no se observaron variaciones del asentamiento en el tiempo en ninguna de las mezclas. Al emplear los agregados en estado seco debieron incrementar el contenido de agua de mezclado, en mayor medida cuanto mayor era el porcentaje de agregado natural reemplazado, lo cual hizo que los asentamientos iniciales resultaran en algunos casos algo diferentes. Respecto a la variación del asentamiento en el tiempo, las mezclas con agregados naturales presentaron una leve pérdida de asentamiento en el tiempo, lo cual no ocurrió con las mezclas recicladas debido a un mayor contenido de agua inicial.

Otro modo de evitar la pérdida de asentamiento que ocurre en las mezclas recicladas es mediante el empleo de aditivos plastificantes y/o superplastificantes. Esta situación resulta de importancia en mezclas de baja razón a/c, donde el contenido de agua de mezclado se encuentra limitado, en cuyo caso podrá mantenerse constante la cantidad de agua a cambio de incrementar la dosis de aditivo con miras de lograr asentamientos similares a los de las mezclas convencionales [Hernández y Fornasier, 2005].

\subsubsection{Peso por unidad de volumen}

La menor densidad que presentan los AGR, debido a la mayor porosidad del mortero de cemento presente en sus partículas, origina que el peso por unidad de volumen en estado fresco $\left(\mathrm{PUV}_{\mathrm{fr}}\right)$ de las mezclas recicladas sea inferior al de las elaboradas con agregados naturales del mismo tipo. Este hecho fue confirmado por diferentes autores [Hansen y Narud, 1983; Sri Ravindrarajah y Tam, 1985; ACI, 2002; Hernández y Fornasier, 2005], quienes obtuvieron valores de PUV de 50 a $150 \mathrm{~kg} / \mathrm{m}^{3}$ menores que en las mezclas convencionales. Este hecho hace que cuanto mayor sea el porcentaje de agregado reciclado menor será el PUV de las mezclas con ellos elaboradas [Di Maio et al, 2002; Topçu y Sengel, 2004].

También se ha indicado que la disminución en el PUV de las mezclas recicladas puede ser atribuida, en parte, a un mayor contenido de aire naturalmente incorporado que pueden presentar las mezclas recicladas [Katz, 2003].

\subsubsection{Aire naturalmente incorporado}

En algunos casos se ha determinado que el porcentaje de aire naturalmente incorporado durante la elaboración del hormigón no variaba de manera significativa entre un 
hormigón convencional y el producido con agregados reciclados [Hansen y Narud, 1983]. Contrariamente, en otros estudios concluyeron que el contenido de aire en los hormigones reciclados resulta superior al de los hormigones convencionales de similares características [Di Maio et al, 2001; Hernández y Fornasier, 2005], señalando incluso que la causa que produce dicho fenómeno no resulta del todo clara [Katz, 2003].

\subsubsection{Comportamiento mecánico}

Las diferentes texturas superficiales de los AGN producen modificaciones en las características de los hormigones con ellos elaborados, ya sea en el estado fresco como así también en el comportamiento mecánico. En el caso de los AGR, su mayor porosidad y rugosidad superficial respecto a los agregados naturales no sólo produce modificaciones de las mezclas en estado fresco, sino que también influirá sobre las propiedades de los hormigones en estado endurecido, debido a una potencial mejora de la zona de interfaz agregado-mortero, con una menor porosidad y por tanto una mayor calidad de la misma, aunque la resistencia del propio agregado reciclado sea menor a la del agregado natural [Poon et al, 2004); Casuccio et al, 2008].

\subsubsection{Resistencia a compresión}

Dada la naturaleza de los agregados reciclados, el porcentaje de empleo como reemplazo de los agregados naturales será de importancia en el comportamiento resistente de los hormigones.

Se ha concluido que la resistencia a compresión del hormigón reciclado resulta semejante a la del hormigón convencional hasta un 30 \% de reemplazo del AGN por el AGR [Limbachiya et al, 2000; Gómez et al, 2001]. En algunos casos, dicho comportamiento se verificó hasta reemplazos del 50 \% en mezclas que habían sido elaboradas con un contenido de cemento de $350 \mathrm{~kg} / \mathrm{m}^{3}$, mostrando el hormigón con $100 \%$ de AGR una disminución de resistencia del 16 \% [Gonçalves et al, 2004]. Si bien no presentan ninguna justificación respecto a dicho descenso de la resistencia, se debe mencionar que, al tener en consideración la absorción de los agregados, las mezclas recicladas fueron elaboradas con mayor cantidad de agua. Por tal motivo, si bien consideran que la razón a/c efectiva es igual en las mezclas de referencia y recicladas, la razón a/c total es muy superior en los hormigones reciclados, lo cual puede ser motivo de la disminución en la resistencia a compresión. 
Estudios de laboratorio realizados a nivel nacional han mostrado que la resistencia a compresión de los hormigones reciclados es semejante a la de sus pares convencionales hasta reemplazos del 75 \% [Di Maio et al, 2002; Di Maio et al, 2005; Zega et al, 2006], ya sea que los AGR provengan de hormigones previamente elaborados para tal fin o que hayan sido obtenidos a partir de la trituración de hormigones de procedencia desconocida.

Hansen y Narud (1983) estudiaron la influencia que tenía la calidad del hormigón de origen sobre las propiedades de los AGR y sobre la de los hormigones reciclados. Se elaboraron hormigones de tres calidades (alta, media y baja) a partir de variar la razón a/c, empleando AGR obtenidos a partir de triturar hormigones de las mismas tres calidades mencionadas. La resistencia a compresión de los hormigones reciclados resultó del mismo orden que la de los hormigones convencionales de igual nivel resistente que dieron origen a los AGR. A diferencia de ello, cuando la calidad del hormigón triturado fue inferior a la del nuevo hormigón la resistencia disminuyó, haciéndolo en mayor medida cuanto menor era la razón a/c de este último (Tabla 2.7). Asimismo, se indica que la resistencia a compresión del hormigón reciclado está muy controlada por la razón a/c del hormigón que dio origen a los AGR, cuando los demás factores permanecen invariables. También informaron que se podrían elaborar hormigones reciclados de alta resistencia aunque el contenido de cemento se vería incrementado en comparación con un hormigón convencional.

Tabla 2.7. Resistencia a compresión de hormigones reciclados en función de la calidad del agregado grueso reciclado.

[Hansen y Narud, 1983]

\begin{tabular}{|c|c|c|c|c|c|c|c|c|c|c|c|c|}
\hline & \multicolumn{12}{|c|}{ Resistencia a compresión (MPa) } \\
\hline Calidad de & \multicolumn{4}{|c|}{ Alta } & \multicolumn{4}{|c|}{ Media } & \multicolumn{4}{|c|}{ Baja } \\
\hline $\begin{array}{l}\text { Calidad del } \\
\qquad \text { AGR }\end{array}$ & - & Alta & Media & Baja & - & Alta & Media & Baja & - & Alta & Media & Baja \\
\hline Serie 1 & 56,4 & 61,2 & 49,3 & 34,6 & 34,4 & 35,1 & 33,0 & 26,9 & 13,8 & 14,8 & 14,5 & 13,4 \\
\hline Serie 2 & 61,2 & 60,7 & - & - & 36,0 & - & 36,2 & - & 14,5 & - & - & 13,6 \\
\hline
\end{tabular}

De igual manera, un estudio actual indica que el empleo de $100 \%$ de agregados reciclados provenientes de hormigones de buena calidad ( $f^{\prime}$ c: $50 \mathrm{MPa}$ ) permitió obtener hormigones reciclados de igual nivel resistente que el hormigón de origen, mientras que ello no fue posible cuando los AGR provinieron de hormigones de calidad media ( $\mathrm{f}^{\prime}$ : $30 \mathrm{MPa}$ ) [Tabsh y Abdelfatah, 2009]. Asimismo, se indica que la disminución de resis- 
tencia debido al uso de agregados reciclados es más significativa en hormigones de menor nivel resistente.

Otros autores por su parte, concluyeron que la resistencia de los hormigones reciclados resultó inferior a la de los hormigones convencionales, tanto cuando la misma se determinó sobre muestras cúbicas como cilíndricas (Tabla 2.8), lo cual fue atribuido a distintas causas: la porosidad total del hormigón reciclado es mayor que la del hormigón original; la resistencia del AGR a las acciones mecánicas es significativamente menor que la del agregado natural; y la cantidad de interfases débiles en el hormigón reciclado es mayor que en el hormigón original. En el caso particular de las mezclas de alta calidad, obtuvieron valores de resistencia algo superiores en los hormigones reciclados que en los hormigones convencionales cuando utilizaron probetas cilíndricas. Además, y contrariamente a lo informado en otros estudios, indican que la resistencia a compresión del hormigón reciclado está gobernada por la razón a/c del nuevo mortero y que la resistencia del hormigón a partir del cual se obtuvieron los agregados reciclados no tiene influencia.

Tabla 2.8. Resistencia a compresión en función de la calidad del agregado reciclado.

[Sri Ravindrarajah y Tam, 1985]

\begin{tabular}{|c|c|c|c|}
\hline \multirow{3}{*}{$\begin{array}{c}\text { Calidad de matriz } \\
\text { la }\end{array}$} & \multirow{2}{*}{$\begin{array}{c}\text { Calidad del } \\
\text { AGR }\end{array}$} & \multicolumn{2}{|c|}{$\begin{array}{r}\text { Resistencia a Compresión (MPa) } \\
\text { (28 días) }\end{array}$} \\
\cline { 3 - 4 } & - & 42,5 & 26,5 \\
\hline \multirow{4}{*}{ Alta } & Alta & 40,5 & 33,0 \\
\cline { 2 - 4 } & Media & 39,0 & 31,0 \\
\cline { 2 - 4 } & Baja & 37,5 & 32,0 \\
\hline \multirow{4}{*}{ Media } & - & 37,5 & 27,5 \\
\cline { 2 - 4 } & Alta & 29,5 & 22,0 \\
\cline { 2 - 4 } & Media & 30,0 & 25,5 \\
\cline { 2 - 4 } & Baja & 28,5 & 22,5 \\
\hline \multirow{4}{*}{ Baja } & - & 28,5 & 20,0 \\
\cline { 2 - 4 } & Alta & 24,5 & 18,5 \\
\cline { 2 - 4 } & Media & 27,0 & 20,5 \\
\cline { 2 - 4 } & Baja & 24,0 & 19,5 \\
\hline
\end{tabular}


$\mathrm{Al}$ analizar la influencia de la razón a/c del nuevo hormigón sobre la resistencia a compresión de los hormigones reciclados, se observó que para razones a/c $<0,45$ la resistencia a compresión del hormigón reciclado era hasta un 30 \% inferior a la del hormigón convencional de similares características; mientras que para razones a/c $>0,45$ ambos tipos de hormigones presentaban similares resistencias (Figura 2.8). Asimismo, se indica que para razones a/c $<0,40$ la resistencia de los hormigones reciclados no se incrementa de manera significativa [Rasheeduzzafar y Khan, 1984].

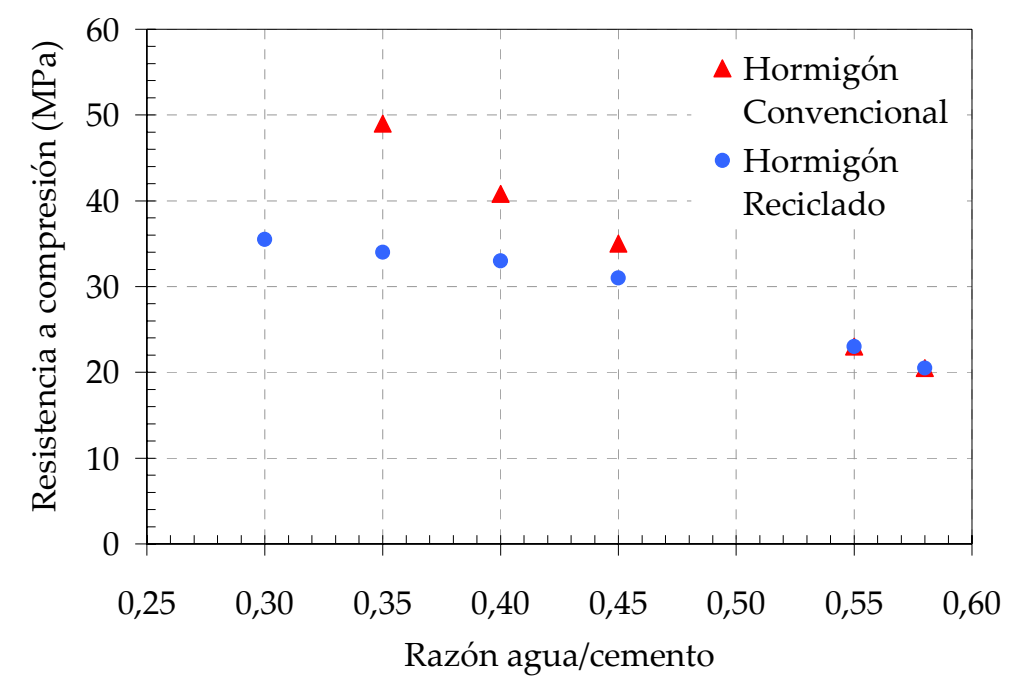

Figura 2.8. Variación de la resistencia a compresión con la razón a/c para hormigones reciclados y convencionales.

(Adaptado de Rasheeduzzafar y Khan, 1984)

En coincidencia con esto, otros autores encontraron que la resistencia a compresión de los hormigones reciclados era igual a la del hormigón convencional para razones a/c 0,40, 0,55 y 0,70, mientras que para una razón a/c 0,25 la resistencia a compresión del hormigón reciclado resultó un $15 \%$ inferior. Este comportamiento lo atribuyeron a que, cuando la razón a/c del nuevo hormigón es mayor a la del hormigón de origen, es decir, a partir del cual se obtuvieron los agregados reciclados, la zona de interfaz agregado reciclado-mortero resulta más débil que la interfaz agregado natural-mortero que forma parte del agregado reciclado, gobernando de este modo la resistencia de los hormigones reciclados; por el contrario, cuando la razón a/c del nuevo hormigón es inferior a la del hormigón de origen, la zona de interfaz agregado reciclado-mortero resulta de mejor calidad, y por lo tanto con una resistencia mayor, que la interfaz agregado natural-mortero del hormigón de origen, por lo que la resistencia del nuevo hormigón estará gobernada por la resistencia de esta última. Este razonamiento se fundamenta en el hecho que para una razón a/c 0,55, la resistencia a compresión de los hormigones elaborados con agregados 
reciclados provenientes de hormigones con distintos niveles resistentes resultaron similares a la del hormigón convencional, mientras que para una razón a/c 0,25 , se produjo un descenso de la resistencia de los hormigones reciclados a medida que la resistencia del agregado reciclado disminuía [Otsuki et al, 2003].

Contrariamente a los resultados mencionados, otros autores señalaron que al disminuir la razón a/c siempre se consiguieron aumentos de resistencia en los hormigones reciclados, aunque no proporcionales a los hallados en hormigones convencionales. Asimismo, se verifica que para un determinado nivel resistente, el contenido de cemento de los hormigones reciclados es mayor que en los hormigones convencionales, incrementándose al hacerlo el nivel resistente [Vázquez y Barra, 2002]. Este hecho fue confirmado por otros autores quienes concluyeron que no sólo los valores de resistencia a compresión del hormigón reciclado son menores a los del hormigón convencional sino que también la diferencia de resistencia entre el hormigón convencional y el reciclado disminuye a medida que la razón a/c se incrementa [Sri Ravindrarajah et al, 1988; Hernández y Fornasier, 2005].

Con relación al empleo de la fracción fina reciclada, se suele indicar que la misma puede ocasionar inconvenientes debido a su elevado contenido de polvo e impurezas [Grübl y Rühl, 1998]. Su utilización ha conducido a resultados dispares en diferentes estudios. En este sentido, algunos autores han concluido que la resistencia de los hormigones elaborados con agregados grueso y fino reciclados era inferior a la de los elaborados con AGR y agregado fino natural, y que ambos presentaban resistencias inferiores a la de los hormigones convencionales [Buyle-Bodin y Hadjieva-Zaharieva, 2002]. Otros, en cambio, observaron que no había diferencias en los valores de resistencia de los diferentes hormigones reciclados elaborados empleando la fracción fina y/o gruesa reciclada triturada a distintas edades, aunque sí de estos respecto al hormigón de referencia, alcanzando a los 28 días una resistencia del 76 \% de dicho hormigón [Katz, 2003]. De manera contraria a lo señalado, Ajdukiewicz y Kliszczewicz (2002) concluyeron que la resistencia de los hormigones reciclados era semejante a la de los hormigones elaborados con agregados naturales, ya sea que para su elaboración hayan empleado la fracción gruesa reciclada o que también hayan utilizado la fracción fina reciclada. En estas últimas experiencias utilizaron agregados reciclados provenientes de la trituración de diferentes estructuras demolidas, con edades de entre 2 y 7 años. El rango de resistencias de estos hormigones estaba comprendido entre 35 y $70 \mathrm{MPa}$. 


\subsubsection{Resistencia a tracción}

Diferentes autores que indicaron una disminución de la resistencia a compresión de los hormigones reciclados con relación a los convencionales de similares características, señalaron las mismas conclusiones al determinar su resistencia a tracción indirecta. En algunos casos indican que la variación de la razón a/c tiene mayor influencia sobre la resistencia a compresión que sobre la resistencia a tracción, aunque el hormigón reciclado se comporta de manera similar al convencional ante dicha variación de la razón a/c [Sri Ravindrarajah et al, 1987]. Otros, en cambio, indican que la resistencia a tracción de los hormigones reciclados es igual a la de los hormigones convencionales para razones a/c superiores a 0,40, estando la misma gobernada por la resistencia de la zona de interfaz agregado reciclado-mortero. Para bajas razones a/c $(\mathrm{a} / \mathrm{c}$ 0,25), la resistencia del hormigón reciclado resulta inferior a la del convencional, estando en este caso gobernada por la resistencia de la zona de interfaz agregado-mortero del hormigón de origen [Otsuki et al, 2003]. De manera contraria a lo mencionado, Tabsh y Abdelfatah (2009) señalan una mayor pérdida de resistencia a tracción en los hormigones reciclados, respecto a los convencionales, cuanto menor es el nivel resistente de los mismos.

Otros estudios indican similar variación de la resistencia a tracción por compresión diametral con la razón a/c para los hormigones reciclados y convencionales, disminuyendo su resistencia a medida que el porcentaje de agregado reciclado es mayor [Di Maio et al, 2001; Gómez et al, 2001; Gómez-Soberón, 2002].

Respecto al tamaño máximo del agregado grueso, Tavakoli y Soroushian (1996) indican que en los hormigones reciclados la resistencia a tracción no se vio afectada por una variación del mismo, mientras que un mayor tamaño máximo provocó un leve incremento de la misma en los hormigones convencionales. Los valores de resistencia a tracción obtenidos fueron, en mayor parte, superiores en los hormigones reciclados que en los convencionales.

La obtención de agregados reciclados a partir de triturar hormigones a edades tempranas (1 día) conduciría a un incremento de la resistencia a tracción indirecta de los hormigones con ellos elaborados, respecto a la obtenida en hormigones en los cuales se emplearon agregados reciclados generados a edades más avanzadas [Katz, 2003]. Este hecho podría ser atribuido a una capacidad cementante latente de las partículas de cemento sin hidratar que se encuentra en los agregados reciclados, debido a la temprana edad a la cual se trituró el hormigón. 
El comportamiento resistente en tracción de hormigones conteniendo AFR ha sido poco estudiado. En tal sentido, algunos autores han obtenido resistencias en hormigones con agregados grueso y fino reciclados similares o levemente inferiores a las obtenidas en hormigones que utilizan sólo la fracción gruesa reciclada, como así también respecto a los convencionales [Ajdukiewicz y Kliszczewicz, 2002], mientras que otros indican una disminución de la resistencia a tracción al incrementarse el porcentaje de AFR utilizado [Evangelista y de Brito, 2007].

El comportamiento del hormigón reciclado en flexión resulta similar al que exhibe en tracción por compresión diametral, presentando un menor módulo de rotura que el hormigón convencional. La variación de la razón a/c tiene más influencia sobre el ensayo de compresión que sobre este ensayo y el comportamiento del hormigón reciclado frente a la variación de la razón a/c es semejante al de un hormigón convencional [Sri Ravindrarajah et al, 1987].

Hernández y Fornasier (2005) concluyeron que el empleo de AGR de menor resistencia, evaluada a través del ensayo de desgaste “Los Ángeles”, conduciría a la obtención de un menor módulo de rotura en flexión en los hormigones con ellos elaborados.

\subsubsection{Módulo de elasticidad estático}

El hormigón por su carácter compuesto posee un módulo de elasticidad estático intermedio entre el del agregado natural y el de la pasta de cemento. En consecuencia, el mismo resulta fuertemente afectado por el tipo de agregado grueso que contenga el hormigón [Mehta y Monteiro, 1998].

En los hormigones elaborados con agregados reciclados, el contenido de mortero será superior al de un hormigón convencional, el de la nueva matriz y el que aportan los agregados reciclados, por lo cual es de esperar que el módulo de elasticidad del hormigón reciclado resulte, en principio, inferior al de un hormigón convencional de igual nivel resistente y elaborado con agregados naturales del mismo tipo.

Diferentes autores han indicado disminuciones del 8 al $15 \%$ en el valor del módulo estático de los hormigones reciclados respecto a los convencionales de igual resistencia, disminuyendo dicha diferencia al aumentar la resistencia de los hormigones [Sri Ravindrarajah y Tam, 1985; Ajdukiewicz y Kliszczewicz, 2002]. Como es de esperar, la disminución del módulo de elasticidad será mayor cuanto más elevado sea el porcentaje de AGR utilizado [Di Maio et al, 2002; Zega et al, 2006]. 


\subsubsection{Desempeño durable}

La durabilidad de los hormigones, es decir, su capacidad para resistir el paso del tiempo sin degradarse, se encuentra íntimamente vinculada a la estructura de poros del material y principalmente a la interconexión de ellos con el medio exterior. Ambas características dependen, en primera instancia, de las cantidades relativas de agua y material cementíceo, como así también del grado de hidratación de la pasta. Al disminuir la razón a/c y aumentar el grado de hidratación se produce la segmentación de la red de poros [Mindess y Young, 1981]. Asimismo, los agregados gruesos juegan un papel importante en dicho comportamiento, debido a que las zonas de interfaz agregado-mortero resultan afectadas por el tamaño máximo y la textura superficial de los agregados.

En el caso de los agregados reciclados, la mayor porosidad que poseen como consecuencia del mortero en su constitución, lleva a que los hormigones presenten también una porosidad más elevada que un hormigón de similares características elaborado con agregados naturales, siendo esta diferencia mayor al incrementarse el porcentaje de agregado reciclado empleado [Gonçalves et al, 2004]. Este hecho hace pensar en una influencia contrapuesta por parte de los AGR sobre el desempeño durable de los hormigones, ya que su mayor porosidad iría en demérito de la durabilidad de los hormigones, mientras que el uso de agregados reciclados permitiría una mejora de la zona de interfaz como consecuencia de su mayor rugosidad superficial.

\subsubsection{Absorción de agua}

Dentro de los parámetros existentes para estimar la porosidad de los hormigones, el ensayo de absorción de agua por inmersión constituye uno de los más simples y fáciles de llevar a la práctica, aunque posee limitaciones para valorar la durabilidad del hormigón [De Schutter y Audenaert, 2004].

Diferentes autores han encontrado que la absorción de agua de los hormigones reciclados resulta superior a la de hormigones convencionales de similares características, incrementándose al aumentar el porcentaje de agregado reciclado utilizado, ya sea que se emplee la fracción gruesa reciclada [Gómez et al, 2001; Gómez-Soberón, 2002] o que también se utilice la fracción fina reciclada [Levy y Helene, 2004].

Rasheeduzzafar y Khan (1984) indican que no existen diferencias significativas entre las absorciones de los hormigones reciclados y de los convencionales cuando la razón a/c de los mismos es superior a la del hormigón original a partir del cual se obtuvieron los 
agregados reciclados. Sin embargo, cuando la razón a/c de los nuevos hormigones (convencional y reciclado) fue inferior a la del hormigón original, la absorción de los hormigones reciclados resultó de 2 a 3 veces superior a la del hormigón convencional. Además, señalan que la elaboración de hormigones reciclados con razones a/c de 0,05 a 0,10 menores a la de los convencionales permitiría obtener similares valores de absorción.

\subsubsection{Permeabilidad al aire}

Existen diferentes métodos para evaluar la permeabilidad al aire de los hormigones, aunque el principio de funcionamiento es semejante en todos ellos y consiste en medir el tiempo que transcurre para restituirse un determinado nivel de vacío previamente generado.

Se ha observado un aumento de la permeabilidad de los hormigones reciclados con relación a los hormigones convencionales. Limbachiya et al (2000) indicaron que, para hormigones con un nivel resistente elevado ( $\mathrm{f}_{c}^{\prime}$ : 50-70 MPa), la permeabilidad al aire de los hormigones reciclados era similar a la del hormigón convencional para reemplazos del AGN por AGR de hasta $30 \%$, incrementándose la misma al aumentar el porcentaje de agregado reciclado utilizado. Cuando el AGN fue sustituido totalmente por el AGR, la permeabilidad resultó tres veces mayor que en el hormigón convencional, a pesar de que el contenido de agua de las mezclas se mantuvo constante. Otros autores alcanzaron conclusiones similares cuando ambos tipos de hormigones fueron curados bajo agua, mientras que cuando las muestras permanecieron al aire las diferencias entre la permeabilidad de los hormigones reciclado y convencional disminuyó, siendo en dicho caso 2,1 veces la de este último [Buyle-Bodin y Hadjieva-Zaharieva, 2002]. En otro trabajo, Zaharieva et al (2003) indicaron que la permeabilidad del hormigón reciclado fue dos veces la del hormigón convencional, aunque el hormigón reciclado presentaba una razón a/c 0,50 mientras que la del convencional era a/c 0,43, hecho que seguramente contribuyó al menor desempeño durable del hormigón reciclado. Cuando utilizaron también el AFR la permeabilidad al aire se incrementó de manera considerable, aunque también lo hicieron las razones $\mathrm{a} / \mathrm{c}$ de tales hormigones, que fueron superiores a 0,60 .

\subsubsection{Carbonatación}

Como se mencionara anteriormente, la mayor porosidad del agregado reciclado redunda en una mayor permeabilidad al aire de los hormigones reciclados, y la carbonatación está directamente vinculada a la misma. Vázquez y Barra (2002) indican que el agregado reciclado puede ayudar a la propagación de la carbonatación debido a que no impide el paso del $\mathrm{CO}_{2}$, como sí lo hace un agregado natural. Asimismo, señalan que este 
efecto dependerá de las porosidades del mortero del nuevo hormigón y de la del mortero presente en los agregados reciclados. Otro factor a tener en cuenta es la interfaz agregadomortero ya que su permeabilidad es en general muy superior a la de la pasta y a la de la roca.

Diversos trabajos evalúan la carbonatación en hormigones reciclados expuestos a procesos acelerados. Katz (2003) concluye que, luego de 7 días de exposición $\left(30^{\circ}\right.$ C, $60 \%$ hr y $5 \% \mathrm{CO}_{2}$ ) los hormigones reciclados presentaron espesores de carbonatación entre 1,3 y 2,5 veces superiores a los medidos en el hormigón convencional, no observándose diferencias significativas entre hormigones reciclados elaborados con agregados reciclados con distintas edades de trituración. Un estudio realizado por la BCSJ (1978) [citado por Hansen, 1986] indica espesores carbonatados medidos en hormigones reciclados un $65 \%$ mayor que los obtenidos en hormigones convencionales (condiciones de exposición: $20^{\circ} \mathrm{C}, 60 \%$ hr y $20 \% \mathrm{CO}_{2}$ ), observando además que la corrosión en barras embebidas en hormigón con 20 a $30 \mathrm{~mm}$ de recubrimiento se hacía visible luego de dos meses.

Buyle-Bodin y Hadjieva-Zaharieva (2002) obtuvieron valores de carbonatación cuatro veces superiores al del hormigón convencional, indicando además que el espesor de carbonatación era al menos dos veces menor cuando el hormigón fue curado en agua. Las muestras fueron expuestas a $20^{\circ} \mathrm{C}, 65 \%$ hr y $50 \% \mathrm{CO}_{2}$. Dichos autores también indicaron que el proceso de difusión del $\mathrm{CO}_{2}$ en el hormigón reciclado cumple con la ley parabólica establecida para el hormigón convencional.

Otsuki et al (2003) indican que el espesor carbonatado de los hormigones reciclados, expuestos a $40^{\circ} \mathrm{C}, 70 \%$ hr y $10 \% \mathrm{CO}_{2}$, resulta superior al de los hormigones de referencia, para razones a/c comprendidas entre 0,25 y 0,70 , siendo mayor la diferencia cuanto más elevada es la razón a/c.

Contrariamente a lo señalado en los párrafos anteriores, Levy y Helene (2004) concluyeron que el espesor carbonatado de los hormigones reciclados disminuye al aumentar el contenido de agregados reciclados, siendo el caso más favorable cuando el mismo se encuentra entre 20 y $50 \%$. Según indicaron, este comportamiento puede atribuirse a una mayor reserva alcalina en los hormigones reciclados debido al mayor contenido unitario de cemento que poseían para alcanzar el mismo nivel resistente que el hormigón convencional. 
De las conclusiones obtenidas en los estudios mencionados en los párrafos anteriores surge que el desempeño de los hormigones reciclados, más allá de las características que posean, se encuentra afectado de manera importante por la concentración de $\mathrm{CO}_{2}$ del ambiente, produciéndose mayor diferencia en el espesor carbonatado entre los hormigones reciclados y convencionales al aumentar la misma. Debido a ello, sería importante determinar a lo largo del tiempo la variación en los espesores carbonatados en hormigones reciclados y convencionales expuestos en ambientes naturales, dado que la concentración de $\mathrm{CO}_{2}$ de la atmósfera es muy inferior a la utilizada en los ensayos acelerados mencionados anteriormente. En tal sentido, se debe señalar que las mediciones de $\mathrm{CO}_{2}$ realizadas recientemente por el Observatorio Mauna Loa, en Hawai (Estados Unidos), indican valores de 390 ppm, equivalente a 0,039 \% [www.cambio-climatico.com].

\subsubsection{Succión capilar}

Diferentes estudios han evaluado la succión capilar de los hormigones reciclados. En general concluyen que los hormigones reciclados poseen mayores valores de absorción capilar [Hernández y Fornasier, 2005]. También se indica que para obtener valores similares a los del hormigón convencional es necesario incrementar el contenido de cemento de los hormigones reciclados en $100 \mathrm{~kg} / \mathrm{m}^{3}$ [Gonçalves et al, 2004].

Otros autores concluyeron que la absorción inicial de los hormigones reciclados, definida como la cantidad de agua absorbida por unidad de superficie al cabo de una hora de comenzado el ensayo, fue cuatro veces superior a la de los hormigones convencionales [Buyle-Bodin y Hadjieva-Zaharieva, 2002], lo cual implica que la penetración de líquidos hacia el interior del hormigón es más rápida y serían, por lo tanto, significativamente más vulnerables al ataque de agentes exteriores. Asimismo, encontraron que la ausencia de un tratamiento de curado adecuado llevó a que la velocidad de succión capilar de los hormigones reciclados (100\% de reemplazo del AGN) fuera 2,5 veces la del hormigón convencional, mientras que cuando el curado fue efectuado bajo agua dicha diferencia se redujo, alcanzando una velocidad de succión capilar de 1,8 veces la del hormigón convencional.

En el estudio de Katz (2003), relacionado con la edad de trituración del hormigón, no se encontraron diferencias significativas entre los valores de succión capilar de hormigones elaborados con agregados reciclados obtenidos a diferentes edades (1, 3 y 28 días), donde los valores resultaron ser aproximadamente el doble que los del hormigón convencional. 
En estudios llevados a cabo en el LEMIT sobre hormigones de razón a/c 0,45 y con $50 \%$ de AGR, se obtuvieron valores de velocidad de succión capilar similares al de los hormigones convencionales, aunque la capacidad de succión resultó algo superior en los reciclados [Villagrán Z. et al, 2005]. En otro caso, donde los hormigones reciclados poseían un $75 \%$ de AGR, se obtuvieron mayores velocidades de succión capilar que para los hormigones convencionales de igual razón a/c, aunque las diferencias disminuyeron al aumentar la resistencia de los hormigones [Taus et al, 2005], resultando para una razón a/c 0,40 valores similares en ambos tipos de hormigones. En otro estudio realizado sobre hormigones de razón a/c 0,50 y elaborados con porcentajes variables de AGR (0, 50, 75 y $100 \%)$, en los cuales se utilizó canto rodado como agregado grueso natural, se concluyó que tanto la velocidad como la capacidad de succión capilar se incrementaron a medida que aumentó el porcentaje de AGR utilizado [Zega et al, 2006].

\subsubsection{Congelación y deshielo}

Como se pudo observar en los puntos anteriores, la mayor porosidad de los hormigones reciclados produce un aumento de la permeabilidad, hecho que permitiría inferir una menor durabilidad de dichos hormigones ante una mayor facilidad al ingreso de agentes agresivos. Un caso particular lo constituyen las estructuras que se encuentran expuestas a congelación y deshielo.

En una revisión de Hansen (1986) se indica que estudios realizados en Japón concluyeron que el comportamiento frente a congelación y deshielo de hormigones reciclados elaborados con aire intencionalmente incorporado, y utilizando $100 \%$ de AGR, era similar al del hormigón convencional. Sin embargo, cuando también emplearon el AFR observaron que la resistencia al congelamiento se redujo de manera importante. Otros estudios complementarios indicaron que la resistencia a congelación y deshielo de los hormigones reciclados con aire intencionalmente incorporado fue siempre inferior a la del hormigón convencional, ya sea que hayan sido elaborados con AGR y arena natural como así también cuando se empleó el AFR, aunque en este último caso el deterioro se produjo mucho más rápido [Hasaba et al, 1981]. Kawamura (1983) observó que el comportamiento de los hormigones reciclados desmejoraba cuando el agregado reciclado fue obtenido de un hormigón de baja calidad, en comparación con un agregado reciclado obtenido a partir del hormigón de un pavimento.

Estudios recientes indican que el comportamiento en congelación y deshielo de los hormigones reciclados, luego de 300 ciclos, fue similar al del hormigón convencional de similares características, aún para el que contenía $100 \%$ de AGR, presentando en todos 
los casos factores de durabilidad superior al $95 \%$ [Limbachiya et al, 2000]. Similares conclusiones surgen de estudios realizados en el LEMIT sobre hormigones con distintos porcentajes de AGR y con aire intencionalmente incorporado, presentando todos los hormigones factores de durabilidad superiores al $98 \%$ [Zega et al, 2005)].

El grado de saturación de los hormigones parece tener una influencia sustancial al momento de someterlos a ciclos de congelación y deshielo. Zaharieva et al (2004) indicaron que los hormigones reciclados presentaron factores de durabilidad menores a los del hormigón convencional, siendo las diferencias mayores al aumentar el grado de saturación, como así también cuando los hormigones fueron elaborados en su totalidad con agregados reciclados. Los hormigones elaborados con AGR y agregado fino natural presentaron un comportamiento aceptable cuando el grado de saturación no fue completo.

La presencia de aire intencionalmente incorporado en el hormigón de origen, sumado a la incorporación intencional de aire en los nuevos hormigones, conduciría a un comportamiento durable satisfactorio frente a congelación y deshielo. Gokce et al (2004) concluyeron que el empleo de agregados reciclados provenientes de un hormigón sin aire incorporado, aún en bajos porcentajes de reemplazo, produjo una rápida disminución del módulo dinámico en los hormigones reciclados, aunque los mismos hayan sido elaborados con aire incorporado, descendiendo debajo del 80 \% del módulo inicial a los 100 ciclos. Dichos resultados sorprenden por el hecho que los porcentajes de reemplazo utilizados no superaron el $25 \%$.

\subsubsection{Ingreso de cloruros}

Existen distintos métodos para evaluar la durabilidad del hormigón frente al ingreso de cloruros, según el mecanismo a través del cual se produce el ingreso. Uno de ellos es el que se produce por difusión, como consecuencia de un gradiente de concentración entre la atmósfera exterior y la solución de poros del hormigón. Esta situación se produce cuando la probeta de hormigón es colocada en solución o bien es expuesta en un ambiente natural, por ejemplo una atmósfera marina o industrial. Estos métodos permiten obtener un coeficiente de difusión aparente $\left(\mathrm{D}_{\mathrm{ap}}\right)$ a partir de aplicar la solución a la segunda Ley de Fick [Nilsson et al, 1996] con los contenidos de cloruro obtenidos a distintas profundidades de las probetas en exposición. Otro mecanismo de ingreso es por migración, es decir, como consecuencia de una diferencia de potencial producida entre ambos lados de una rodaja de hormigón, que se encuentra en contacto por uno de sus lados con la solución de cloruros y por el otro con agua; existen diferentes ensayos aunque los más empleados son el de la Celda de Difusión y el método de migración CTH. El método de la 
Celda de Difusión permite obtener un coeficiente de difusión $\left(\mathrm{DF}_{\mathrm{F}}\right)$, mientras que mediante el método CTH se obtiene un coeficiente de migración (Dстн) [Nilsson et al, 1996]. Una consideración en la determinación de los coeficientes se refiere a si la concentración de cloruro en un punto determinado de la muestra varía en el tiempo o se mantiene constante, denominándose régimen no estacionario o estacionario, respectivamente. En el caso del $D_{a p}$, su obtención es en régimen no estacionario; el Dстн se obtiene en régimen estacionario; mientras que el DF puede ser obtenido en cualquiera de los dos estados.

Otro método empleado en la determinación del ingreso de cloruros es la técnica de coloración por humedecimiento con solución acuosa de nitrato de plata, del cual no se obtienen valores cuantitativos sino que indica rangos de contenidos de cloruros por cambio en la coloración del hormigón [Nilsson et al, 1996], semejante al método de teñido con fenolftaleina utilizado en la determinación del espesor carbonatado.

En hormigones reciclados y convencionales, elaborados con dos contenidos de cemento (350 y $450 \mathrm{~kg} / \mathrm{m}^{3}$ ), se concluyó que el hormigón reciclado presentaba un coeficiente

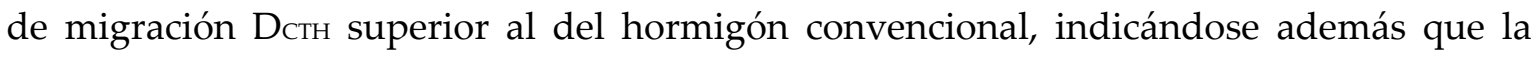
diferencia entre ambos tipos de hormigones disminuyó al mejorar la calidad de la nueva matriz [Gonçalves et al, 2004]. Para un contenido de cemento de $350 \mathrm{~kg} / \mathrm{m}^{3}$, los $D_{\text {снт fue- }}$ ron de 16,5 y $20,1 \times 10^{-12} \mathrm{~m}^{2} / \mathrm{s}$ en los hormigones convencionales y reciclados respectivamente, mientras que para un contenido de $450 \mathrm{~kg} / \mathrm{m}^{3}$ de cemento no se apreciaron diferencias significativas entre ambos tipos de hormigones, tomando dicho coeficiente valores de 12,5 y $13,4 \times 10^{-12} \mathrm{~m}^{2} / \mathrm{s}$ para los convencionales y reciclados, respectivamente. Si bien los autores atribuyen los mayores coeficientes de migración de los hormigones reciclados a una interfaz agregado-matriz menos densa debido a la porosidad de los agregados reciclados, hecho que contradice lo mencionado por otros estudios, la razón a/c total de los hormigones reciclados fue considerablemente mayor, lo que justificaría en mejor medida las diferencias obtenidas.

Equivalentes conclusiones fueron alcanzadas al evaluar hormigones de alta resistencia, con porcentajes variables de AGR hasta $100 \%$, por medio del ensayo de la celda de difusión, obteniendo valores del DF similares en todos los hormigones, hecho que fue atribuido a la elevada calidad de la nueva matriz [Limbachiya et al, 2000]. Los valores del DF obtenidos fueron del orden de $65 \times 10^{-12} \mathrm{~m}^{2} / \mathrm{s}$ ( $f^{\prime}$ c: $50 \mathrm{MPa}$ ), $45 \times 10^{-12} \mathrm{~m}^{2} / \mathrm{s}$ ( $f^{\prime}$ c: $\left.60 \mathrm{MPa}\right), y$ $38 \times 10^{-12} \mathrm{~m}^{2} / \mathrm{s}$ ( $\mathrm{f}^{\prime}$ с: $70 \mathrm{MPa}$ ). Estos valores resultan muy elevados en comparación con los indicados en el párrafo anterior, hecho que debe atribuirse al método utilizado en su determinación. 
Estudios realizados en el LEMIT, concluyen que los hormigones elaborados con hasta un $50 \%$ de AGR presentan un comportamiento semejante al del hormigón convencional de igual razón a/c al ser expuestos en un ambiente marino natural [Villagrán Z.

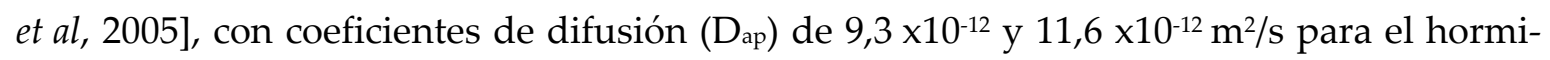
gón reciclado y convencional respectivamente.

Cuando el ingreso de cloruro fue evaluado mediante la técnica de coloración con nitrato de plata, luego de 28 días de inmersión en solución de cloruro de sodio al $3 \%$, se obtuvieron espesores contaminados con cloruros levemente superiores en los hormigones reciclados, y un incremento de la razón a/c produjo un aumento de dicho espesor en ambos tipos de hormigones por igual [Otsuki et al, 2003].

\subsection{Consideraciones finales}

A partir de lo indicado en la bibliografía sobre el desempeño de los hormigones reciclados, tanto en el estado fresco como endurecido, y en este último caso respecto a su comportamiento mecánico y durable, surge que:

- La mayor absorción de los agregados reciclados puede ocasionar pérdidas considerables de trabajabilidad si la misma no es tenida en cuenta. Para contrarrestar dicho efecto, las metodologías adoptadas consisten en presaturar los agregados con anterioridad a su empleo, o bien ajustar la cantidad de agua de mezclado en función de la absorción efectiva. En el caso de emplear aditivos plastificantes, y según el porcentaje de agregado reemplazado, podrá incrementarse la dosis de aditivo de manera que los asentamientos resulten similares. El empleo de agregados reciclados sumado al uso de aditivos puede conducir a un incremento en el contenido natural de aire. Otra particularidad de las mezclas recicladas es su menor PUV con relación a una mezcla de similares características elaborada con agregados naturales, debido a la menor densidad de los agregados reciclados.

- El empleo de AGR en reemplazo de los AGN para la elaboración de hormigones, conduce a niveles resistentes en compresión similares a los de los hormigones convencionales, aunque el porcentaje máximo para el cual se produce esta situación resulta muy variado, siendo en algunos casos del $30 \%$ y en otros alcanza el $100 \%$. En este hecho adquieren importancia tanto el nivel resistente del hormigón de origen como el de la nueva matriz. 
- El comportamiento en tracción de los hormigones reciclados difiere de un autor a otro, dependiendo de la calidad de los AGR. La variación de la resistencia a tracción de los hormigones reciclados con la razón a/c es similar a la que se produce en los hormigones convencionales, aunque los niveles resistentes pueden verse reducidos cuanto mayor es el porcentaje de AGR empleado.

- La presencia del mortero en los AGR produce una disminución del módulo de elasticidad estático de los hormigones, mayor cuanto más elevado es el porcentaje de AGR utilizado.

- La capacidad de absorción de los hormigones reciclados se ve modificada con relación a la de los hormigones convencionales, debido al mayor contenido de mortero de los mismos, es decir, el propio de la nueva matriz más el que se encuentra formando parte de los AGR, siendo dicha influencia de mayor importancia cuanto mayor sea la calidad de la nueva matriz. Sin embargo, podría pensarse que cuanto mejor sea la calidad de la nueva matriz en la cual van a estar insertos los AGR, ésta produciría un efecto de aislamiento del agregado reciclado disminuyendo sus posibilidades de entrar en contacto con el ambiente exterior, y de este modo, los hormigones reciclados se podrían comportar satisfactoriamente desde el punto de vista durable.

- El mayor contenido de mortero de los hormigones reciclados produce una mayor permeabilidad al aire de los mismos con relación a los hormigones convencionales, aunque para bajos porcentajes de reemplazo del AGN por AGR el comportamiento de ambos tipos de hormigones resulta similar.

- Los espesores carbonatados resultan superiores en lo hormigones reciclados, y en mayor medida al aumentar la razón a/c de los mismos. El desempeño de los hormigones reciclados estaría afectado de manera importante por la concentración de $\mathrm{CO}_{2}$ en ensayos acelerados, produciéndose mayor diferencia en el espesor carbonatado entre los hormigones reciclados y convencionales al aumentar dicha concentración.

- En general, se observa un aumento de los parámetros de succión capilar en los hormigones reciclados con relación a los elaborados con agregados naturales, mayor cuanto más elevado es el porcentaje de AGR utilizado, aunque la calidad de la 
matriz del nuevo hormigón y la del agregado reciclado tendrán un rol importante en el valor final que se obtenga de dicha determinación.

- El comportamiento durable en congelación y deshielo de los hormigones reciclados es aún un tema controvertido. Algunos estudios indican diferencias poco significativas entre hormigones que incorporan diferentes porcentajes de reemplazo de agregados reciclados, mientras que otros establecen que el factor de durabilidad disminuye de manera considerable cuando se incrementa el porcentaje de agregado reciclado utilizado.

- Si bien el hormigón reciclado presenta una mayor porosidad, ésta se ve compensada por una mayor capacidad de fijación de cloruros a causa del contenido de mortero extra que aportan los agregados reciclados, dando como resultado contenidos de cloruro libres similares al de hormigones convencionales de igual razón a/c. Estos últimos son los que interesan para valorar los procesos de corrosión, ya que se encuentran en la solución de poros del hormigón e interactúan con las armaduras. 


\section{Capítulo 3 \\ Programa Experimental}

\subsection{Introducción}

Debido a la composición de las partículas de los agregados reciclados, sus propiedades estarán influenciadas tanto por las características del mortero proveniente del hormigón de origen como por las de la roca que compone el agregado natural. Sin embargo, no se tiene conocimiento sobre cómo puede influir el tipo de agregado grueso natural (AGN) del hormigón de origen sobre las propiedades de los agregados gruesos reciclados (AGR), como así tampoco sobre el comportamiento de los hormigones.

Por otro lado, como fuera mencionado en el Capítulo 2, el comportamiento durable que presentan los hormigones reciclados puede ser muy variado según sean las características de los hormigones estudiados, el porcentaje de agregado reciclado utilizado y el tipo de mecanismo que produce la acción de deterioro.

A partir de ello, y con el fin de dar cumplimiento a los objetivos planteados en el presente trabajo de tesis, se evalúan distintas propiedades de los AGR y posteriormente se estudia el comportamiento mecánico y durable de hormigones elaborados con AGR, comparativamente con hormigones convencionales.

\subsection{Experiencias}

\subsubsection{Materiales}

\subsubsection{Agregados gruesos naturales}

Se seleccionaron cuatro AGN de tamaño nominal 4,75-19 mm, los cuales presentan marcadas diferencias tanto en su composición como en sus propiedades físico-mecánicas y durables, forma y textura superficial de las partículas, los que son habitualmente empleados en diversas regiones de la República Argentina. Se utilizaron tres piedras partidas, que comprenden un granito $(\mathrm{G})$ de la zona de Olavarría, una cuarcita $(\mathrm{Q})$ de la zona de Mar del Plata y un basalto (B) de la Provincia de Córdoba, mientras que el cuarto agregado seleccionado fue un canto rodado silíceo (S), procedente del Río Uruguay. 
El agregado G consiste en una migmatita granítica, de grano medio, muy compacta e inalterada, con porcentajes de cuarzo del 30-40 \% con estructura cataclástica, con extinción ondulante. El agregado $\mathrm{Q}$ consiste en una ortocuarcita de origen sedimentario, constituidas por cuarzo en un 97-99\%, formando granos subredondeados, subangulosos e incluso angulosos, ligados por cemento silíceo. Poseen una estructura de grano fino con tamaños comprendidos entre 0,5 y $0,8 \mathrm{~mm}$, de color amarillo a castaño oscuro debido a hidrólisis de hierro. El agregado B por su parte proviene de rocas basálticas alcalinas originadas por derrame de fractura, cuya composición petrográfica corresponde a basanitas nefelinas, de grano fino, masivas poco alteradas. El agregado $S$ está constituido por clastos redondeados en cuya composición mineralógica se encuentran cuarzo ( 30\%), calcedonia $(\sim 50 \%)$ y areniscas-limolitas ( 20\%).

Debido a los diferentes orígenes que tienen dichos AGN, se observan diferentes tamaños de grano, y la resistencia de la roca que los compone también resulta sumamente variable [Giaccio y Zebino, 1997]. En la Tabla 3.1 se resumen las características físicas relacionadas con la forma, textura superficial y tamaño de grano de cada uno de ellos.

Tabla 3.1. Características de los agregados gruesos naturales.

\begin{tabular}{|c|c|c|c|}
\hline \multirow{2}{*}{ Agregado } & \multicolumn{3}{|c|}{ Características físicas } \\
& Forma & $\begin{array}{c}\text { Textura } \\
\text { superficial }\end{array}$ & $\begin{array}{c}\text { Tamaño de } \\
\text { grano }\end{array}$ \\
\hline G & \multirow{2}{*}{ irregular } & rugosa & medio \\
Q & & & fino \\
\hline B & redondeada & lisa & \\
\hline
\end{tabular}

En la Figura 3.1 se presentan las fotografías de cada uno de los agregados naturales anteriormente descriptos, pudiéndose observar algunas de las características mencionadas. 

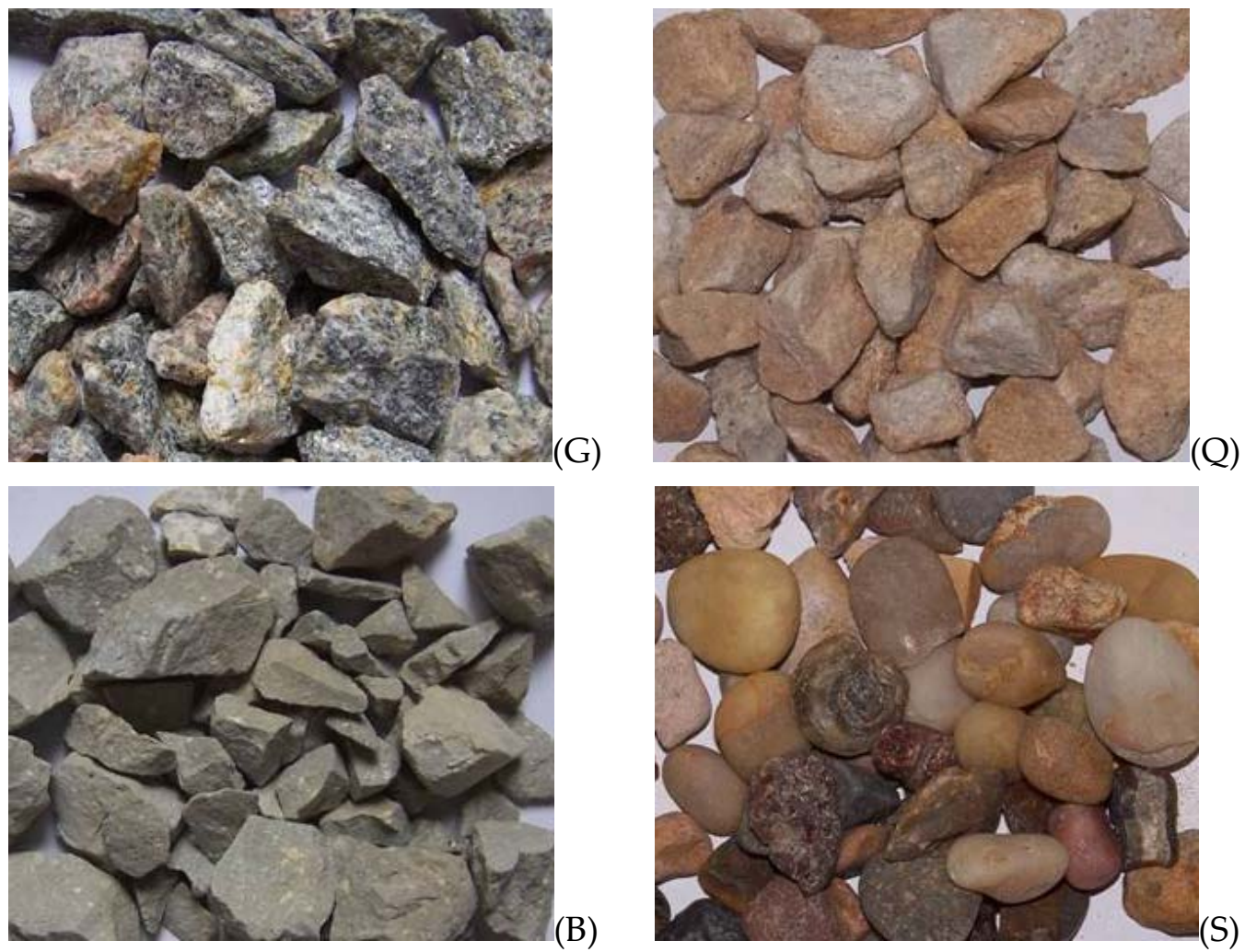

Figura 3.1. Agregados gruesos naturales.

\subsubsection{Agregados gruesos reciclados}

Cada uno de los cuatro AGN definidos en el punto anterior fue empleado para la elaboración de hormigones convencionales (HC) de razones a/c 0,45 y 0,65, ajustando las proporciones de las mezclas con el fin de obtener en todos los casos mezclas de consistencia plástica, denominando a los mismos como hormigones originales. Dichas razones a/c permitieron obtener dos niveles resistentes bien diferenciados, uno de tipo estructural que permite a la vez cumplir con los requisitos de durabilidad del Proyecto de Reglamento Argentino de Estructuras de Hormigón [CIRSOC 201:2005], mientras que la razón a/c más elevada conduce a la obtención de hormigones con un nivel resistente menor, siendo los que habitualmente se utilizan en la industria de la construcción local.

Con dichos hormigones se moldearon probetas, las que fueron mantenidas durante 28 días en condiciones normalizadas de temperatura y humedad (T: $23 \pm 2^{\circ} \mathrm{C}$; hr: $95 \%$ ). Posteriormente, las mismas fueron trituradas mediante el empleo de una trituradora de mandíbulas (Figura 3.2-a) generando partículas de agregados con un tamaño de hasta $38 \mathrm{~mm}\left(1 \frac{1}{2}{ }^{\prime \prime}\right)$. Con el fin de generar AGR de tamaño nominal 4,75-19 mm y poder aprovechar el material cuyo tamaño excedía el límite mencionado, se empleó una segunda trituradora más pequeña, también de mandíbulas (Figura 3.2-b), generando partículas de tamaño máximo $12,7 \mathrm{~mm}\left(1 / 2^{\prime \prime}\right)$. El procedimiento de trituración adoptado para la genera- 
ción de los agregados reciclados, el cual se esquematiza en la Figura 3.3, consistió en triturar los hormigones convencionales mediante la primera trituradora, tamizar el material con una malla de abertura $19 \mathrm{~mm}\left(3 / 4^{\prime \prime}\right)$ y procesar la fracción retenida mediante la segunda trituradora. El material resultante de este último proceso fue mezclado con el obtenido de la primera trituradora, y que había pasado por el tamiz de $19 \mathrm{~mm}$, y posteriormente tamizado por una malla de abertura $4,75 \mathrm{~mm}$, obteniéndose AGR de tamaño nominal 4,75-19 mm sobre el cual se realizaron las evaluaciones presentadas en este trabajo de tesis, y AFR (0-4,75 mm) el cual fue reservado para estudios futuros.
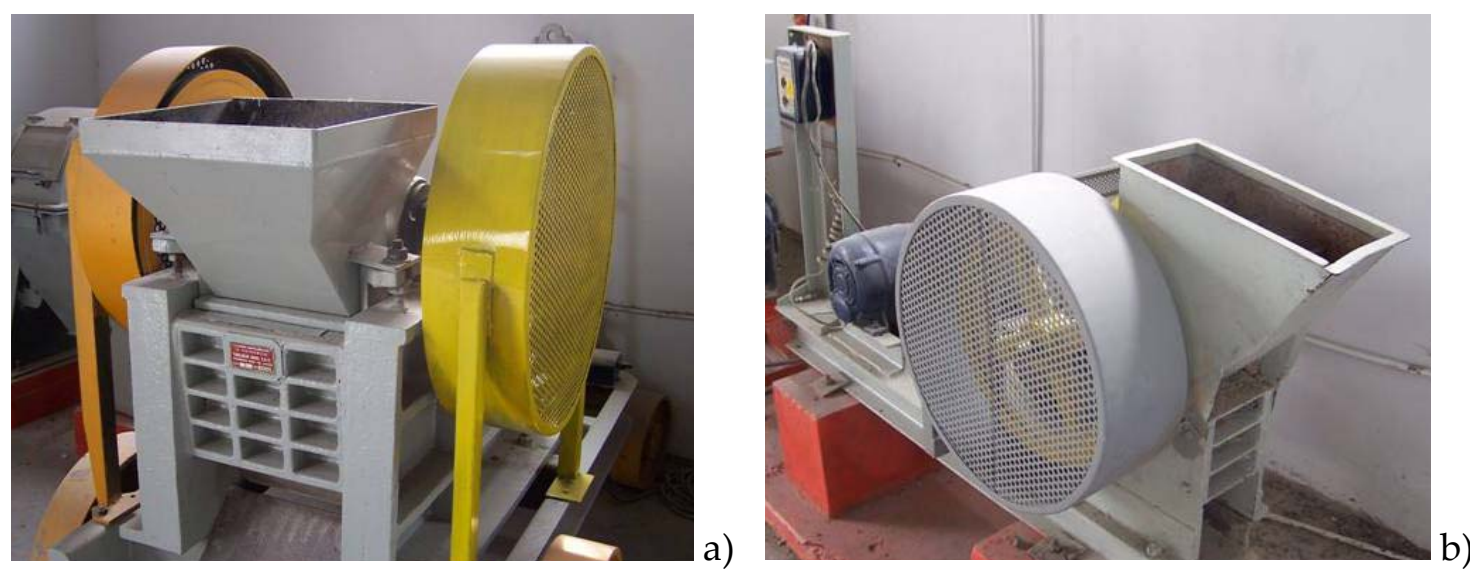

Figura 3.2. Trituradoras de mandíbulas utilizadas para generar los AGR.

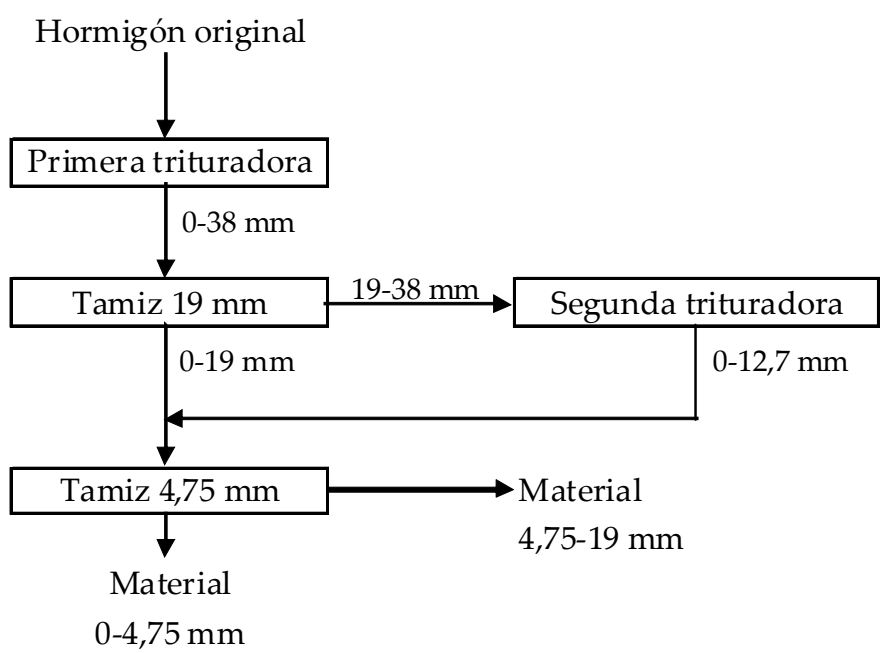

Figura 3.3. Procedimiento para la generación del agregado reciclado.

Los AGR son identificados con la letra correspondiente al tipo de AGN que contienen, anteponiendo la letra $\mathrm{R}$ y posponiendo un número que hace referencia a la razón a/c del hormigón del cual proviene. De este modo, los agregados RG45 y RG65 hacen referencia a los obtenidos de la trituración de los hormigones originales elaborados con el agregado natural granítico (G) de razón a/c 0,45 y 0,65, respectivamente. En la Tabla 3.2 se 
resumen las denominaciones de cada uno de los ocho AGR generados, los cuales fueron caracterizados previamente a su empleo mediante la evaluación de diferentes propiedades físico-mecánicas habitualmente determinadas a los AGN. Los resultados obtenidos, los cuales forman parte de los estudios llevados a cabo a fin de dar cumplimiento a los objetivos planteados, se presentan en el Capítulo 4.

Tabla 3.2. Denominación de los agregados gruesos reciclados.

\begin{tabular}{|c|c|c|}
\hline \multirow{2}{*}{ Denominación } & \multirow{2}{*}{ Tipo de AGN } & $\begin{array}{c}\text { Razón a/c del } \\
\text { hormigón original }\end{array}$ \\
\hline RG45 & \multirow{2}{*}{ Granito } & 0,45 \\
RG65 & & 0,65 \\
\hline RQ45 & \multirow{2}{*}{ Cuarcita } & 0,45 \\
RQ65 & \multirow{2}{*}{ Basalto } & 0,65 \\
\cline { 1 - 1 } RB45 & \multirow{2}{*}{ Canto rodado } & 0,45 \\
\cline { 1 - 1 } RB65 & silíceo & 0,65 \\
\cline { 1 - 1 } RS45 & & 0,45 \\
\hline RS65 & & 0,65 \\
\hline
\end{tabular}

\subsubsection{Otros materiales componentes}

Además de los AGN y AGR mencionados, para la elaboración de los diferentes hormigones se emplearon dos arenas silíceas naturales, Cemento Portland Compuesto (CPC-40), cuyas propiedades físico-químicas se informan en la Tabla 3.3, y un aditivo reductor del agua de mezclado de medio rango (Pozzolith $\left.{ }^{\circledR} 390 \mathrm{~N}\right)$ de base química polimérica [www.southamerica.basf-cc.com].

En la Figura 3.4 se presentan las granulometrías de las arenas utilizadas, las cuales se conocen en el ámbito de la construcción como arenas silíceas "argentina" y "oriental", junto con las curvas límites indicadas en la Norma IRAM 1627. En la Tabla 3.4 se presentan las propiedades determinadas a las arenas naturales, como densidad en condición de saturada y superficie seca ( $\mathrm{D}_{\mathrm{sss}}$ ), absorción de agua, y pasa tamiz de $75 \mu \mathrm{m}$. 
Tabla 3.3. Propiedades del cemento.

\begin{tabular}{|l|c|}
\hline \multicolumn{2}{|c|}{ Ensayos físicos } \\
\hline Retenido tamiz IRAM 75 $\mu \mathrm{m}(\%)$ & 13,6 \\
\hline Tiempo de fraguado inicial (horas) & $4: 10$ \\
\hline Tiempo de fraguado final (horas) & $6: 05$ \\
\hline Agua para pasta normal (\%) & 28 \\
\hline Superficie específica Blaine (cm²/g) & 392 \\
\hline Resistencia a compresión a 28 días (MPa) & 47,7 \\
\hline \multicolumn{2}{|c|}{ Análisis químico } \\
\hline Residuo insoluble (\%) & 1,40 \\
\hline Pérdida por calcinación (\%) & 4,70 \\
\hline Anhídrido sulfúrico (SO3) (\%) & 1,98 \\
\hline Óxido de magnesio (MgO) (\%) & 1,50 \\
\hline Cloruros (\%) & 0,01 \\
\hline Sulfatos (\%) & 0,01 \\
\hline
\end{tabular}

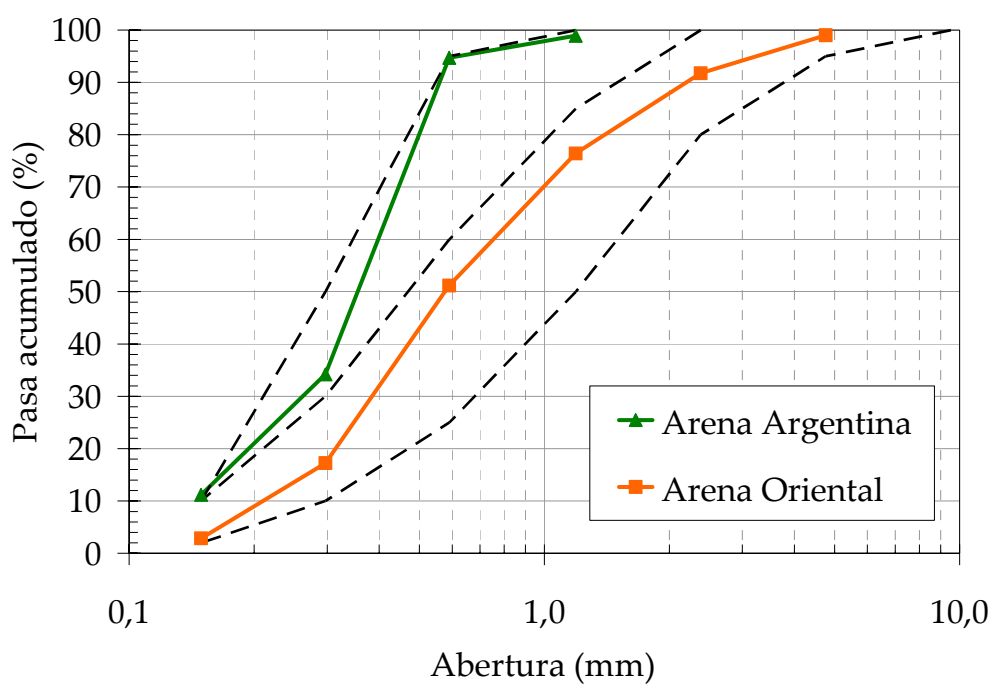

Figura 3.4. Granulometrías de las arenas naturales.

Tabla 3.4. Propiedades de las arenas naturales.

\begin{tabular}{|l|c|c|}
\hline \multicolumn{1}{|c|}{ Propiedades } & Arena Argentina & Arena Oriental \\
\hline$D_{\text {sss }}$ & 2,60 & 2,59 \\
\hline Absorción $(\%)$ & 0,9 & 0,2 \\
\hline Pasa tamiz de $75 \mu \mathrm{m}(\%)$ & 1,52 & 0,46 \\
\hline
\end{tabular}




\subsubsection{Hormigones reciclados}

Diferentes estudios realizados en el LEMIT han concluido que la utilización de AGR en porcentajes de hasta un $75 \%$, en reemplazo del AGN, permite obtener hormigones con niveles resistentes semejantes al del hormigón original de similares características, ya sea que los agregados reciclados hayan sido obtenidos de hormigones previamente elaborados en dicho laboratorio [Di Maio et al, 2002] o bien procedan de hormigones de desecho de características desconocidas y variadas [Zega y Di Maio, 2003]. Debe mencionarse que, en ambos casos, los hormigones de origen contenían piedra partida granítica como AGN.

En base a ello, los porcentajes adoptados fueron 25 y $75 \%$ en volumen, en reemplazo del AGN, dado que el primero se encuentra próximo al porcentaje de reemplazo máximo admitido por recomendaciones vigentes en algunos países para la utilización del AGR [Grübl y Rühl, 1998; RILEM, 1994; EHE, 2008], mientras que el segundo porcentaje, como se mencionara anteriormente, surgió de los resultados obtenidos en estudios realizados a nivel local.

Cada AGR descripto en la Tabla 3.2 se empleó para la elaboración de hormigones reciclados de similares características a las del hormigón de origen, utilizándolo en reemplazo del correspondiente AGN en los porcentajes antes mencionados, manteniendo constante las proporciones de los demás materiales. De este modo, el mortero con que se elaboró el hormigón reciclado es semejante al del hormigón original, o sea, al que forma parte de las partículas del AGR. Este hecho permite reducir el número de variables al momento de comparar los desempeños de los hormigones reciclados con los originales, preponderando el efecto que podría tener el tipo de AGN, principalmente en lo que respecta al comportamiento durable.

Así, por ejemplo, los hormigones denominados HRG45-25 y HRG45-75 hacen referencia a los elaborados utilizando el agregado reciclado RG45 en reemplazo del agregado natural de granito $(\mathrm{G})$ en un 25 y $75 \%$, respectivamente. Los hormigones originales, por su parte, son denominados con la letra correspondiente al tipo de AGN que contienen y la razón a/c; por ejemplo, HG45 y HG65 se refieren a los producidos con el agregado natural de granito, de razón a/c 0,45 y 0,65, respectivamente. (Ver Tabla 3.5) 
Tabla 3.5. Hormigones originales y reciclados.

\begin{tabular}{|c|c|c|c|}
\hline $\begin{array}{c}\text { Hormigón } \\
\text { original }\end{array}$ & $\begin{array}{c}\text { AGR } \\
\text { generado }\end{array}$ & Hormigones reciclados & Observación \\
\hline HG45 & RG45 & HRG45-25; HRG45-75 & \multirow{8}{*}{$\begin{array}{l}\text { Mismas proporciones en vo- } \\
\text { lumen; reemplazo del AGN } \\
\text { por el correspondiente AGR. }\end{array}$} \\
\hline HG65 & RG65 & HRG65-25; HRG65-75 & \\
\hline HQ45 & RQ45 & HRQ45-25; HRQ45-75 & \\
\hline HQ65 & RQ65 & HRQ65-25; HRQ65-75 & \\
\hline HB45 & RB45 & HRB45-25; HRB45-75 & \\
\hline HB65 & RB65 & HRB65-25; HRB65-75 & \\
\hline HS45 & RS45 & HRS45-25; HRS45-75 & \\
\hline HS65 & RS65 & HRS65-25; HRS65-75 & \\
\hline
\end{tabular}

Los hormigones originales y reciclados en estudio fueron caracterizados en el estado fresco, determinándose el asentamiento, a través del cono de Abrams (IRAM 1536), peso por unidad de volumen (IRAM 1562) y contenido de aire naturalmente incorporado, este último evaluado mediante el método de presión (IRAM 1602-1).

En el estado endurecido se evaluó el comportamiento mecánico de los hormigones mediante la determinación de la resistencia a compresión y módulo de elasticidad estático, resistencia a tracción por compresión diametral y módulo de rotura en flexión con carga centrada, determinándose también algunos parámetros que miden diferentes ensayos semi-destructivos y no destructivos (END) como presión Break-Off, tiempo de pasaje del pulso ultrasónico y frecuencia de resonancia para la obtención del módulo de elasticidad dinámico. Además, se evaluaron diferentes parámetros que permiten caracterizar a los hormigones a partir de su estructura de poros, brindando una idea del comportamiento durable de los mismos. Se realizaron los ensayos de absorción de agua, succión capilar, penetración de agua a presión y difusión de cloruros en inmersión, los cuales involucran diferentes mecanismos de transporte. En la Tabla 3.6 se presenta una síntesis del programa experimental desarrollado.

De manera complementaria, se realizaron observaciones sobre cortes obtenidos de probetas correspondientes a diferentes hormigones, mediante el empleo de una lupa estereoscópica binocular. Dada la similitud que posee el mortero del hormigón original con el nuevo mortero de los hormigones reciclados, como fue mencionado anteriormente, las probetas sobre las que se iban a realizar dichas observaciones fueron moldeadas con hor- 
migones a los cuales se les adicionó una pequeña cantidad de pigmento negro con el fin de poder diferenciar ambas matrices de cemento.

Además, como un hecho particular, y con el fin de tomar un mayor conocimiento sobre el comportamiento durable de los hormigones reciclados, se presentan los resultados obtenidos de una experiencia de campo realizada con hormigones con distintos contenidos de AGR al ser expuestos en suelo con sulfato. Se evaluaron un hormigón con agregados naturales (R-0) y hormigones reciclados en los cuales el agregado grueso natural (piedra partida granítica, $D_{\text {sss: }}$ 2,72; Ab: 0,3 \%) fue reemplazado por AGR en porcentajes del 25 y 75 \% (R-25 y R-75). Los hormigones fueron elaborados con un contenido unitario de cemento $(\mathrm{CPN})$ de $310 \mathrm{~kg} / \mathrm{m}^{3}$, presentando una razón a/c 0,48, al igual que el hormigón original a partir del cual se obtuvieron los AGR (Dsss: 2,46; Ab: 5,0 \%). En estas experiencias se decidió presaturar a los agregados gruesos, naturales y reciclados, debido a la mayor absorción que presenta el AGR respecto al natural, hecho que permitió obtener en todos los casos mezclas de consistencia plástica (As: $80 \pm 20 \mathrm{~mm}$ ). La resistencia media a compresión a 28 días fue del orden de $27 \mathrm{MPa}$ para todos los hormigones.

Tabla 3.6. Síntesis del programa experimental.

\begin{tabular}{|c|c|c|c|c|}
\hline Hormigones & Estado fresco & $\begin{array}{l}\text { Comportamiento } \\
\text { mecánico }\end{array}$ & END & Durabilidad \\
\hline $\begin{array}{l}\text { HC } \\
\text { HR-25 } \\
\text { HR-75 }\end{array}$ & $\begin{array}{l}\text { - Asentamiento } \\
\text { - Peso por unidad } \\
\text { de volumen } \\
\text { - Contenido de } \\
\text { aire }\end{array}$ & $\begin{array}{l}\text { - Resistencia a } \\
\text { compresión } \\
\text { - Módulo de elasticidad } \\
\text { estático } \\
\text { - Resistencia a tracción } \\
\text { por compresión } \\
\text { diametral } \\
\text { - Resistencia a flexión }\end{array}$ & $\begin{array}{l}\text { - Break-Off } \\
\text { - Ultrasónico } \\
\text { - Frecuencia de } \\
\text { resonancia }\end{array}$ & $\begin{array}{l}\text { - Absorción de } \\
\text { agua } \\
\text { - Succión } \\
\text { capilar } \\
\text { - Penetración de } \\
\text { agua a presión } \\
\text { - Difusión de } \\
\text { cloruro } \\
\text { - Ataque por } \\
\text { sulfato }\end{array}$ \\
\hline
\end{tabular}

\subsection{Metodologías de ensayo}

\subsubsection{Evaluación de los agregados gruesos naturales}

Las propiedades evaluadas sobre muestras representativas de cada uno de los AGN incluyeron granulometría, densidad en condición de saturado y superficie seca 
$\left(D_{s s s}\right)$, densidad seca $\left(D_{s}\right)$, absorción de agua en inmersión, pérdida de peso por desgaste “Los Ángeles", pasa tamiz de $75 \mu \mathrm{m}$, peso por unidad de volumen en estado suelto (PUVs), porcentaje de vacíos, índices de lajosidad (IL) y elongación (IE), y, en el caso del basalto pérdida de peso por inmersión en etanodiol (etilenglicol), expresada en por ciento del peso inicial, determinada a 30 días. En la Tabla 3.7 se indican las Normas IRAM utilizadas en cada uno de los ensayos mencionados.

Con relación a la distribución del tamaño de las partículas de los AGN, en la Figura 3.5 se presentan las granulometrías correspondientes a los cuatro agregados, junto con los límites establecidos en la Norma IRAM 1627.

Tabla 3.7. Normas de ensayo utilizadas.

\begin{tabular}{|l|l|}
\hline \multicolumn{1}{|c|}{ Propiedades } & \multicolumn{1}{c|}{ Normas IRAM } \\
\hline Granulometría & IRAM 1505:2005 \\
\hline Densidad y Absorción & IRAM 1533:2002 \\
\hline Desgaste “Los Ángeles” & IRAM 1532:2000 \\
\hline Pasa tamiz 75 $\mu \mathrm{m}$ & IRAM 1540:2004 \\
\hline PUVs & IRAM 1548:2003 \\
\hline Vacíos & IRAM 1548:2003 \\
\hline Índice de lajosidad & IRAM 1687-1:1996 \\
\hline Índice de elongación & IRAM 1687-2:1997 \\
\hline Pérdida en etanodiol & IRAM 1519:1982 \\
\hline
\end{tabular}

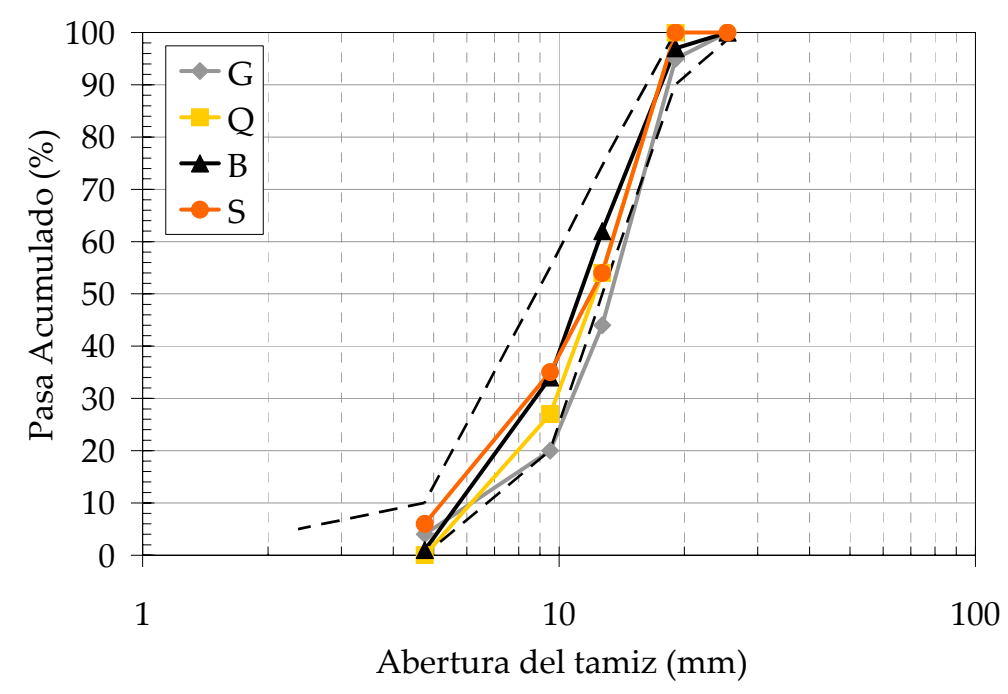

Figura 3.5. Granulometría de los agregados gruesos naturales. 
En la Tabla 3.8 se indican los resultados de las diferentes propiedades determinadas sobre cada uno de los AGN. Puede observarse que el agregado Q presenta los mayores valores de absorción y desgaste "Los Ángeles", como así también una menor densidad, hecho que está directamente vinculado con el origen de dicho agregado. El agregado $S$ presenta el mayor valor de PUVs, a pesar que su densidad no es la más elevada, y el menor índice de lajosidad, hechos que se encuentran directamente vinculados con la forma de sus partículas, lo cual le otorga un menor contenido de vacíos.

Tabla 3.8. Propiedades de los agregados gruesos naturales.

\begin{tabular}{|l|c|c|c|c|}
\hline \multicolumn{1}{|c|}{ Propiedades } & $\mathrm{G}$ & $\mathrm{Q}$ & $\mathrm{B}$ & $\mathrm{S}$ \\
\hline $\mathrm{D}_{\text {sss }}$ & 2,72 & 2,48 & 3,03 & 2,60 \\
\hline $\mathrm{D}_{\mathrm{s}}$ & 2,71 & 2,43 & 3,01 & 2,59 \\
\hline Absorción (\%) & 0,3 & 2,0 & 0,8 & 0,5 \\
\hline Desgaste “Los Ángeles” (\%) & 25,0 & 59,8 & 9,1 & 18,8 \\
\hline Pasa tamiz de 75 $\mu \mathrm{m}(\%)$ & 0,6 & 0,9 & 0,3 & 0,2 \\
\hline PUVs (kg/m $\left.{ }^{3}\right)$ & 1410 & 1310 & 1530 & 1580 \\
\hline Vacíos (\%) & 48,0 & 46,2 & 49,3 & 38,4 \\
\hline IL (\%) & 19,2 & 25,3 & 26,7 & 9,9 \\
\hline IE (\%) & 26,6 & 21,6 & 28,5 & 21,3 \\
\hline Pérdida en etanodiol (\%) & - & - & 2,5 & - \\
\hline
\end{tabular}

\subsubsection{Evaluación de los agregados gruesos reciclados}

Dado que a nivel nacional no se cuenta con ninguna normativa y/o recomendación para la evaluación de los agregados reciclados, sus propiedades fueron determinadas mediante la aplicación de las normas vigentes en nuestro país para los AGN, las cuales fueron presentadas en la Tabla 3.7. Las propiedades evaluadas sobre muestras representativas de cada uno de los AGR generados, fueron las mismas que se determinaron a los AGN, excluyendo el ensayo de pérdida en etilenglicol, y se incluye la pérdida por digestión ácida con el fin de determinar el contenido de mortero de los AGR (Contenido de Mortero). Los resultados obtenidos se informan en el Capítulo 4.

Para la determinación de la distribución granulométrica de los agregados, de acuerdo al tamaño nominal obtenido en los mismos, se emplearon los tamices IRAM $25 \mathrm{~mm}$ (1"), $19 \mathrm{~mm}\left(3 / 4^{\prime \prime}\right), 12,7 \mathrm{~mm}\left(1 / 2^{\prime \prime}\right), 9,5 \mathrm{~mm}$ (3/8") y 4,75 mm (№ 4), pertenecientes a la denominada "serie estándar" [IRAM 1501-2]. 
La resistencia al desgaste determinada mediante la máquina “Los Ángeles" se realizó sobre cada una de las muestras de AGR, y sobre los correspondientes agregados naturales. Dado el tamaño nominal de los mismos, se adoptó la gradación “B” definida en la norma respectiva, para lo cual se emplearon $2500 \pm 10 \mathrm{~g}$ de material retenido en cada uno de los tamices de 12,7 y 9,5 mm, con un peso total aproximado de 5000 \pm 10 g. Además, se adicionaron 11 bolas de acero cuyo peso se ajustó al límite de la norma de $4584 \pm 25 \mathrm{~g}$. Los agregados junto con las bolas fueron sometidas a 500 vueltas del tambor de la citada máquina. Luego, el material resultante fue tamizado por el tamiz IRAM № 12 registrándose el peso del material en él retenido.

Con relación a la determinación del contenido de mortero presente en los AGR, el procedimiento adoptado consistió en tomar muestras correspondientes a la fracción 10$20 \mathrm{~mm}$ de cada uno de los AGR, las cuales se cubrieron con un volumen conocido de agua y se le adicionó igual volumen de ácido clorhídrico, resultando una dilución 1:1. Los agregados en dilución fueron calentados hasta ebullición incipiente luego de lo cual permanecieron en solución durante 24 horas. Finalmente, las muestras fueron lavadas, secadas hasta peso constante y posteriormente tamizadas por el tamiz № 4, registrándose el peso de las partículas de roca del AGN original. Los valores informados corresponden a la pérdida porcentual neta de mortero (expresada en volumen) de cada uno de los AGR, ya que a los mismos le ha sido descontada la pérdida correspondiente a cada uno de los AGN (determinada mediante el mismo procedimiento) y se corrigió por la densidad del agregado natural.

\subsubsection{Evaluación del hormigón endurecido}

\subsubsection{Ensayos de resistencia}

En lo referente al comportamiento mecánico, se realizaron determinaciones de la resistencia a compresión [IRAM 1546] y el módulo de elasticidad estático [ASTM C 469], sobre probetas cilíndricas de 150 × 300 mm. Además, se evaluó la resistencia a tracción por compresión diametral [IRAM 1658], sobre probetas cilíndricas de 100 x $120 \mathrm{~mm}$ y el módulo de rotura en flexión con carga centrada, sobre probetas prismáticas de 75 x 100 mm de sección y 400 mm de luz libre entre apoyos.

Para la determinación del módulo de elasticidad cuerda se consideraron la tensión correspondiente al 40 \% de la carga última y la deformación en correspondencia con ella, y la tensión correspondiente a una deformación longitudinal de 50 strains. 
En la bibliografía se indica que el estado tensional al que se encuentra sometida la probeta durante el ensayo de tracción por compresión diametral se ve modificado según la dimensión del apoyo colocado entre la probeta a ensayar y el plato de la máquina [Rocco et al, 1999]. En tal sentido, al disminuir la base de dicho apoyo, la sección central de la probeta en correspondencia con el plano de aplicación de la carga se encontrará en mayor proporción sometida a tracción, disminuyendo el volumen de hormigón que se encuentra comprimido en correspondencia con el apoyo. Así, y de acuerdo con la dimensión de las probetas a ensayar, se adoptaron apoyos de madera con $4 \mathrm{~mm}$ de base.

\subsubsection{Ensayos no destructivos}

El empleo de los denominados Ensayos No Destructivos (END) tiene por objetivo evaluar el estado general en que se encuentra el hormigón, ya sea a nivel superficial como internamente.

Dentro de la gran cantidad de END que existen, uno de los más utilizados es el de la determinación del tiempo de pasaje del pulso ultrasónico mediante el cual, conociendo la distancia de su recorrido, es posible calcular la velocidad ultrasónica. Este parámetro se encuentra íntimamente vinculado con la estructura interna del material, la cual depende fuertemente la densidad del agregado grueso con que fue elaborado el hormigón [Di Maio et al, 1985]. Además, debido a que la velocidad del pulso ultrasónico mantiene cierta relación con la resistencia a compresión del hormigón, en determinados casos de evaluación de estructuras resulta importante disponer de curvas de correlación velocidad-resistencia, la cual será diferente según el tipo de AGN que contenga el hormigón, incluyendo si ha sido elaborado con agregados reciclados [Di Maio et al, 2005].

Sobre las probetas cilíndricas moldeadas con los hormigones en estudio, previo al ensayo de compresión, se determinó el tiempo de pasaje del pulso ultrasónico, mediante el empleo de un equipo digital portátil con una frecuencia de $54 \mathrm{kHz}$ y una precisión de 0,1 $\mu$ s. En la Figura 3.6 se muestra el equipo ultrasónico utilizado junto con los transductores encargados de emitir y recibir la señal ultrasónica generada.

Además, sobre las mismas probetas cilíndricas se aplicó también el método de frecuencia de resonancia, mediante el cual es posible obtener el módulo de elasticidad dinámico del hormigón, para lo cual se utilizó un equipo electrónico con un rango de frecuencia que oscila entre $10 \mathrm{kHz}$ y $100 \mathrm{kHz}$ (Figura 3.7). 


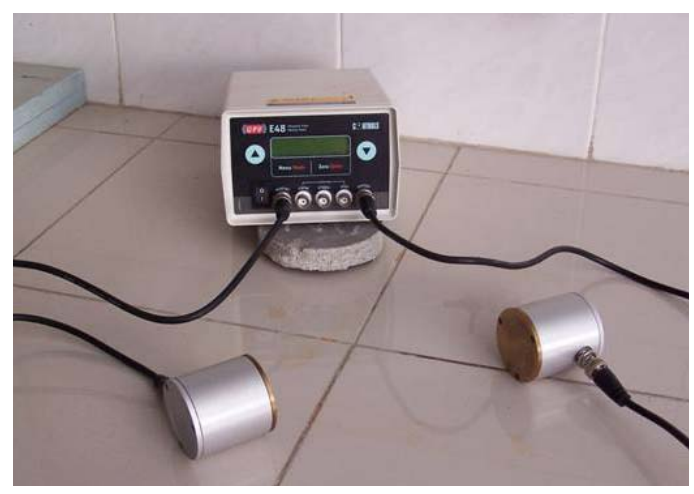

Figura 3.6. Equipo ultrasónico digital.

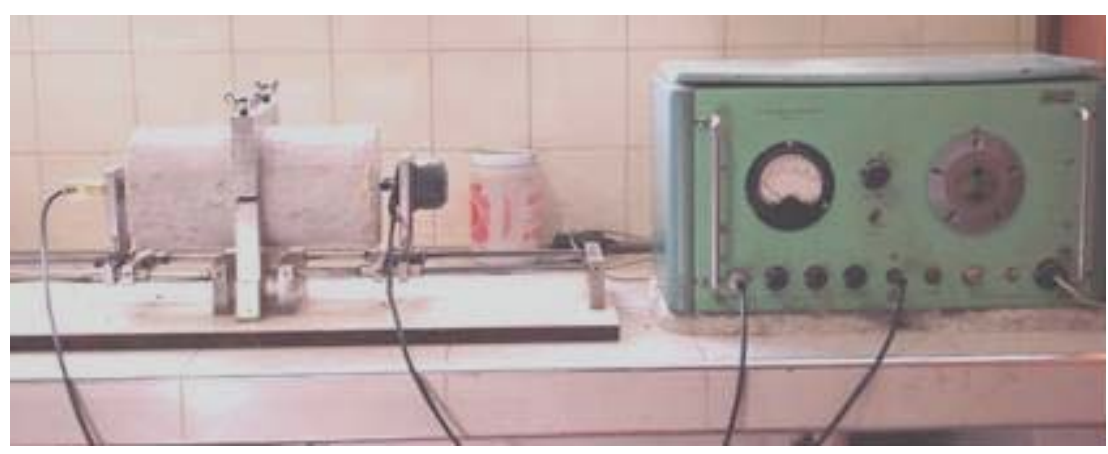

Figura 3.7. Equipo de frecuencia de resonancia.

El contenido de humedad que presenten las probetas al momento de realizar los ensayos de ultrasonido y de frecuencia de resonancia resulta de importancia dado que ambos métodos evalúan la estructura interna del material. Por tal motivo, el acondicionamiento de las probetas previo a la realización de los ensayos, consistió en retirarlas de la cámara húmeda y mantenerlas en ambiente de laboratorio durante aproximadamente dos horas, logrando el secado superficial de las mismas.

Otro de los ensayos empleados en la evaluación de los hormigones en estudio fue el Break-Off [ASTM C 1150], el cual constituye un Ensayo Semi-Destructivo que permite estimar "in situ" la resistencia a compresión del hormigón. Del mismo modo que con el método ultrasónico, con este ensayo es posible obtener curvas de correlación entre la resistencia a compresión y la presión Break-Off. Para ello, cuando el hormigón se encuentra aún en estado fresco, es preciso colocar insertos plásticos de forma cilíndrica (Figura 3.8) los cuales son retirados a las 24 horas, quedando materializados los testigos de ensayo de $55 \mathrm{~mm}$ de diámetro y $70 \mathrm{~mm}$ de altura, los cuales permanecen empotrados a la masa del hormigón en uno de sus extremos. Otra alternativa para la generación de dichos testigos, pero en el hormigón endurecido, es mediante el calado con broca diamantada (Figura 3.8). 

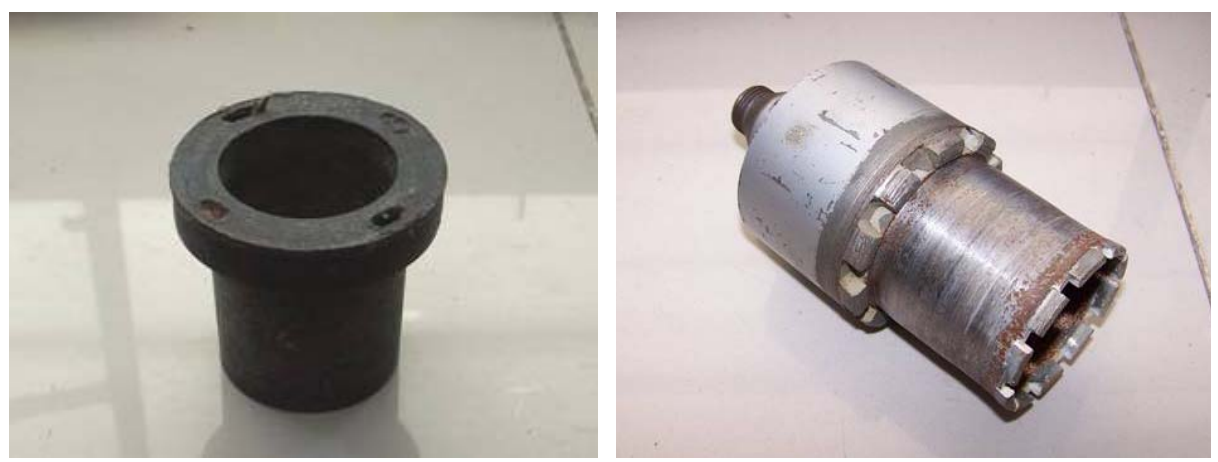

Figura 3.8. Molde plástico y broca diamantada para generar los testigos del ensayo Break-Off.

Junto con la materialización del testigo se genera también una base donde apoya la celda de carga, la cual consiste fundamentalmente en un cilindro con un sector de círculo móvil, el cual mediante un sistema hidráulico accionado manualmente produce una presión que se registra en un manómetro una vez producida la rotura del cilindro. En la Figura 3.9 se muestra el testigo y la base de apoyo generados, y la celda de carga ubicada en la posición de ensayo.
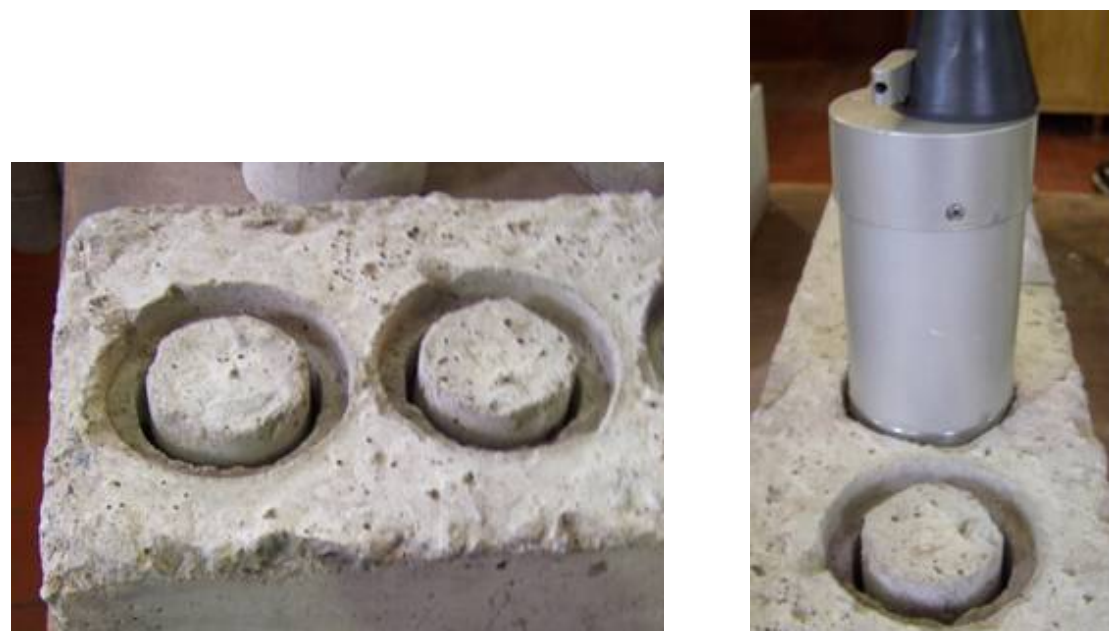

Figura 3.9. Testigo y base de apoyo de la celda de carga del ensayo Break-Off.

El ensayo Break-Off se realizó con un equipo marca Scancem (Figura 3.10), que posee un rango de presión de $16 \mathrm{MPa}$ y una precisión de lectura de 0,2 MPa. Las determinaciones se realizaron manteniendo el equipo en el nivel superior de presión (Nivel H: hormigones con un nivel resistente de hasta $75 \mathrm{MPa}$ ), aplicando la carga hasta alcanzar la rotura del material a razón de $0,2 \mathrm{MPa} / \mathrm{s}$. 


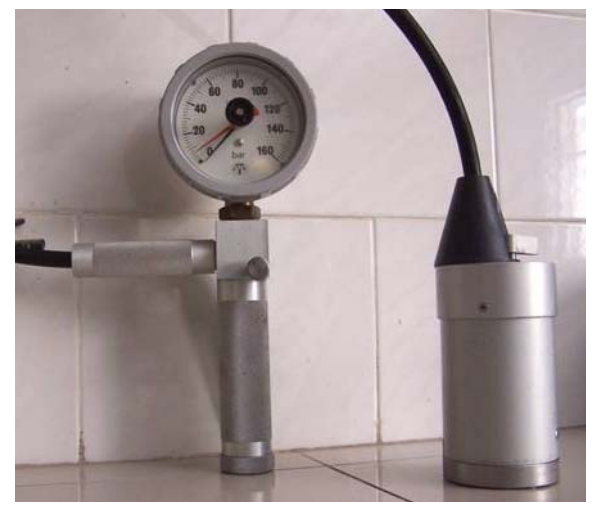

Figura 3.10. Celda de carga, válvula de presión y manómetro del equipo Break-Off.

Los cilindros de ensayo fueron materializados mediante los insertos plásticos, según se describió anteriormente, sobre la cara de moldeo de vigas de 150 × 150 × 500 mm, elaboradas con cada uno de los hormigones originales y reciclados en estudio.

\subsubsection{Ensayos de durabilidad}

Con relación al comportamiento durable de los hormigones elaborados con los diferentes AGR, los cuales fueron evaluados de manera comparativa al de los hormigones originales, se realizaron ensayos con diferentes mecanismos de transporte que permiten la caracterización del material a partir de evaluar la resistencia que opone al pasaje de líquido a través de su estructura porosa. Se realizaron los ensayos de absorción de agua por inmersión, succión capilar, penetración de agua a presión y difusión de cloruros en inmersión. Además, se realizó una experiencia de campo, en la cual se evaluó el comportamiento de hormigones reciclados respecto a uno elaborado con agregados naturales al ser expuestos en suelo con sulfato. A continuación se presenta una descripción del procedimiento realizado para cada uno de estos ensayos.

\section{- Absorción de agua por inmersión}

El ensayo de absorción de agua se realizó siguiendo los lineamientos indicados en la Norma ASTM C 642, utilizando muestras representativas de cada uno de los hormigones en estudio. Las mismas fueron colocadas en estufa (T: $103 \pm 2^{\circ} \mathrm{C}$ ) hasta constancia de peso (diferencia menor a 0,5\%), registrándose el peso seco. Luego, se colocaron en inmersión de agua hasta peso constante (diferencia en pesadas sucesivas durante 24 horas menor a $0,5 \%$ ), registrándose los pesos sumergido y saturado a superficie seca de cada muestra. Con los datos obtenidos se calculó la absorción de agua de cada uno de los hormigones como el cociente entre la cantidad de agua absorbida y el peso seco de la muestra, expresado en por ciento (\%). 


\section{- Succión capilar}

En el Proyecto de Reglamento Argentino de Estructuras de Hormigón [CIRSOC 201:2005] se establece que los hormigones destinados a estructuras sometidas a determinadas clases de exposición (definidas por dicho reglamento) deben cumplir con el límite máximo de velocidad de succión capilar, como condición para ser considerado de buen desempeño durable. La Norma IRAM 1871 regla el procedimiento para realizar el ensayo de succión capilar, indicando también el acondicionamiento previo de las probetas y el modo de cálculo de los parámetros velocidad y capacidad de succión capilar ( $\mathrm{V}_{\mathrm{sc}} \mathrm{y} \mathrm{C}_{\mathrm{sc}}$ ).

El ensayo de succión capilar se realizó sobre la cara inferior de probetas cilíndricas de $100 \mathrm{~mm}$ de diámetro y $50 \mathrm{~mm}$ de espesor, las cuales fueron aserradas a partir de cilindros de $100 \times 200 \mathrm{~mm}$, descartando los $30 \mathrm{~mm}$ inferiores que se encontraban en contacto con el molde (Figura 3.11).

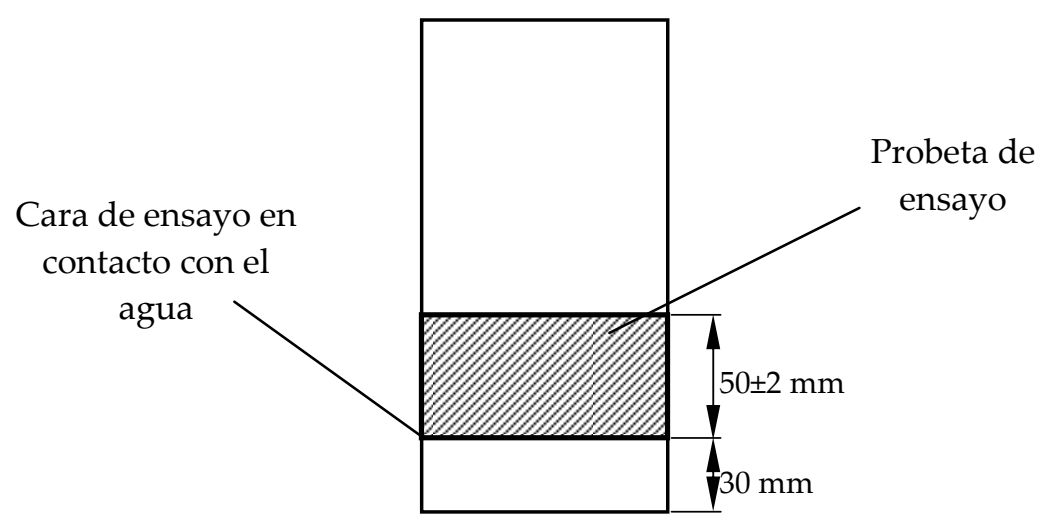

Figura 3.11. Probeta para el ensayo de succión capilar.

Las probetas fueron impermeabilizadas en su perímetro mediante un esmalte sintético a base de caucho clorado. Luego, se sumergieron en agua durante 72 horas y posteriormente se colocaron en estufa ( $\mathrm{T}: 50 \pm 2^{\circ} \mathrm{C}$ ) para su secado hasta peso constante, considerando que alcanzaron dicho estado cuando la diferencia entre pesadas sucesivas, realizadas cada 24 horas, era menor al 0,1\%.

El ensayo propiamente dicho consiste en someter a las probetas en contacto con agua por su cara inferior, la cual se encuentra sumergida a una profundidad de $3 \mathrm{~mm}$ (Figura 3.12), y registrar los cambios en su peso como consecuencia de la absorción de agua por capilaridad. Se registra el peso a intervalos de 30 minutos, 1, 2, 3, 4, 5, 6, 24, 48 horas y a continuación cada 24 horas hasta que la variación entre pesadas sucesivas sea inferior al $0,1 \%$. 


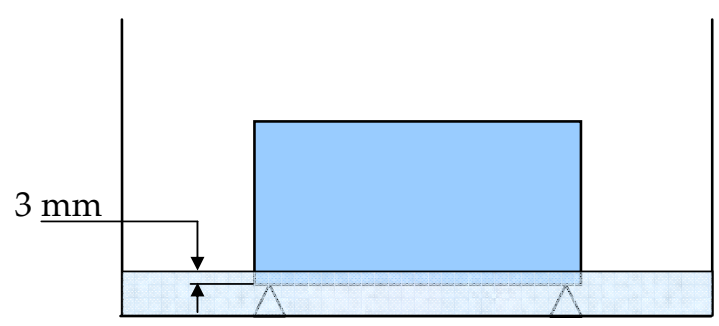

Figura 3.12. Esquema del ensayo de succión capilar.

A partir de los datos registrados es posible representar la ganancia de peso por unidad de área de las probetas en función de la raíz cuadrada del tiempo, obteniendo de este modo una curva de absorción por cada una de ellas. Si bien la norma citada no hace referencia a la obtención de una curva promedio, igualmente se decidió obtenerla para los hormigones en estudio a fin de poder comparar el comportamiento de los hormigones con AGR respecto al de los elaborados con AGN. Para la obtención de la curva promedio se consideró que las curvas individuales de cada probeta ensayada no se aparten en $\pm 15 \%$ de la misma, descartando las que no cumplan con dicha condición, obteniendo una nueva curva. Siguiendo el mismo criterio que establece la norma para el cálculo de la velocidad $\left(\mathrm{V}_{\mathrm{sc}}\right)$, se adoptó dicho rango de variación. En la Figura 3.13 se presenta, a modo de ejemplo, las curvas individuales de cada probeta, la curva promedio y las curvas límite obtenidas en un dado hormigón. Se ensayaron un total de cinco probetas por hormigón.

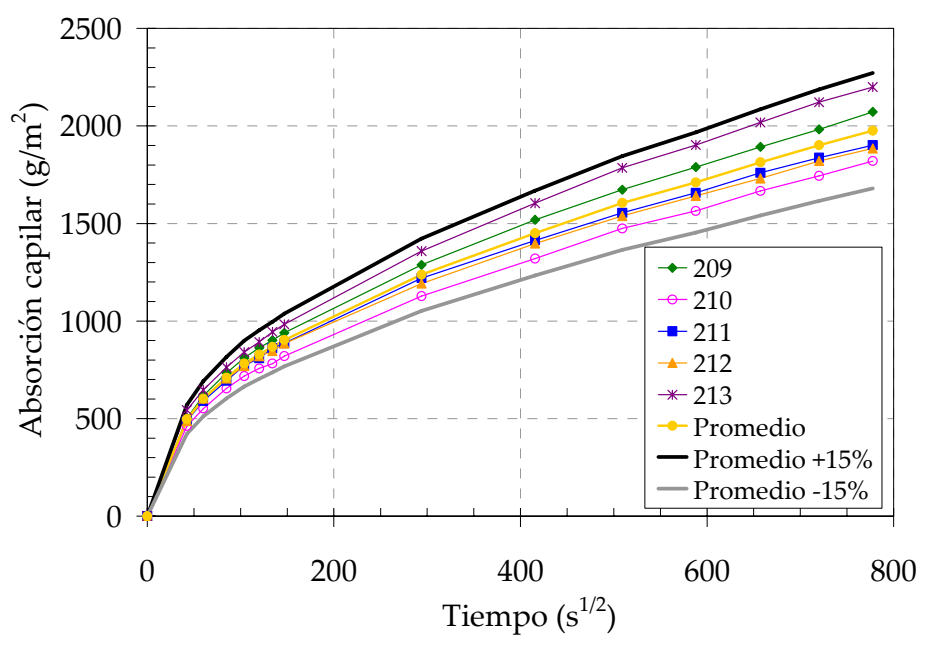

Figura 3.13. Curvas individuales, promedio y curvas límite obtenidas en el ensayo de succión capilar.

La capacidad de succión capilar de cada probeta está definida en la citada norma como el valor de absorción, expresado en gramos por metro cuadrado, correspondiente al instante de tiempo para el cual la variación de peso es menor que 0,1 \% entre dos determinaciones sucesivas. El promedio de las capacidades individuales de cada probeta es 
considerado como la capacidad de succión capilar del hormigón. Nuevamente, aunque la norma correspondiente no hace referencia a la dispersión máxima aceptable para el cálculo de la capacidad, la misma quedó definida a partir del $\pm 15 \%$ indicado anteriormente para la obtención de la curva promedio.

La velocidad de succión capilar del hormigón, expresada en gramos por metro cuadrado por segundo a la un medio, esta definida por la pendiente de la recta obtenida mediante ajuste por mínimos cuadrados de la serie de puntos, correspondientes al total de las muestras. En la norma se establece que los puntos a considerar en el cálculo de la velocidad $\mathrm{V}_{\mathrm{sc}}$ deben estar comprendidos entre 0,1 y 0,9 de la $\mathrm{C}_{\mathrm{sc}}$ individual de cada probeta, como así también deben estar dentro del rango de $\pm 15 \%$ de su promedio, para cada instante de tiempo considerado. En la Figura 3.14 se presenta, a modo de ejemplo, la serie de puntos, la curva de ajuste y la ecuación de la misma. El hormigón del ejemplo presenta una velocidad $\left(\mathrm{V}_{\mathrm{sc}}\right)$ de $2,11 \mathrm{~g} / \mathrm{m}^{2} / \mathrm{s}^{1 / 2}$.

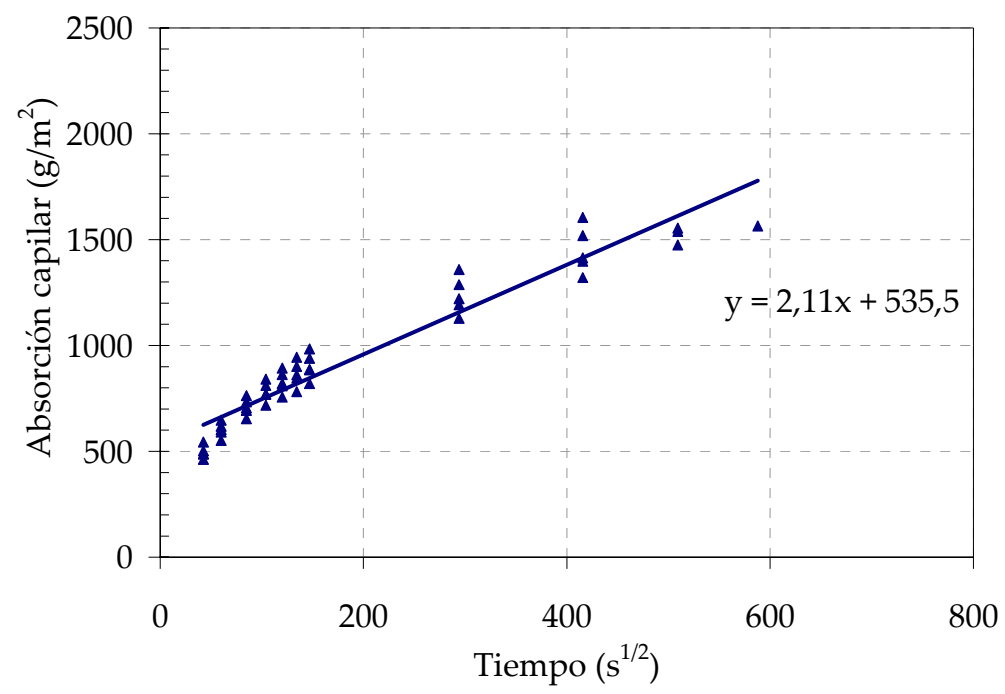

Figura 3.14. Gráfico de velocidad de succión capilar.

\section{- Penetración de agua a presión}

En el caso de hormigones de estructuras destinadas a contener o conducir agua, y que requieran una elevada impermeabilidad, el Reglamento CIRSOC 201:2005 establece también límites para las penetraciones de agua determinadas a dichos hormigones.

El ensayo para determinar la penetración de agua a presión en probetas de hormigón endurecido se encuentra detallado en la Norma IRAM 1554, indicándose el empleo de tres probetas por hormigón. Para su realización se utilizaron probetas de sección cuadrada de $200 \mathrm{~mm}$ de lado. Según se indica en la citada norma, el área de contacto entre el 
agua y la probeta debe ser tal que su dimensión sea la mitad del lado de la cara en cuestión. En este caso, el área de contacto fue circular con un diámetro de 100 mm. En la Figura 3.15 se muestra una fotografía del equipo de permeabilidad que posee el LEMIT, el cual fue utilizado para realizar el ensayo de penetración de agua a presión.

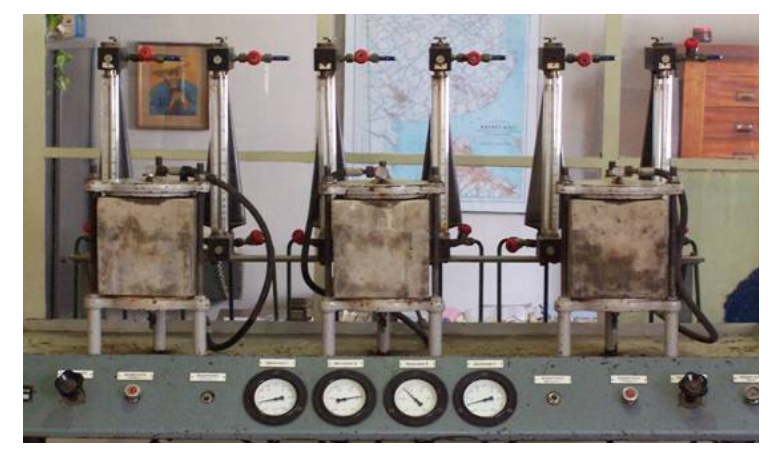

Figura 3.15. Equipo para evaluar la penetración de agua a presión.

Las probetas fueron sometidas a una presión de agua variable durante un período de 96 horas (48 horas a $1 \mathrm{~kg} / \mathrm{cm}^{2}, 24$ horas a $3 \mathrm{~kg} / \mathrm{cm}^{2}$, y 24 horas a $7 \mathrm{~kg} / \mathrm{cm}^{2}$ ). Finalizado dicho período, las probetas se ensayaron a tracción por compresión diametral con el fin de exponer y marcar los perfiles de penetración de agua sobre cada una de las mitades generadas. Posteriormente, se midió la profundidad de penetración de agua a lo largo de la distancia de contacto de $100 \mathrm{~mm}$, realizando las lecturas cada $5 \mathrm{~mm}$, de modo de obtener 21 lecturas sobre cada mitad de probeta. El valor de penetración de cada probeta surge del promedio de los 42 valores, y el valor de penetración de agua a presión del hormigón resulta del promedio de tres ensayos, considerando en este último caso una variación máxima de $\pm 15 \%$ respecto al valor medio.

En la Figura 3.16 se presenta, a modo de ejemplo, el perfil de penetración de agua a presión delineado sobre las dos mitades de una probeta.

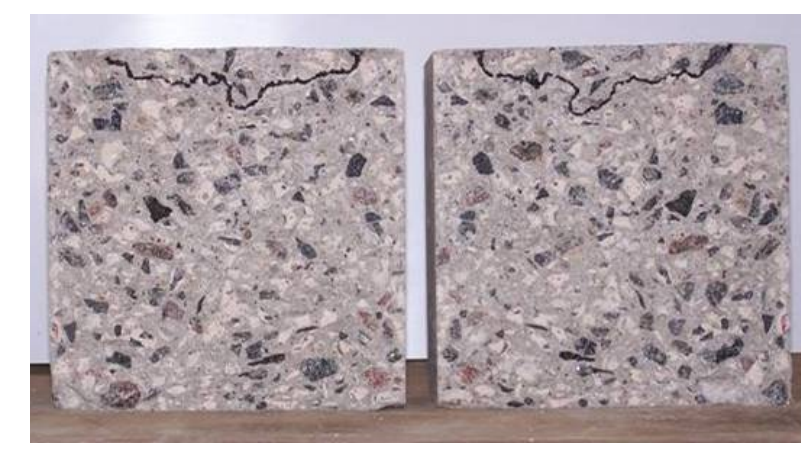

Figura 3.16. Perfil de penetración marcado sobre cada mitad de una probeta. 


\section{- Difusión de cloruro}

El pasaje de fluidos conteniendo sustancias agresivas a través de la estructura porosa del hormigón puede producir la degradación del mismo en el tiempo o bien, en el caso del hormigón armado, si se trata de cloruros, provocar el ataque a las armaduras contenidas en su interior. En tal caso, al producirse la difusión de los cloruros hacia el interior de la estructura de poros, una parte de los mismos serán retenidos por los productos de hidratación del cemento (cloruros retenidos) mientras que los restantes permanecerán en la solución de poros, siendo denominados cloruros libres.

Por tal motivo, otra de las evaluaciones realizadas a los hormigones convencionales y reciclados, con el fin de estudiar su comportamiento frente a ambientes agresivos, fue la determinación del contenido de cloruros ingresados al hormigón por difusión.

Con cada hormigón en estudio se moldearon probetas prismáticas de $85 \times 150 \times 250 \mathrm{~mm}$, las que fueron impermeabilizadas mediante la aplicación de un esmalte sintético a base de caucho clorado sobre sus caras laterales y la cara de fondo, dejando libre la de moldeo.

Para que el ingreso de cloruros se efectúe básicamente por difusión en inmersión, resulta necesario que la estructura de poros del hormigón se encuentre en estado de saturación, por lo que previamente se procedió a sumergir las probetas en una solución alcalina durante 5 días. Luego, las mismas fueron inmersas en una solución acuosa de cloruro de sodio con una concentración del $3 \%$, hasta la edad de 140 días.

El procedimiento de ensayo se realizó en base a experiencias anteriores [VillagránZaccardi et al, 2008]. A la edad anteriormente mencionada, se aserró una porción de las probetas inmersas en solución. De cada una de estas porciones se aserraron ocho fetas, las cuales fueron posteriormente molidas para proceder a la determinación del contenido de cloruro en cada una de ellas. El procedimiento adoptado para realizar los análisis químicos consistió en realizar preparados con aproximadamente $20 \mathrm{~g}$ de muestra molida (pesada al 0,001 g) y $100 \mathrm{ml}$ de agua destilada, dejándolos en reposo durante 24 horas. Luego, se tomó una alícuota del sobrenadante límpido de los preparados y se realizó la titulación según el método de Mohr [Skoog et al, 2005], obteniéndose de este modo el contenido de cloruro soluble en agua. Sobre los remanentes de los preparados se realizó el ataque ácido y la valoración según el método descripto en la Norma IRAM 1857, Método C, obteniéndose el contenido de cloruro soluble en ácido. 
En la Figura 3.17 se muestra el esquema de la probeta y de la porción a partir de la cual se obtuvieron las fetas. En el esquema de la izquierda (porción o pieza de evaluación) puede observarse que la feta en correspondencia con la cara de moldeo de la probeta es la que presentaría el mayor contenido de cloruros, ya que es la que se encuentra en contacto directo con la solución, disminuyendo dicho contenido en las sucesivas fetas.

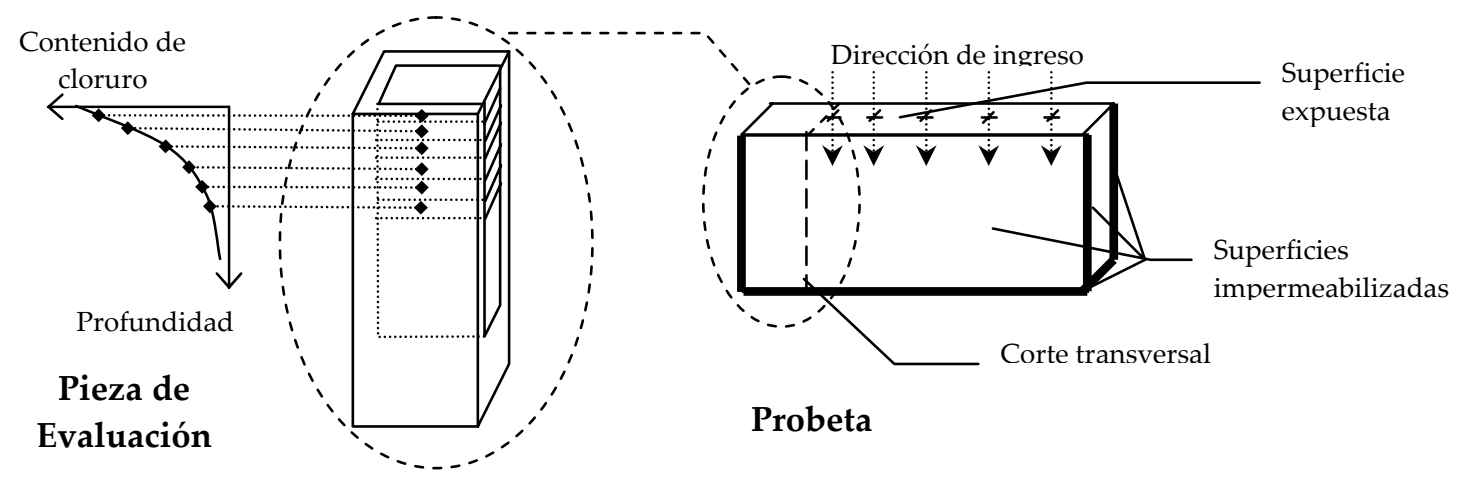

Figura 3.17. Esquema de la probeta y determinación del perfil de cloruros.

Una vez determinado el perfil de ingreso de cloruros, es decir, conociendo la concentración de cloruros a cada profundidad, es posible determinar el coeficiente de difusión aparente de cloruros ( $\mathrm{D}_{\mathrm{ap}}$ ) mediante la aplicación de la solución a la segunda Ley de Fick, la cual está definida por la siguiente expresión:

$$
c(x, t)=c_{0} *\left(1-\operatorname{erf} \frac{x}{2 \sqrt{D_{\text {ap }}{ }^{* t}}}\right)
$$

Donde:

$c(x, t)$ : concentración a la profundidad $x$ en el tiempo $t$

Co: concentración superficial

$\mathrm{x}$ : distancia desde la superficie

Dap: coeficiente de difusión

t: tiempo

\section{- Experiencia de campo: exposición en suelo con sulfato}

La presencia de sulfato en el suelo de contacto de una estructura de hormigón puede ocasionar, debido a sucesivos ciclos de humedecimiento y secado, una degradación del hormigón causada por la acción física de precipitación de sales. Con el fin de evaluar 
el comportamiento de los hormigones reciclados frente a este tipo de agresión, se realizó una prueba de campo con hormigones elaborados con diferentes contenidos de AGR.

Se moldearon probetas prismáticas de $75 \times 100 \times 430$ mm, las cuales fueron mantenidas en condiciones normalizadas de temperatura y humedad (T: $23 \pm 2^{\circ} \mathrm{C}$; hr: $95 \%$ ) durante 28 días. Posteriormente, y previo a su exposición, las mismas fueron evaluadas mediante los métodos ultrasónico y de frecuencia de resonancia, los cuales permiten realizar un seguimiento del comportamiento de los hormigones en el tiempo. La colocación en el campo experimental se realizó de manera que las probetas quedaran semi-enterradas respecto a su eje longitudinal, giradas $90^{\circ}$ respecto a la dirección de llenado, manteniendo siempre dicha orientación.

El campo de experimentación en el cual se colocaron las probetas posee un suelo clasificado como arena limosa con un contenido aproximado de sulfato de sodio del $1 \%$. El clima del lugar de emplazamiento del campo experimental (La Plata, Argentina) se caracteriza por tener un régimen de lluvias de $1000 \mathrm{~mm} / \mathrm{año}$, temperatura máxima media de $30^{\circ} \mathrm{C}$ y mínima media de $5^{\circ} \mathrm{C}$. Dicho régimen permite suponer que las probetas se encuentran sometidas a 15-20 ciclos de mojado y secado por año.

En la Figura 3.18 se muestra el campo experimental en el cual se ubicaron las probetas, pudiéndose observar que las mismas se encuentran protegidas por una cubierta metálica de modo que las variaciones climáticas (cambios meteorológicos) no modifiquen de manera considerable la concentración de sulfato del suelo y las condiciones en que se hallan las probetas.
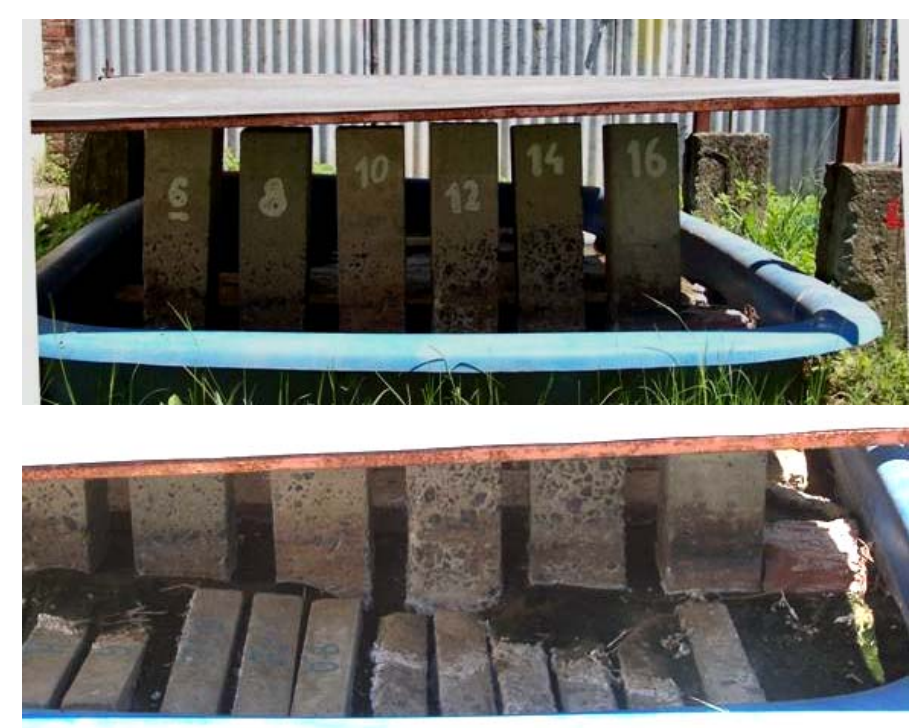

Figura 3.18. Ubicación de las probetas en el campo experimental. 
Durante su exposición, las muestras fueron evaluadas nuevamente mediante los métodos mencionados anteriormente, efectuándose las determinaciones cada 180 días al comienzo de la exposición y luego cada 365 días aproximadamente. En cada edad de evaluación, las probetas son retiradas del suelo y permanecen 48 horas en ambiente de laboratorio para permitir que el contenido de humedad se estabilice con el del ambiente. La evaluación comprende una inspección visual y registro fotográfico de cada una de las probetas y posteriormente la determinación del peso, el tiempo de pasaje de la onda ultrasónica y la frecuencia de resonancia. 


\section{Capítulo 4 \\ Caracterización de Agregados Gruesos Reciclados}

\subsection{Introducción}

A partir del análisis bibliográfico realizado en el Capítulo 2, surge que los estudios llevados a cabo hasta el presente indican que las propiedades de los agregados gruesos reciclados dependen fundamentalmente de la calidad del mortero del hormigón original, sin hacer referencia a la importancia que podría tener el tipo de agregado grueso natural empleado.

Por tal motivo, y con el fin de tomar conocimiento respecto a lo mencionado en el párrafo anterior, en este trabajo de tesis se elaboraron hormigones de dos niveles resistentes empleando cuatro tipos de agregados gruesos naturales, con el objetivo de determinar la posible influencia de los mismos sobre las propiedades de los agregados gruesos reciclados.

En este capítulo se informan los resultados de las diferentes propiedades evaluadas sobre cada uno de los AGR, y se realiza un análisis comparativo con las correspondientes a las de los agregados naturales. Debido a que a nivel nacional no existe una normativa o recomendación para la utilización de los agregados reciclados, y fundamentalmente sobre cómo evaluar sus propiedades, se decidió aplicar los procedimientos descriptos en las normas vigentes para los agregados gruesos naturales, según se mencionó en el Capítulo 3.

\subsection{Aspecto visual}

Es conocido que las partículas que componen los AGR pueden estar compuestas por roca natural y mortero en diferentes proporciones. En algunos casos las mismas pueden estar constituidas enteramente por roca mientras que en otras el mortero aparece formando una única partícula. La presencia del mortero modifica por lo tanto las características del agregado natural original, en algunos casos de manera considerable. 
La obtención de agregados gruesos reciclados a partir de la trituración de hormigones con distintos tipos de agregados naturales permitió comprobar las diferencias existentes entre ellos y los correspondientes AGN, pudiéndose observar en el caso de los AGR partículas con mayor rugosidad superficial, hecho que se relaciona con la presencia del mortero presente en los mismos.

A modo ilustrativo, en las Figuras 4.1-a) - d) se presentan las características de los AGR generados a partir de la trituración de hormigones elaborados con los cuatro agregados gruesos naturales seleccionados, cuya caracterización se presentó en el Capítulo 3.
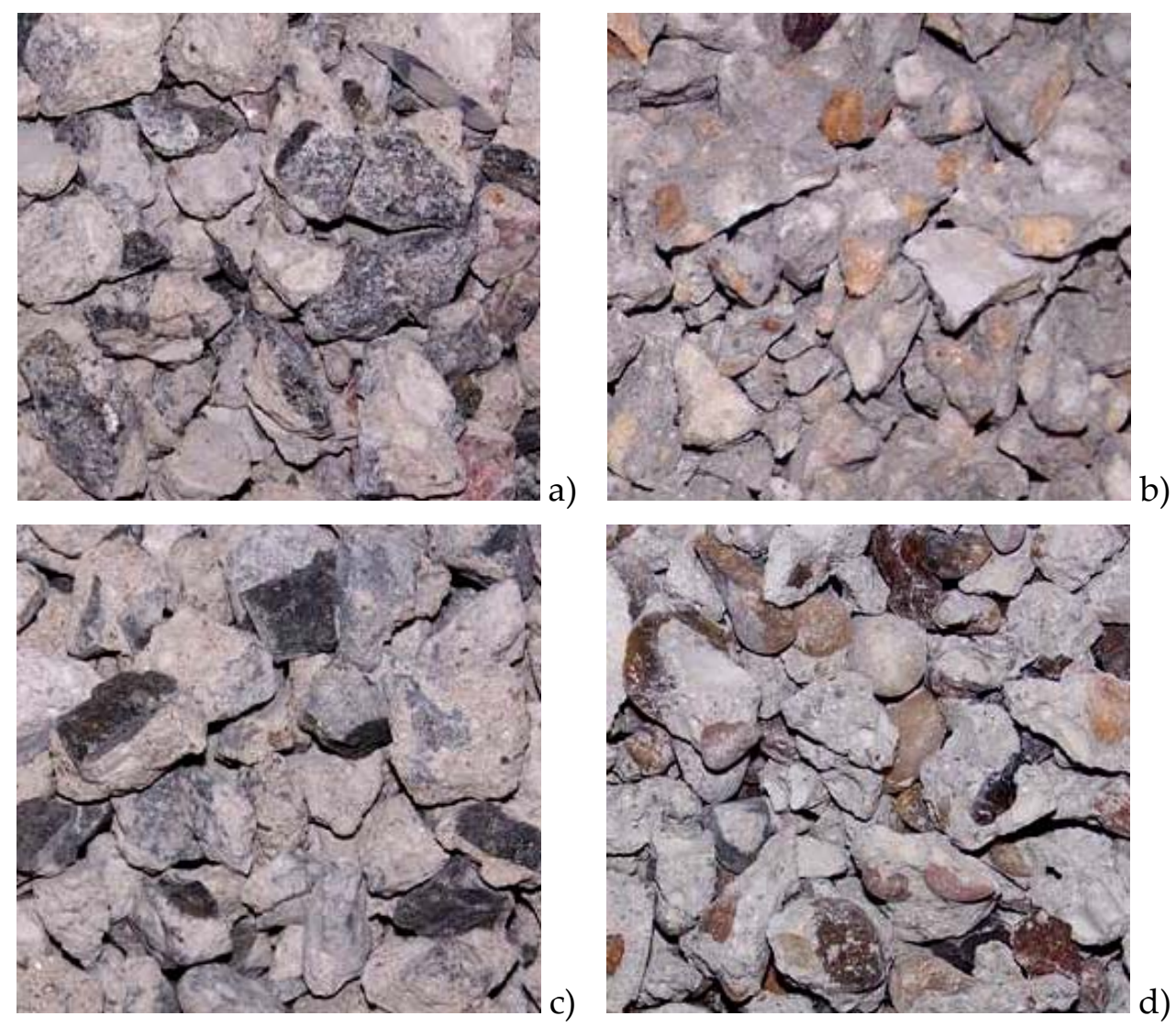

Figura 4.1. AGR obtenido de un hormigón con: a) granito; b) cuarcita;

c) basalto; d) canto rodado silíceo.

Para los agregados reciclados que contienen piedra partida de granito, cuarcita y basalto, Figuras 4.1-a), b) y c) respectivamente, las diferencias visuales más significativas respecto a sus pares naturales están relacionadas con una mayor rugosidad superficial y angulosidad de sus partículas. En el caso de los AGR que contienen canto rodado silíceo, Figura 4.1-d), las diferencias respecto a los AGN se relacionan con el cambio de forma y rugosidad de sus partículas, que para los agregados reciclados es irregular y rugosa mientras que para los naturales es redondeada y lisa. 
Además de las diferencias mencionadas en cuanto a las características que presentan las partículas de los AGR, pudo observarse que en algunas varía su composición según sea el tipo de AGN que contienen. Las partículas de los AGR provenientes de hormigones elaborados con piedra partida de cuarcita están constituidas, en su gran mayoría, por mortero y agregado natural en forma conjunta, hecho atribuido a la baja resistencia de la roca natural y a su rugosidad superficial que permite una buena adherencia, posibilitando que el agregado natural y el mortero se fracturen con igual facilidad durante el proceso de triturado. Por otro lado, las partículas de los AGR que contienen canto rodado muestran una baja proporción de agregados naturales fracturados y gran cantidad de partículas formadas enteramente de mortero, hecho que debe ser atribuido a la elevada resistencia de la roca que compone el agregado natural y a su textura superficial lisa, que favorece la separación del mismo. Las características mencionadas se pueden observar en las Figuras 4.2-a) y b).
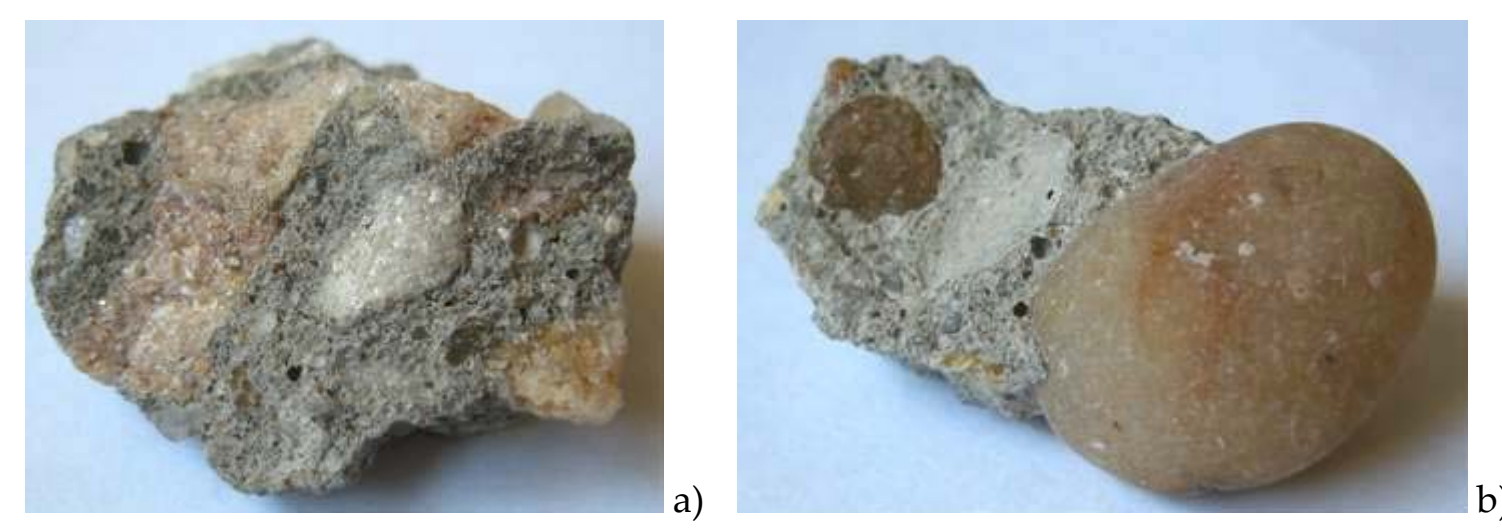

Figura 4.2. Partícula de AGR obtenido de un hormigón con:

a) cuarcita; b) canto rodado silíceo.

\subsection{Propiedades evaluadas}

Sobre los AGR en estudio se evaluaron las mismas propiedades determinadas a los AGN, cuyos resultados se presentaron en el Capítulo 3, incluyendo granulometría, densidad en condición de saturado y superficie seca $\left(D_{s s s}\right)$, densidad seca $\left(D_{s}\right)$, absorción de agua, resistencia al desgaste con la máquina "Los Ángeles”, material fino que pasa el tamiz de $75 \mu \mathrm{m}$, peso por unidad de volumen en estado suelto (PUVs), porcentaje de vacíos, índices de lajosidad (IL) y elongación (IE), determinándose también el contenido de mortero adherido. En la Tabla 4.1 se resumen los valores obtenidos en el caso de los AGR. 
Tabla 4.1. Propiedades de los agregados gruesos reciclados.

\begin{tabular}{|l|c|c|c|c|c|c|c|c|}
\hline \multicolumn{1}{|c|}{ Propiedades } & RG45 & RG65 & RQ45 & RQ65 & RB45 & RB65 & RS45 & RS65 \\
\hline Módulo de finura & 6,69 & 6,69 & 6,71 & 6,67 & 6,71 & 6,61 & 6,57 & 6,57 \\
\hline$D_{\text {sss }}$ & 2,52 & 2,51 & 2,37 & 2,35 & 2,66 & 2,65 & 2,45 & 2,44 \\
\hline$D_{\text {s }}$ & 2,42 & 2,41 & 2,24 & 2,22 & 2,56 & 2,53 & 2,36 & 2,34 \\
\hline Absorción (\%) & 4,0 & 4,1 & 5,9 & 6,0 & 3,9 & 4,5 & 3,9 & 4,4 \\
\hline Desgaste “Los Ángeles” (\%) & 34,8 & 37,4 & 52,2 & 55,4 & 25,3 & 30,3 & 31,6 & 37,0 \\
\hline Pasa tamiz de 75 $\mu \mathrm{m}(\%)$ & 0,6 & 0,2 & 0,2 & 0,2 & 0,2 & 0,4 & 0,1 & 0,1 \\
\hline PUVs (kg/m $\left.{ }^{3}\right)$ & 1220 & 1190 & 1100 & 1140 & 1260 & 1290 & 1190 & 1210 \\
\hline Vacíos (\%) & 49,4 & 50,9 & 50,9 & 48,5 & 50,9 & 49,2 & 49,5 & 48,1 \\
\hline IL (\%) & 12,9 & 10,1 & 14,9 & 12,7 & 11,3 & 9,9 & 11,2 & 10,4 \\
\hline IE (\%) & 23,2 & 28,2 & 36,6 & 16,3 & 24,6 & 20,1 & 31,3 & 22,2 \\
\hline Contenido de Mortero (\%) & 38,6 & 34,7 & 61,3 & 53,5 & 41,2 & 33,1 & 44,4 & 38,2 \\
\hline
\end{tabular}

\subsubsection{Granulometría}

Las distribuciones granulométricas correspondientes a cada uno de los ochos AGR en estudio, se presentan en la Tabla 4.2.

Tabla 4.2. Granulometría de los agregados gruesos reciclados.

\begin{tabular}{|l|c|c|c|c|c|c|c|c|}
\hline \multirow{2}{*}{ Tamiz IRAM } & \multicolumn{7}{|c|}{ Pasa acumulado (\%) } \\
\cline { 2 - 10 } & RG45 & RG65 & RQ45 & RQ65 & RB45 & RB65 & RS45 & RS65 \\
\hline $25 \mathrm{~mm}\left(1^{\prime \prime}\right)$ & 100 & 100 & 100 & 100 & 100 & 100 & 100 & 100 \\
\hline $19 \mathrm{~mm}\left(3 / 4^{\prime \prime}\right)$ & 100 & 100 & 100 & 100 & 100 & 100 & 100 & 100 \\
\hline $12,7 \mathrm{~mm}\left(1 / 2^{\prime \prime}\right)$ & 52 & 51 & 57 & 56 & 56 & 57 & 67 & 69 \\
\hline $9,5 \mathrm{~mm}\left(3 / 8^{\prime \prime}\right)$ & 25 & 26 & 28 & 29 & 27 & 30 & 39 & 41 \\
\hline $4,75 \mathrm{~mm}\left(\mathrm{~N}^{\circ}\right.$ 4) & 2 & 2 & 1 & 3 & 2 & 5 & 2 & 2 \\
\hline $2,38 \mathrm{~mm}\left(\mathrm{~N}^{\circ} 8\right)$ & 1 & 1 & 0 & 1 & 0 & 2 & 1 & 0 \\
\hline
\end{tabular}

En la Figura 4.3 se comparan las curvas granulométricas correspondientes a cada uno de los AGR con los límites granulométricos indicados en la Norma IRAM 1627 para agregados naturales de igual tamaño máximo nominal. Puede observarse que el proceso de trituración adoptado permitió obtener en todos los casos AGR con distribuciones granulométricas semejantes, independientemente del tipo de AGN y de la razón a/c del hormigón de origen a partir del cual fueron obtenidos. 


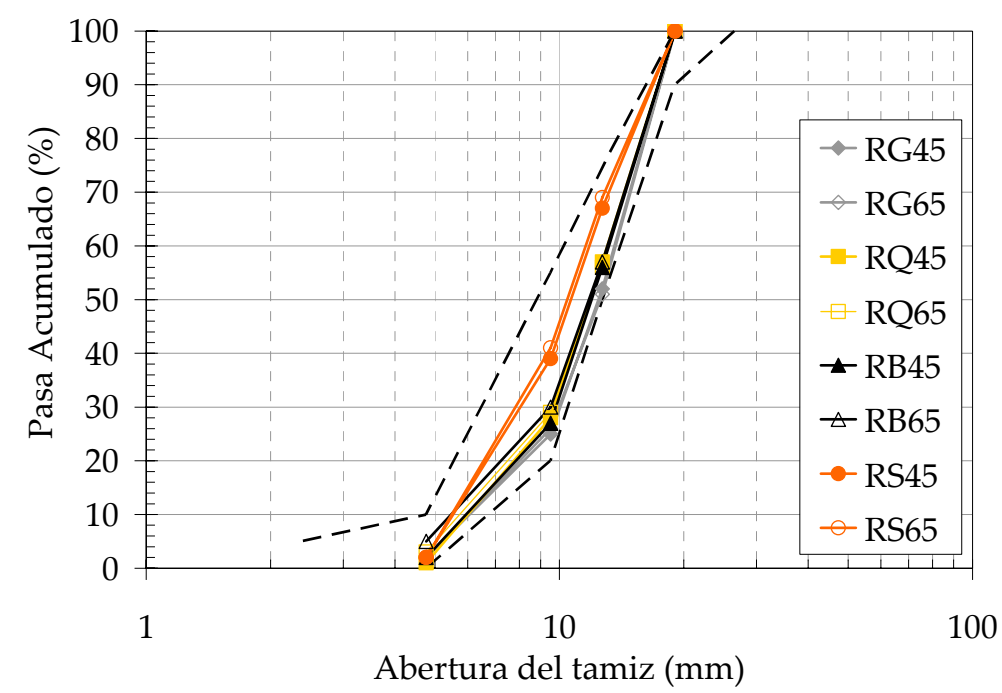

Figura 4.3. Curvas granulométricas de los agregados gruesos reciclados.

\subsubsection{Densidad y Absorción}

Las densidades determinadas a cada uno de los AGR obtenidos son presentadas en la Figura 4.4, junto con la del correspondiente AGN.

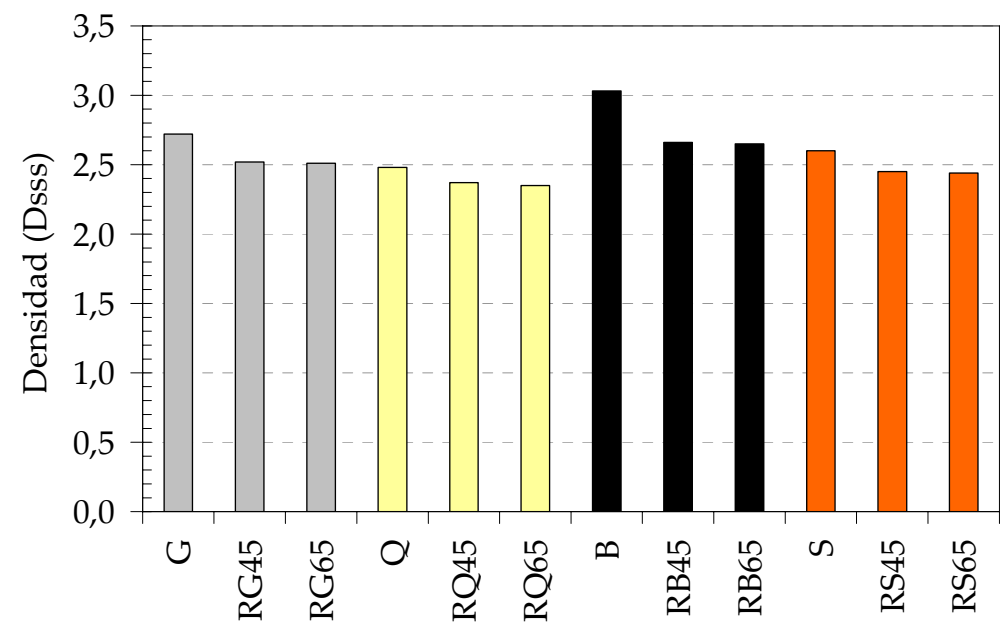

Figura 4.4. Densidad de los agregados gruesos naturales y reciclados.

Puede observarse que las densidades de los AGR son inferiores a la del correspondiente agregado natural, debido al mortero presente en los mismos, el cual posee menor densidad que la roca natural. Además, los AGR provenientes de hormigones elaborados con un mismo agregado grueso natural y distinta razón a/c presentan similares valores de densidad (variación menor al $1 \%$ ), hecho que resulta coincidente con lo indicado en la bibliografía [Hansen y Narud, 1983; Di Maio et al, 2001]. Esto podría explicarse a partir de considerar que, por un lado, la mayor razón a/c de la matriz ocasiona una mayor porosi- 
dad de la misma y en consecuencia menor densidad, mientras que su inferior resistencia causaría una mayor pérdida de mortero durante la trituración, hechos contrapuestos y que justificarían los resultados alcanzados.

Las disminuciones obtenidas en los valores de densidad de los AGR fueron 7, 5, 12 y $6 \%$ aproximadamente con relación a las de los agregados naturales G, Q, B y S, respectivamente. Una particularidad que se observa en la Figura 4.4 es que algunos agregados reciclados presentan mayores densidades que otros agregados naturales, tal el caso de los agregados RB con relación a los agregados naturales Q y S, independientemente de la razón a/c del hormigón de origen. Este hecho puede resultar de gran importancia debido a que muchas propiedades de los hormigones, como por ejemplo el módulo de elasticidad estático, se encuentran fuertemente relacionadas con las características de los agregados utilizados para su elaboración [Mehta y Monteiro, 1998].

En la bibliografía consultada se han encontrado diferentes métodos propuestos para evaluar la absorción de los agregados reciclados, los cuales buscan evitar que el mortero adherido se desprenda ocasionalmente durante el secado superficial, a la vez que permiten determinar la tasa de absorción [Leite et al, 2000; Tam et al, 2008]. No obstante, en este estudio se decidió aplicar el procedimiento indicado en la Norma IRAM 1533 para los AGN y así poder comparar los valores obtenidos en los agregados reciclados con la de estos últimos, además de considerar que representa un método práctico, tomando las debidas precauciones.

Las absorciones determinadas sobre los diferentes AGR, junto con las obtenidas en los respectivos agregados naturales, se presentan en la Figura 4.5. Como era de esperar, la absorción de agua determinada a los diferentes AGR es muy superior a la del correspondiente AGN, para los diferentes tipos de agregados naturales utilizados. Este hecho se encuentra directamente vinculado con la presencia de mortero como parte constituyente de los AGR. Las absorciones de los AGR resultaron, en promedio, aproximadamente 14, 3, 5 y 8 veces mayores que las obtenidas para los agregados naturales G, Q, B y S, respectivamente.

En algunos estudios, en los cuales emplearon agregados naturales de tipo calcáreo o granítico, se indica que la absorción de agua de los AGR resulta independiente de la calidad del hormigón de origen [Hansen y Narud, 1983; Sri Ravindrarajah y Tam, 1985; Hasaba et al, 1981, citado por Hansen, 1986; Di Maio et al, 2001]. En contradicción a lo se- 
ñalado, en un estudio reciente se indican mayores valores de absorción para los AGR provenientes de hormigones de mayor resistencia [Padmini et al, 2009].

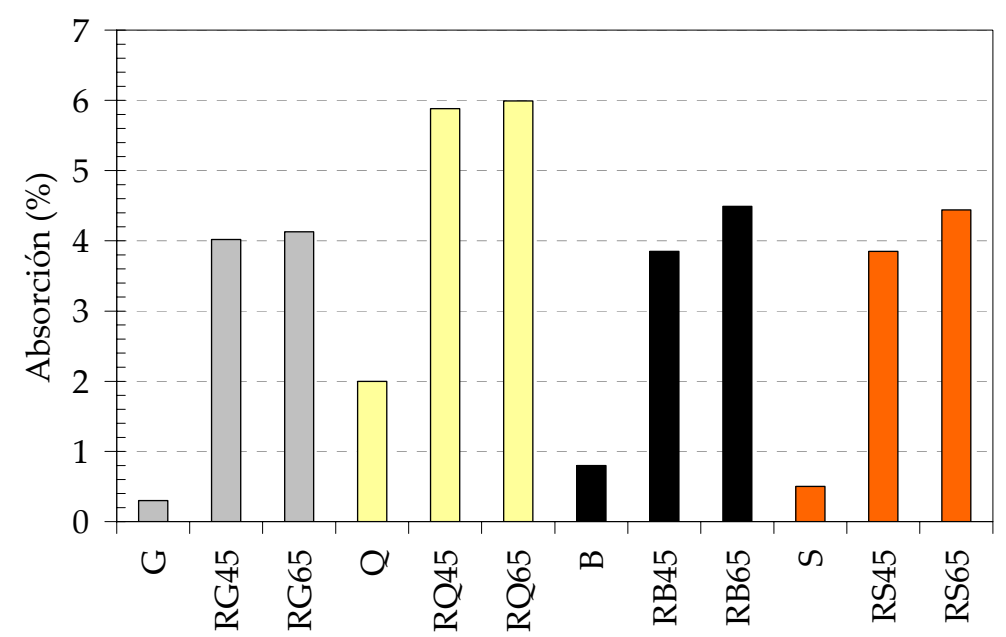

Figura 4.5. Absorción de los agregados gruesos naturales y reciclados.

De los resultados obtenidos en estos estudios surge que, para los AGN de basalto y canto rodado silíceo, la absorción de los AGR provenientes de un hormigón con razón a/c 0,65 es superior a la de los AGR que provienen de un hormigón con razón a/c 0,45, mientras que para los AGN de granito y cuarcita, si bien se mantienen la misma tendencia, las diferencias respecto de la influencia de la razón a/c son despreciables. Otro hecho que se observa es que el agregado reciclado RQ45 posee una absorción 40 \% superior que la correspondiente a otros AGR obtenidos de hormigones elaborados con otros tipos de AGN y con mayor razón a/c.

\subsubsection{Desgaste “Los Ángeles”}

Los valores de desgaste obtenidos para los diferentes AGR en estudio, como así también para los agregados gruesos naturales, se presentan en la Figura 4.6. Puede observarse que los agregados reciclados RG, RB y RS presentan pérdidas de peso superiores a la de los correspondientes agregados naturales, con incrementos promedio para cada uno de ellos del 45, 200 y $82 \%$, respectivamente, aunque los porcentajes de pérdida resultan inferiores al límite del 50 \% establecido en la Norma IRAM 1531, el cual es indicado en dicha figura. Puede apreciarse también que el mayor desgaste en los AGR se produce en los hormigones que contienen una matriz más débil $(\mathrm{a} / \mathrm{c} 0,65)$, hecho esperable y coincidente con lo indicado en la bibliografía [Hansen y Narud, 1983; Tavakoli y Soroushian, 1996]. 


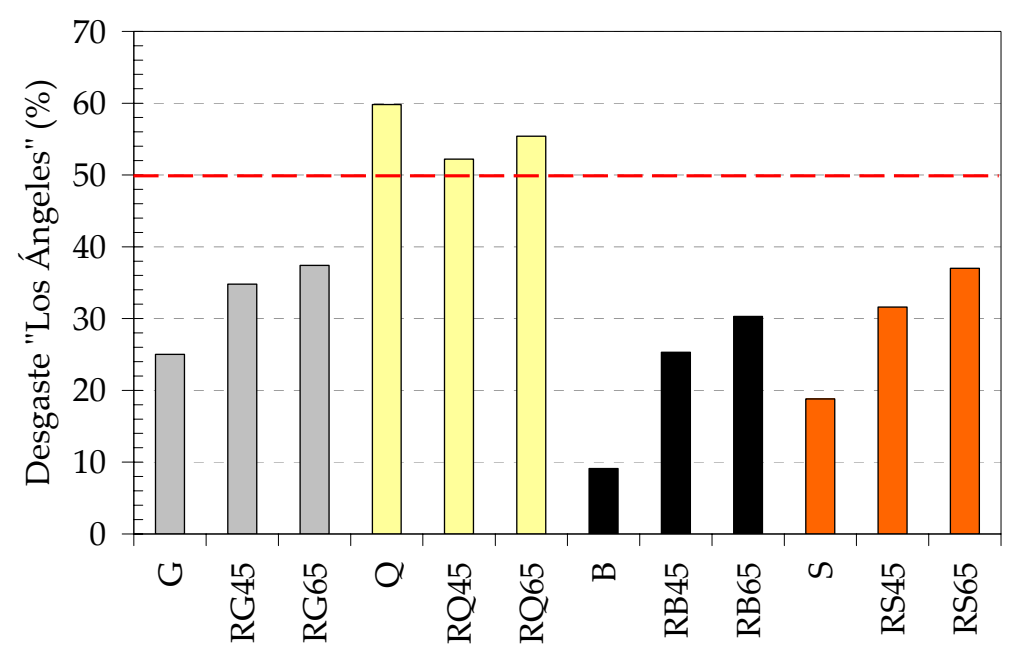

Figura 4.6. Desgaste “Los Ángeles” de los agregados gruesos naturales y reciclados.

En el caso del agregado cuarcítico se da un hecho particular, ya que los agregados reciclados presentaron un desgaste inferior al del AGN ( 10\%). Si bien dicho porcentaje puede parecer poco significativo, se debe resaltar que lo esperable es que los agregados reciclados presenten un desgaste superior al del agregado natural que contienen, producto de la presencia de mortero de cemento el cual resulta, en general, más débil que la roca natural [Hansen, 1986; Zega et al, 2005; Zega y Di Maio, 2007]. En este caso se pone en evidencia la baja resistencia y tenacidad que presenta el agregado natural, ya que aún el AGR proveniente del hormigón con razón a/c 0,65 presentó un desgaste inferior al AGN.

Otro hecho distintivo que puede apreciarse de los resultados obtenidos en el ensayo de desgaste "Los Ángeles", es que los agregados reciclados RG, RB y RS presentan pérdidas inferiores a la del agregado natural $Q$, aún para los provenientes de hormigones con la mayor razón a/c evaluada. Por otro lado, al igual que sucede con la absorción, el agregado RQ45 presenta un desgaste superior al de agregados reciclados provenientes de hormigones que contienen otro tipo de agregado natural y elaborados con mayor razón a/c. Este hecho estaría indicando que en algunos AGR existe una mayor influencia relativa del agregado original que de la razón a/c.

En la Figura 4.7 se presentan las diferencias de desgaste "Los Ángeles" entre los AGR y los AGN en función del valor de desgaste del correspondiente agregado natural. Puede observarse una relación inversa entre ambos valores, donde se evidencia una menor diferencia de desgaste AGR-AGN al incrementarse el desgaste del agregado natural, llegando a igualarse potencialmente para un determinado valor de desgaste. En el caso de los hormigones estudiados que dieron origen a los AGR, dicho valor para el cual ambos tipos de agregados presentarían un mismo desgaste sería del orden del $45 \%$ para los AGR 
provenientes de los hormigones con razón a/c 0,45, y del 50 \% para los que surgieron de los hormigones con razón a/c 0,65.

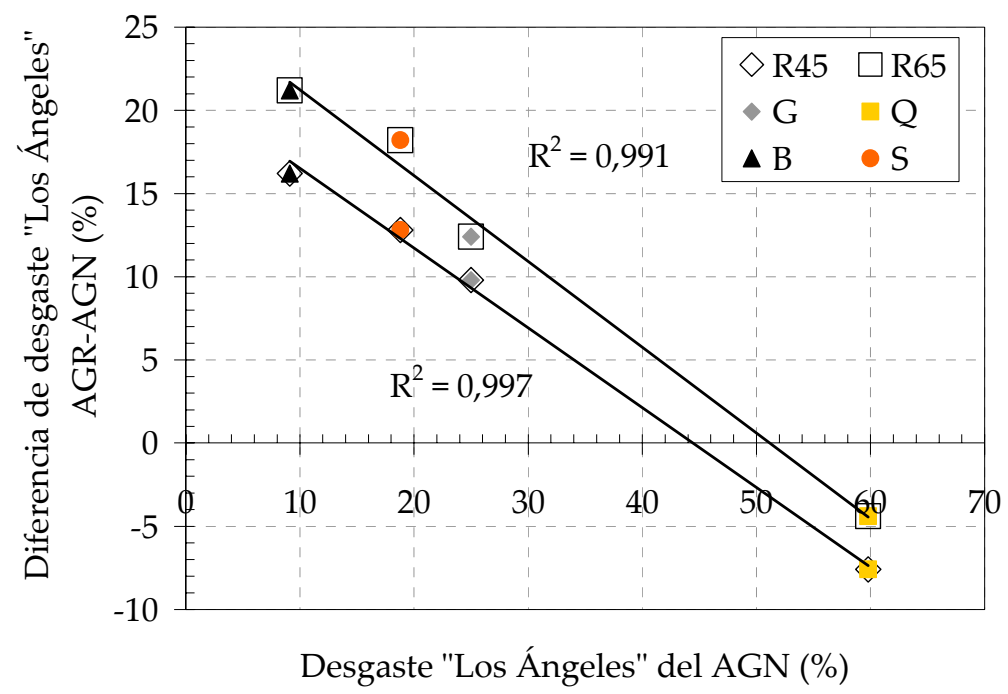

Figura 4.7. Desgaste de los AGR relativos a los del AGN.

\subsubsection{Pasa tamiz de $75 \mu \mathrm{m}$}

En la Figura 4.8 se comparan los porcentajes de material pasante por el tamiz de abertura de malla $75 \mu \mathrm{m}$ determinados para los diferentes AGR en estudio, con los correspondientes a los AGN. Se puede observar que todos los agregados cumplen con el límite máximo estipulado en la Norma IRAM 1531 (1,5\%).

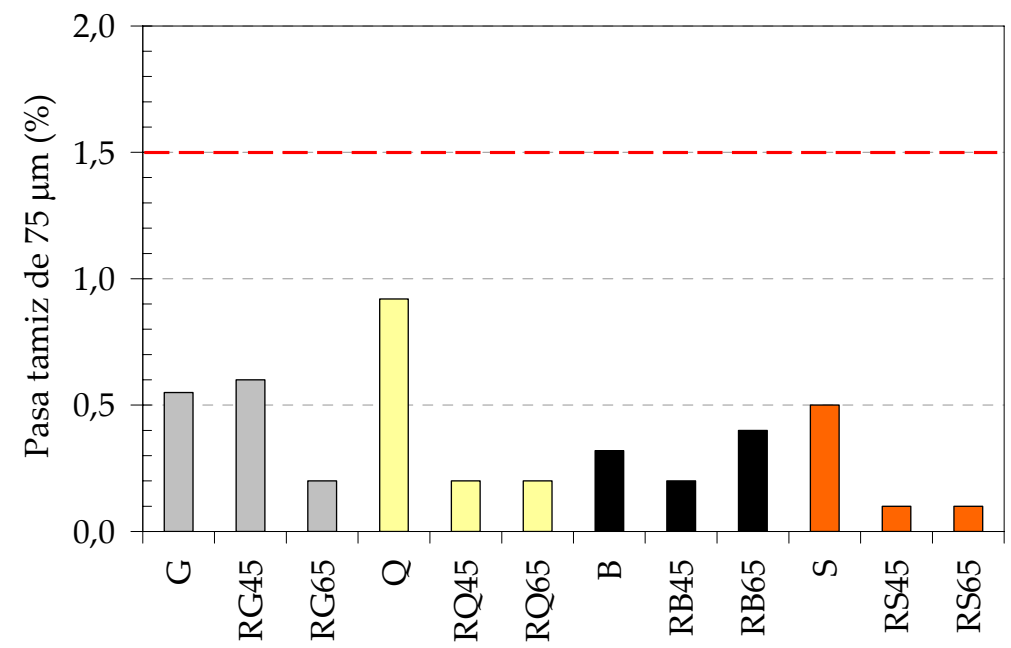

Figura 4.8. Pasa tamiz de $75 \mu \mathrm{m}$ de los agregados gruesos naturales y reciclados.

Si bien en el presente estudio no se evalúan los agregados finos reciclados, es decir, la fracción de agregado que pasa el tamiz de abertura de malla 4,75 mm, y en la cual la 
cantidad de polvo puede resultar elevada, la determinación del contenido de material que pasa el tamiz de $75 \mu \mathrm{m}$ en los AGR también sería un requisito a evaluar en este tipo de agregados.

\subsubsection{Peso por unidad de volumen y porcentaje de vacíos}

Los pesos por unidad de volumen de los ocho AGR en estudio, determinados en condición de suelto (PUVs), junto con los correspondientes a los agregados naturales, se presentan en la Figura 4.9. Puede observarse que los pesos por unidad de volumen de los AGR son inferiores a los de los respectivos agregados naturales, con disminuciones promedio del $16 \%$ para los AGN de trituración y del $24 \%$ para los de canto rodado. Este hecho está asociado a la menor densidad que poseen los AGR, debido al mortero de cemento que presentan en su constitución como fue mencionado en capítulos anteriores.

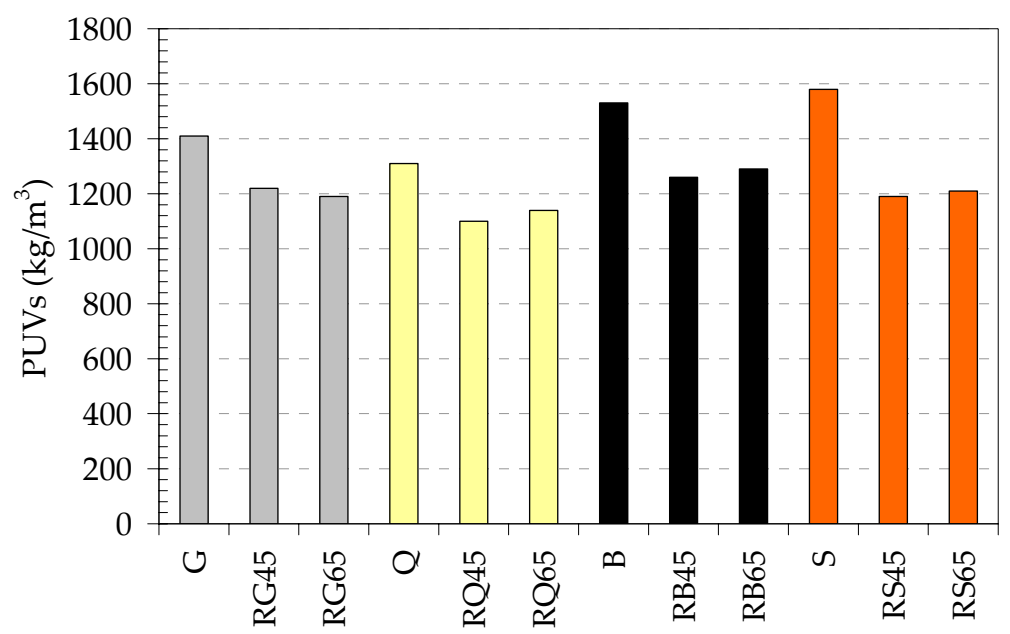

Figura 4.9. PUVs de los agregados gruesos naturales y reciclados.

Otra particularidad que se observa en la Figura 4.9 es que los PUVs resultan similares entre AGR que provienen de hormigones elaborados con un mismo tipo de agregado natural pero con distinta razón a/c, con una variación menor al 2 \%, lo cual se corresponde con el mismo comportamiento observado en el caso de la densidad.

Con relación a los porcentajes de vacío, en la Figura 4.10 se presentan los valores obtenidos para los agregados gruesos reciclados y naturales. Cabe mencionar que para la determinación de dicho parámetro se consideró la densidad del agregado en estado seco $\left(D_{s}\right)$ y el PUVs del mismo. 


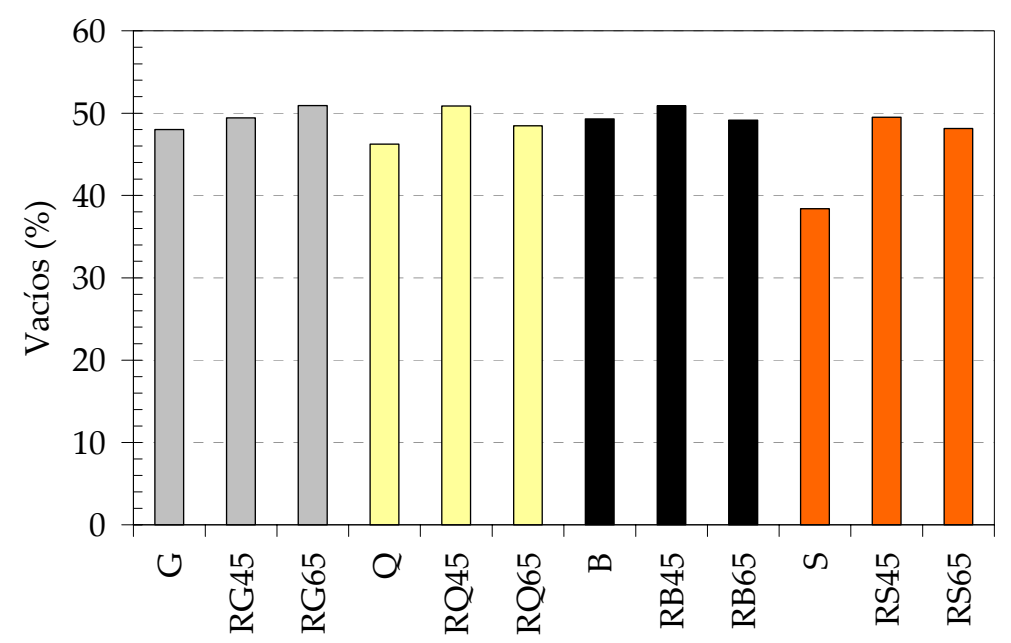

Figura 4.10. Porcentaje de vacíos de los agregados gruesos naturales y reciclados.

Puede observarse que todos los AGR presentaron similares porcentajes de vacíos, independientemente de la razón a/c y del tipo de agregado natural del hormigón original, debido a que las curvas granulométricas de los mismos son similares. Cuando dichos valores son comparados con los de los agregados naturales, puede observarse una diferencia entre los AGR que proceden de hormigones elaborados con agregados naturales de trituración de aquellos en los cuales se utilizó canto rodado. Los porcentajes de vacíos de los agregados RG, RQ y RB son, en promedio, un 5, 7 y $2 \%$ superiores al de los correspondientes agregados naturales. En el caso de los agregados RS, el incremento promedio es del $27 \%$ respecto al agregado natural. Este último hecho debe ser atribuido a la forma irregular que presentan las partículas del agregado reciclado como consecuencia del mortero adherido, impidiendo alcanzar el mismo grado de compacidad que en el agregado natural al ser depositadas sin aplicación de compactación alguna.

\subsection{6. Índices de lajosidad y elongación}

Los índices de lajosidad (IL) obtenidos para cada AGR estudiado, con relación a los del correspondiente agregado natural, se presentan en la Figura 4.11. En el caso de los agregados reciclados RG y RQ los índices de lajosidad son, en promedio, un 42 \% menor al de los correspondientes AGN, mientras que en los RB la disminución es del orden del $60 \%$. Como se mencionó en el Capítulo 2, la existencia de planos preferenciales de fractura en algunas rocas naturales hace que el proceso de trituración cause una mayor fractura sobre dichos planos originando mayor cantidad de partículas lajosas en los AGN [Poole y Sims, 2003; Czarnecka y Gillott, 1982]. En los hormigones que se trituran, los planos de debilidad (interfaces) se encuentran distribuidos sin una orientación definida, provocando que las partículas de los AGR presenten similares dimensiones en las tres direcciones. En 
el caso de los AGR obtenidos de los hormigones elaborados con canto rodado, el comportamiento difiere del señalado para los otros AGN. Puede observarse que los agregados RS presentan índices de lajosidad del orden del $9 \%$ superiores al del agregado natural (S), debido a que este último posee partículas con una mayor redondez.

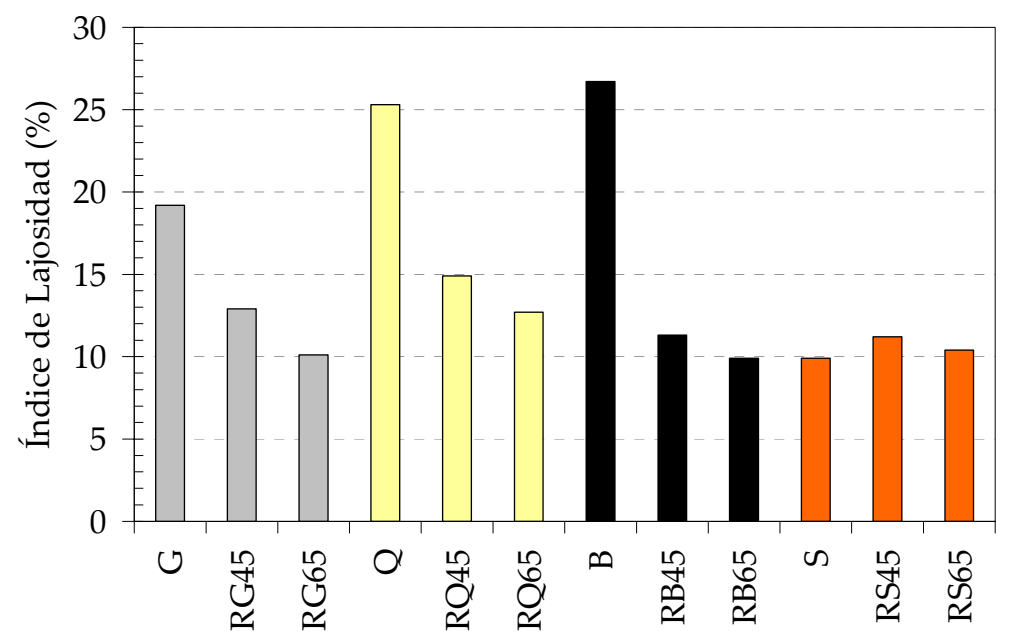

Figura 4.11. Índice de lajosidad de los agregados gruesos naturales y reciclados.

En la Figura 4.11 también puede observarse que los agregados reciclados obtenidos de los hormigones con mayor razón a/c presentan una menor lajosidad, verificándose para los cuatro tipos de AGN utilizados. La menor resistencia de la matriz de los hormigones con razón a/c 0,65 produciría una mayor pérdida de mortero durante la trituración de los mismos, haciendo que las partículas sean menos lajosas que las provenientes de los hormigones con razón a/c 0,45. Este hecho puede ser verificado a partir de los resultados obtenidos en otros ensayos, como se mencionará en el punto 4.3.7.

En la Figura 4.12 se presentan los índices de elongación (IE) correspondientes a los AGR, comparativamente con los obtenidos para los AGN. Puede observarse que no existe una marcada tendencia como la producida para el índice de lajosidad. En el caso del agregado de canto rodado, se observa que el agregado reciclado proveniente del hormigón con menor resistencia (RS65) presenta un menor índice de elongación que el agregado obtenido del hormigón de mejor calidad (RS45), asemejándose su valor al del agregado natural. Para el agregado de cuarcita el comportamiento es similar al mencionado. En el caso del agregado de basalto se produce una disminución de los índices de elongación en ambos agregados reciclados (RB45 y RB65), mientras que para el agregado de granito se observan similares índices en los reciclados y el natural. 


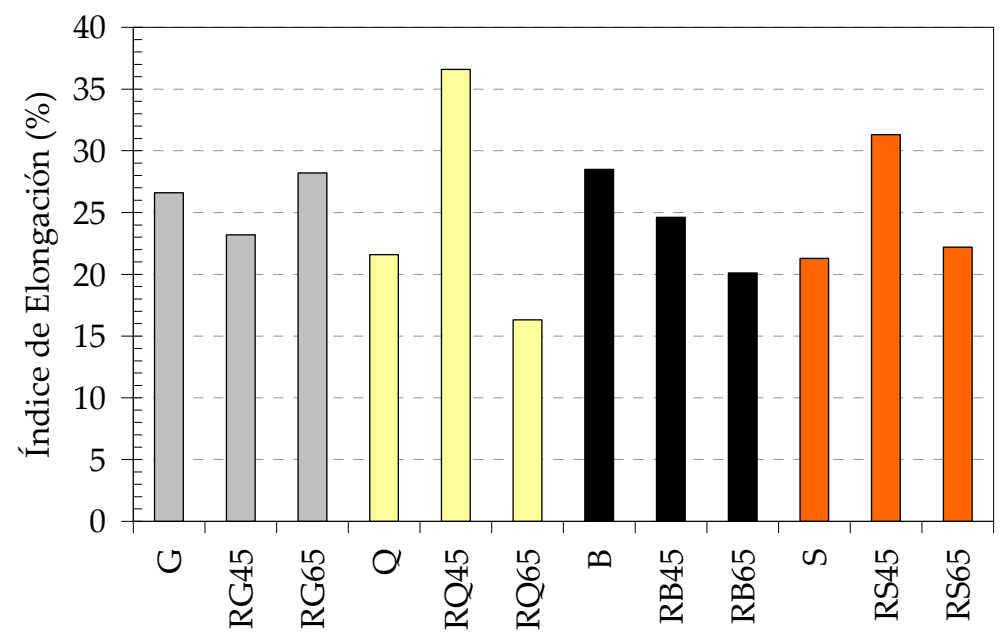

Figura 4.12. Índice de elongación de los agregados gruesos naturales y reciclados.

\subsubsection{Contenido de mortero}

Debido a la composición que poseen las partículas del agregado reciclado, roca y mortero, resulta importante conocer las proporciones relativas en que cada uno de estos elementos se encuentra presente, lo cual podría ayudar a comprender las propiedades que adquieren los AGR y los hormigones con ellos elaborados.

Como se mencionó en el Capítulo 3, muestras representativas de cada uno de los AGR en estudio fueron atacadas con ácido clorhídrico con el fin de disolver el mortero que se encontraba adherido a las partículas de agregado natural. En la Figura 4.13 se presentan los contenidos netos de mortero, en peso, determinados a los AGR en estudio.

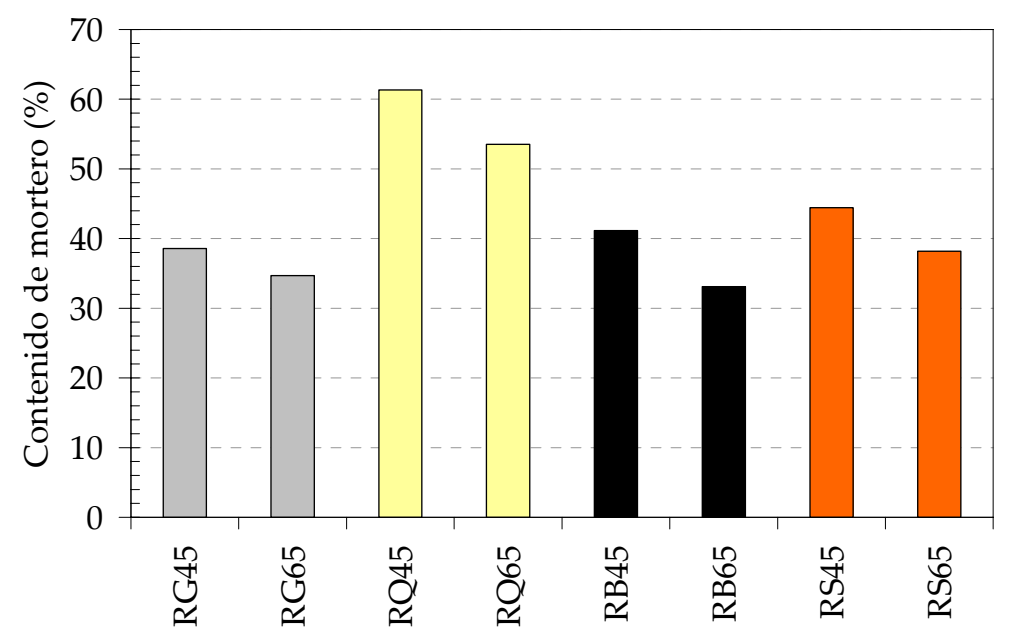

Figura 4.13. Contenido de mortero de los agregados gruesos reciclados. 
Los resultados hallados muestran claramente que el contenido de mortero presente en los AGR disminuye con la calidad del hormigón (aumento de la razón a/c), lo cual se produce para los cuatro tipos diferentes de AGN seleccionados, hecho que debe ser atribuido a la menor resistencia de la matriz que posibilita un mayor desprendimiento de la misma durante la trituración. La disminución del contenido de mortero de los agregados reciclados correspondientes a la razón a/c 0,65 es de aproximadamente 10, 13, 20 y 14 \% para los RG, RQ, RB y RS, respectivamente, con relación a los de razón a/c 0,45.

En la Figura 4.13 se puede observar también que los agregados reciclados de cuarcita presentan, para ambas razones a/c, entre un 40 y 60 \% más de mortero que los restantes agregados reciclados. Este hecho debe ser atribuido, tal como se menciona en el punto 4.2, a la mejor adherencia que posee dicho AGN, mayor resistencia de las interfaces AGN-mortero, conjuntamente con una baja resistencia del agregado natural [Giaccio y Zerbino, 1997], lo cual pudo ser visualizado luego de la trituración de los hormigones.

Sobre las partículas de agregado natural resultantes del ataque con ácido clorhídrico se determinó su distribución granulométrica, lo cual permite en cierta forma confirmar los resultados obtenidos. En las Figuras 4.14-a) - d) se presentan, para cada tipo de AGN empleado, la distribución de tamaño de partículas de los agregados naturales (G, Q, B y S) y las correspondientes a los agregados naturales que resultaron del ataque ácido a los agregados gruesos reciclados. Estos últimos se denominan con la letra del agregado natural indicando además el AGR del cual provienen; de este modo, para el caso del agregado de granito, las denominaciones son “G en RG45” y “G en RG65".

En la Figura 4.14-c) puede observarse que la gradación del agregado “B en RB45" es la que más se aparta de la del agregado natural B. Este hecho estaría indicando que en el caso del agregado RB45 el proceso de fractura durante la trituración también ocurre a través del agregado natural debido a la mayor resistencia de la matriz. En el caso del RB65, debido a la menor resistencia de la matriz, el proceso de fractura ocurre a través de dicha matriz produciendo partículas más gruesas que en el primer caso, aunque más finas que las del agregado B. 

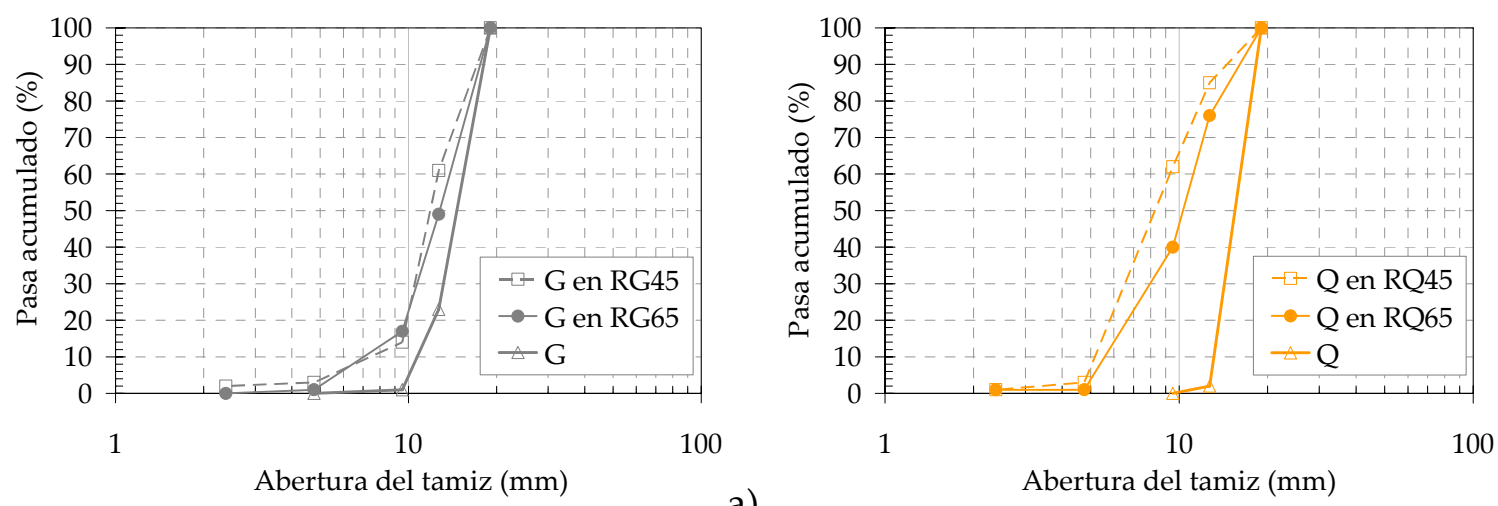

a)
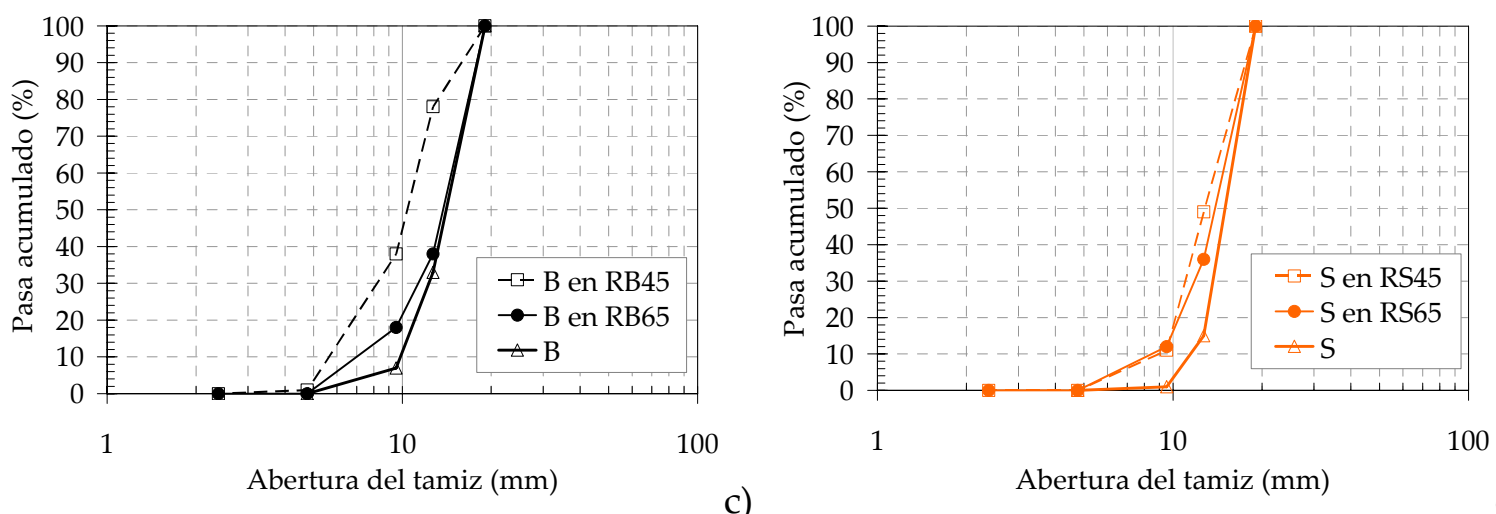

b)

Figura 4.14. Gradación de los agregados naturales luego del ataque ácido realizado sobre los AGR: a) Granito; b) Cuarcita; c) Basalto; d) Rodado silíceo.

En el caso de los agregados reciclados de cuarcita, Figura 4.14-b), se aprecia un mayor apartamiento de las curvas correspondientes a las partículas resultantes del ataque ácido con relación a la del agregado natural Q. Este hecho estaría confirmando lo señalado en el punto 4.2 del presente capítulo (Figura 4.2-a) con relación a la composición de las partículas de los AGR que provienen de los hormigones elaborados con dicho AGN, produciéndose una mayor fractura de los agregados naturales a causa de la baja resistencia de la roca natural.

En las Figuras 4.14-a) y d) puede observarse, en cada caso, que las gradaciones de las partículas naturales correspondientes a los agregados R45 y R65 que resultaron del ataque ácido son semejantes entre sí. Este hecho estaría indicando el bajo grado de trituración que experimentaron en ambos casos las partículas del agregado natural.

El mayor apartamiento señalado para las curvas correspondientes a las partículas luego del ataque ácido en el caso de las Figuras 4.14-b) y c) puede haber sido favorecido por mayores índices de lajosidad de los agregados naturales Q y B. (Ver Tabla 3.8) 


\subsubsection{Relaciones entre diferentes propiedades}

Para poder interpretar mejor la influencia que tiene el tipo de agregado grueso natural del hormigón de origen sobre las propiedades de los agregados gruesos reciclados obtenidos a partir de su trituración, como así también respecto a su nivel resistente, se plantean diferentes relaciones entre algunos de los parámetros determinados anteriormente.

En la Figura 4.15 se vincula la absorción de los agregados, naturales y reciclados, con su densidad en condición de saturado y superficie seca ( $D_{s s s}$ ), para los cuatro tipos de agregados naturales empleados.

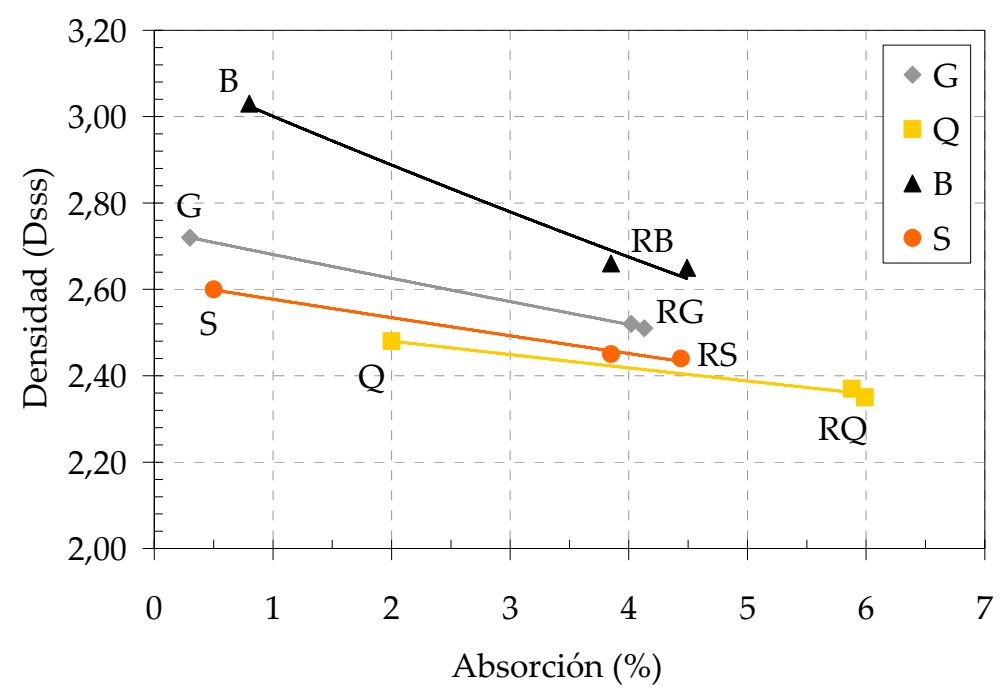

Figura 4.15. Relación absorción-densidad para los AGN y AGR.

Se verifica la correlación inversa existente entre ambos parámetros según se indica en la bibliografía [Hansen, 1986; Zega, 2008; Sánchez de Juan y Alaejos Gutiérrez, 2009], dependiendo las diferencias observadas del tipo de agregado grueso natural que contenga el agregado reciclado. En tal sentido, como se mencionara anteriormente, se observa una mayor disminución de la densidad del AGR cuanto más elevada es la correspondiente al agregado natural. Un hecho importante a resaltar de la Figura 4.15 es que las densidades de los AGR se encuentran en el rango 2,35-2,66, las cuales resultan acotadas teniendo en cuenta que se trata de agregados que provienen de hormigones de distintos niveles resistentes y con diferentes AGN. La absorción de agua por su parte varía de 3,9 a $6 \%$, la cual estaría en función del contenido de mortero de los AGR. 
En la Tabla 4.3 se presentan, nuevamente, los valores de contenido de mortero, absorción y desgaste “Los Ángeles" de los agregados reciclados en estudio. Puede observarse que, para un mismo tipo de AGN, los agregados reciclados obtenidos de un hormigón de mejor calidad (menor razón a/c) poseen menor absorción de agua y pérdida por desgaste que los provenientes de un hormigón de mayor razón a/c, a pesar que su contenido de mortero resulta superior al de estos últimos. Sin embargo, en dicha Tabla se puede observar también la mayor influencia relativa que puede tener el tipo de AGN del hormigón de origen sobre las propiedades de los AGR, evidenciándose en el caso de los agregados reciclados de cuarcita valores superiores a los de los restantes AGR en cada uno de los tres parámetros indicados, independientemente de la razón a/c.

Tabla 4.3. Valores del contenido de mortero, absorción de agua y desgaste "Los Ángeles" de los AGR.

\begin{tabular}{|c|c|c|c|}
\hline Agregados & $\begin{array}{c}\text { Contenido } \\
\text { de mortero } \\
(\%)\end{array}$ & $\begin{array}{c}\text { Absorción } \\
\text { de agua } \\
(\%)\end{array}$ & $\begin{array}{c}\text { Desgaste } \\
\text { "Los Ángeles” } \\
(\%)\end{array}$ \\
\hline RG45 & 38,6 & 4,0 & 34,8 \\
RG65 & 34,7 & 4,1 & 37,4 \\
\hline RQ45 & 61,3 & 5,9 & 52,2 \\
RQ65 & 53,5 & 6,0 & 55,4 \\
\hline RB45 & 41,1 & 3,9 & 25,3 \\
RB65 & 33,1 & 4,5 & 30,3 \\
\hline RS45 & 44,4 & 3,9 & 31,6 \\
RS65 & 38,2 & 4,4 & 37,0 \\
\hline
\end{tabular}

Otro hecho que surge también de los resultados presentados en la Tabla 4.3 tiene que ver con la vinculación que existe entre el contenido de mortero de los AGR y la absorción de agua o el desgaste "Los Ángeles" de los mismos, para una misma calidad del hormigón de origen e independientemente del AGN que contengan. 


\subsection{Conclusiones sobre las propiedades de los agregados gruesos reciclados}

Del análisis de los resultados presentados en este capítulo sobre las propiedades de los agregados gruesos reciclados obtenidos de la trituración de hormigones elaborados con distintos tipos de agregados gruesos naturales y diferentes razones a/c, surge que:

- $\quad$ El tipo de AGN que contiene el hormigón de origen tiene mayor influencia que la razón a/c sobre propiedades como la densidad, la absorción de agua, la resistencia a la abrasión y el contenido de mortero de los AGR que resulten de su trituración.

- Si bien la densidad de los AGR resulta inferior a la de los AGN que contienen, la variación que se produce entre densidades de distintos AGR es semejante a la que se obtiene al comparar distintos tipos de AGN. Hecho similar ocurre con el PUV de dichos agregados.

- La absorción de los AGR resulta entre 3 y 14 veces superior a la de los AGN, viéndose afectada también por la calidad de estos últimos.

- La pérdida por abrasión de los AGR, conteniendo un mismo tipo AGN empleado, resulta mayor en los agregados que provienen de hormigones de menor nivel resistente. En general, la resistencia al desgaste es inferior en los AGR respecto al AGN que contienen, siendo la excepción el agregado de cuarcita para el cual las pérdidas obtenidas en los respectivos AGR resultan $10 \%$ menores.

- Los porcentajes de vacíos de los AGR resultan semejantes entre sí, independientemente del tipo de AGN que contienen. Además, no se observan diferencias importantes con relación al porcentaje de vacíos de los agregados naturales obtenidos por trituración. En el caso del canto rodado natural, debido al origen del mismo, el porcentaje de vacíos es del orden del $27 \%$ inferior al de los correspondientes AGR.

- $\quad$ El índice de lajosidad de los agregados RG y RQ son, en promedio, un $42 \%$ menor al de los correspondientes AGN, mientras que en los RB la disminución es del orden del $60 \%$, debido al mortero adherido. En el caso del agregado RS, los índices de lajosidad son del orden del $9 \%$ superior al del agregado natural. El índice de elongación no muestra una marcada tendencia. 
- $\quad$ El contenido de mortero de los AGR es menor en los provenientes de hormigones con mayor razón a/c, hecho atribuido a la menor resistencia de la matriz que origina un mayor desprendimiento del mortero durante la trituración. Los AGR de cuarcita presentan un contenido de mortero de entre 40 y $60 \%$ superiores al de los demás AGR, debido a la mayor adherencia y baja resistencia que posee el agregado natural de cuarcita. 


\section{Capítulo 5 \\ Comportamiento Mecánico de Hormigones Reciclados}

\subsection{Introducción}

Como fuera mencionado en capítulos anteriores, la elevada absorción de agua que presentan los AGR puede conducir, si la misma no es considerada, a una pérdida de trabajabilidad de las mezclas recicladas. En los estudios que se presentan, donde los AGR fueron empleados en la condición de secos al aire, se decidió mantener para la elaboración de los hormigones reciclados el contenido de agua de mezclado de los hormigones originales, y utilizar un aditivo plastificante para lograr asentamientos semejantes a los obtenidos en estos últimos. Los AGR fueron empleados en dicha condición a fin de dar una mayor preponderancia al efecto que puede provocar su presencia sobre el desempeño de los hormigones, ya que la saturación de los mismos previo a su empleo podría ocasionar un aporte de agua extra.

Se empleó Cemento Portland Compuesto, como agregado fino se utilizó arena silícea natural de río, y como agregado grueso cuatro tipos de AGN (piedras partidas de granito, cuarcita y basalto, y canto rodado silíceo), los cuales fueron caracterizados en el Capítulo 3. En los hormigones reciclados se emplearon además AGR en reemplazo de los AGN en un 25 y $75 \%$ en volumen. Como fue indicado en capítulos anteriores, dichos AGR fueron obtenidos a partir de la trituración de hormigones de dos niveles resistentes conteniendo los cuatro tipos de AGN mencionados. Las características y propiedades de los AGR fueron presentadas y analizadas en el Capítulo 4.

\subsection{Mezclas}

En la elaboración de las mezclas, se planteó como objetivo lograr hormigones de igual trabajabilidad sin modificar las características de la matriz, empleando en los reciclados un aditivo plastificante. De este modo se evita que se produzcan modificaciones en las resistencias y principalmente en la durabilidad de los hormigones a causa de diferentes porosidades de la matriz. 
Los hormigones fueron elaborados mediante una mezcladora basculante de eje horizontal con una capacidad de 160 litros. El procedimiento de mezclado consistió en premezclar los materiales con un $70 \%$ del agua total, incorporando el $30 \%$ restante junto con el aditivo plastificante. Este criterio de mezclado se debió a que anteriormente se habían producido mezclas mediante dicho procedimiento, utilizando los AGR en estado secos al aire, habiéndose alcanzado resultados satisfactorios en cuanto a la trabajabilidad de los hormigones estudiados. De esta forma se evita que la elevada absorción de los AGR disminuya el efecto del aditivo, ya que de incorporarse inicialmente con toda el agua de mezclado parte del mismo es absorbido por el AGR. Asimismo, la dosis de aditivo fue incrementada a medida que se aumentó el porcentaje de AGR utilizado.

Las proporciones de las mezclas elaboradas con los diferentes AGN y AGR, correspondientes a las dos razones a/c evaluadas $(0,45$ y 0,65$)$, se presentan en las Tablas 5.1 y 5.2, respectivamente. Puede observarse que los hormigones con cuarcita poseen un contenido de agua más elevado con relación a los demás hormigones originales, debido a la mayor absorción que posee el agregado natural $Q$, la cual fue considerada de manera de obtener asentamientos semejantes a los de los hormigones con otros tipos de AGN. Dadas las características de forma y textura superficial que posee el agregado de canto rodado silíceo, los hormigones con ellos producidos resultaron con un menor contenido de agua para lograr igual consistencia.

Tabla 5.1. Proporciones de las mezclas de razón a/c 0,45.

\begin{tabular}{|c|c|c|c|c|c|c|c|}
\hline \multirow{2}{*}{ Hormigones } & \multicolumn{6}{|c|}{ Materiales $\left(\mathrm{kg} / \mathrm{m}^{3}\right)$} & \multirow{2}{*}{$\begin{array}{l}\text { Razón a/c } \\
\text { potencial }\end{array}$} \\
\hline & Agua & Cemento & Ag. fino & AGN & AGR & Aditivo & \\
\hline HG45 & 165 & 370 & 855 & 1010 & - & - & 0,45 \\
\hline HRG45-25 & 165 & 370 & 855 & 755 & 235 & 1,1 & 0,42 \\
\hline HRG45-75 & 165 & 370 & 855 & 245 & 700 & 1,9 & 0,37 \\
\hline HQ45 & 180 & 400 & 800 & 900 & - & - & 0,45 \\
\hline HRQ45-25 & 180 & 400 & 800 & 675 & 215 & 1,6 & 0,42 \\
\hline HRQ45-75 & 180 & 400 & 800 & 225 & 645 & 2,0 & 0,36 \\
\hline HB45 & 165 & 370 & 855 & 1125 & - & - & 0,45 \\
\hline HRB45-25 & 165 & 370 & 855 & 840 & 245 & 1,1 & 0,42 \\
\hline HRB45-75 & 165 & 370 & 855 & 280 & 740 & 1,9 & 0,37 \\
\hline HS45 & 160 & 360 & 870 & 955 & - & - & 0,45 \\
\hline HRS45-25 & 160 & 360 & 870 & 725 & 225 & 1,0 & 0,43 \\
\hline HRS45-75 & 160 & 360 & 870 & 240 & 680 & 1,8 & 0,40 \\
\hline
\end{tabular}


Tabla 5.2. Proporciones de las mezclas de razón a/c 0,65.

\begin{tabular}{|c|c|c|c|c|c|c|c|}
\hline \multirow{2}{*}{ Hormigones } & \multicolumn{6}{|c|}{ Materiales $\left(\mathrm{kg} / \mathrm{m}^{3}\right)$} & \multirow{2}{*}{$\begin{array}{l}\text { Razón a/c } \\
\text { potencial }\end{array}$} \\
\hline & Agua & Cemento & Ag. fino & AGN & AGR & Aditivo & \\
\hline HG65 & 165 & 255 & 950 & 1010 & - & - & 0,65 \\
\hline HRG65-25 & 165 & 255 & 950 & 755 & 235 & 0,8 & 0,61 \\
\hline HRG65-75 & 165 & 255 & 950 & 245 & 700 & 1,3 & 0,55 \\
\hline HQ65 & 180 & 275 & 880 & 900 & - & - & 0,65 \\
\hline HRQ65-25 & 180 & 275 & 880 & 675 & 215 & 1,1 & 0,61 \\
\hline HRQ65-75 & 180 & 275 & 880 & 225 & 640 & 1,4 & 0,52 \\
\hline HB65 & 165 & 255 & 950 & 1125 & - & - & 0,65 \\
\hline HRB65-25 & 165 & 255 & 950 & 840 & 245 & 0,8 & 0,61 \\
\hline HRB65-75 & 165 & 255 & 950 & 280 & 740 & 1,3 & 0,53 \\
\hline HS65 & 160 & 245 & 960 & 955 & - & - & 0,65 \\
\hline HRS65-25 & 160 & 245 & 960 & 725 & 225 & 0,7 & 0,61 \\
\hline HRS65-75 & 160 & 245 & 960 & 240 & 680 & 1,2 & 0,53 \\
\hline
\end{tabular}

En las mezclas originales el contenido unitario de cemento fue ajustado en función del contenido de agua, de manera de mantener las dos razones a/c adoptadas. Debido a que los AGR se emplearon en estado secos al aire, y a que la cantidad de agua de mezclado se mantuvo invariable, es posible hablar en el caso de los hormigones reciclados de razón a/c potencial o efectiva, la cual surge de considerar la capacidad de absorción de los AGR al momento de la elaboración de los hormigones y el porcentaje de empleo. Las razones a/c potenciales indicadas en las Tablas 5.1 y 5.2 deben ser consideradas como las mínimas posibles, en el caso que los AGR colmen su capacidad de absorción, ya que la cantidad de agua que los AGR son capaces de absorber dentro de la mezcla es difícilmente cuantificable.

\subsection{Estado fresco}

Sobre las mezclas en estado fresco se realizaron determinaciones de asentamiento (As), peso por unidad de volumen ( $\mathrm{PUV}_{\mathrm{fr}}$ ) y contenido de aire naturalmente incorporado, cuyos resultados se presentan en las Tablas 5.3 y 5.4, para las razones a/c 0,45 y 0,65. 
Tabla 5.3. Propiedades en estado fresco de hormigones de razón a/c 0,45.

\begin{tabular}{|l|c|c|c|}
\hline Hormigones & As $(\mathrm{mm})$ & $\mathrm{PUV}_{\text {fr }}\left(\mathrm{kg} / \mathrm{m}^{3}\right)$ & Aire $(\%)$ \\
\hline HG45 & 70 & 2410 & 1,8 \\
\hline HRG45-25 & 60 & 2375 & 3,0 \\
\hline HRG45-75 & 75 & 2325 & 3,2 \\
\hline HQ45 & 55 & 2325 & 1,8 \\
\hline HRQ45-25 & 70 & 2315 & 3,3 \\
\hline HRQ45-75 & 85 & 2310 & 3,2 \\
\hline HB45 & 65 & 2520 & 2,0 \\
\hline HRB45-25 & 90 & 2505 & 2,3 \\
\hline HRB45-75 & 60 & 2435 & 2,5 \\
\hline HS45 & 75 & 2335 & 1,7 \\
\hline HRS45-25 & 65 & 2330 & 3,5 \\
\hline HRS45-75 & 80 & 2265 & 3,5 \\
\hline
\end{tabular}

Tabla 5.4. Propiedades en estado fresco de hormigones de razón a/c 0,65.

\begin{tabular}{|l|c|c|c|}
\hline Hormigones & As $(\mathrm{mm})$ & $\mathrm{PUV}_{\mathrm{fr}}\left(\mathrm{kg} / \mathrm{m}^{3}\right)$ & Aire (\%) \\
\hline HG65 & 60 & 2400 & 2,0 \\
\hline HRG65-25 & 50 & 2330 & 3,7 \\
\hline HRG65-75 & 40 & 2335 & 3,2 \\
\hline HQ65 & 55 & 2280 & 1,8 \\
\hline HRQ65-25 & 50 & 2280 & 4,0 \\
\hline HRQ65-75 & 60 & 2265 & 3,5 \\
\hline HB65 & 55 & 2495 & 2,4 \\
\hline HRB65-25 & 50 & 2440 & 3,3 \\
\hline HRB65-75 & 45 & 2380 & 3,2 \\
\hline HS65 & 50 & 2325 & 2,0 \\
\hline HRS65-25 & 45 & 2305 & 4,0 \\
\hline HRS65-75 & 35 & 2280 & 4,5 \\
\hline
\end{tabular}

En todos los casos se obtuvieron hormigones de consistencia plástica. Los valores de asentamiento se encontraron en el rango $70 \pm 20 \mathrm{~mm}$ para los hormigones de razón

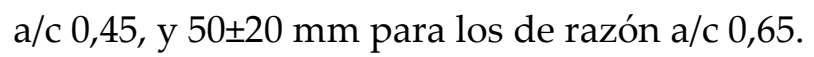


Con relación al peso por unidad de volumen, como era de esperar, los correspondientes a las mezclas recicladas disminuyen al aumentar el porcentaje de AGR utilizado, debido a la menor densidad que poseen los mismos respecto a los AGN que contienen.

En el caso del aire naturalmente incorporado, las mezclas recicladas presentan un porcentaje mayor con relación a los determinados en las mezclas elaboradas con agregados naturales, aunque no se observa ninguna tendencia relacionada con el porcentaje de agregado reciclado utilizado. Dichas diferencias pueden ser atribuidas al empleo del aditivo plastificante en las mezclas recicladas. Los contenidos de aire naturalmente incorporado fueron del orden del $2 \%$ para las mezclas originales, mientras que las mezclas recicladas presentaron porcentajes del orden del 3 al $4 \%$.

Con cada uno de los hormigones elaborados se moldearon probetas de diferentes formas y dimensiones, acorde con los ensayos a realizar, las cuales fueron desmoldadas a las 24 horas y colocadas en condiciones normalizadas de temperatura y humedad (T: 23 \pm 2 ํ C; hr: 95 \%) [IRAM 1534]. Finalizado el período de curado de 28 días, se procedió a la evaluación del comportamiento físico-mecánico y durable de los hormigones en estudio.

A continuación se presentan y analizan los resultados alcanzados de las propiedades mecánicas, junto con los parámetros determinados mediante los ensayos no destructivos, en tanto que los resultados de las propiedades de transporte, relacionados con el desempeño durable de los hormigones, son presentados y analizados en el Capítulo 6.

\subsection{Propiedades mecánicas}

El hormigón, por su naturaleza de material frágil, presenta un buen desempeño mecánico cuando se encuentra sometido a esfuerzos de compresión, siendo ésta la propiedad que habitualmente se evalúa en el estado endurecido debido también a que la misma guarda cierta relación con otras propiedades como su resistencia a la tracción y su durabilidad. Otra propiedad de vital importancia es su capacidad de deformación bajo cargas de corta duración la cual es interpretada a partir de la determinación del módulo de elasticidad estático.

Entre los principales factores que modifican el comportamiento del hormigón en estado endurecido se encuentran la razón a/c, el tipo y contenido unitario de cemento, y el tipo de curado efectuado, viéndose modificado también por la naturaleza del agregado 
grueso que contiene [Mehta y Monteiro, 1998]. Debido a las características distintivas que presentan los AGR, su utilización en hormigones estructurales puede ocasionar diferencias significativas con relación a los producidos con agregados naturales.

En las Tablas 5.5 y 5.6 se presentan los resultados de resistencia a compresión $\left(f^{\prime} c\right)$, módulo de elasticidad estático $(\mathrm{E})$, resistencia a tracción por compresión diametral $\left(\mathrm{f}_{\mathrm{tc}}\right) \mathrm{y}$ módulo de rotura en flexión (MR) obtenidos en los hormigones originales y reciclados, para las razones a/c 0,45 y 0,65 respectivamente. En el caso de la resistencia a compresión, el módulo de elasticidad estático y el módulo de rotura en flexión, los valores informados corresponden al promedio de tres ensayos, mientras que en el ensayo de tracción por compresión diametral se realizaron cinco determinaciones. Se indica en cada caso el desvío estándar (s).

Tabla 5.5. Propiedades mecánicas de hormigones de razón a/c 0,45.

\begin{tabular}{|l|c|c|c|c|c|c|c|c|}
\hline \multirow{2}{*}{ Hormigón } & \multicolumn{2}{|c|}{$\mathrm{f}^{\prime} \mathrm{c}(\mathrm{MPa})$} & \multicolumn{2}{c|}{$\mathrm{E}(\mathrm{GPa})$} & \multicolumn{2}{c|}{$\mathrm{f}_{\mathrm{tc}}(\mathrm{MPa})$} & \multicolumn{2}{c|}{ MR (MPa) } \\
\cline { 2 - 9 } & Promedio & $\mathrm{s}$ & Promedio & $\mathrm{s}$ & Promedio & $\mathrm{s}$ & Promedio & $\mathrm{s}$ \\
\hline HG45 & 37,9 & 0,3 & 32,4 & 0,8 & 4,1 & 0,2 & 5,0 & 0,1 \\
\hline HRG45-25 & 41,8 & 2,4 & 31,5 & 1,0 & 4,4 & 0,1 & 6,8 & 0,2 \\
\hline HRG45-75 & 39,4 & 2,9 & 28,2 & 2,0 & 3,8 & 0,2 & 5,7 & 0,2 \\
\hline HQ45 & 41,7 & 0,6 & 26,4 & 0,1 & 4,1 & 0,2 & 6,0 & 0,2 \\
\hline HRQ45-25 & 53,8 & 3,3 & 28,3 & 1,0 & 5,0 & 0,2 & 7,6 & 0,6 \\
\hline HRQ45-75 & 42,6 & 1,4 & 25,7 & 0,6 & 4,2 & 0,2 & 6,5 & 0,2 \\
\hline HB45 & 38,9 & 1,5 & 36,3 & 0,1 & 4,3 & 0,2 & 6,2 & 0,2 \\
\hline HRB45-25 & 41,1 & 0,8 & 36,3 & 0,1 & 4,6 & 0,1 & 7,2 & 0,2 \\
\hline HRB45-75 & 40,7 & 2,5 & 30,2 & 1,6 & 4,1 & 0,1 & 6,4 & 0,1 \\
\hline HS45 & 35,4 & 0,2 & 40,0 & 0,4 & 3,6 & 0,2 & 5,2 & 0,3 \\
\hline HRS45-25 & 37,3 & 2,1 & 35,0 & 0,8 & 3,8 & 0,2 & 5,4 & 0,1 \\
\hline HRS45-75 & 38,7 & 1,2 & 32,3 & 1,1 & 3,7 & 0,2 & 6,1 & 0,3 \\
\hline
\end{tabular}


Tabla 5.6. Propiedades mecánicas de hormigones de razón a/c 0,65.

\begin{tabular}{|l|c|c|c|c|c|c|c|c|}
\hline \multirow{2}{*}{ Hormigón } & \multicolumn{2}{|c|}{$\mathrm{f}^{\prime} \mathrm{c}(\mathrm{MPa})$} & \multicolumn{2}{c|}{$\mathrm{E}(\mathrm{GPa})$} & \multicolumn{2}{c|}{$\mathrm{f}_{\mathrm{tc}}(\mathrm{MPa})$} & \multicolumn{2}{c|}{ MR (MPa) } \\
\cline { 2 - 9 } & Promedio & $\mathrm{s}$ & Promedio & $\mathrm{s}$ & Promedio & $\mathrm{s}$ & Promedio & $\mathrm{s}$ \\
\hline HG65 & 25,4 & 0,2 & 26,4 & 0,3 & 3,2 & 0,1 & 3,9 & 0,2 \\
\hline HRG65-25 & 29,3 & 0,3 & 27,9 & 0,5 & 3,5 & 0,2 & 5,2 & 0,2 \\
\hline HRG65-75 & 26,0 & 1,3 & 25,4 & 1,9 & 3,0 & 0,1 & 4,2 & 0,4 \\
\hline HQ65 & 25,9 & 1,2 & 22,2 & 0,4 & 3,0 & 0,1 & 4,4 & 0,4 \\
\hline HRQ65-25 & 33,2 & 0,9 & 24,3 & 0,3 & 3,6 & 0,4 & 5,4 & 0,1 \\
\hline HRQ65-75 & 32,2 & 1,3 & 23,3 & 0,6 & 3,4 & 0,2 & 5,1 & 0,2 \\
\hline HB65 & 25,1 & 0,5 & 25,0 & 0,7 & 3,1 & 0,1 & 4,1 & 0,1 \\
\hline HRB65-25 & 28,7 & 0,5 & 30,2 & 0,1 & 3,3 & 0,2 & 5,6 & 0,4 \\
\hline HRB65-75 & 26,1 & 0,7 & 28,6 & 2,1 & 2,9 & 0,1 & 4,4 & 0,3 \\
\hline HS65 & 22,4 & 0,8 & 31,6 & 0,1 & 3,2 & 0,2 & 4,3 & 0,2 \\
\hline HRS65-25 & 24,2 & 0,7 & 29,8 & 0,6 & 3,0 & 0,1 & 4,2 & 0,3 \\
\hline HRS65-75 & 26,5 & 0,7 & 26,9 & 0,7 & 3,2 & 0,2 & 4,9 & 0,2 \\
\hline
\end{tabular}

\subsubsection{Resistencia a compresión}

En las Figuras 5.1 y 5.2 se presentan las resistencias relativas a compresión de los hormigones reciclados, para las razones a/c 0,45 y 0,65, respectivamente. Se puede observar que en los hormigones reciclados se alcanzaron, en la mayoría de los casos, niveles resistentes similares y/o superiores a los determinados en los hormigones originales, independientemente del tipo de AGN y el porcentaje de AGR empleado.

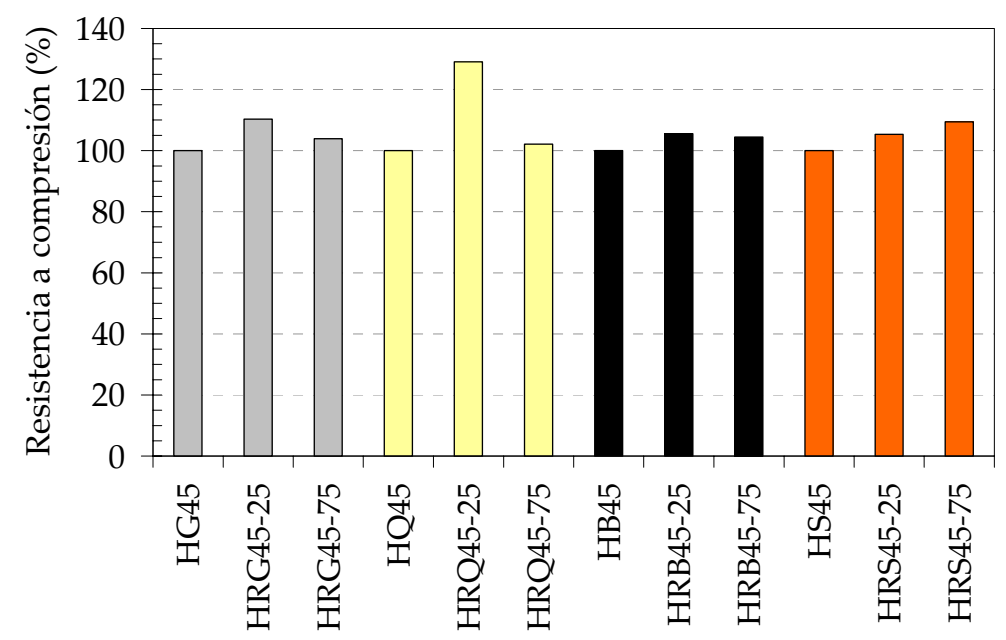

Figura 5.1. Resistencia a compresión relativa de hormigones de razón a/c 0,45. 


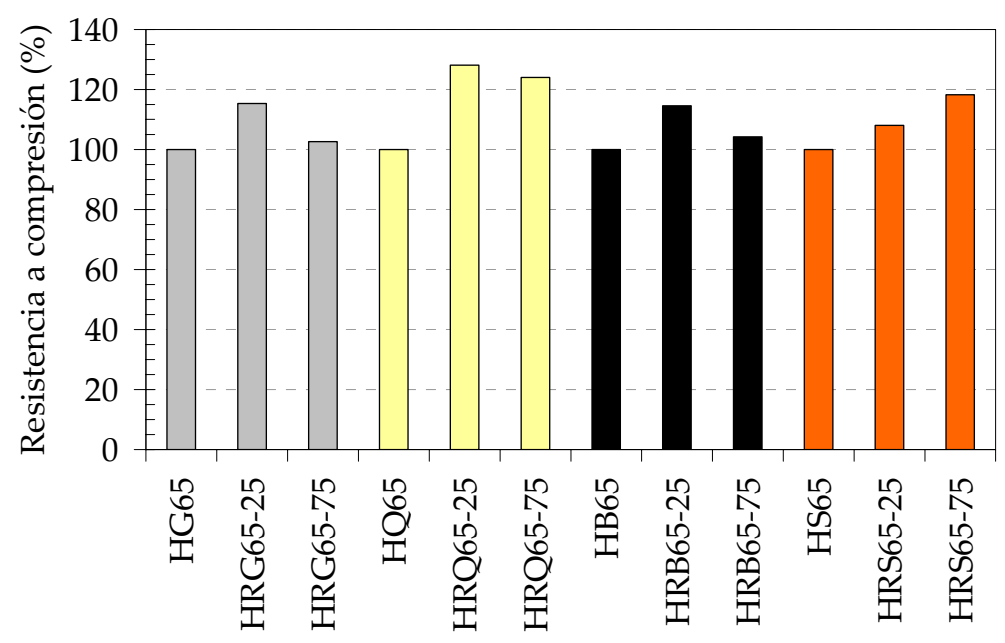

Figura 5.2. Resistencia a compresión relativa de hormigones de razón a/c 0,65.

Para ambos niveles resistentes, se observa un comportamiento diferente de los hormigones reciclados según sea el tipo de AGN que contienen, pudiéndose diferenciar entre los elaborados con los AGN de trituración ( $G, Q$ y B) y los de canto rodado silíceo (S). En el caso de la razón a/c 0,45, la resistencia a compresión de los hormigones elaborados con $25 \%$ de AGR de granito, cuarcita y basalto presentan incrementos del 10, 29 y $6 \%$ respecto a los hormigones originales con igual tipo de AGN. En el caso de los que contienen $75 \%$ de AGR, los incrementos son del 4, 2 y $5 \%$ respectivamente. Los hormigones de razón a/c 0,65 y con $25 \%$ de AGR presenten aumentos de resistencia del 15, 28 y $15 \%$, mientras que en los que contienen $75 \%$ de AGR el incremento es del 3, 24 y $4 \%$, cuando fueron elaborados con los agregados RG, RQ y RB, respectivamente. Dicho comportamiento concuerda con resultados hallados en experiencias previas en las cuales los hormigones con $25 \%$ de AGR presentaron las mayores resistencias [Di Maio et al, 2002].

En el caso de los hormigones elaborados con canto rodado, en las Figuras 5.1 y 5.2 puede observarse que en los hormigones reciclados se produce un incremento de la resistencia a compresión a medida que aumenta el porcentaje de AGR empleado. Los incrementos son del 5 y $9 \%$ para la razón a/c 0,45, y del 8 y 18 \% para a/c 0,65, cuando se empleó 25 y $75 \%$ de AGR, respectivamente.

En los hormigones con granito, cuarcita y basalto, el comportamiento observado puede ser atribuido a la acción conjunta y contrapuesta de, por un lado una menor razón a/c efectiva y mejor calidad de las interfaces agregado reciclado-mortero, y por otro la menor resistencia que presentan los agregados reciclados con relación a los naturales. Para bajos porcentajes de AGR (25\%) la disminución de la razón a/c conduce a un incremento de la resistencia a compresión, mientras que para el reemplazo del $75 \%$ la existencia de 
una mayor cantidad de partículas débiles ocasiona una disminución de la misma. También puede observarse que los hormigones HRQ45-25 y HRQ65-25 son los que presentan el mayor incremento, hecho que, como fue indicado en el punto 4.2, debe ser atribuido a la mayor adherencia que posee el agregado de cuarcita.

Para los hormigones HRS, al efecto contrapuesto indicado para los hormigones con G, Q y B, se suma y adquiere relevancia el cambio en la forma de la partícula de agregado, que para el natural es redondeada y lisa mientras que para el reciclado es irregular y rugosa, hecho que mejora la adherencia agregado-mortero, provocando un incremento de la resistencia aún cuando se emplea una mayor cantidad de agregado reciclado.

En la Figura 5.3 se presentan imágenes de las interfaces AGN-mortero para los cuatro agregados naturales empleados, granito $(\mathrm{G})$, cuarcita $(\mathrm{Q})$, basalto $(B)$ y canto rodado silíceo (S). En la observación al microscopio pudo observarse que las interfaces generadas entre los agregados naturales de trituración $(\mathrm{G}, \mathrm{Q}$ y B) y el mortero son de mejor calidad que la producida entre el canto rodado y el mortero. Este hecho se encuentra relacionado con la forma irregular y la textura superficial rugosa de sus partículas, produciéndose en el caso del agregado de cuarcita una interfaz más compacta, donde el mortero y el agregado presentan mayor continuidad.
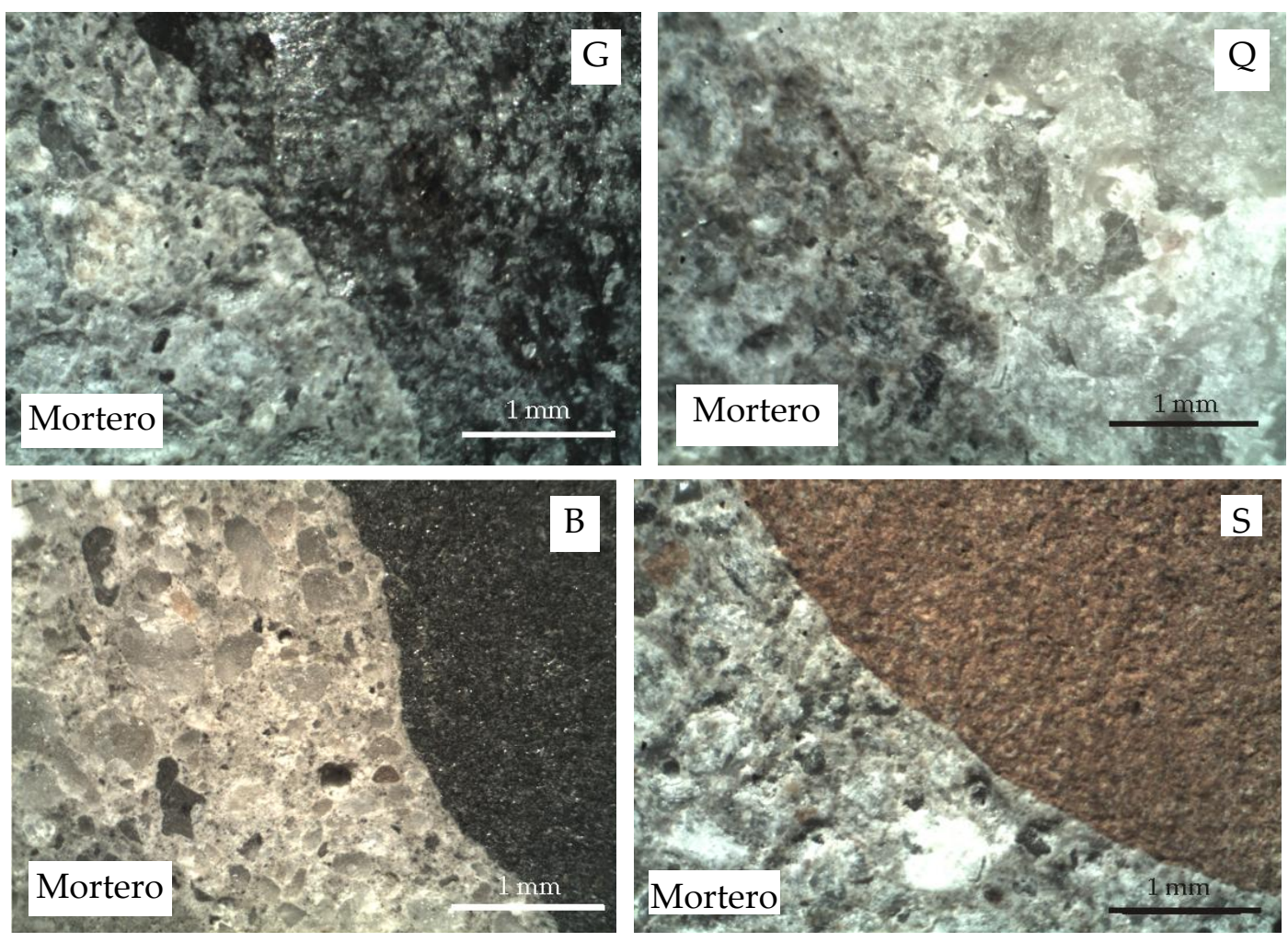

Figura 5.3. Interfaces AGN-mortero. 
En el caso de los agregados reciclados, en la observación al microscopio fue posible diferenciar claramente el mortero viejo que forma parte de los AGR del mortero de la nueva matriz (Figura 5.4) debido a que cada uno de ellos presentan diferentes tonalidades, permitiendo este hecho distinguir la zona de interfaz. La misma resulta uniforme y sin presencia de defectos al nivel de aumento observado.

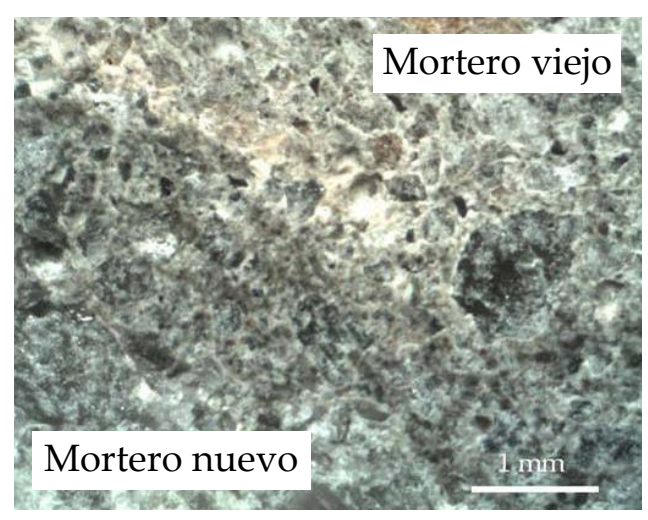

Figura 5.4. Interfaz mortero viejo-mortero nuevo.

\subsubsection{Resistencia a tracción por compresión diametral}

En las Figuras 5.5 y 5.6 se presentan los valores relativos de las resistencias a tracción por compresión diametral de los hormigones reciclados, de razones a/c 0,45 y 0,65, respectivamente. En el caso de la razón a/c 0,45, las resistencias a tracción por compresión diametral de los hormigones reciclados se encuentran en el rango $\pm 10 \%$ de la correspondiente al hormigón de origen, a excepción del hormigón HRQ45-25 que presenta un incremento del $20 \%$. Para la razón a/c 0,65, los hormigones reciclados presentan un comportamiento similar al de la razón a/c 0,45, observándose también como excepción que los hormigones HRQ65-25 y HRQ65-75 presentan incrementos del 19 y 15 \% respectivamente. Este comportamiento debe ser atribuido, al igual que en el caso de la resistencia a compresión, a la acción conjunta de una menor razón a/c efectiva, mejor calidad de las interfaces agregado reciclado-mortero, y al bajo porcentaje de AGR utilizado. 


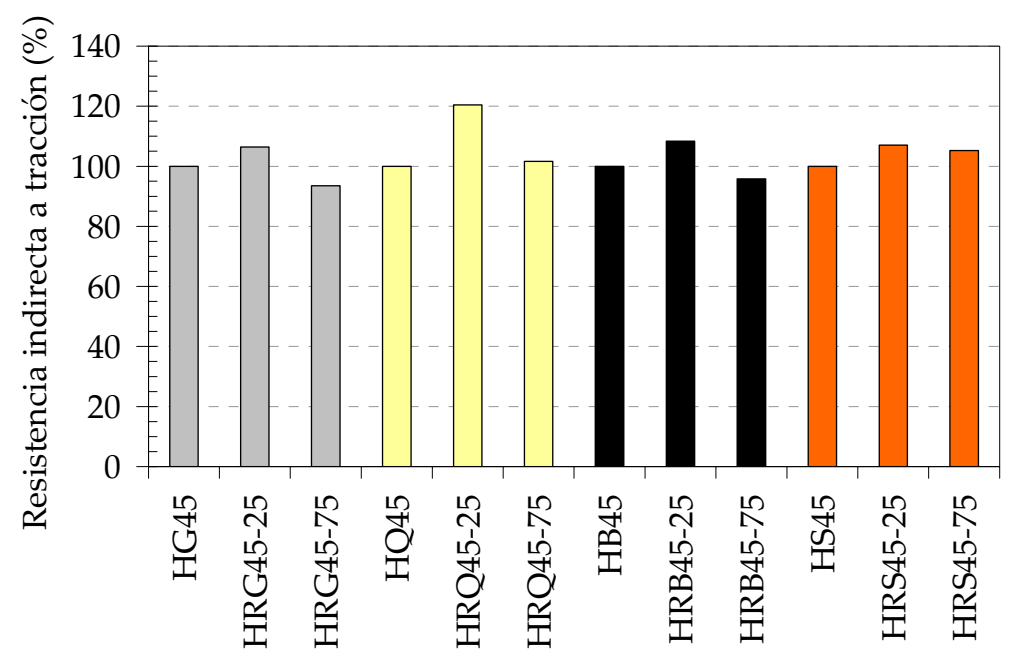

Figura 5.5. Resistencia a tracción por compresión diametral relativa de hormigones de razón a/c 0,45.

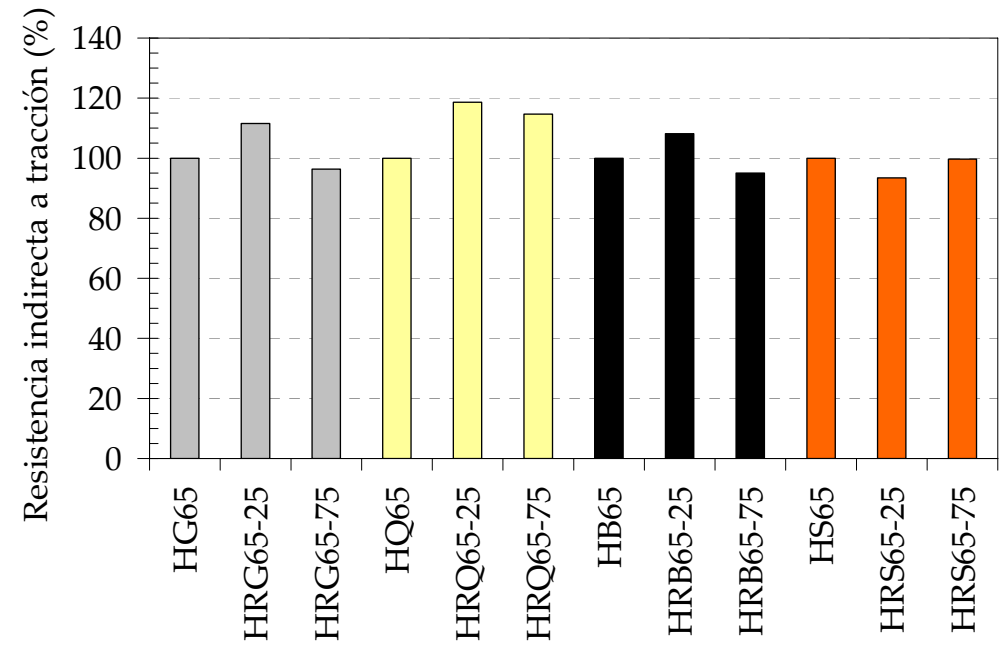

Figura 5.6. Resistencia a tracción por compresión diametral relativa de hormigones de razón a/c 0,65.

\subsubsection{Resistencia a flexión}

Otra medida de la resistencia a tracción del hormigón puede obtenerse a partir de la determinación del módulo de rotura en el ensayo de flexión. En las Figuras 5.7 y 5.8 se presentan los módulos de rotura en flexión obtenidos en los hormigones reciclados, en valores relativos a los determinados en los hormigones originales, para los dos niveles resistentes estudiados. Puede observarse que los hormigones reciclados alcanzaron los niveles resistentes obtenidos en los hormigones originales, superando en muchos casos a los de estos últimos. 


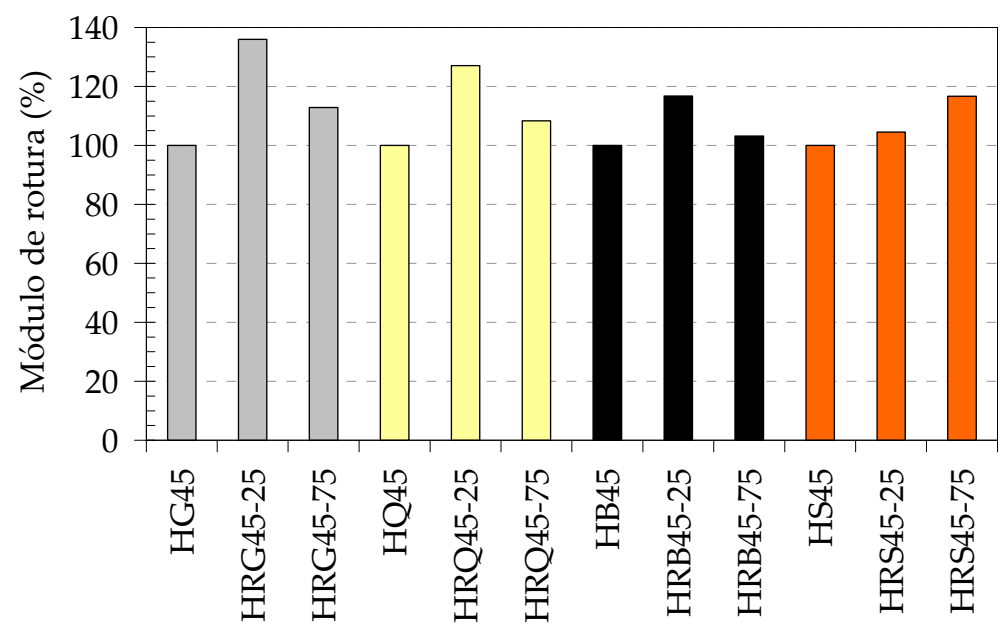

Figura 5.7. Módulo de rotura relativo de hormigones de razón a/c 0,45.

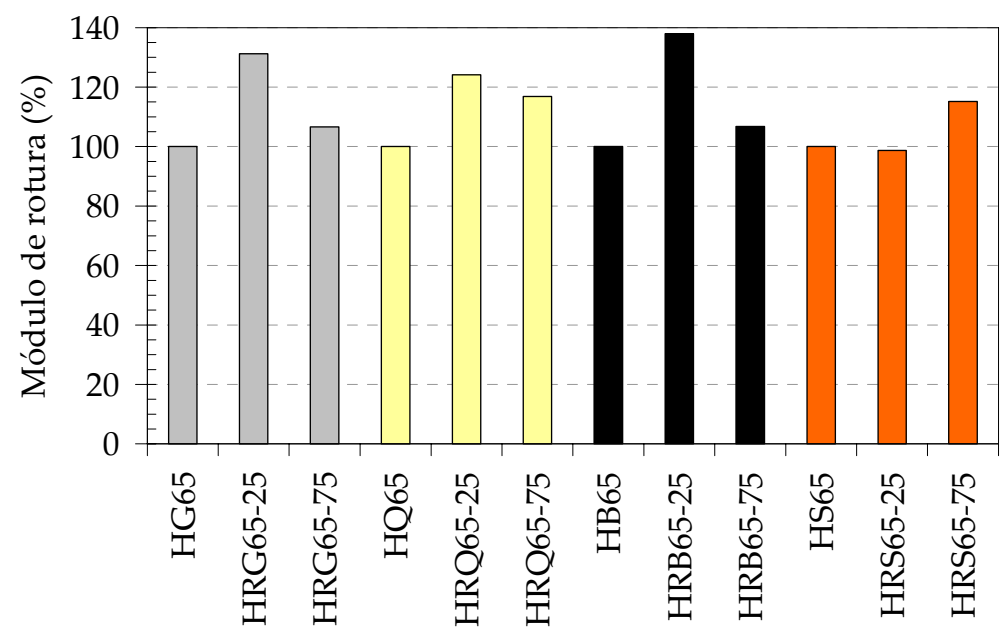

Figura 5.8. Módulo de rotura relativo de hormigones de razón a/c 0,65.

Los hormigones que contienen agregados naturales de trituración $(\mathrm{G}, \mathrm{Q}$ y B) presentan los mayores incrementos cuando se utilizó 25 \% de AGR, siendo los mismos del 36, 27 y 17 \% en el caso de la razón a/c 0,45, y del 31, 24 y 38 \% en la razón a/c 0,65, respectivamente. Este hecho, como fue mencionado en el caso de la resistencia a compresión, puede atribuirse a la acción conjunta de una menor razón a/c efectiva y el bajo porcentaje de reemplazo, ya que el aumento del contenido de AGR implica una mayor cantidad de partículas de menor resistencia que los AGN.

En los hormigones con canto rodado silíceo se obtuvieron, para ambas razones a/c, mayores módulos de rotura a flexión cuanto mayor fue el porcentaje de AGR utilizado, alcanzando un incremento promedio del $16 \%$ cuando se empleó $75 \%$ de AGR. Este último hecho es atribuido al efecto contrapuesto mencionado, sumado a las modificaciones producidas en las partículas de los agregados reciclados respecto al agregado natural. 


\subsubsection{Módulo de elasticidad estático}

El módulo de elasticidad estático se encuentra fuertemente vinculado al tipo de AGN y al nivel resistente del hormigón, por lo que una variación en cualquiera de ellos redundará en una modificación de la rigidez del hormigón [Neville, 1977; Mindess y Young, 1981]. Debido a la composición que poseen los agregados reciclados, en los cuales la roca y el mortero del hormigón original están presentes en proporciones variables, y donde el mortero es el material que posee una menor calidad y mayor deformabilidad, es esperable que el módulo de elasticidad del hormigón reciclado resulte inferior al de un hormigón de igual nivel resistente elaborado en su totalidad con AGN del mismo tipo [Sri Ravindrarajah y Tam, 1985; Hansen, 1986; Zega et al, 2005a); Zega y Di Maio, 2007]. Dicha diferencia será más importante cuanto mayor es el porcentaje de AGR empleado [Di Maio et al, 2002; Zega et al, 2006].

En las Figuras 5.9 y 5.10 se presentan los módulos de elasticidad estático relativos para los hormigones de razón a/c 0,45 y 0,65 respectivamente, según el tipo de AGN que contienen.

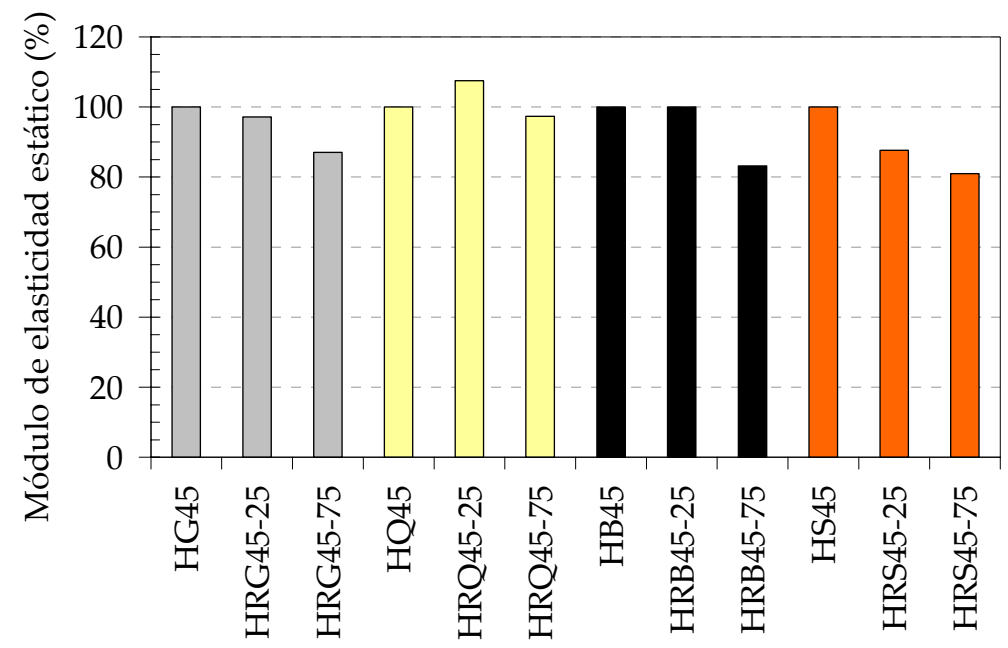

Figura 5.9. Módulo de elasticidad estático relativo de hormigones de razón a/c 0,45.

En el caso de la razón a/c 0,45 se observa que en los hormigones HRG45, HRB45 y HRS45 el módulo estático disminuye a medida que se incrementa el porcentaje de AGR empleado, a pesar que la resistencia a compresión de dichos hormigones resultó superior a la de los respectivos hormigones originales. El máximo descenso producido alcanza el $20 \%$. En los hormigones HRQ45, si bien se observa una leve disminución, del orden del $3 \%$ en el hormigón con $75 \%$ de AGR (la cual es considerablemente menor que la obtenida para los hormigones reciclados elaborados con otro tipo de AGN y el mismo porcentaje 
de reemplazo), en el elaborado con $25 \%$ de AGR se produce un incremento del $7 \%$ respecto al hormigón original. Este hecho debe ser atribuido a la mayor resistencia a compresión del hormigón HRQ45-25 y al bajo porcentaje de reemplazo utilizado.

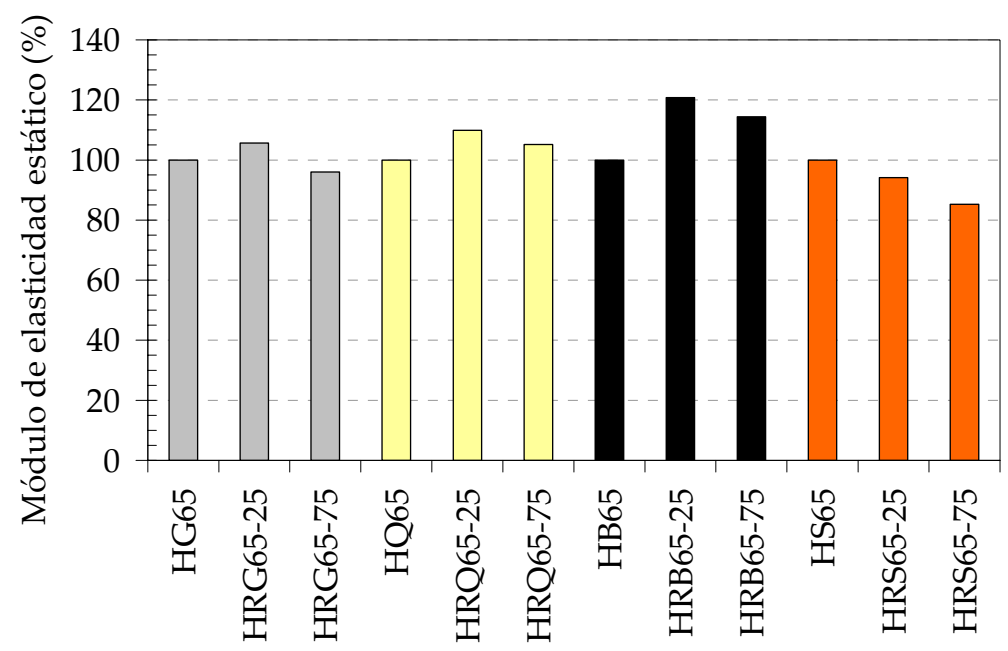

Figura 5.10. Módulo de elasticidad estático relativo de hormigones de razón a/c 0,65.

Para la razón a/c 0,65 puede hacerse una diferenciación en el comportamiento observado entre los hormigones elaborados con canto rodado silíceo y aquellos que contienen AGN de trituración. En el caso de los primeros se observa un comportamiento semejante al mostrado para el mayor nivel resistente (a/c 0,45), donde el módulo de elasticidad disminuye al incrementarse el porcentaje de AGR utilizado, mientras que en los hormigones que contienen AGN de trituración se observan mayores módulos de elasticidad en los hormigones reciclados, aunque el mismo disminuye con el porcentaje de AGR utilizado. El mayor módulo de elasticidad que presentan los hormigones reciclados que contienen $25 \%$ de AGR, puede ser atribuido a la mayor resistencia a compresión obtenida en dichos hormigones y al bajo porcentaje de AGR utilizado.

En las Figuras 5.11 y 5.12 se representan, para cada tipo de AGN utilizado, los módulos de elasticidad estático de los hormigones en función del porcentaje de AGR utilizado, para las razones a/c 0,45 y 0,65, respectivamente. Puede observarse que, si bien el módulo de elasticidad estático de los hormigones reciclados tiende a disminuir con el porcentaje de AGR empleado, los hormigones reciclados que contienen los agregados de basalto (B) y canto rodado silíceo (S) presentan módulos de elasticidad superiores al de los hormigones originales con granito $(\mathrm{G})$ o cuarcita $(\mathrm{Q})$, situación que se encuentra relacionada con las diferentes rigideces de los agregados naturales. Este hecho pone de manifiesto que la modificación que puede presentar el módulo de elasticidad estático debido al empleo de los AGR es semejante a la que puede ocurrir al cambiar el tipo de AGN. 


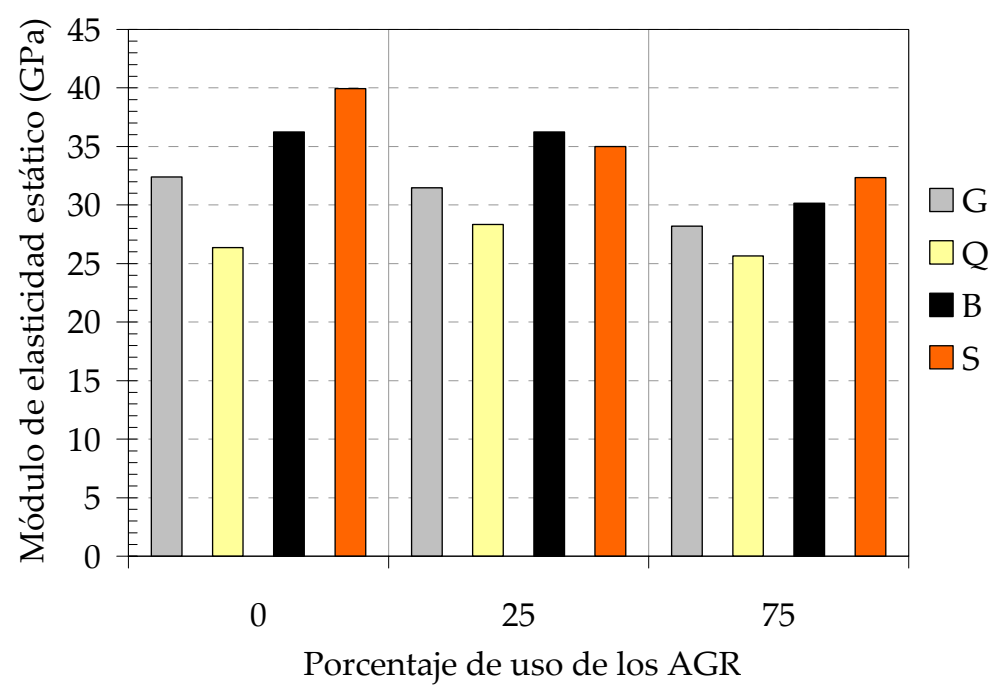

Figura 5.11. Módulo de elasticidad estático de hormigones de razón a/c 0,45.

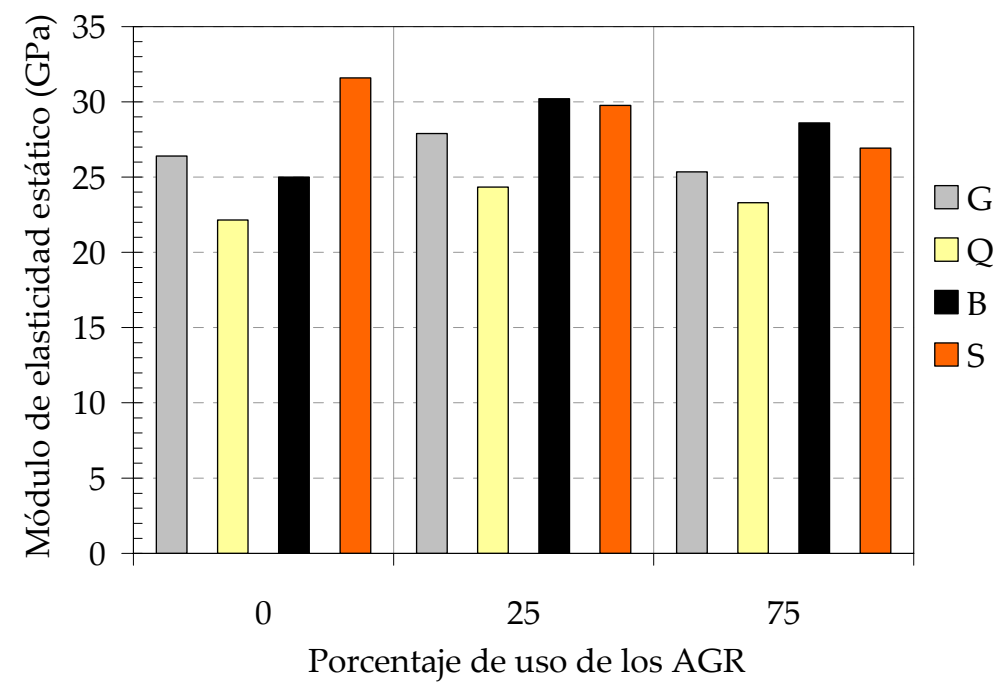

Figura 5.12. Módulos de elasticidad estático de hormigones de razón a/c 0,65.

\subsection{Ensayos no destructivos}

Como se menciona en el Capítulo 3, diferentes Ensayos Semi-destructivos y No Destructivos (END) fueron utilizados en la evaluación de los hormigones en estudio. En las Tablas 5.7 y 5.8 se presentan los resultados obtenidos para los hormigones de razón a/c 0,45 y 0,65, respectivamente, informándose la presión Break-Off (BO), la velocidad del pulso ultrasónico $(\mathrm{V})$ y el módulo de elasticidad dinámico (Ed). 
Tabla 5.7. Parámetros de END de hormigones de razón a/c 0,45.

\begin{tabular}{|l|c|c|c|c|c|c|}
\hline \multirow{2}{*}{ Hormigón } & \multicolumn{2}{|c|}{ BO $(\mathrm{MPa})$} & \multicolumn{2}{c|}{$\mathrm{V}(\mathrm{km} / \mathrm{s})$} & \multicolumn{2}{c|}{ Ed (GPa) } \\
\cline { 2 - 7 } & Promedio & $\mathrm{s}$ & Promedio & $\mathrm{s}$ & Promedio & $\mathrm{s}$ \\
\hline HG45 & 8,0 & 0,2 & 4,62 & 0,01 & 38,0 & 0,5 \\
\hline HRG45-25 & 9,5 & 0,1 & 4,48 & 0,05 & 37,1 & 0,3 \\
\hline HRG45-75 & 9,3 & 0,5 & 4,43 & 0,02 & 35,5 & 0,5 \\
\hline HQ45 & 9,0 & 0,6 & 4,33 & 0,01 & 34,2 & 0,2 \\
\hline HRQ45-25 & 10,2 & 0,5 & 4,38 & 0,01 & 35,9 & 0,2 \\
\hline HRQ45-75 & 9,8 & 0,5 & 4,31 & 0,01 & 33,0 & 0,1 \\
\hline HB45 & 8,9 & 0,1 & 4,63 & 0,01 & 40,1 & 0,7 \\
\hline HRB45-25 & 10,5 & 0,2 & 4,55 & 0,04 & 40,1 & 0,4 \\
\hline HRB45-75 & 10,2 & 0,4 & 4,52 & 0,02 & 37,5 & 0,2 \\
\hline HS45 & 7,5 & 0,2 & 4,61 & 0,02 & 40,8 & 0,3 \\
\hline HRS45-25 & 8,9 & 0,6 & 4,53 & 0,05 & 37,9 & 0,4 \\
\hline HRS45-75 & 8,6 & 0,4 & 4,52 & 0,03 & 37,4 & 0,7 \\
\hline
\end{tabular}

Tabla 5.8. Parámetros de END de hormigones de razón a/c 0,65.

\begin{tabular}{|l|c|c|c|c|c|c|}
\hline \multirow{2}{*}{ Hormigón } & \multicolumn{2}{|c|}{ BO (MPa) } & \multicolumn{2}{c|}{ V (km/s) } & \multicolumn{2}{c|}{ Ed (GPa) } \\
\cline { 2 - 7 } & Promedio & $\mathrm{s}$ & Promedio & $\mathrm{s}$ & Promedio & $\mathrm{s}$ \\
\hline HG65 & 7,6 & 0,3 & 4,43 & 0,01 & 34,7 & 0,4 \\
\hline HRG65-25 & 8,0 & 0,1 & 4,36 & 0,04 & 34,3 & 0,3 \\
\hline HRG65-75 & 7,5 & 0,3 & 4,29 & 0,02 & 31,4 & 0,3 \\
\hline HQ65 & 6,7 & 0,1 & 4,11 & 0,01 & 30,5 & 0,2 \\
\hline HRQ65-25 & 8,5 & 0,7 & 4,25 & 0,05 & 32,1 & 0,3 \\
\hline HRQ65-75 & 8,2 & 0,2 & 4,17 & 0,03 & 29,8 & 0,3 \\
\hline HB65 & 6,6 & 0,4 & 4,46 & 0,01 & 35,0 & 0,2 \\
\hline HRB65-25 & 8,6 & 0,5 & 4,39 & 0,07 & 35,7 & 0,4 \\
\hline HRB65-75 & 8,2 & 0,6 & 4,38 & 0,02 & 33,1 & 0,1 \\
\hline HS65 & 6,6 & 0,7 & 4,50 & 0,03 & 36,4 & 0,2 \\
\hline HRS65-25 & 7,8 & 0,4 & 4,39 & 0,03 & 34,6 & 0,3 \\
\hline HRS65-75 & 7,6 & 0,3 & 4,34 & 0,03 & 34,1 & 0,5 \\
\hline
\end{tabular}

Cada valor informado en las Tablas 5.7 y 5.8 corresponde, en el caso de la presión Break-Off al promedio de cinco determinaciones, mientras que para la velocidad ultrasónica y el módulo dinámico corresponde al promedio de al menos tres probetas, indicándose además en cada uno de ellos el desvío estándar (s). De los resultados presentados 
puede observarse que los desvíos estándar obtenidos en los hormigones reciclados resultan semejantes a los de los hormigones originales, para los tres parámetros evaluados y las dos razones a/c estudiadas.

\subsubsection{Presión Break-Off}

En las Figuras 5.13 y 5.14 se presentan las presiones Break-Off relativas de los hormigones conteniendo los distintos tipos de AGR, para las razones a/c 0,45 y 065, respectivamente. En ambos casos, se observa que los hormigones reciclados presentan mayores presiones Break-Off que los correspondientes hormigones originales, siendo en los elaborados con $25 \%$ de AGR del orden del 13 al $18 \%$ para la razón a/c 0,45 y del 6 al $30 \%$ para la razón a/c 0,65.

El incremento indicado puede ser atribuido a la mejora producida en las interfaces agregado reciclado-mortero como consecuencia de la mayor rugosidad superficial de los AGR, sumado a la reducción de la razón a/c efectiva al emplear los AGR en estado secos al aire. El menor incremento que presentan los hormigones con $75 \%$ de AGR puede ser atribuido a la menor resistencia de las partículas recicladas, que facilitan la propagación de las fisuras a través de ellas.

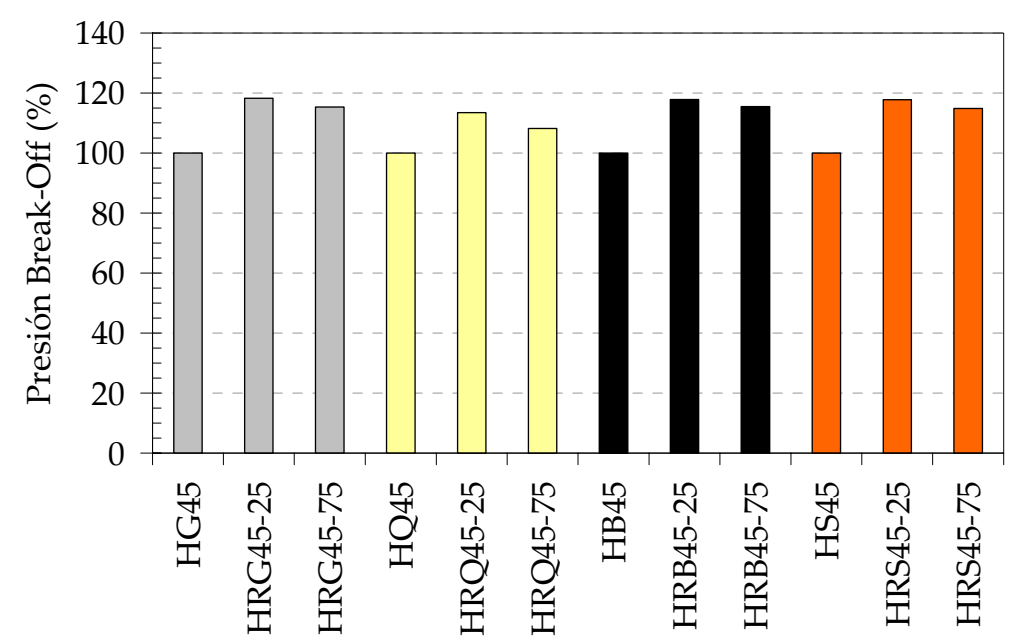

Figura 5.13. Presión Break-Off relativa de hormigones de razón a/c 0,45. 


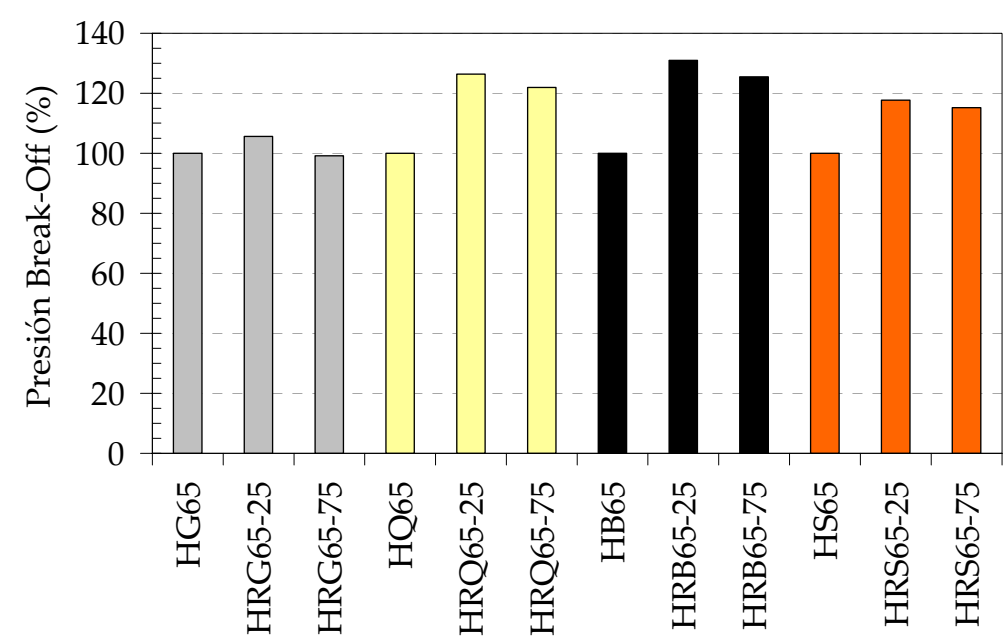

Figura 5.14. Presión Break-Off relativa de hormigones de razón a/c 0,65.

\subsubsection{Velocidad del pulso ultrasónico}

En las Figuras 5.15 y 5.16 se presentan los valores relativos de las velocidades del pulso ultrasónico de los hormigones reciclados, para las razones a/c 0,45 y 0,65, respectivamente. En ambas figuras puede observarse que en los hormigones con granito, basalto y canto rodado silíceo la velocidad del pulso ultrasónico disminuye al aumentar el porcentaje de AGR utilizado, hecho que se corresponde con la menor densidad de estos últimos respecto a los AGN. La disminución de la velocidad ultrasónica es, aproximadamente, del orden del $2 \%$ para los hormigones con $25 \%$ de AGR y del 2,8\% para aquellos con $75 \%$ de AGR. En los hormigones HRQ, se observa un mayor incremento de la velocidad ultrasónica en los elaborados con $25 \%$ de AGR (del orden del 1 al 3\%), siendo más notorio a medida que aumenta la razón a/c.

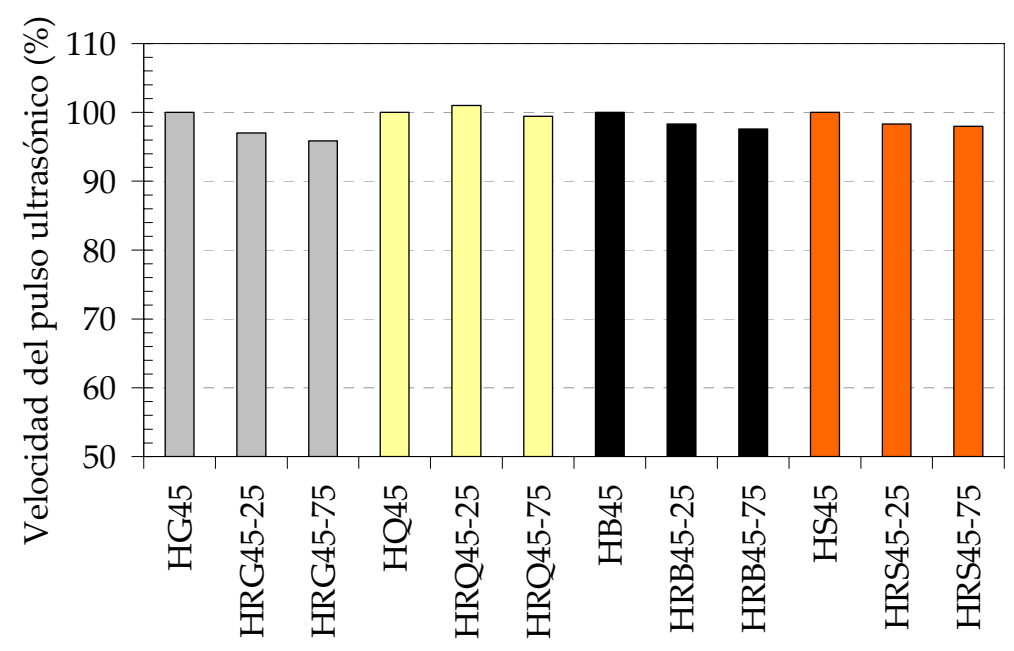

Figura 5.15. Velocidad del pulso ultrasónico relativa de hormigones de razón a/c 0,45. 


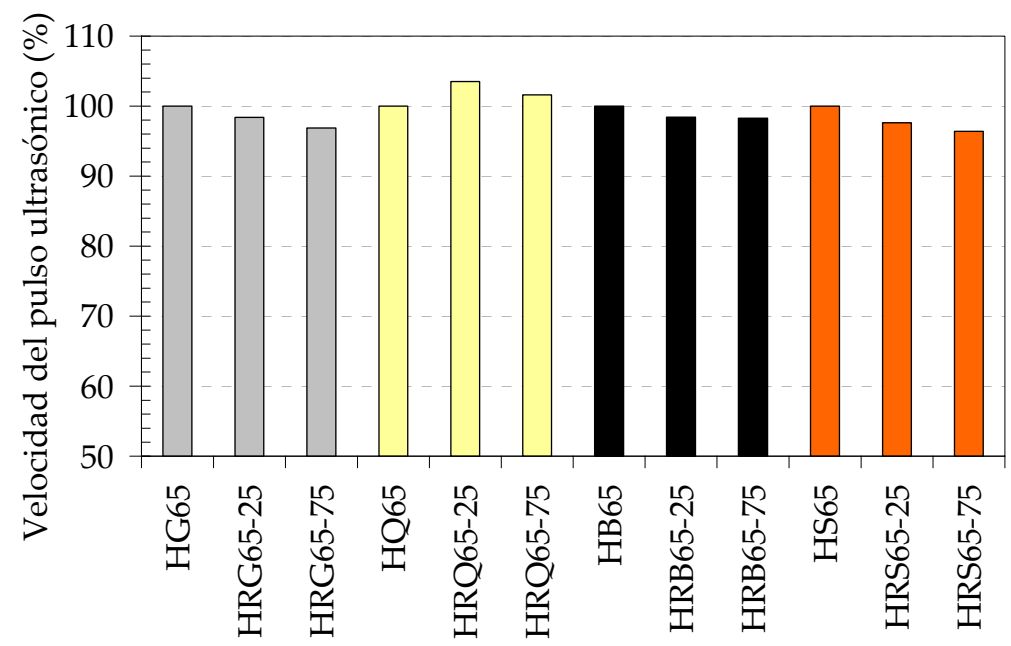

Figura 5.16. Velocidad del pulso ultrasónico relativa de hormigones de razón a/c 0,65.

En la Figura 5.17 se relacionan las velocidades del pulso ultrasónico con las densidades en estado seco $\left(D_{s}\right)$, diferenciando el tipo de AGN que contiene y el porcentaje de AGR empleado. En general, se verifica para todos los hormigones un descenso de la velocidad con la densidad de los mismos. Puede observarse también que en los hormigones con $75 \%$ de AGR, a pesar de poseer una menor densidad, presentan una mayor velocidad ultrasónica que los elaborados con $25 \%$, y en el caso de los producidos con cuarcita hasta es superior a la del hormigón original. Este hecho debe ser atribuido a un mayor contenido de humedad como consecuencia del mayor porcentaje de AGR empleado, dadas las características de los mismos.

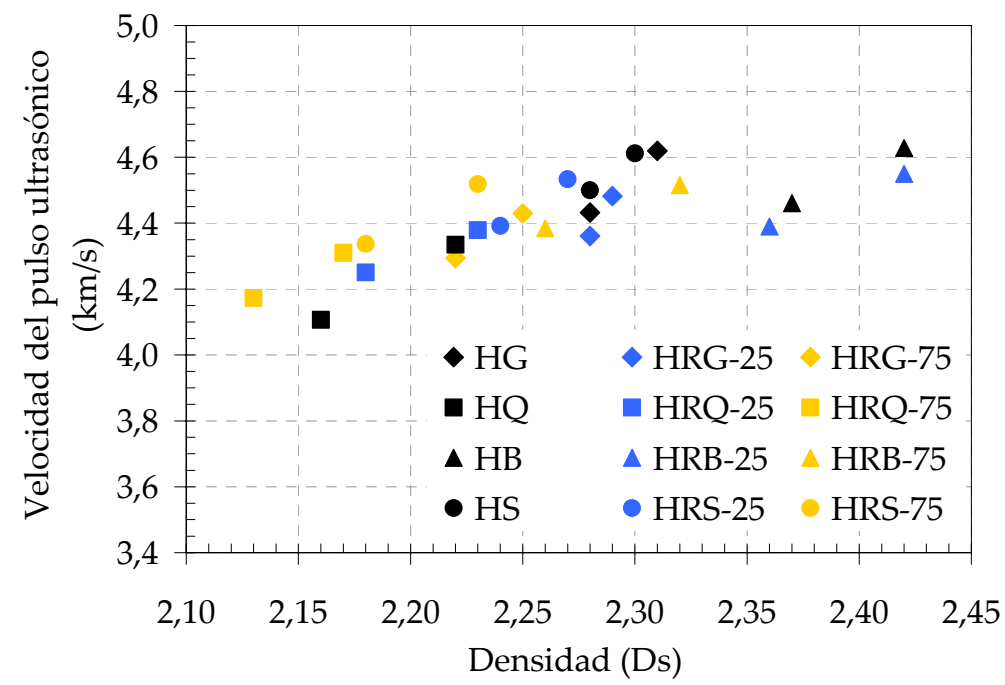

Figura 5.17. Velocidad ultrasónica vs. densidad de los hormigones. 
En general, se observa que la velocidad del pulso ultrasónico en los hormigones reciclados resulta inferior a la de los hormigones originales que contienen igual tipo de AGN, debido a la menor densidad de los AGR. Sin embargo, la modificación producida en la velocidad ultrasónica puede considerarse semejante a la que se produciría al variar el tipo de AGN en hormigones convencionales.

\subsubsection{Módulo de elasticidad dinámico}

En las Figuras 5.18 y 5.19 se presentan los módulos de elasticidad dinámico (Ed) de los hormigones en estudio, para las razones a/c 0,45 y 0,65, respectivamente. De manera similar a lo que sucede con la velocidad del pulso ultrasónico, en este caso también se observa en ambas razones a/c una mayor disminución del módulo dinámico al aumentar el porcentaje de AGR empleado, para los hormigones con granito, basalto y canto rodado silíceo. El Ed en los hormigones con 25 \% de AGR disminuye un 7 \% para la razón a/c 0,45 y un $5 \%$ para la razón a/c 0,65, mientras que en aquellos con $75 \%$ de AGR llegan al 8 y $10 \%$ respectivamente. En el caso de los hormigones con cuarcita, puede observarse un aumento del módulo de elasticidad dinámico del $5 \%$ en los elaborados con $25 \%$ de AGR con relación a los hormigones originales, mientras que los que contienen $75 \%$ de AGR presentan una disminución del $3 \%$.

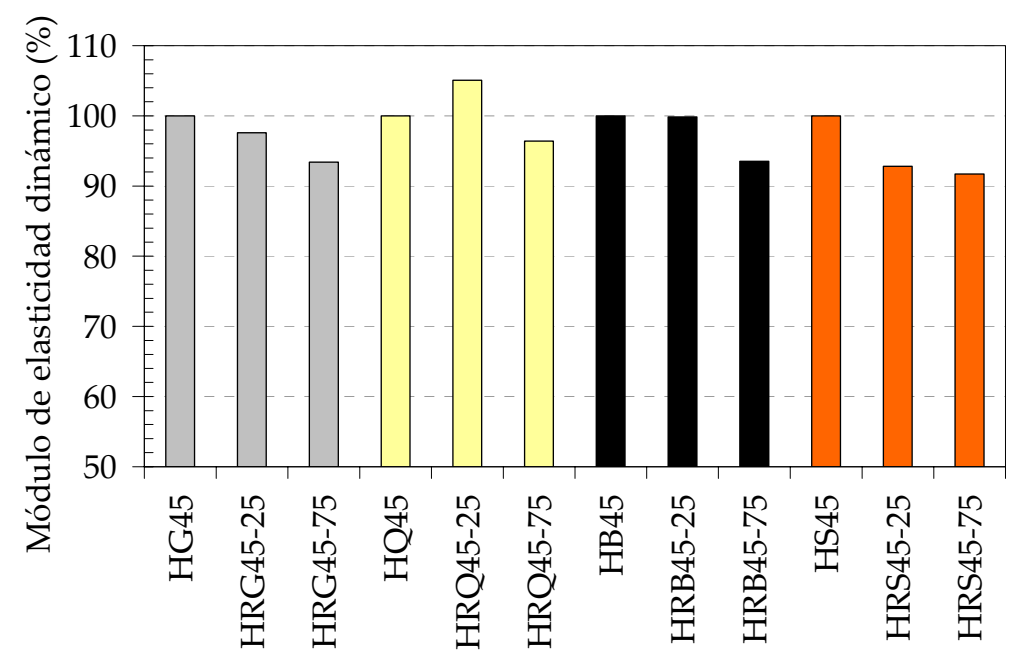

Figura 5.18. Módulo de elasticidad dinámico relativo de hormigones de razón a/c 0,45. 


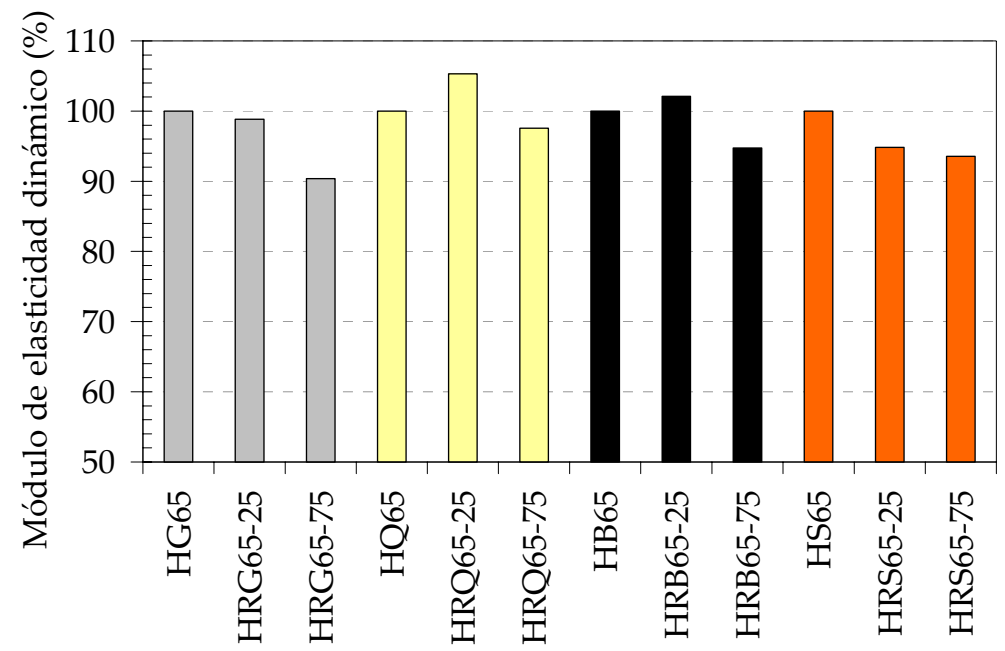

Figura 5.19. Módulo de elasticidad dinámico relativo de hormigones de razón a/c 0,65.

En la Figura 5.20 se relacionan los módulos de elasticidad dinámico con las densidades en estado seco $\left(D_{s}\right)$, diferenciando el tipo de AGN y el porcentaje de AGR empleados. Se verifica para todos los hormigones, al igual que sucede para la velocidad ultrasónica, una relación directa entre ambos parámetros, donde una disminución de la densidad del hormigón ocasiona un descenso del módulo dinámico. Puede observarse también que la disminución de la densidad en los hormigones con 75 \% de AGR resulta más importante que la producida en el módulo dinámico. Este hecho, como fuera mencionado anteriormente, debe ser atribuido a un mayor contenido de humedad como consecuencia del mayor porcentaje de AGR empleado.

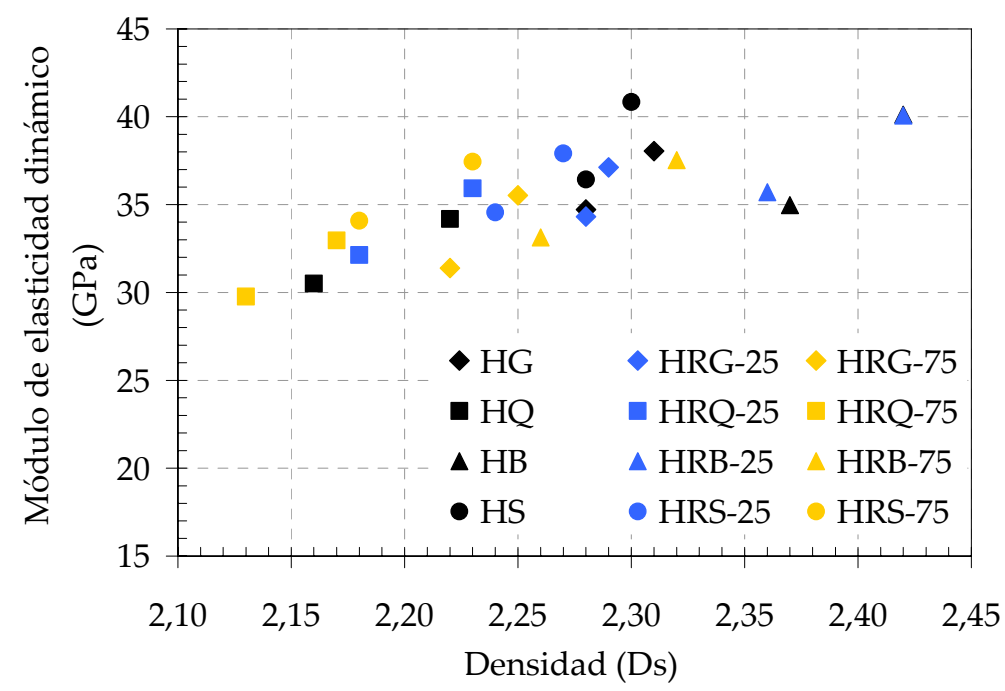

Figura 5.20. Módulo de elasticidad dinámico vs. densidad de los hormigones. 
Al igual de lo que sucede con la velocidad del pulso ultrasónico, el módulo de elasticidad dinámico de los hormigones reciclados resulta inferior al de los hormigones originales que contienen el mismo tipo de AGN, debido a las diferentes densidades entre los agregados naturales y reciclados. En este caso también se puede considerar que la modificación que se produce en el módulo dinámico al emplear los AGR es semejante a la que ocurriría si se cambia el tipo de AGN en los hormigones convencionales.

\subsection{Relaciones entre parámetros mecánicos y END}

Una de las propiedades del hormigón que se relaciona con su resistencia a compresión $\left(f^{\prime} c\right)$ es la resistencia a tracción, ya sea que la misma se determine mediante el ensayo de compresión diametral $\left(\mathrm{f}_{\mathrm{tc}}\right)$ o mediante el módulo de rotura $(\mathrm{MR})$ en flexión. En ambos casos, la resistencia relativa a tracción presenta una variación inversa con el nivel resistente del hormigón [Mindess y Young, 1981; Giaccio y Zerbino, 1998].

En las Figuras 5.21 y 5.22 se presentan las relaciones $\mathrm{ftc}_{\mathrm{tc}} / \mathrm{f}_{\mathrm{c}}^{\prime}$ y $\mathrm{MR} / \mathrm{f}^{\prime} \mathrm{c}$ para los hormigones originales y reciclados elaborados con los diferentes tipos de AGN. Se verifica la disminución de dichas relaciones a medida que aumenta el nivel resistente, presentando los hormigones reciclados un comportamiento semejante al de los hormigones originales, independientemente del porcentaje y tipo de AGR que contengan. Los valores que adquiere la relación $\mathrm{ftc}_{\mathrm{t}} / \mathrm{f}^{\prime} \mathrm{c}$ se encuentran en el rango 0,09-0,15, mientras que para la relación $\mathrm{MR} / \mathrm{f}^{\prime}{ }_{\mathrm{c}}$ se encuentran en el rango 0,14-0,20, para niveles resistentes en compresión entre 20 y $50 \mathrm{MPa}$.

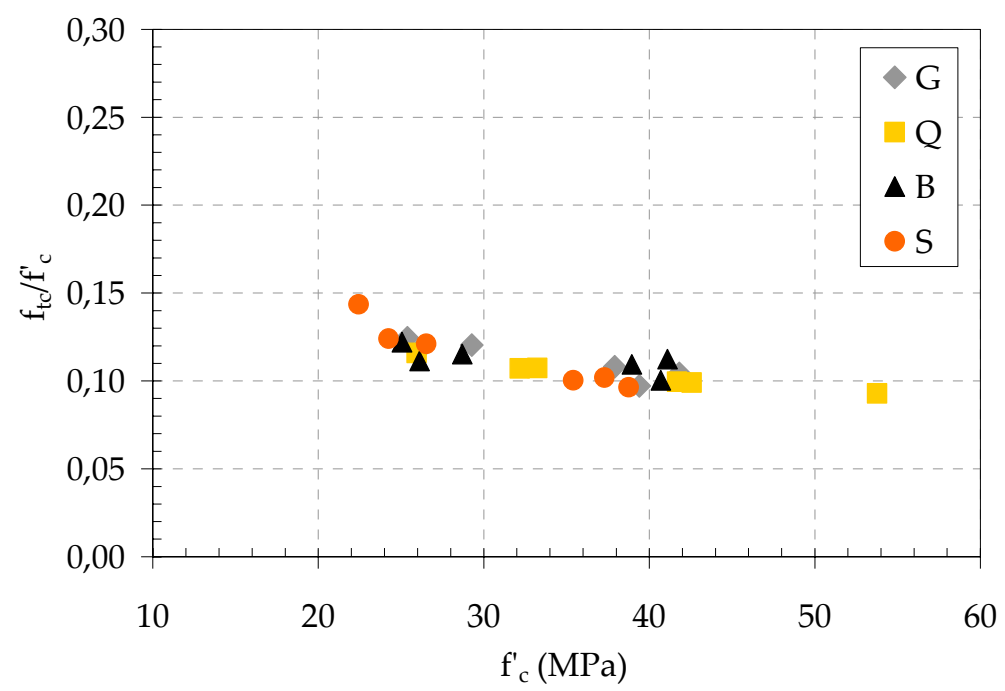

Figura 5.21. Relación entre la resistencia a tracción por compresión diametral y la resistencia a compresión. 


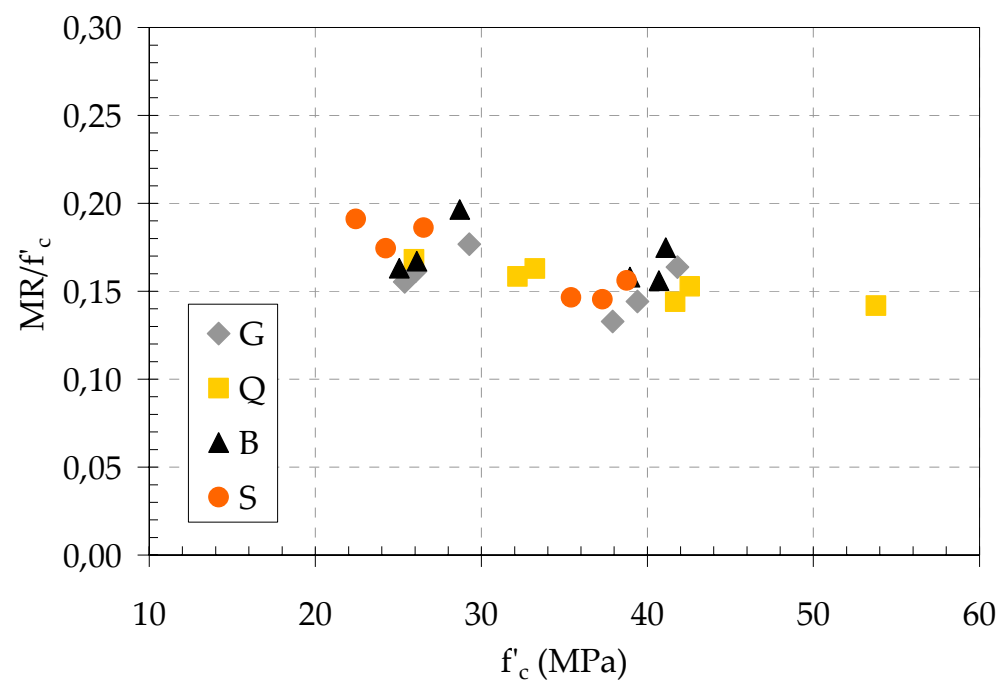

Figura 5.22. Relación entre el módulo de rotura a flexión y la resistencia a compresión.

En la Figura 5.23 se presenta la variación del módulo de elasticidad con la resistencia a compresión, para los diferentes hormigones originales y reciclados en estudio, diferenciándose el tipo de AGN que contienen, indicándose también las curvas obtenidas mediante el empleo de la ecuación del ACI. Puede observarse que para el agregado de canto rodado (S) se produce una modificación importante en la relación $\mathrm{f}^{\prime}{ }^{\prime}$-E al variar el porcentaje de AGR empleado, debido a las diferencias que existen entre el mortero adherido y el agregado natural. Sin embargo, para el agregado de cuarcita $(Q)$ dicha relación es la misma para los hormigones originales y reciclados, hecho que debe ser atribuido, como se mencionó en el Punto 4.2, a las similares características que presentan el agregado natural Q y los correspondientes AGR.

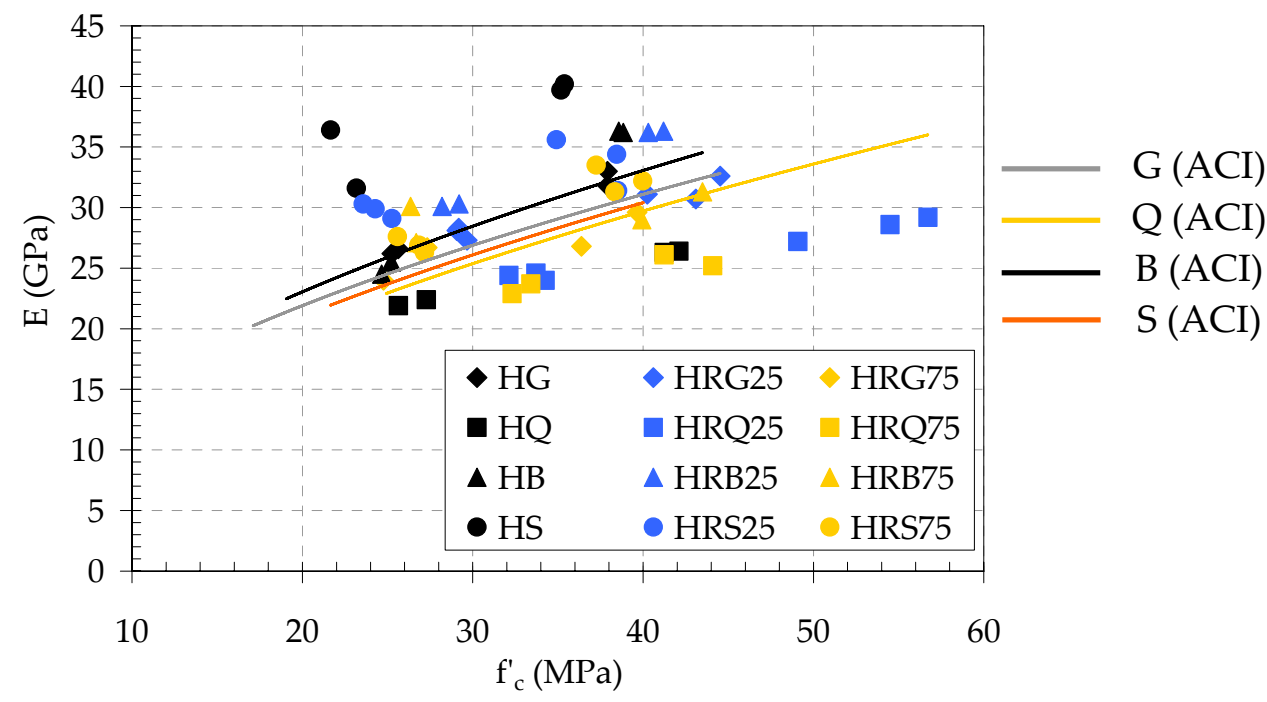

Figura 5.23. Relación entre el módulo de elasticidad y la resistencia a compresión. 
La relación existente entre el módulo de elasticidad estático y la resistencia a compresión del hormigón, variable según el tipo de AGN que el mismo contenga, ha llevado a plantear ecuaciones empíricas que tienen en cuenta ambas características del hormigón (resistencia y tipo de AGN) para la estimación del módulo de elasticidad. Una de las más difundidas es la establecida en el Reglamento ACI 318M [ACI 318M, 2002] (ecuación 5.1), la cual es aplicable a hormigones con agregados naturales, que son tenidos en cuenta a través del peso unitario del hormigón. A nivel nacional no se cuenta con ninguna correlación de este tipo, aceptándose en el Proyecto de Reglamento CIRSOC 201:2005 la ecuación del ACI para la estimación del módulo de elasticidad.

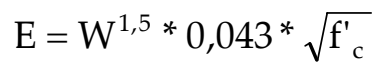

Donde:
E: módulo de elasticidad estático (MPa)
$\mathrm{W}$ : peso unitario del hormigón $\left(\mathrm{kg} / \mathrm{m}^{3}\right)$
$\mathrm{f}^{\prime}$ : : resistencia a compresión $(\mathrm{MPa})$

En las Tablas 5.9 y 5.10 se presentan los módulos de elasticidad medidos en los hormigones, los estimados mediante la ecuación 5.1 y la diferencia producida.

Tabla 5.9. Módulo de elasticidad estático estimado

para hormigones de razón a/c 0,45.

\begin{tabular}{|l|c|c|c|c|c|}
\hline Hormigón & $\begin{array}{c}\mathrm{f}^{\prime} \mathrm{c} \\
(\mathrm{MPa})\end{array}$ & $\begin{array}{c}\text { PUV } \\
\left(\mathrm{kg} / \mathrm{m}^{3}\right)\end{array}$ & $\begin{array}{c}\text { E medido } \\
(\mathrm{GPa})\end{array}$ & $\begin{array}{c}\text { E estimado } \\
(\mathrm{GPa})\end{array}$ & $\begin{array}{c}\text { Diferencia } \\
(\%)\end{array}$ \\
\hline HG45 & 37,9 & 2395 & 32,4 & 29,6 & $-8,7$ \\
\hline HRG45-25 & 41,8 & 2360 & 31,5 & 31,8 & $+1,2$ \\
\hline HRG45-75 & 39,4 & 2305 & 28,2 & 29,9 & $+5,9$ \\
\hline HQ45 & 41,7 & 2300 & 26,4 & 30,0 & $+13,9$ \\
\hline HRQ45-25 & 53,8 & 2310 & 28,3 & 35,0 & $+23,7$ \\
\hline HRQ45-75 & 42,6 & 2280 & 25,7 & 30,5 & $+19,1$ \\
\hline HB45 & 38,9 & 2495 & 36,3 & 30,3 & $-16,5$ \\
\hline HRB45-25 & 41,1 & 2475 & 36,3 & 33,9 & $-6,4$ \\
\hline HRB45-75 & 40,7 & 2400 & 30,2 & 32,2 & $+6,9$ \\
\hline HS45 & 35,4 & 2355 & 40,0 & 29,3 & $-26,7$ \\
\hline HRS45-25 & 37,3 & 2320 & 35,0 & 29,3 & $-16,3$ \\
\hline HRS45-75 & 38,7 & 2305 & 32,3 & 29,6 & $-8,4$ \\
\hline
\end{tabular}


Tabla 5.10. Módulo de elasticidad estático estimado

para hormigones de razón a/c 0,65.

\begin{tabular}{|l|c|c|c|c|c|}
\hline Hormigón & $\begin{array}{c}\mathrm{f}^{\prime} \mathrm{c} \\
(\mathrm{MPa})\end{array}$ & $\begin{array}{c}\text { PUV } \\
\left(\mathrm{kg} / \mathrm{m}^{3}\right)\end{array}$ & $\begin{array}{c}\text { E medido } \\
(\mathrm{GPa})\end{array}$ & $\begin{array}{c}\text { E estimado } \\
(\mathrm{GPa})\end{array}$ & $\begin{array}{c}\text { Diferencia } \\
(\%)\end{array}$ \\
\hline HG65 & 25,4 & 2375 & 26,4 & 23,7 & $-10,4$ \\
\hline HRG65-25 & 29,3 & 2330 & 27,9 & 26,1 & $-6,3$ \\
\hline HRG65-75 & 26,0 & 2300 & 25,4 & 24,1 & $-4,8$ \\
\hline HQ65 & 25,9 & 2265 & 22,2 & 23,6 & $+6,6$ \\
\hline HRQ65-25 & 33,2 & 2270 & 24,3 & 26,8 & $+10,2$ \\
\hline HRQ65-75 & 32,2 & 2250 & 23,3 & 26,0 & $+11,6$ \\
\hline HB65 & 25,1 & 2465 & 25,0 & 23,2 & $-7,3$ \\
\hline HRB65-25 & 28,7 & 2425 & 30,2 & 27,5 & $-8,8$ \\
\hline HRB65-75 & 26,1 & 2345 & 28,6 & 25,0 & $-12,7$ \\
\hline HS65 & 22,4 & 2325 & 31,6 & 22,8 & $-27,7$ \\
\hline HRS65-25 & 24,2 & 2299 & 29,8 & 23,3 & $-21,8$ \\
\hline HRS65-75 & 26,5 & 2255 & 26,9 & 23,8 & $-11,8$ \\
\hline
\end{tabular}

En las Tablas 5.9 y 5.10 se puede observar que la diferencia existente en la estimación del módulo de elasticidad de los hormigones reciclados, para los que contienen los agregados naturales de trituración, resulta similar a la diferencia que se produce en el caso de los correspondientes hormigones convencionales. En los hormigones reciclados con canto rodado, la estimación del módulo de elasticidad mediante la ecuación 5.1 conduce a diferencias menores que las obtenidas para los respectivos hormigones originales.

A partir de aplicar la ecuación 5.1 para estimar el módulo de elasticidad estático de los hormigones reciclados, surge que el efecto que tiene el empleo de los AGR no es mucho más importante que el mero cambio del AGN, teniendo el mismo nivel de incertidumbre que para el hormigón elaborado con el mismo tipo de agregado natural.

En el caso de los END, el método ultrasónico es el más utilizado para evaluar la homogeneidad interna de un elemento estructural. Debido a que la resistencia a compresión $\left(f^{\prime} c\right)$ puede ser relacionada con la velocidad ultrasónica $(V)$, la determinación de esta última en estructuras construidas permite, en algunos casos, estimar la resistencia del material. 
Como se mencionó en el Capítulo 3, la velocidad del pulso ultrasónico es afectada por la densidad del AGN del hormigón, por lo que la relación $V-f^{\prime}{ }_{c}$ se va a ver modificada según el tipo de AGN con que hayan sido elaborados los hormigones. A partir de lo mencionado anteriormente, y considerando la menor densidad que poseen los AGR, se obtuvieron curvas de correlación entre ambos parámetros para los hormigones en estudio.

En las Figuras 5.24-a) - d) se presentan las variaciones de la velocidad del pulso ultrasónico con la resistencia a compresión en los hormigones originales y reciclados, para cada tipo de AGN utilizado. Se puede observar que, en el caso de los hormigones con granito (a), basalto (c) y canto rodado silíceo (d), si bien hay una tendencia creciente entre ambos parámetros, se produce una diferenciación de dicha relación entre los hormigones originales y los que contienen agregados reciclados.

Para los hormigones con cuarcita (Figura 5.24-b), además de verificarse la tendencia creciente entre ambos parámetros, se observa que los puntos correspondientes a los hormigones originales y reciclados podrían ser ajustados mediante una misma curva. Este comportamiento debe ser atribuido a la similitud en la composición del agregado reciclado y el agregado natural de cuarcita, hecho que también se verificó en la relación E-f'c.
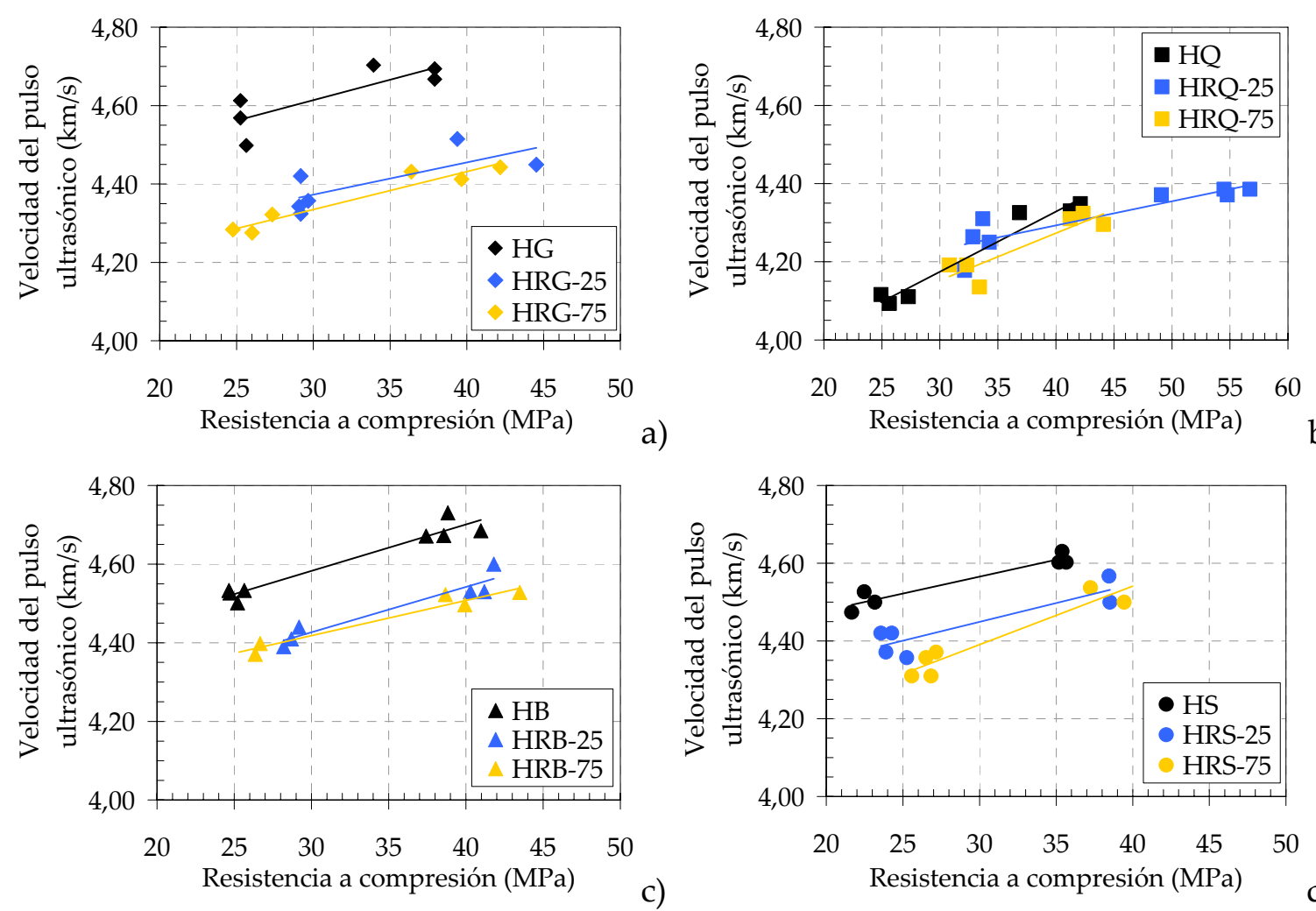

b)

Figura 5.24. Relación entre la velocidad del pulso ultrasónico y la resistencia a compresión, para los hormigones originales y reciclados. 
En la Figura 5.25 se presenta la relación entre los módulos de elasticidad estático y dinámico. Puede observarse que todos los hormigones mantienen una misma tendencia independientemente del tipo de AGN y del porcentaje de AGR que contengan. Además, se observa que para los hormigones reciclados el módulo de elasticidad dinámico resulta superior al módulo estático, disminuyendo la diferencia al aumentar la resistencia de los hormigones [Mindess y Young, 1981].

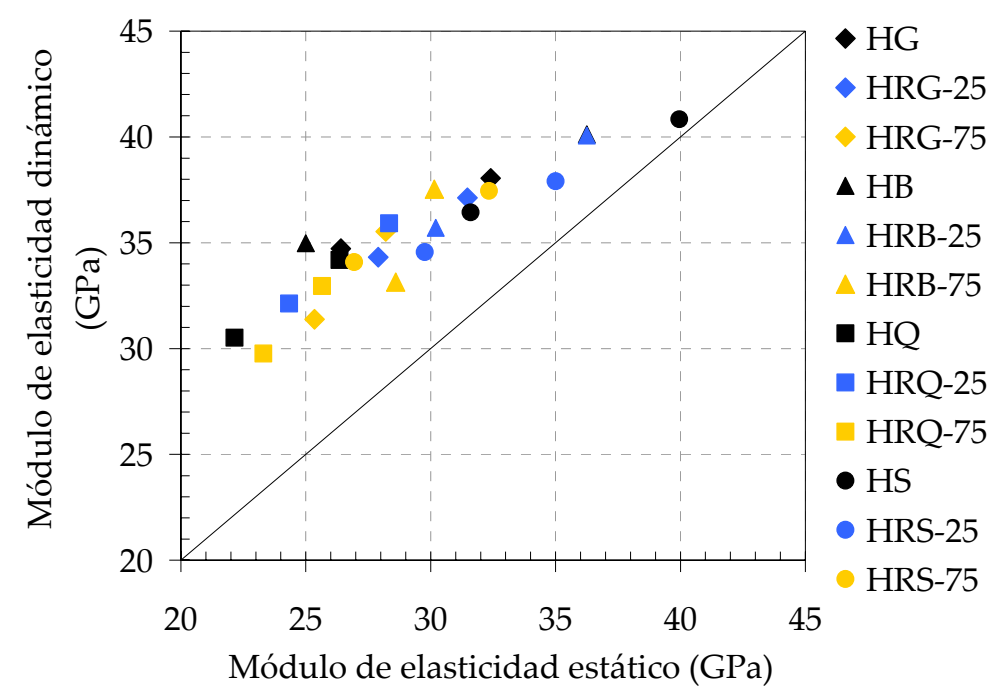

Figura 5.25. Relación entre los módulos de elasticidad estático y dinámico.

\subsection{Conclusiones sobre el comportamiento mecánico de los hormigones reciclados}

De los resultados presentados en este capítulo sobre el comportamiento mecánico de hormigones de dos niveles resistentes $(\mathrm{a} / \mathrm{c} 0,45$ y 0,65$)$ y elaborados con distintos porcentajes de agregados gruesos reciclados, obtenidos de la trituración de hormigones que contenían diferentes tipos de agregados gruesos naturales, se puede concluir que:

- Los niveles resistentes en compresión de los hormigones con $25 \%$ de AGR resultan, en general, entre 5 y $15 \%$ superiores al de los hormigones originales, siendo la excepción los elaborados con los AGR de cuarcita que presentan incrementos superiores al $20 \%$. Para los hormigones con $75 \%$ de AGR, las resistencias a compresión son similares a las de los hormigones originales, salvo en el caso de los hormigones HRQ65-75 y HRS65-75 que presentan incrementos del orden del $20 \%$.

- Las resistencias a tracción por compresión diametral de los hormigones reciclados se encuentran en el rango $\pm 10 \%$ de las obtenidas en los hormigones originales. Los hormigones elaborados con $25 \%$ de AGR, conteniendo AGN de trituración, pre- 
sentan módulos de rotura en flexión entre 17 y 38 \% superiores al de los hormigones originales. En el caso de los elaborados con canto rodado se produce un incremento del $16 \%$ en los elaborados con $75 \%$ de AGR.

- $\quad$ El mejor comportamiento mecánico que presentan los hormigones reciclados respecto a los originales puede ser atribuido al empleo de los AGR en estado seco al aire, lo cual ocasiona una reducción de la razón a/c efectiva y una mejora en la calidad de las interfaces. Sin embargo, para reemplazos del $75 \%$, la menor resistencia de los agregados reciclados conduce a una disminución de la resistencia de los hormigones.

- La relación entre las resistencias a tracción y compresión presenta el mismo comportamiento para los hormigones reciclados y originales, motivo por el cual no se observa una influencia del tipo de agregado empleado.

- El módulo de elasticidad estático de los hormigones reciclados disminuye, en general, al incrementarse el porcentaje de AGR empleado, debido a la menor rigidez del mismo, pudiendo alcanzar una disminución del $20 \%$ en los elaborados con $75 \%$ de AGR. Sin embargo, un incremento en la resistencia del hormigón implicará un aumento también en el módulo de elasticidad, hecho que se verifica para los hormigones de cuarcita con $25 \%$ de AGR.

- La modificación que se produce en el módulo de elasticidad estático del hormigón al variar el tipo de AGR puede considerarse semejante a la que ocurre en un hormigón convencional al variar el AGN, pudiéndose obtener mayores módulos de elasticidad al emplear AGR que contengan diferentes tipos de AGN.

- En los hormigones reciclados, la velocidad del pulso ultrasónico resulta hasta un $3 \%$ inferior a la de los hormigones originales que contienen el mismo tipo de AGN, debido a la menor densidad de los AGR. Sin embargo, la modificación producida en la velocidad ultrasónica puede considerarse semejante a la que se produciría al variar el tipo de AGN en hormigones convencionales.

- Dicho descenso de la velocidad ultrasónica conduce a que la relación velocidadresistencia a compresión resulte diferente para los hormigones originales y reciclados. En el caso del agregado de cuarcita, dicha relación resulta similar para ambos 
tipos de hormigones, debido a la similar composición que presenta el mortero adherido en comparación con dicho agregado natural.

- El módulo de elasticidad dinámico presenta un comportamiento semejante al descripto en el caso de la velocidad del pulso ultrasónico, siendo en los hormigones reciclados entre 5 y $10 \%$ inferiores debido a la menor densidad de los AGR. En este caso también se puede considerar que la variación que se produce en el módulo dinámico como consecuencia del empleo de los AGR resulta semejante a la que puede ocurrir al variar el agregado natural en hormigones convencionales. 


\section{Capítulo 6 \\ Durabilidad de Hormigones Reciclados}

\subsection{Introducción}

La durabilidad de un material constituye la capacidad del mismo para mantener sus propiedades físicas y mecánicas a lo largo del tiempo, sin experimentar un proceso de degradación. En el caso del hormigón, dicha capacidad se encuentra relacionada con su estructura porosa y con la posibilidad de ingreso de agentes agresivos. Esta misma capacidad es la que permite a las estructuras de hormigón armado mantenerse en servicio un determinado período de tiempo, conocido como vida útil, durante el cual no sería necesario realizar reparaciones de gran importancia. La vida útil de una estructura, por lo tanto, es función de las características geométricas de la misma, de las condiciones atmosféricas que la rodean y de las propiedades de los materiales empleados en su construcción.

La determinación de las propiedades de transporte de fluidos en el hormigón permite tomar conocimiento respecto a su desempeño durable, el cual se encuentra vinculado a la distribución y tamaño de poros, y a la conectividad entre ellos, factores que dependen de la razón a/c y el grado de hidratación del cemento [Mehta y Monteiro, 1998]. Otro factor de importancia que afecta el comportamiento durable lo constituye la zona de interfaz agregado-mortero, cuyas propiedades están ligadas a las de la matriz de cemento y a las características de los agregados gruesos, principalmente a su textura superficial. Los factores que influyen sobre las propiedades de transporte del hormigón no se corresponden necesariamente con los que modifican su comportamiento resistente. Este hecho conduce a que un determinado nivel resistente no garantice una adecuada durabilidad, mientras que un hormigón con un comportamiento durable satisfactorio seguramente presentará un nivel resistente acorde con el requerido.

Como se mencionó en el Capítulo 2, la durabilidad de los hormigones reciclados constituye aún una temática sobre la cual no existen demasiados estudios, y en los que se han realizado, aparece una alta variabilidad de resultados. En el caso de los hormigones reciclados, teniendo en cuenta las características que los mismos poseen, principalmente su mayor absorción de agua, debe ponerse un mayor énfasis en su potencial desempeño 
durable, aún cuando su nivel resistente sea similar o superior al de hormigones elaborados en su totalidad con agregados naturales.

En este capítulo se presentan y analizan los resultados obtenidos en los estudios de durabilidad realizados sobre los hormigones reciclados, comparativamente al de los hormigones con AGN. Debe recordarse que se emplearon AGR obtenidos de la trituración de hormigones de dos niveles resistentes elaborados con cuatro tipos de AGN, los cuales poseen diferentes características físico-mecánicas. Los AGR fueron empleados en un 25 y $75 \%$ en volumen en reemplazo del correspondiente AGN. Sobre dichos hormigones se realizaron diferentes determinaciones que permiten evaluar la estructura de poros del material, hecho que posibilita tomar conocimiento sobre distintos factores relacionados con la durabilidad de los mismos. Además, se presentan los resultados obtenidos en una experiencia de campo, empleando hormigones con agregados gruesos naturales y reciclados en distintas proporciones ( 0,25 y $75 \%$ de AGR) expuestos en suelo con sulfato.

\subsection{Propiedades durables}

Para evaluar la estructura porosa del hormigón se realizaron diferentes ensayos que involucran distintos mecanismos de transporte, dentro de los cuales se seleccionaron el de absorción de agua por inmersión, succión capilar, obteniéndose los parámetros de velocidad y capacidad $\left(\mathrm{V}_{\mathrm{sc}}, \mathrm{C}_{\mathrm{sc}}\right)$, penetración de agua a presión, determinándose las penetraciones media ( $\left.\mathrm{P}_{\mathrm{med}}\right)$ y máxima (Pmáx), y difusión de cloruro en inmersión, obteniendo el perfil de ingreso y el coeficiente de difusión ( $\left.\mathrm{D}_{\mathrm{ap}}\right)$, a la edad de 140 días. El procedimiento adoptado en la realización de cada uno de los ensayos, como así también el acondicionamiento previo de las probetas, fue presentado en el Capítulo 3.

En las Tablas 6.1-a) y b) y 6.2-a) y b) se resumen los resultados obtenidos en cada uno de los parámetros evaluados, correspondientes a los hormigones de razones a/c 0,45 y 0,65 , respectivamente. 
Tabla 6.1-a). Propiedades de transporte de hormigones de razón a/c 0,45.

\begin{tabular}{|l|c|c|c|c|c|}
\hline \multirow{2}{*}{ Hormigón } & $\begin{array}{c}\text { Absorción } \\
(\%)\end{array}$ & $\begin{array}{c}\mathrm{V}_{\mathrm{sc}} \\
\left(\mathrm{g} / \mathrm{m}^{2} / \mathrm{s}^{1 / 2}\right)\end{array}$ & $\begin{array}{c}\mathrm{C}_{\mathrm{sc}} \\
\left(\mathrm{g} / \mathrm{m}^{2}\right)\end{array}$ & $\begin{array}{c}\text { Penetración de agua } \\
(\mathrm{mm})\end{array}$ \\
\cline { 2 - 6 } & Promedio & Promedio & Promedio & $P_{\text {med }}$ & $P_{\text {máx }}$ \\
\hline HG45 & 4,2 & 1,6 & 1360 & 11 & 19 \\
\hline HRG45-25 & 5,1 & 2,1 & 1775 & 14 & 25 \\
\hline HRG45-75 & 4,5 & 3,9 & 3415 & 23 & 31 \\
\hline HQ45 & 5,3 & 3,5 & 3250 & 15 & 23 \\
\hline HRQ45-75 & 6,7 & 5,3 & 3950 & 15 & 25 \\
\hline HB45 & 4,3 & 2,6 & 1890 & 11 & 19 \\
\hline HRB45-25 & 5,0 & 2,9 & 2260 & 13 & 22 \\
\hline HRB45-75 & 4,5 & 3,6 & 3365 & 26 & 37 \\
\hline HS45 & 4,6 & 3,8 & 3060 & 12 & 24 \\
\hline HRS45-25 & 4,3 & 2,6 & 2245 & 10 & 17 \\
\hline HRS45-75 & 5,6 & 3,6 & 3055 & 11 & 19 \\
\hline
\end{tabular}

Tabla 6.1-b). Coeficientes de difusión de cloruro en hormigones de razón a/c 0,45.

\begin{tabular}{|l|c|c|}
\hline Hormigón & $\begin{array}{c}\text { Dap soluble en agua } \\
\left(\times 10^{-12}\right)\left(\mathrm{m}^{2} / \mathrm{s}\right)\end{array}$ & $\begin{array}{c}\text { Dap soluble en ácido } \\
\left(\times 10^{-12}\right)\left(\mathrm{m}^{2} / \mathrm{s}\right)\end{array}$ \\
\hline HG45 & 5,9 & 7,5 \\
\hline HRG45-25 & 9,6 & 14,3 \\
\hline HRG45-75 & 13,7 & 16,2 \\
\hline HQ45 & 7,7 & 9,5 \\
\hline HRQ45-25 & 5,9 & 6,8 \\
\hline HRQ45-75 & 5,9 & 7,6 \\
\hline HB45 & 6,4 & 6,6 \\
\hline HRB45-25 & 7,0 & 8,5 \\
\hline HRB45-75 & 13,6 & 19,5 \\
\hline HS45 & 8,8 & 7,5 \\
\hline HRS45-25 & 7,1 & 8,6 \\
\hline HRS45-75 & 4,9 & 6,7 \\
\hline
\end{tabular}


Tabla 6.2-a). Propiedades de transporte de hormigones de razón a/c 0,65.

\begin{tabular}{|l|c|c|c|c|c|}
\hline \multirow{2}{*}{ Hormigón } & $\begin{array}{c}\text { Absorción } \\
(\%)\end{array}$ & $\begin{array}{c}\mathrm{V}_{\mathrm{sc}} \\
\left(\mathrm{g} / \mathrm{m}^{2} / \mathrm{s}^{1 / 2}\right)\end{array}$ & $\begin{array}{c}\mathrm{C}_{\mathrm{sc}} \\
\left(\mathrm{g} / \mathrm{m}^{2}\right)\end{array}$ & $\begin{array}{c}\text { Penetración de agua } \\
(\mathrm{mm})\end{array}$ \\
\cline { 2 - 6 } & Promedio & Promedio & Promedio & Pmed $_{\text {máx }}$ & $P_{\text {máx }}$ \\
\hline HG65 & 5,0 & 5,4 & 3520 & 30 & 39 \\
\hline HRG65-25 & 5,3 & 5,8 & 3555 & 24 & 39 \\
\hline HRG65-75 & 5,1 & 7,5 & 4685 & 39 & 49 \\
\hline HRQ65-25 & 5,9 & 11,9 & 4745 & 20 & 28 \\
\hline HRQ65-75 & 6,9 & 14,6 & 5260 & 20 & 29 \\
\hline HB65 & 5,1 & 6,7 & 3590 & 32 & 44 \\
\hline HRB65-25 & 5,5 & 6,7 & 3660 & 31 & 41 \\
\hline HRB65-75 & 5,1 & 9,7 & 4980 & 35 & 48 \\
\hline HS65 & 4,6 & 9,5 & 3955 & 24 & 31 \\
\hline HRS65-25 & 4,7 & 5,9 & 3710 & 21 & 34 \\
\hline HRS65-75 & 5,8 & 9,6 & 4410 & 18 & 27 \\
\hline
\end{tabular}

Tabla 6.2-b). Coeficientes de difusión de cloruro en hormigones de razón a/c 0,65.

\begin{tabular}{|l|c|c|}
\hline Hormigón & $\begin{array}{c}\text { Dap soluble en agua } \\
\left(\times 10^{-12}\right)\left(\mathrm{m}^{2} / \mathrm{s}\right)\end{array}$ & $\begin{array}{c}\text { Dap soluble en ácido } \\
\left(\times 10^{-12}\right)\left(\mathrm{m}^{2} / \mathrm{s}\right)\end{array}$ \\
\hline HG65 & 12,4 & 14,3 \\
\hline HRG65-25 & 20,2 & 38,4 \\
\hline HRG65-75 & 19,3 & 25,9 \\
\hline HQ65 & 21,5 & 25,4 \\
\hline HRQ65-25 & 17,4 & 23,9 \\
\hline HRQ65-75 & 12,2 & 19,0 \\
\hline HB65 & 14,0 & 15,3 \\
\hline HRB65-25 & 15,4 & 17,5 \\
\hline HRB65-75 & 22,6 & 30,6 \\
\hline HS65 & 13,8 & 14,7 \\
\hline HRS65-25 & 15,9 & 23,6 \\
\hline HRS65-75 & 14,5 & 17,9 \\
\hline
\end{tabular}




\subsubsection{Absorción de agua}

En las Figuras 6.1 y 6.2 se presentan las absorciones de agua de los hormigones originales y reciclados, según el tipo de AGN que contienen, para las razones a/c 0,45 y 0,65, respectivamente. Para ambas razones a/c, puede observarse que el ensayo de absorción no manifiesta una marcada tendencia en el comportamiento de los hormigones reciclados. Las absorciones de agua de los hormigones reciclados resultan, en general, similares o superiores a las de los respectivos hormigones originales, debido a la mayor porosidad de los AGR.

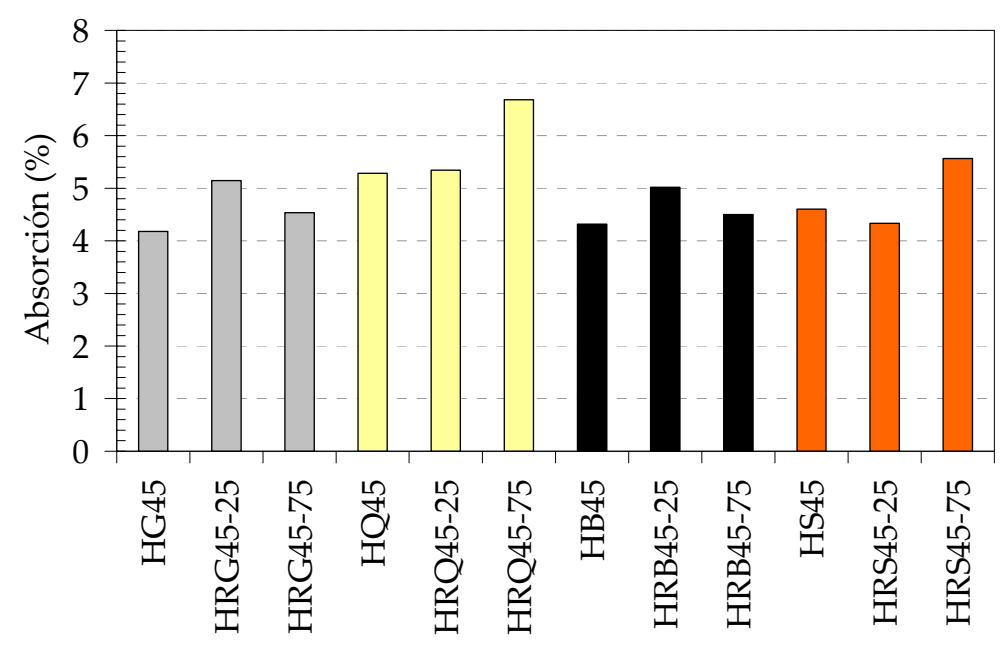

Figura 6.1. Absorción de agua en hormigones de razón a/c 0,45.

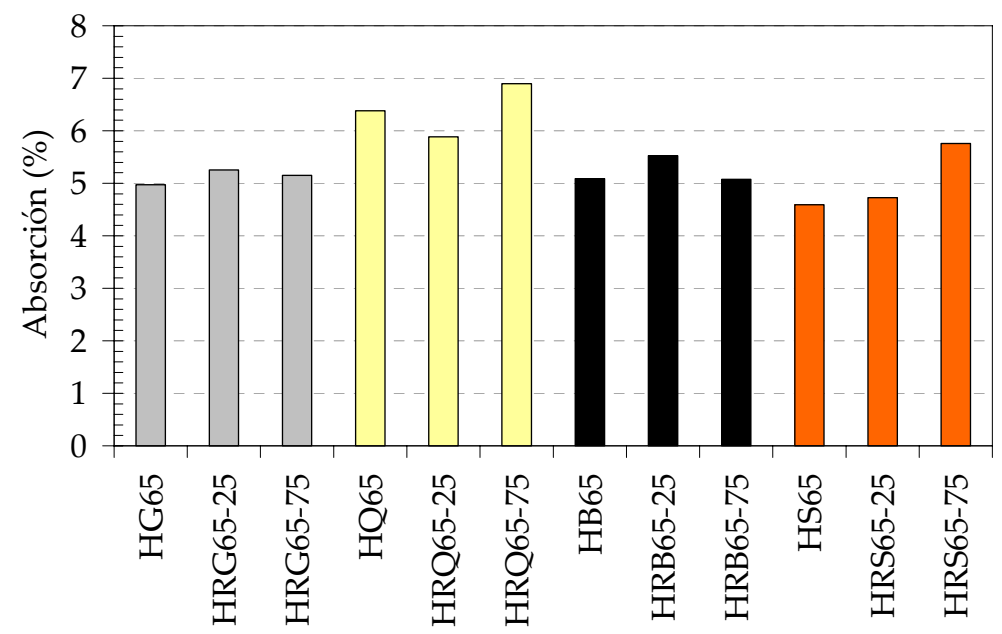

Figura 6.2. Absorción de agua en hormigones de razón a/c 0,65.

En ambas figuras se puede observar que en los hormigones originales y reciclados elaborados con cuarcita la absorción resulta superior a la del resto de los hormigones. Este 
hecho debe atribuirse a la mayor absorción del agregado natural $Q$ y al mayor contenido de mortero que presentan los agregados RQ, según se indicó en el punto 4.3.7.

Debe destacarse que la absorción del hormigón reciclado HRS45-75 es prácticamente similar a la del HQ45, y ambos resultan inferiores a la de los hormigones con cuarcita de razón a/c 0,65, original y reciclados, lo que demuestra la importancia que tiene en este ensayo la razón a/c por sobre el tipo de agregado empelado.

Si bien la determinación de la absorción de agua del hormigón permite tener una estimación de su porosidad, en la bibliografía se concluye que no existe una relación directa entre la absorción y el comportamiento durable de los hormigones, el cual se encuentra directamente vinculado con el tamaño y la conectividad de poros de la red capilar. Además, se indica que los resultados obtenidos mediante este ensayo deben considerarse orientativos de la calidad del hormigón pero nunca definitorios en cuanto a su desempeño durable [De Schutter y Audenaert, 2004].

\subsubsection{Succión capilar}

Como fuera indicado anteriormente, el ensayo de succión capilar proporciona una idea de la estructura porosa del hormigón a partir de evaluar la cantidad de agua absorbida por unidad de área en el tiempo, al colocar las probetas en contacto con agua. Como resultado del ensayo se obtienen los parámetros de velocidad $\left(\mathrm{V}_{\mathrm{sc}}\right)$ y capacidad $\left(\mathrm{C}_{\mathrm{sc}}\right) \mathrm{de}$ succión capilar.

En las Figuras 6.3-a) - d) se presentan las curvas promedio de absorción capilar correspondientes a los hormigones original y reciclados de razón a/c 0,45, agrupándolos según el tipo de AGN que contienen, y en las Figuras 6.4-a) - d) se presentan las curvas correspondientes a los hormigones de razón a/c 0,65.

En el caso de la razón a/c 0,45, para los hormigones con agregados naturales de trituración (G, Q y B), los elaborados con 75 \% de AGR presentan las mayores absorciones, hecho que, como se menciona anteriormente, debe ser atribuido al mayor contenido de mortero de los mismos. La capacidad de succión capilar de dichos hormigones es del orden de $3400 \mathrm{~g} / \mathrm{m}^{2}$ (G y B) y de $3950 \mathrm{~g} / \mathrm{m}^{2}$ (Q), mientras que para los originales es de $1360 \mathrm{~g} / \mathrm{m}^{2}$ (G), $1890 \mathrm{~g} / \mathrm{m}^{2}$ (B) y $3250 \mathrm{~g} / \mathrm{m}^{2}$ (Q). Los hormigones con $25 \%$ de AGR presentan absorciones levemente superiores a las de los hormigones originales, con valores de capacidad de $1775 \mathrm{~g} / \mathrm{m}^{2}$ (G), $2260 \mathrm{~g} / \mathrm{m}^{2}$ (B) y $3275 \mathrm{~g} / \mathrm{m}^{2}(\mathrm{Q})$. 

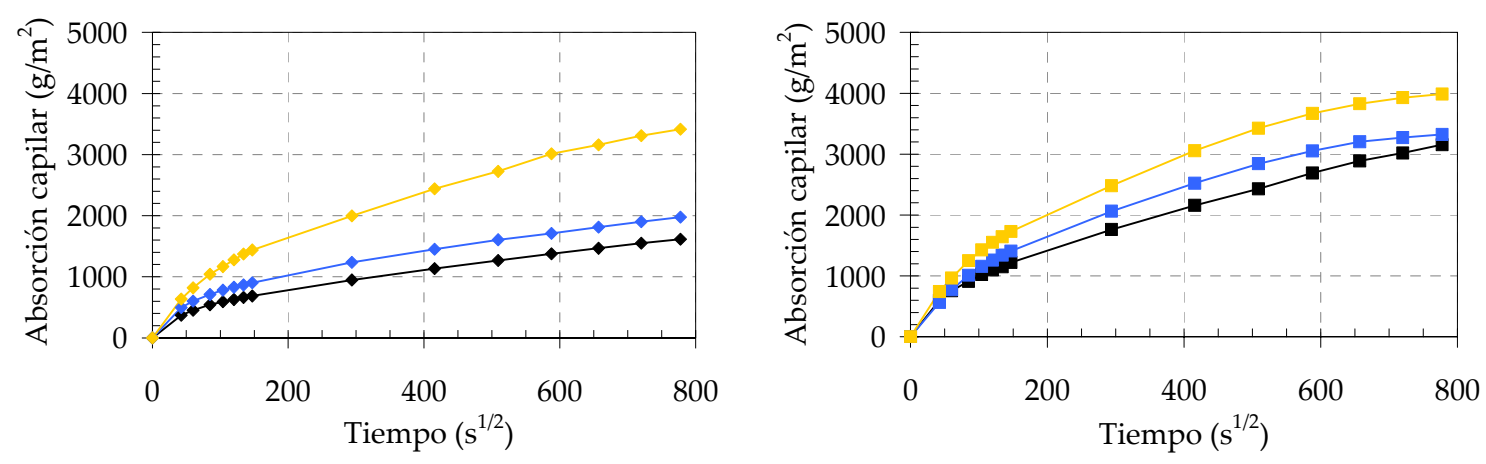

$\rightarrow$ HG45 $\rightarrow$ HRG45-25 $\rightarrow$ HRG45-75

a)
- HQ45 - HRQ45-25 - HRQ45-75

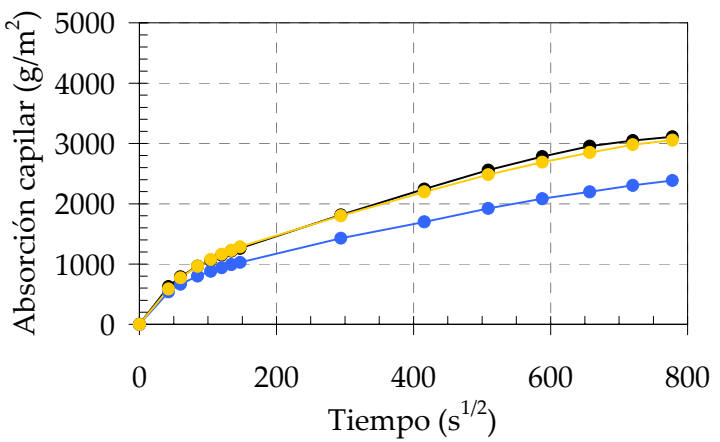

b)

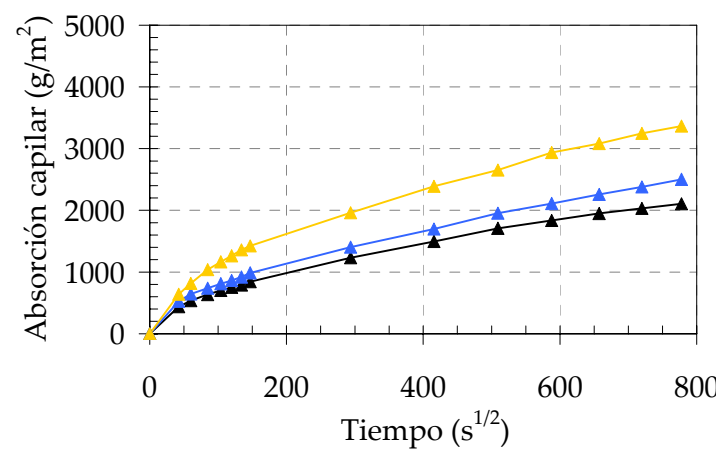

$\star$ HB45 $₫$ HRB45-25 $₫$ HRB45-75 c) $\quad$ HS45 $\rightarrow$ HRS45-25 $\rightarrow$ HRS45-75

c) $-\mathrm{HS} 45-\mathrm{HRS} 45-25-\mathrm{HRS} 45-75$

d)

Figura 6.3. Succión capilar en hormigones de razón a/c 0,45 elaborados con:

a) granito; b) cuarcita; c) basalto; d) canto rodado silíceo.
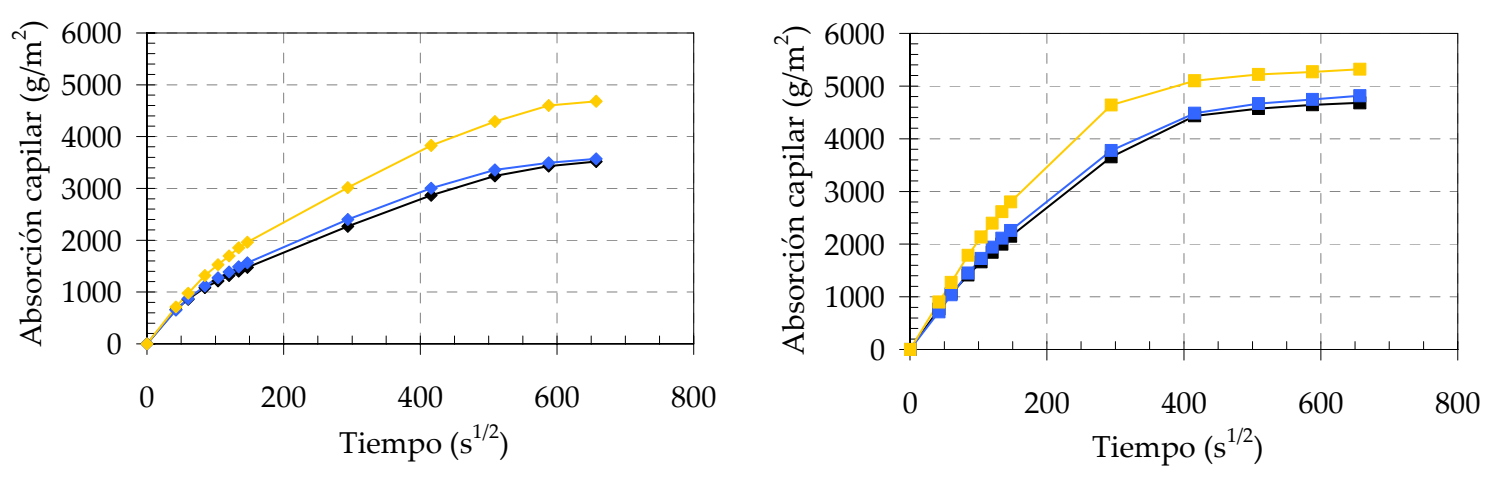

$\rightarrow$ HG65 $\rightarrow$ HRG65-25 $\rightarrow$ HRG65-75

a)

$-\mathrm{HQ65}=\mathrm{HRQ65-25}=\mathrm{HRQ65-75}$

b)
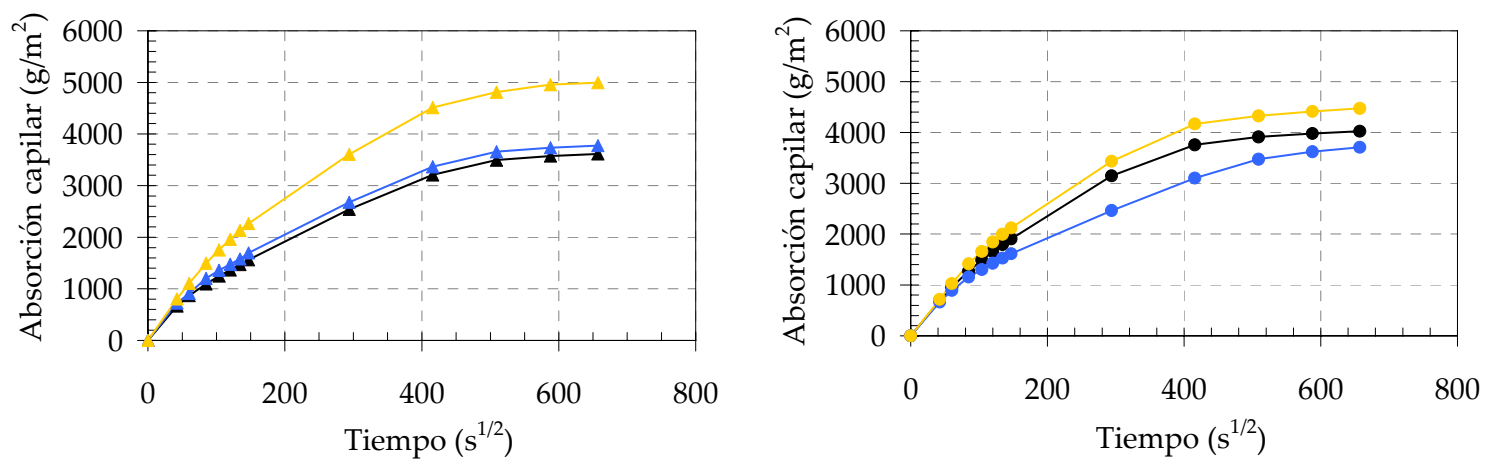

$\star \mathrm{HB} 65 \nrightarrow \mathrm{HRB} 65-25-\mathrm{HRB} 65-75$

c)

-HS65 - HRS65-25 - HRS65-75

d)

Figura 6.4. Succión capilar en hormigones de razón a/c 0,65 con:

a) granito; b) cuarcita; c) basalto; d) canto rodado silíceo. 
En la Figura 6.3 puede observarse también que el hormigón con canto rodado silíceo (S) elaborado con $75 \%$ de AGR presenta un comportamiento semejante al del hormigón original, y ambos poseen mayor succión capilar que el hormigón con 25 \% de AGR. En este caso, el comportamiento señalado es atribuido, como fue mencionado anteriormente, a los efectos opuestos de mayor porosidad de los AGR y mejor calidad de las interfaces AGR-mortero. Los hormigones HS45 y HRS45-75 alcanzan valores de capacidad de succión capilar del orden de $3060 \mathrm{~g} / \mathrm{m}^{2}$, mientras que para el HRS45-25 es de $2245 \mathrm{~g} / \mathrm{m}^{2}$.

Para la razón a/c 0,65 se observa un comportamiento semejante al descripto anteriormente, con mayores capacidades de succión en los hormigones con $75 \%$ de AGR y similares capacidades entre los elaborados con $25 \%$ de AGR y los originales, aunque las diferencias entre estos últimos se reduce con relación a la mostrada para la razón a/c 0,45.

En las Figuras 6.5 y 6.6 se presentan las velocidades de succión capilar obtenidas para los hormigones reciclados, comparativamente a la de los hormigones originales, para las razones a/c 0,45 y 0,65, respectivamente. En ambas figuras se observa un comportamiento diferente entre los hormigones elaborados con los AGN de trituración y los de canto rodado silíceo. En el caso de los primeros se produce un aumento de la velocidad de succión al aumentar el porcentaje de AGR utilizado, hecho que se encuentra relacionado con la mayor porosidad de los AGR, debido al mortero adherido. Para los hormigones con canto rodado se observa una disminución de la velocidad en los elaborados con $25 \%$ de AGR, presentando los hormigones con $75 \%$ de AGR velocidades de succión similares a las de los hormigones originales. En este caso, el comportamiento observado puede ser atribuido a la acción conjunta de dos efectos opuestos, la mayor porosidad de los AGR, que ocasiona una mayor absorción capilar, y una mejora en la calidad de las interfaces AGR-mortero, respecto a las producidas en los agregados naturales, debido a una reducción de la razón a/c efectiva y al cambio de forma y textura superficial de los agregados.

Además, en la Figura 6.5 se puede observar que los hormigones elaborados con los agregados de granito, basalto y canto rodado presentan velocidades de succión inferiores al límite de $4 \mathrm{~g} / \mathrm{m}^{2} / \mathrm{s}^{1 / 2}$, establecido en el Proyecto de Reglamento CIRSOC 201:2005 como condición para un hormigón durable, aún en los que contienen 75 \% de AGR. En el caso de los hormigones reciclados de cuarcita, presentan velocidades de succión superiores a dicho límite, para los dos porcentajes de reemplazo utilizados. Este hecho debe ser atribuido, en parte, al mayor contenido de mortero que posee el agregado RQ45 con relación a los restantes agregados reciclados (ver Figura 4.13), y a las características propias de la cuarcita, ya que el hormigón original elaborado con dicho AGN presenta mayor velocidad 
de succión que los producidos con otros agregados naturales de trituración, e incluso mayor que la de los hormigones con $25 \%$ de los AGR de granito, basalto y canto rodado.

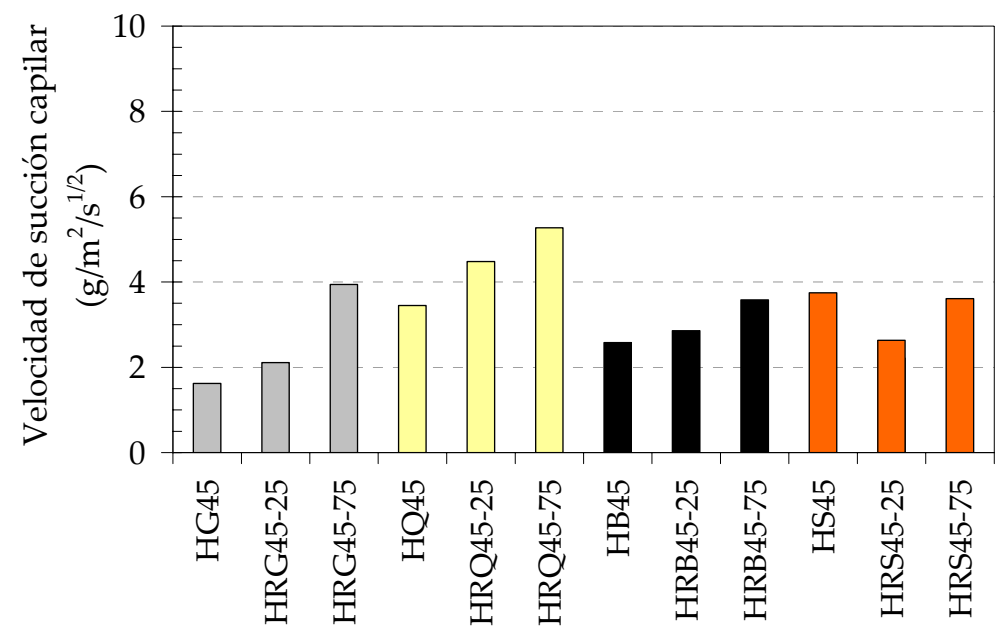

Figura 6.5. Velocidad de succión capilar en hormigones de razón a/c 0,45.

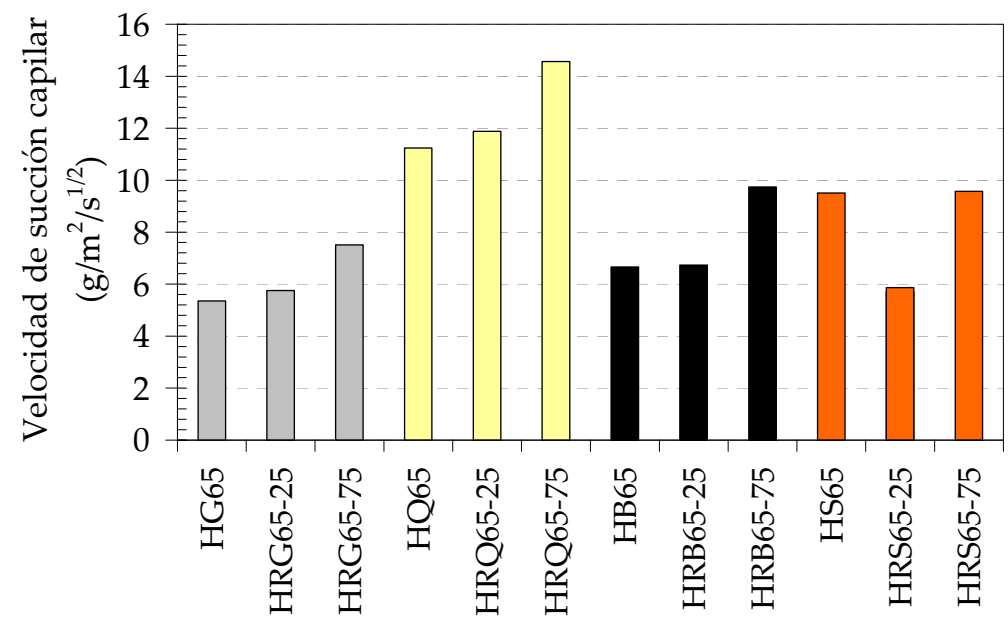

Figura 6.6. Velocidad de succión capilar en hormigones de razón a/c 0,65.

Para la razón a/c 0,65 (Figura 6.6) todos los hormigones presentan velocidades de succión capilar superiores al límite mencionado anteriormente. Además, para este nivel resistente, se observa también que los hormigones con cuarcita presentan las mayores velocidades de succión, debido al mayor contenido de mortero del agregado RQ65 respecto a los otros agregados reciclados (ver Figura 4.13) y a las características propias del agregado natural Q, pudiéndose observar que los hormigones con 25 y $75 \%$ de AGR de granito, basalto y canto rodado silíceo presentan velocidades de succión inferiores a la del hormigón original de cuarcita. 


\subsubsection{Penetración de agua a presión}

Como fue mencionado en el Capítulo 3, el ensayo de penetración de agua a presión permite evaluar la permeabilidad del hormigón como consecuencia de una diferencia de presiones, variable en el tiempo, entre la aplicada en la superficie del material y la existente en el interior de la estructura de poros del hormigón. Como resultado del ensayo se obtiene un valor medio de la profundidad alcanzada por el agua, aunque resulta también importante conocer la variación de dicha profundidad a lo largo de la sección involucrada en el ensayo, lo que se conoce como perfil de penetración de agua. Este perfil nos proporcionará una mayor idea de la homogeneidad del material.

En las Figuras 6.7 y 6.8 se presentan de modo comparativo las penetraciones medias de los hormigones de razón a/c 0,45 y 0,65, respectivamente, agrupándolos según el tipo de AGN que contienen y el porcentaje de AGR utilizado.

En la Figura 6.7 se observa que el empleo de bajas razones a/c permite obtener hormigones con penetraciones medias inferiores a $30 \mathrm{~mm}$, aún los que contienen $75 \%$ de AGR, siendo dicho valor el límite máximo establecido en el Proyecto de Reglamento CIRSOC 201:2005 como requerimiento de durabilidad. Para los hormigones con granito (G) y basalto (B), los valores de penetración media se incrementan al hacerlo también el porcentaje de AGR, mientras que para los elaborados con cuarcita (Q) y canto rodado silíceo (S) las penetraciones de los hormigones reciclados resultan similares o inferiores a las del respectivo hormigón original, aún para aquellos con $75 \%$ de AGR.

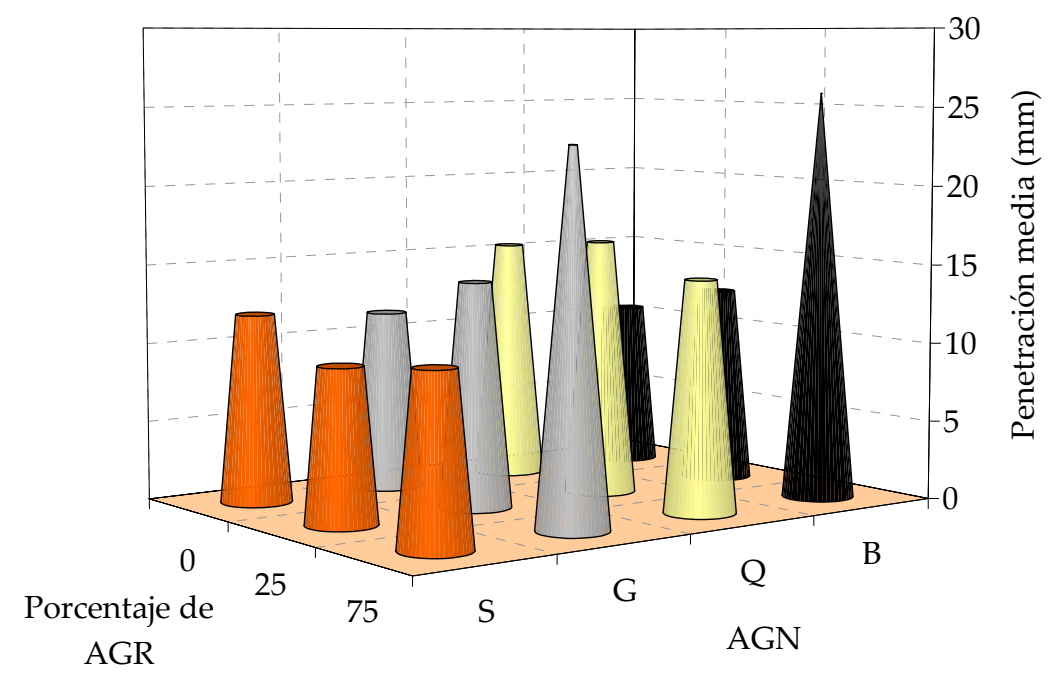

Figura 6.7. Penetración media de agua en hormigones de razón a/c 0,45. 


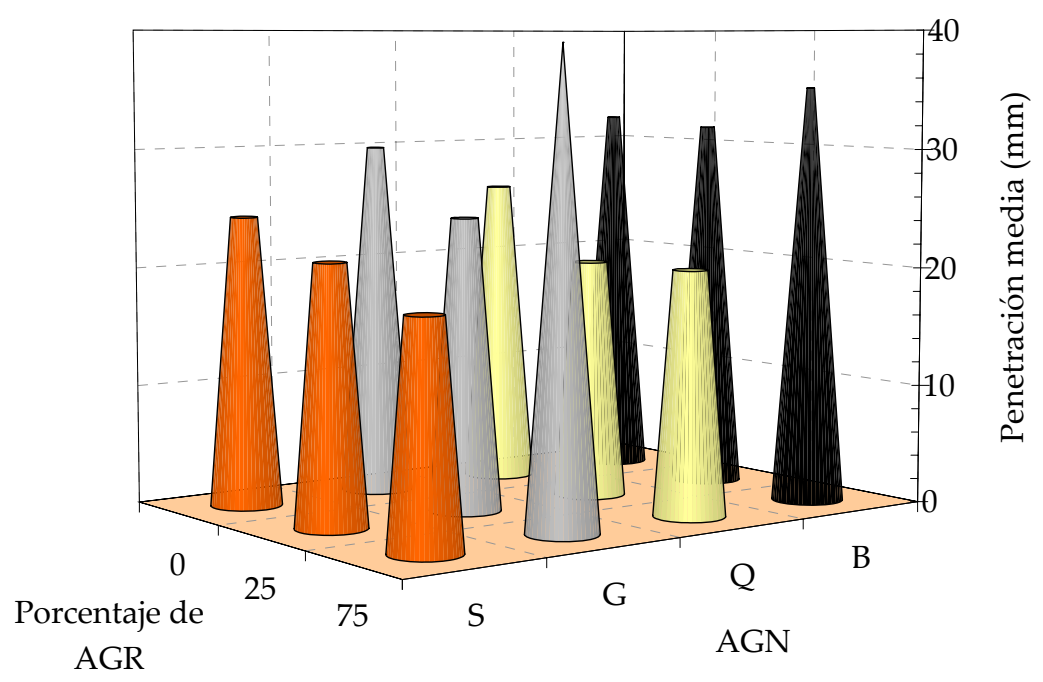

Figura 6.8. Penetración media de agua en hormigones de razón a/c 0,65.

Para la razón a/c 0,45, en los hormigones con $25 \%$ de AGR los valores de Pmed se encuentran en el rango 10-16 mm, los cuales resultan similares a los obtenidos en los respectivos hormigones originales $(11-16 \mathrm{~mm})$, hecho que debe atribuirse a una menor razón a/c efectiva en los hormigones reciclados y al bajo porcentaje de AGR utilizado. En los hormigones con $75 \%$ de AGR, cuyos valores de Pmed se encuentran en el rango 11-26 mm, si bien presentarían una menor razón a/c efectiva que los elaborados con $25 \%$ de AGR, hecho que mejoraría la calidad de las interfaces, el mayor contenido de agregado reciclado adquiere mayor importancia sobre la penetración de agua. Para los agregados naturales de baja porosidad ( $\mathrm{G}$ y B) la presencia de los agregados reciclados conduce a un aumento de la penetración de agua, debido a un aumento en la porosidad del agregado. En el caso de los agregados de cuarcita y canto rodado, el mejor comportamiento que presentan los hormigones reciclados puede atribuirse a la acción conjunta de la reducción de la razón a/c efectiva y la mejor calidad de las interfaces entre el agregado RS45 y el nuevo mortero.

Con relación a los hormigones de razón a/c 0,65 (Figura 6.8), puede observarse que no todos los hormigones cumplen con el límite anteriormente mencionado de $30 \mathrm{~mm}$, aunque ello constituye un hecho esperable teniendo en cuenta la elevada porosidad de su matriz, razón por la cual dicha razón a/c no es admitida por el CIRSOC 201:2005 para hormigones con requerimientos durables. Asimismo, el comportamiento que presentan los hormigones reciclados respecto a los originales resulta semejante al descripto para la razón a/c 0,45. En los hormigones con granito y basalto se observa un incremento de los valores de penetración media de agua a presión al aumentar el porcentaje de AGR utilizado. Por el contrario, en los hormigones con cuarcita y canto rodado silíceo se observa una disminución de la penetración de agua en los hormigones reciclados con relación a 
los originales, hecho que debe ser atribuido también a la menor razón a/c efectiva, la mejor calidad de la zona de interfaz AGR-mortero y a la modificación de las características de los agregados reciclados respecto a los naturales.

\subsubsection{Difusión de cloruro}

Como fuera indicado en el Capítulo 3, el ensayo de difusión de cloruro permite evaluar la resistencia del hormigón a la penetración de cloruro a partir de someter a las probetas en una solución de cloruro de sodio con una concentración del $3 \%$, durante un intervalo de tiempo determinado. Como resultado del ensayo se obtiene el perfil de cloruro, representando en ordenadas el contenido de cloruro $\left(\mathrm{Cl}^{-}\right)$, expresado en porcentaje del peso de hormigón, y en abscisas la profundidad a la cual se realizó la determinación, y el coeficiente de difusión ( $\mathrm{Dap}_{\mathrm{p}}$ ).

En cada una de las Figuras 6.9 y 6.10 se presentan los perfiles de contenido de cloruro soluble en agua y soluble en ácido determinados, a la edad de 140 días, en los hormigones de razón a/c 0,45 y 0,65, respectivamente. En cada una de ellas se representan los perfiles correspondientes al hormigón original y a los reciclados con 25 y $75 \%$ de AGR que contienen un mismo tipo de AGN. Debe recordarse, como se indicara en el Capítulo 3, que los contenidos de cloruro soluble en agua y los de soluble en ácido fueron obtenidos a partir del mismo preparado para cada hormigón.

Se debe mencionar que los perfiles de contenido de cloruro obtenidos para cada hormigón resultaron de la evaluación de una muestra de cada uno de ellos. Este hecho, sumado a la dispersión propia del método empleado para realizar las titulaciones, hace dificultoso analizar comparativamente el comportamiento de los hormigones reciclados respecto a los elaborados con AGN. Sin embargo, para cada tipo de AGN empleado, se puede observar que los perfiles de cloruro soluble en ácido resultan algo más elevados que los de cloruro soluble en agua. Éste constituye un hecho esperable debido a que la disolución en ácido involucra al total de cloruros ingresados al hormigón, mientras que la disolución en agua incluye a los que se encuentran en la solución de poros.

De la observación de las Figuras 6.9 y 6.10 surge que los perfiles de cloruro obtenidos en todos los casos se ajustan con una alta correlación a la solución de la segunda Ley de Fick, la cual fue mostrada en la ecuación 3.1. Además, las determinaciones realizadas de perfiles alcanzan para todos los hormigones contenidos de cloruro nulos. 
Perfiles de cloruro soluble en agua

Perfiles de cloruro soluble en ácido
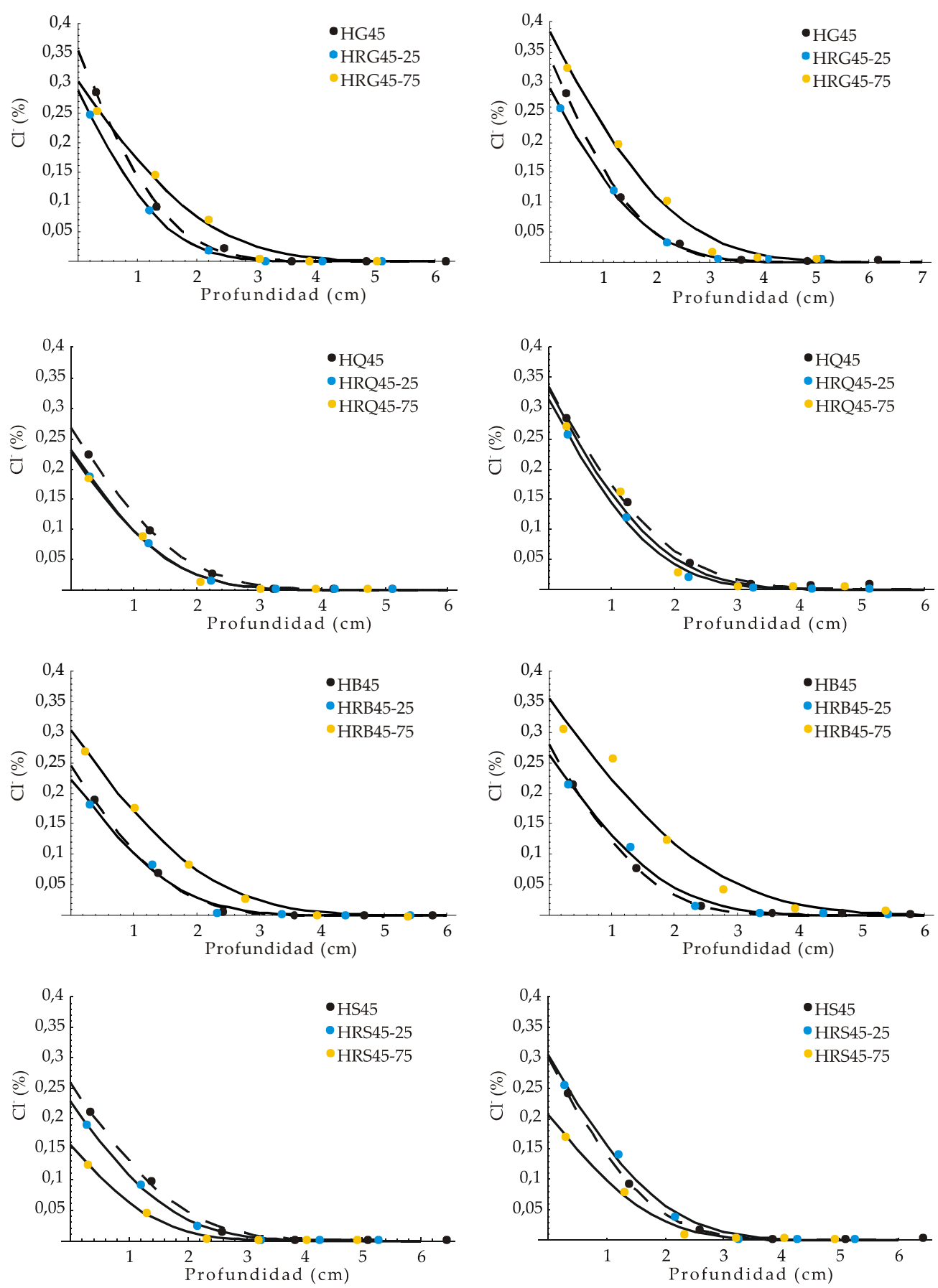

Figura 6.9. Perfiles de cloruro en hormigones de razón a/c 0,45. 
Perfiles de cloruro soluble en agua

Perfiles de cloruro soluble en ácido
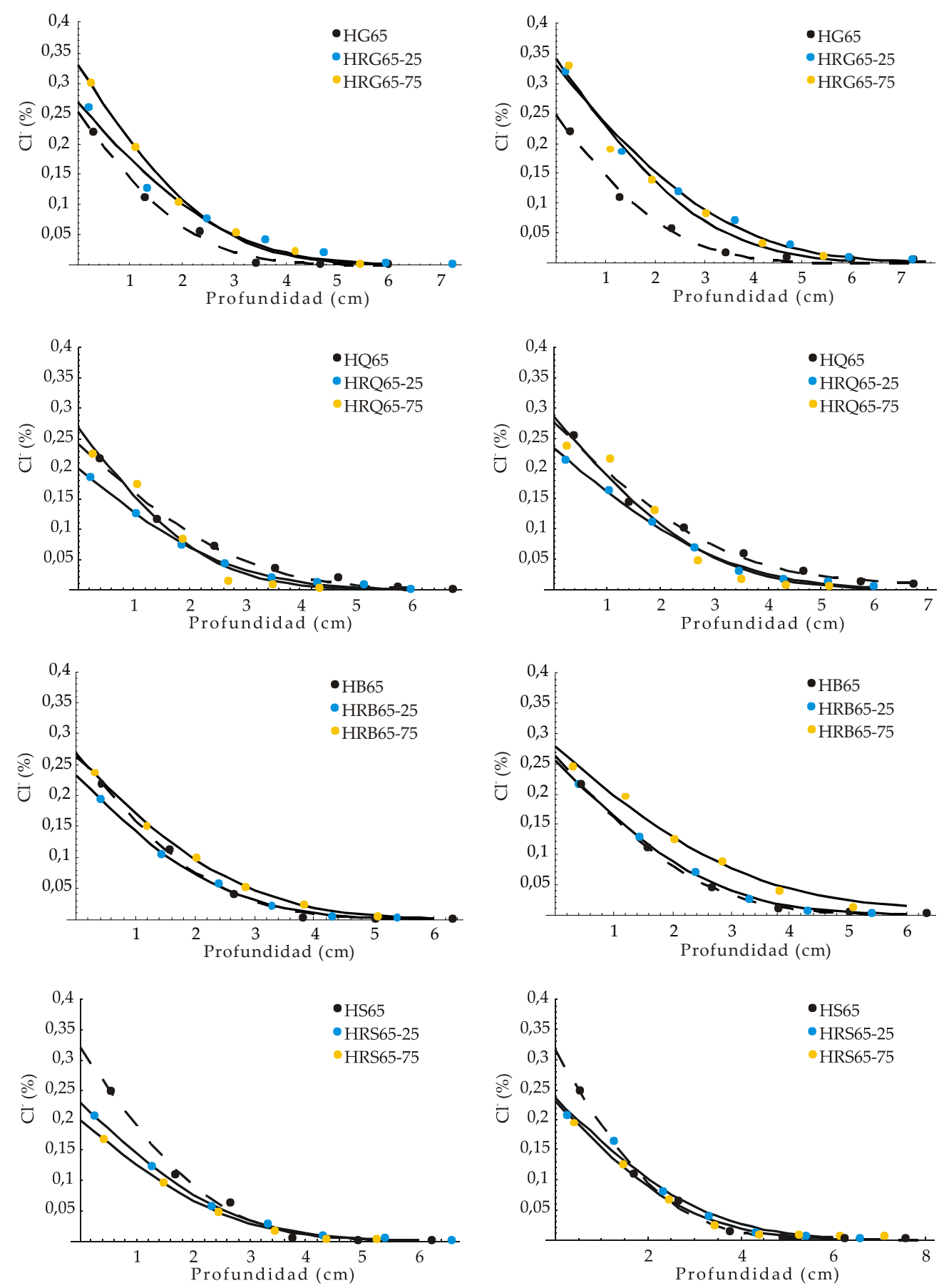

Figura 6.10. Perfiles de cloruro en hormigones de razón a/c 0,65.

A partir de los perfiles de cloruro determinados, los cuales fueron presentados en las figuras 6.9 y 6.10, y mediante la aplicación de la solución a la segunda Ley de Fick (ecuación 3.1), fue posible obtener los coeficientes de difusión aparente ( $\mathrm{D}_{a p}$ ) de cloruro soluble en agua de los hormigones en estudio. En las Figuras 6.11 y 6.12 se presentan dichos coeficientes de difusión, a la edad de 140 días, para los hormigones de razón a/c 0,45 y 0,65 , respectivamente. 


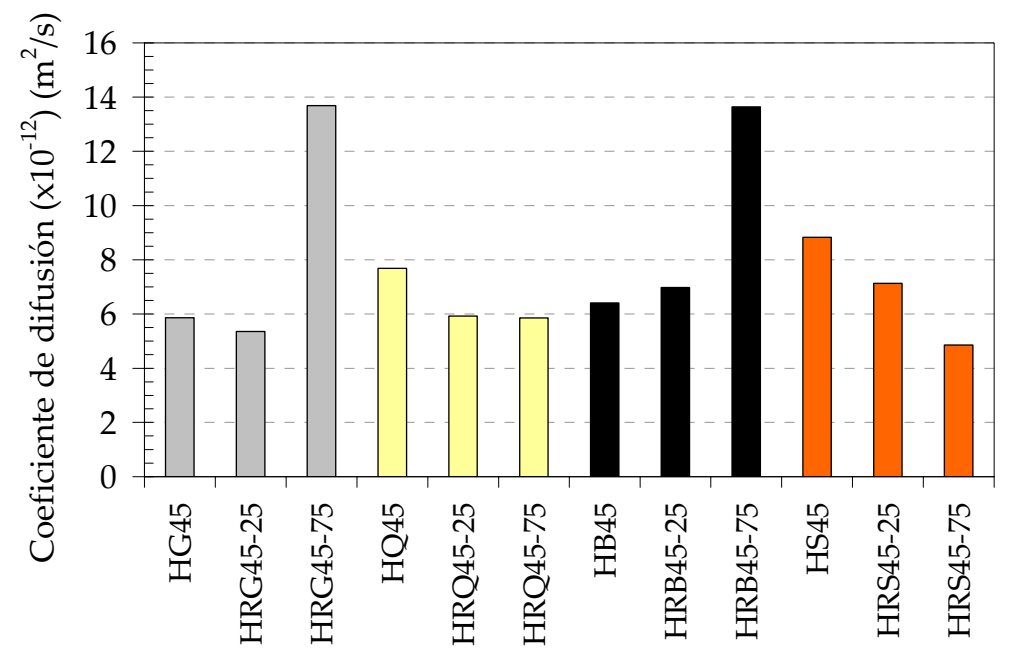

Figura 6.11. Coeficientes de difusión de cloruro soluble en agua de hormigones de razón a/c 0,45.

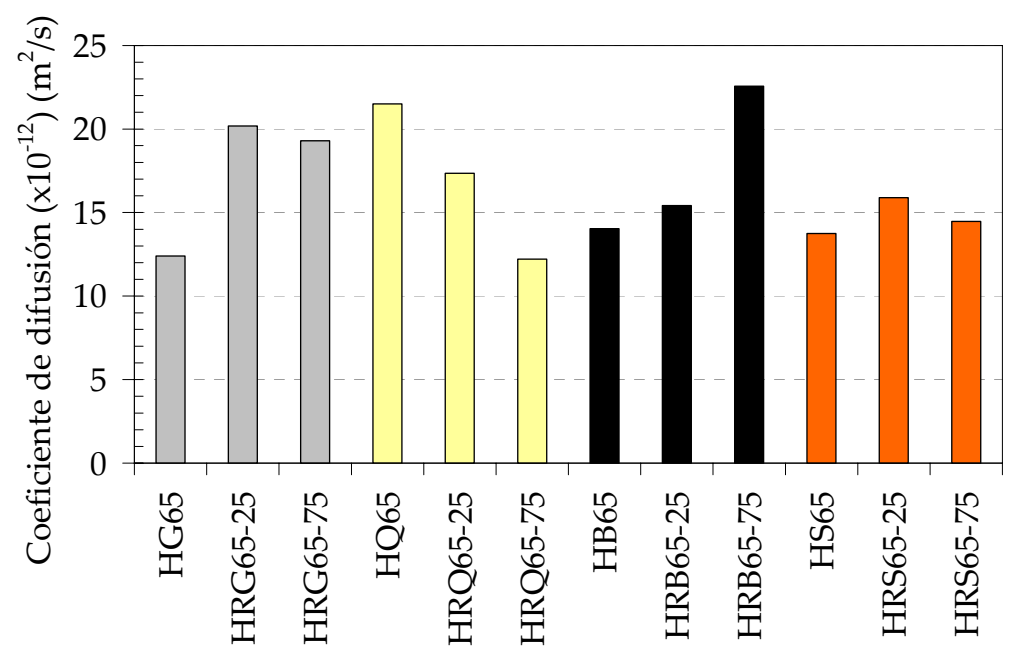

Figura 6.12. Coeficientes de difusión de cloruro soluble en agua de hormigones de razón a/c 0,65.

Para la razón a/c 0,45 se puede observar que la mayoría de los hormigones presentan coeficientes de difusión inferiores a $10 \times 10^{-12} \mathrm{~m}^{2} / \mathrm{s}$, a excepción de los elaborados con $75 \%$ de AGR de granito y basalto, cuyos $\mathrm{D}_{\text {ap }}$ resultaron del orden del doble de los correspondientes al resto de los hormigones. Este último hecho puede ser atribuido a la mayor porosidad de los AGR respecto a los naturales y al elevado porcentaje de reemplazo de dichos hormigones.

En la Figura 6.11 se evidencia también que los hormigones con agregados de cuarcita, natural y reciclado, presentan similares coeficientes de difusión entre sí, mientras que en los de canto rodado dicho coeficiente Dap muestra una tendencia en disminución al incrementarse el porcentaje de AGR utilizado. El comportamiento que presentan estos 
hormigones debe ser atribuido a una menor razón a/c efectiva, sumado a una mayor capacidad de retención de cloruro de los hormigones reciclados de cuarcita, debido al mayor contenido de mortero de los agregados $R Q$, y a la modificación en la forma y textura superficial de las partículas de los agregados reciclados de canto rodado respecto al natural, hecho que contribuye a mejorar la calidad de las interfaces.

Para los hormigones de razón a/c 0,65 (Figura 6.12), los coeficientes de difusión (Dap) resultan en todos los casos superiores a $10 \times 10^{-12} \mathrm{~m}^{2} / \mathrm{s}$, independientemente del tipo de AGN y el porcentaje de AGR empleados, hecho que manifiesta que la resistencia del hormigón a la penetración de cloruro se encuentra asociada a la calidad de la matriz, y no así al tipo de agregado grueso empleado. En el caso puntual de los hormigones con cuarcita, se evidencia una disminución del coeficiente $\mathrm{D}_{\mathrm{ap}}$ al incrementarse el porcentaje de AGR utilizado, debido a las mismas causas mencionadas en el caso de la razón a/c 0,45.

De los coeficientes $D_{a p}$ indicados en la bibliografía [Frederiksen et al, 1997; Villagrán et al, 2006], los cuales fueron obtenidos mediante la misma metodología utilizada en el presente trabajo, surge que valores del Dap de hasta $10 \times 10^{-12} \mathrm{~m}^{2} / \mathrm{s}$ se corresponden con hormigones de razón a/c inferiores a 0,45. Cabe recordar que dicha razón a/c es la máxima permitida por el Reglamento CIRSOC 201:2005 para hormigones con requisitos de durabilidad. Por lo tanto, considerando lo mencionado anteriormente, es de esperar que hormigones cuyos valores del $D_{a p}$ se encuentren por debajo del valor indicado presenten un adecuado comportamiento durable en ambientes con cloruro. Los valores obtenidos para los hormigones HRG45-75 y HRB45-75 se corresponden, de acuerdo con la bibliografía citada, con hormigones de razón a/c 0,55.

En las Figuras 6.13 y 6.14 se relacionan los contenidos de cloruro soluble en agua con los de cloruro retenido (obtenidos por diferencia con los contenidos de cloruro soluble en ácido) para los hormigones de razón a/c 0,45 y 0,65, respectivamente. A partir de dicha relación es posible determinar, de manera comparativa, la capacidad de retención de cloruro de cada hormigón. En cada figura se presentan los hormigones original y reciclados elaborados con un mismo tipo de AGN. Si bien la cantidad de determinaciones realizadas es insuficiente como para establecer una correlación, en dichas figuras se incluyen las líneas de tendencia, las cuales permiten comprender en mejor medida el comportamiento que presenta cada hormigón. 

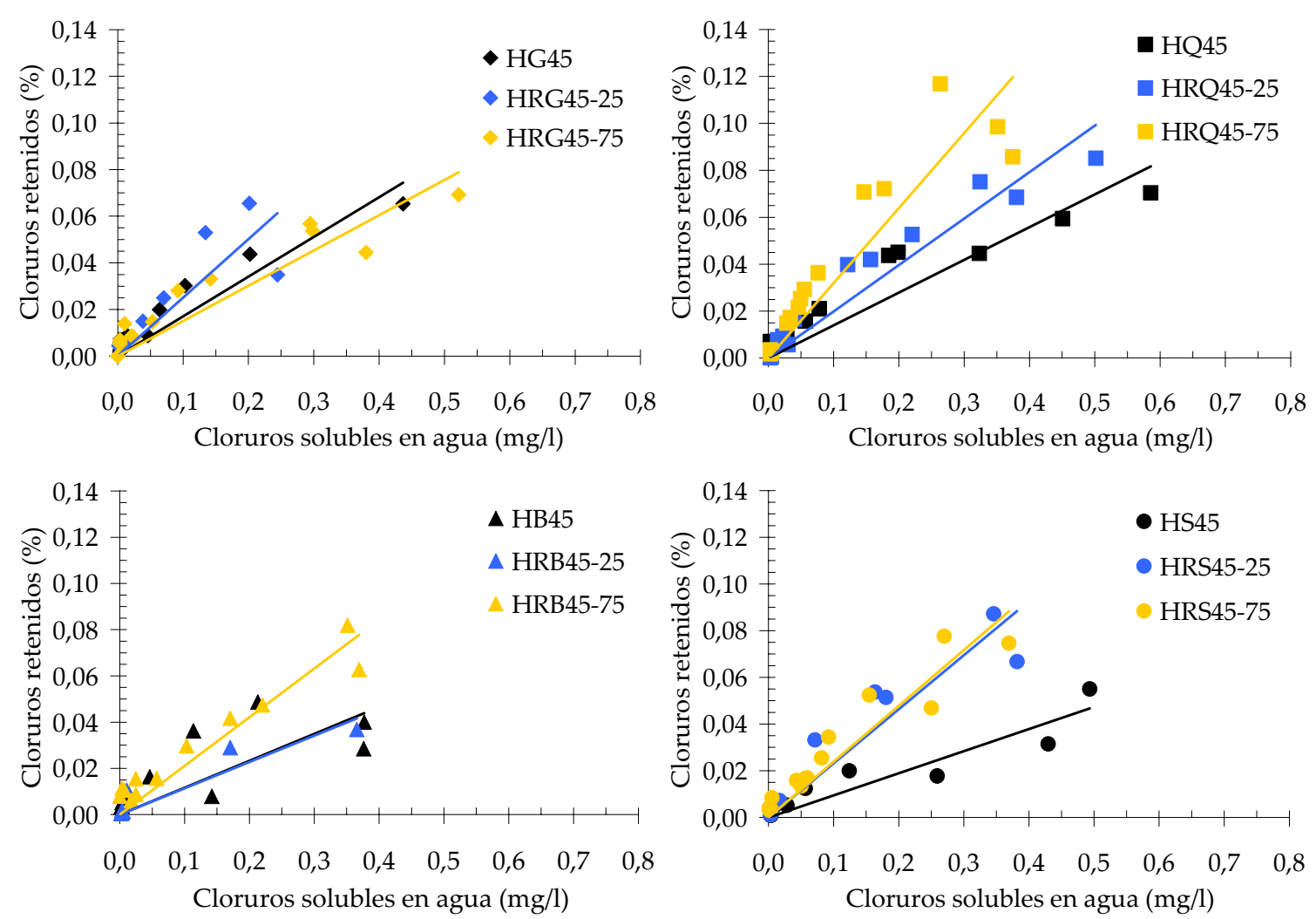

Figura 6.13. Relación cloruro soluble en agua - cloruro retenido

para hormigones de razón a/c 0,45.
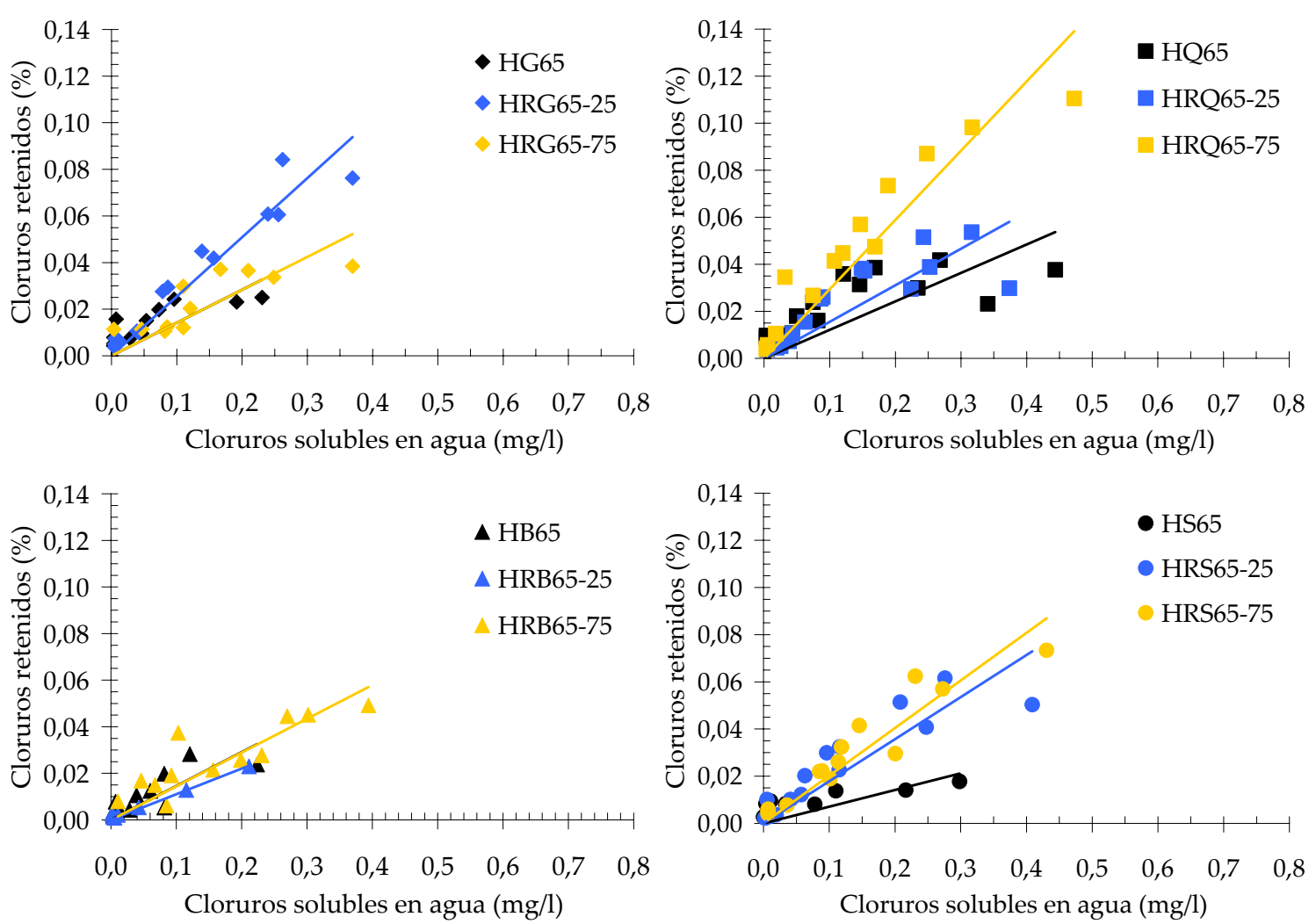

Figura 6.14. Relación cloruro soluble en agua - cloruro retenido

para hormigones de razón a/c 0,65. 
Para ambas razones a/c evaluadas, se observa que los hormigones con AGR de cuarcita y de canto rodado presentan una mayor capacidad de retención de cloruros, hecho que debe ser atribuido al mayor contenido de productos de hidratación de cemento que poseen los hormigones reciclados. Dicha capacidad se ve favorecida, en el caso de los hormigones con cuarcita por el mayor contenido unitario de cemento que presentaron dichos hormigones, y en el caso de los elaborados con canto rodado silíceo por la mejora en la calidad de las interfaces debido a la modificación en la forma y textura superficial de las partículas de agregados.

Con el fin de determinar si la mayor capacidad de retención que presentan los hormigones reciclados resulta independiente del tipo de AGN que contienen, en la Figura 6.15 se relacionan los contenidos de cloruro soluble en agua con los de cloruro retenido para los hormigones de razón a/c 0,45, agrupando los resultados según el porcentaje de AGR utilizado, independientemente del tipo de AGN de los mismos.

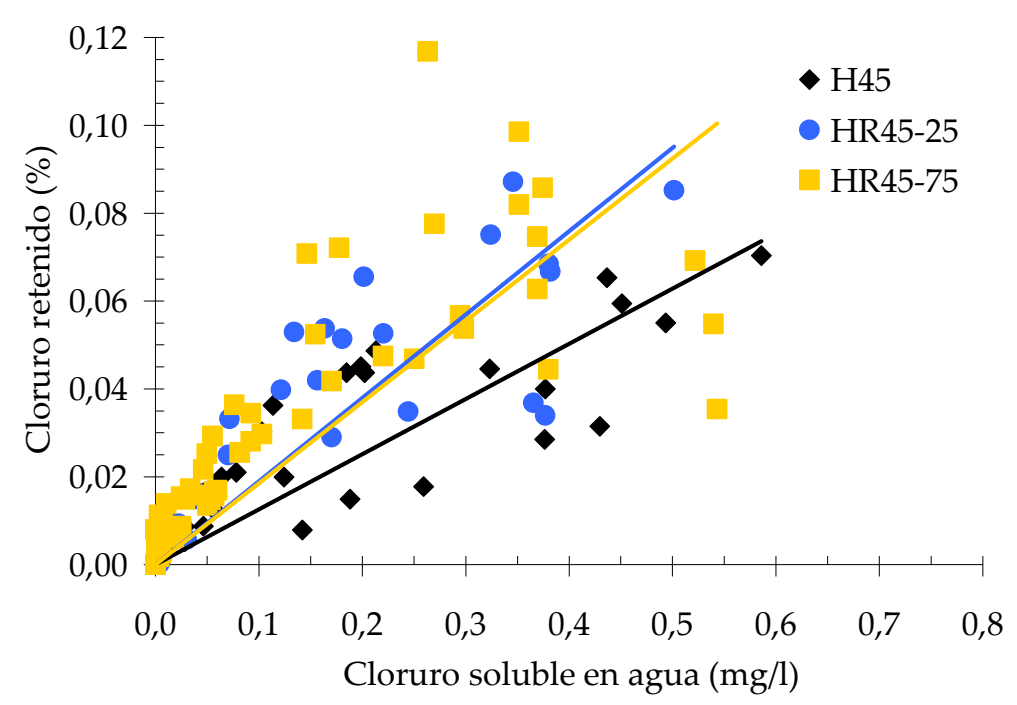

Figura 6.15. Relación cloruro soluble en agua - cloruro retenido en función del contenido de AGR, en hormigones de razón a/c 0,45.

En la Figura 6.15 puede observarse, a partir de las líneas de tendencia, que la correspondiente a los hormigones reciclados presenta una mayor pendiente que la de los hormigones con AGN, hecho que está indicando una mayor capacidad de retención de cloruro por parte de los hormigones reciclados, debido, como fue mencionado anteriormente, al mayor contenido de productos de hidratación del cemento; sin embargo, no se produce una diferenciación entre los elaborados con 25 y 75 \% de AGR. Este comportamiento debe ser atribuido a una mayor dispersión de los resultados correspondientes a los 
hormigones con $75 \%$ de AGR, hecho que se relaciona con los diferentes tipos de AGN que contienen, como se muestra a continuación.

En la Figura 6.16 se presenta nuevamente la relación entre los contenidos de cloruro soluble en agua y los de cloruro retenido para los hormigones de razón a/c 0,45, agrupando en este caso los resultados en función del tipo de AGN que contienen, independientemente del porcentaje de AGR empleado (0, 25 y $75 \%$ ). Puede observarse que los elaborados con los agregados de cuarcita presentan una mayor capacidad de retención de cloruro, evidenciado por la mayor pendiente de la línea de tendencia. Este hecho, sumado al mostrado en la Figura 6.15, permiten verificar lo mencionado anteriormente respecto a la mayor capacidad de retención de cloruro de los hormigones reciclados al aumentar el contenido de AGR, siendo este comportamiento más importante en el caso de los hormigones con cuarcita.

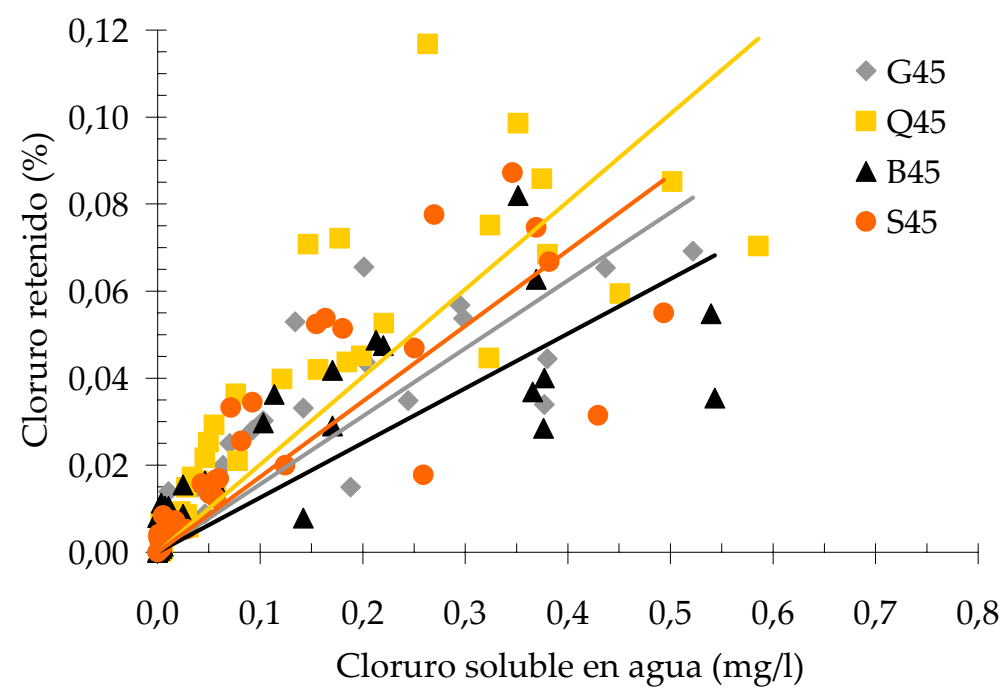

Figura 6.16. Relación cloruro soluble en agua - cloruro retenido en función del tipo de AGN, en hormigones de razón a/c 0,45.

La relación entre los contenidos de cloruro soluble en agua y los de cloruro retenido para los hormigones de razón a/c 0,65, se presenta en la Figura 6.17, agrupando los resultados según el porcentaje de AGR utilizado, y en la Figura 6.18 se hace lo propio a partir de considerar el tipo de AGN que contienen.

En las Figuras 6.17 y 6.18 se puede observar que el comportamiento que presentan los hormigones de razón a/c 0,65 es semejante al de los hormigones de razón a/c 0,45, evidenciándose una mayor capacidad de retención en los hormigones reciclados, principal- 
mente en aquellos que contienen AGN de cuarcita y canto rodado silíceo. Este hecho es atribuido a las mismas causas mencionadas para la razón a/c 0,45.

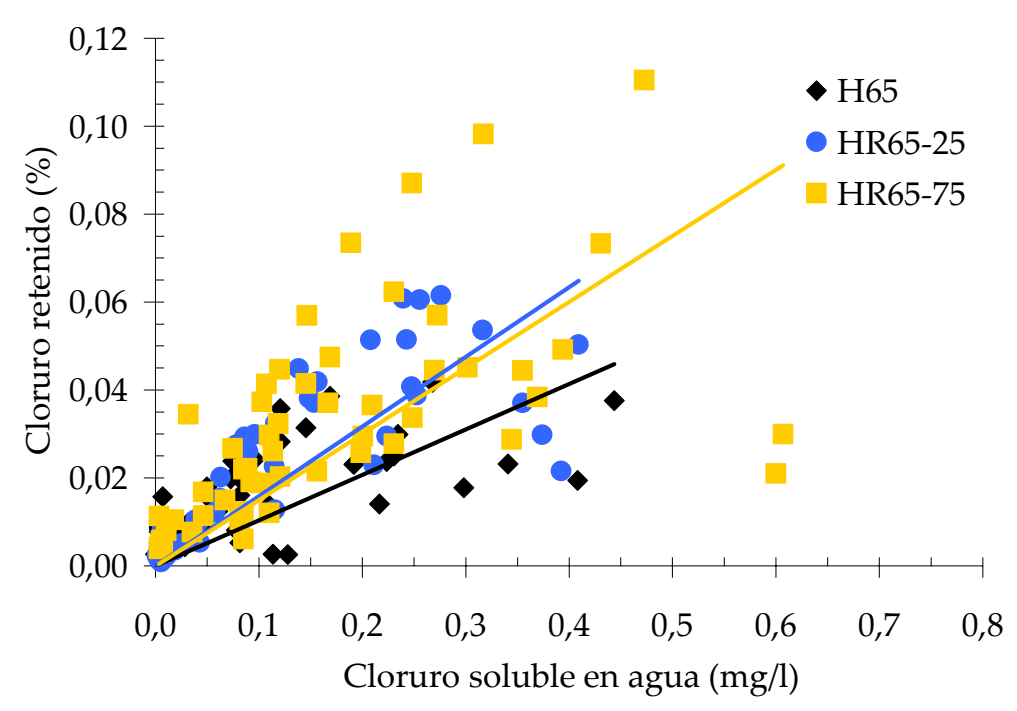

Figura 6.17. Relación cloruro soluble en agua - cloruro retenido en función del contenido de AGR, en hormigones de razón a/c 0,65.

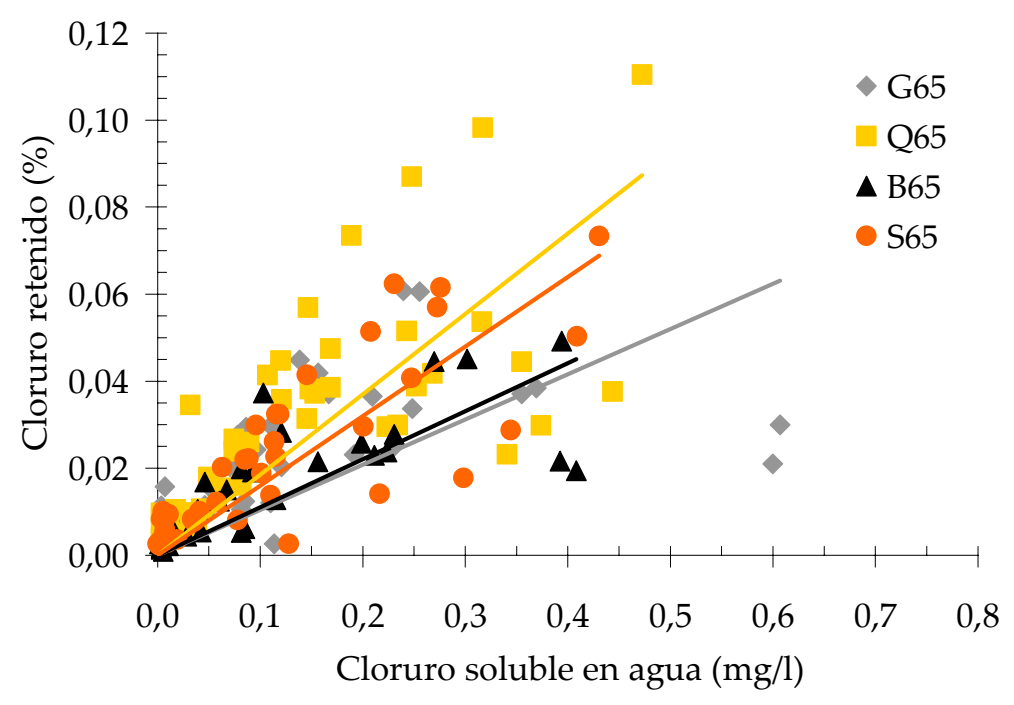

Figura 6.18. Relación cloruro soluble en agua - cloruro retenido en función del tipo de AGN, en hormigones de razón a/c 0,65.

\subsection{Relaciones entre la absorción de agua de los agregados y parámetros durables}

Con el fin de analizar la influencia relativa de la razón a/c y el tipo de AGN de los hormigones sobre los diferentes parámetros durables evaluados, a continuación se plantean relaciones entre cada uno de ellos y la absorción de agua del conjunto granular AGNAGR, según las proporciones en que se emplearon para la elaboración de los hormigones. 
En la Figura 6.19 se relaciona la absorción de agua del AGN-AGR con la velocidad de succión capilar $\left(\mathrm{V}_{\mathrm{sc}}\right)$ de los hormigones. Además, para cada razón a/c, se muestran las líneas de tendencia, independientemente del tipo de AGN y el porcentaje de AGR empleado. Se puede observar que la razón a/c del hormigón constituye la variable de primer orden que modifica la velocidad $\mathrm{V}_{\text {sc, }}$ presentando los hormigones de razón a/c 0,65 velocidades superiores al límite de $4 \mathrm{~g} / \mathrm{m}^{2} / \mathrm{s}^{1 / 2}$ establecido en el Proyecto de Reglamento CIRSOC 201:2005, indicado en dicha figura en línea de trazos. También se observa un suave incremento de la velocidad $\mathrm{V}_{s c}$ al aumentar la absorción del conjunto AGN-AGR, el cual es más pronunciado en los hormigones de mayor razón a/c. En el caso de los hormigones de razón a/c 0,45, a pesar de la baja sensibilidad que presenta la velocidad $\mathrm{V}_{\text {sc }}$ al cambio en la absorción de los agregados, puede observarse que algunos cumplen con dicho límite mientras que otros presentan valores de velocidad $V_{s c}$ superiores, hecho que se verifica para absorciones de agua del conjunto AGN-AGR superiores al $3 \%$.

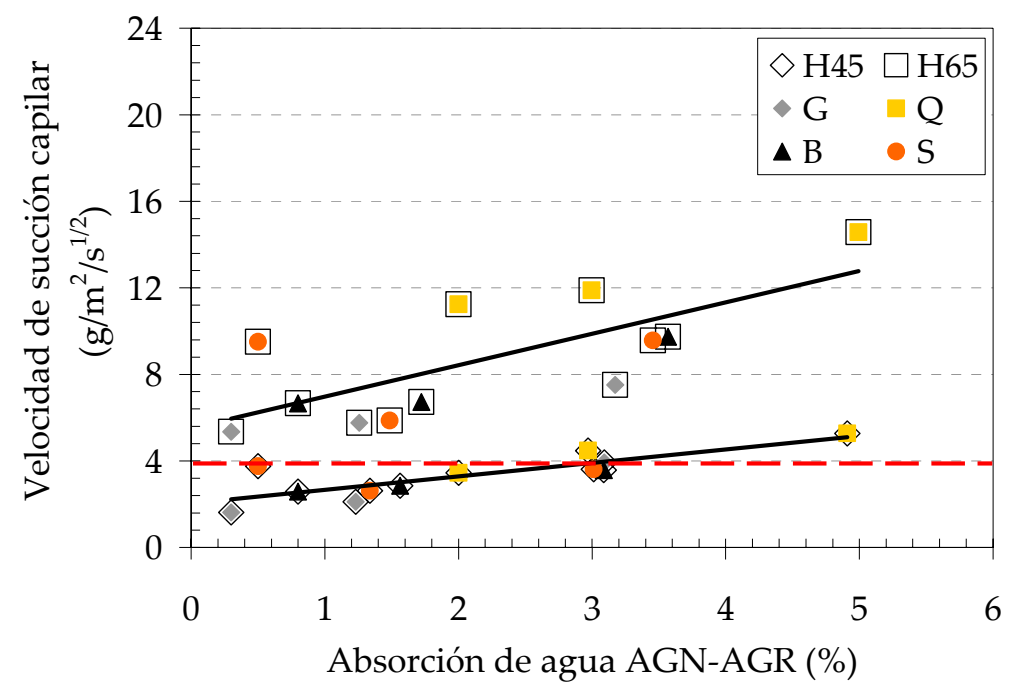

Figura 6.19. Relación entre la absorción de agua AGN-AGR y la velocidad de succión capilar.

A partir del comportamiento que presentan los hormigones mostrados en la Figura 6.19, surge que la absorción del AGN puede ser más importante que el porcentaje de AGR empleado en los valores de velocidad $V_{\text {sc. }}$ En dicha figura se puede observar que, por ejemplo, la absorción del AGN de cuarcita ( $2 \%$ ) es superior que la del conjunto granular compuesto por $25 \%$ de AGR y $75 \%$ de otro tipo de AGN (1,20 a 1,60\%). Por tal motivo, se podría limitar la absorción del conjunto AGN-AGR, según las proporciones de empleo, de modo de obtener hormigones con un adecuado comportamiento durable en el ensayo de succión capilar. Este hecho permitiría tener en cuenta de manera simultánea las calidades de ambos tipos de agregados gruesos. 
Si bien en el Reglamento CIRSOC 201:2005 no se indican valores máximos para la capacidad de succión capilar, al representar la misma en función de la absorción del conjunto AGN-AGR (Figura 6.20) puede observarse también una clara diferencia entre las dos razones a/c estudiadas. Al considerar la absorción máxima del $3 \%$ para el conjunto granular AGN-AGR, adoptada a partir de la Figura 6.19 como límite para la obtención de un hormigón durable, de la Figura 6.20 resulta una capacidad de succión con valores del orden de 3000 a $3500 \mathrm{~g} / \mathrm{m}^{2}$.

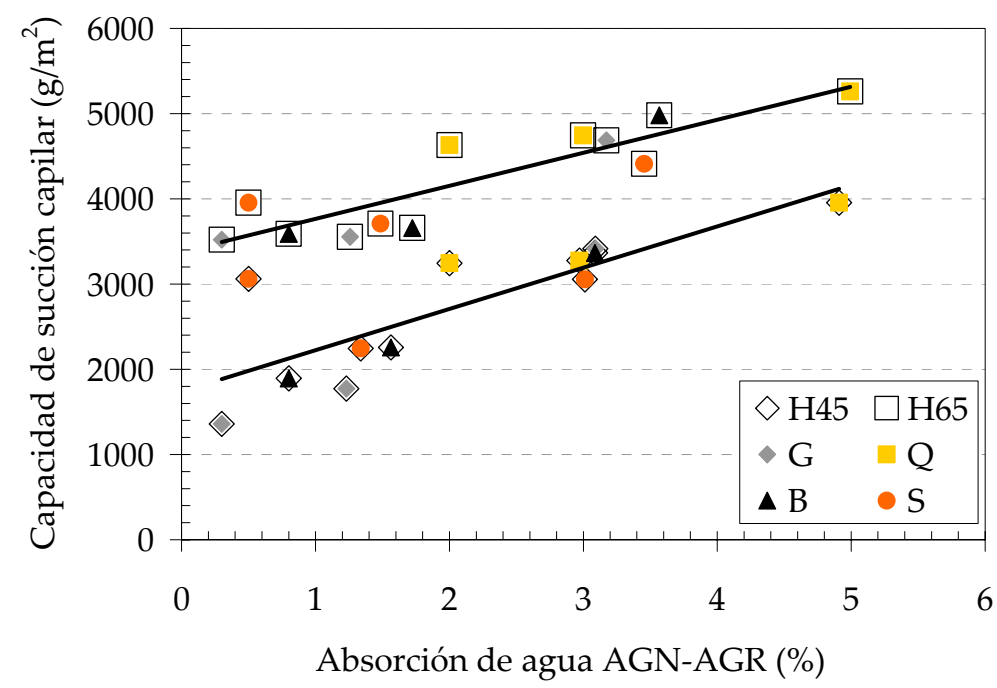

Figura 6.20. Relación entre la absorción de agua AGN-AGR y la capacidad de succión capilar.

En la Figura 6.21 se vincula la absorción de agua del conjunto granular AGN-AGR con los coeficientes de difusión aparente de cloruro soluble en agua de los correspondientes hormigones originales y reciclados. Se presentan también las líneas de tendencia para cada razón a/c, independientemente del tipo de AGN y el porcentaje de AGR empleado. Se puede observar, a diferencia de lo mostrado para la velocidad de succión capilar, que no hay una vinculación directa entre la absorción del agregado y el coeficiente de difusión. En este caso también se verifica que la razón a/c de la nueva matriz constituye la variable de primer orden que modifica el desempeño de los hormigones. 


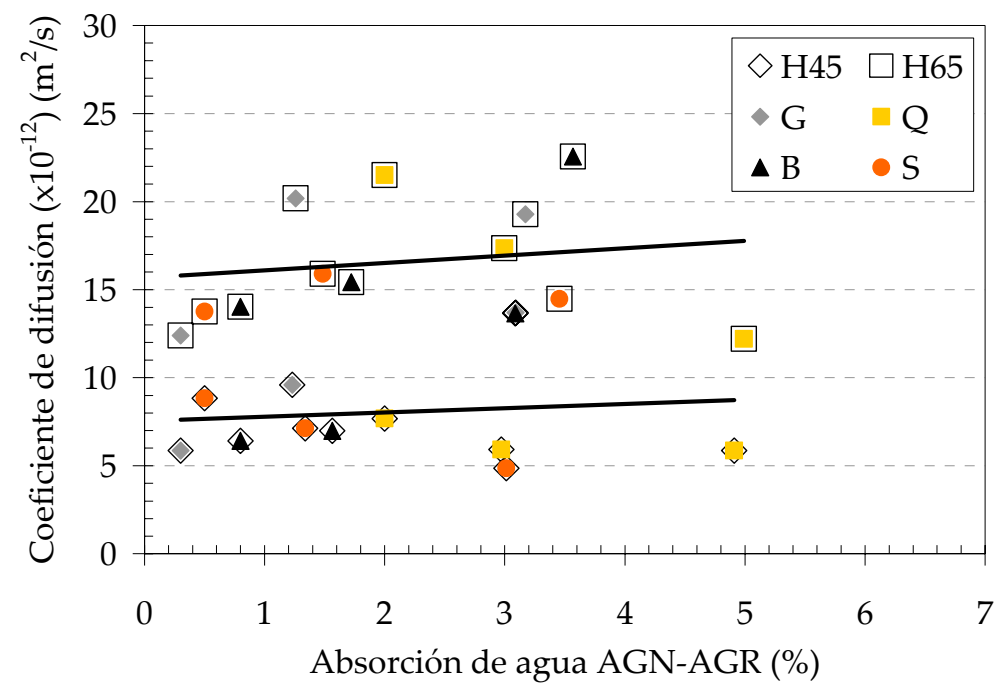

Figura 6.21. Relación entre la absorción de agua AGN-AGR y el coeficiente de difusión de cloruro soluble en agua.

En la Figura 6.22 se relacionan las absorciones del conjunto granular AGN-AGR con los valores de penetración media de agua a presión de los respectivos hormigones, presentándose también las líneas de tendencia para cada razón a/c. En este caso, también se diferencia el comportamiento de los hormigones según la razón a/c de la matriz, independientemente del tipo de AGN y el porcentaje de AGR empleado.

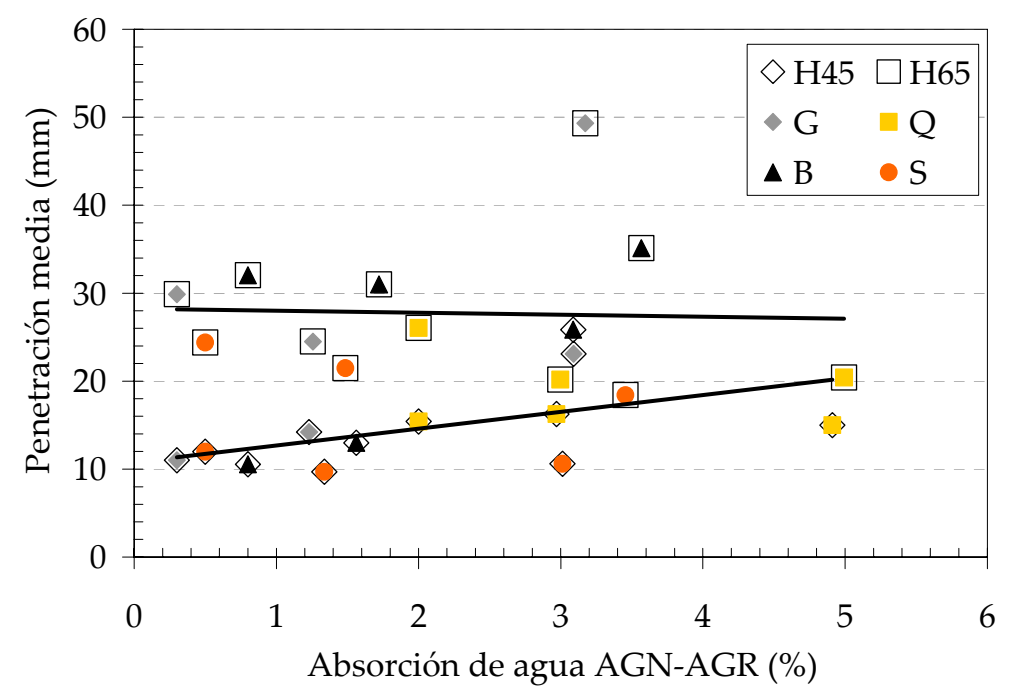

Figura 6.22. Relación entre la absorción de agua AGN-AGR y

la penetración media de agua a presión.

\subsection{Relaciones entre la resistencia a compresión y parámetros durables}

Dado que la caracterización del hormigón se realiza habitualmente a partir de la resistencia a compresión, la cual permite estimar a priori el comportamiento durable que 
puede tener el mismo, en el caso de los hormigones elaborados con distintos porcentajes de AGR, resulta importante vincular su nivel de resistencia con los parámetros durables evaluados.

En la Figura 6.23 se relaciona la resistencia a compresión $\left(f_{c}^{\prime}\right)$ con la velocidad de succión capilar $\left(\mathrm{V}_{\mathrm{sc}}\right)$ de los diferentes hormigones en estudio. Puede observarse que en el caso de los hormigones reciclados se cumple también que para una mayor resistencia del hormigón se produce una mejora en su comportamiento durable, asociado en este caso con una menor velocidad $\mathrm{V}_{\text {sc. }}$ Para resistencias superiores a $35 \mathrm{MPa}$ las velocidades $\mathrm{V}_{\mathrm{sc}}$ varían en el rango $1,6-5,3 \mathrm{~g} / \mathrm{m}^{2} / \mathrm{s}^{1 / 2}$, mientras que para resistencia por debajo de la mencionada las velocidades presentan una mayor variación, ubicándose en el rango 5,4 $14,6 \mathrm{~g} / \mathrm{m}^{2} / \mathrm{s}^{1 / 2}$, debido a las características de cada AGN y al porcentaje de AGR empleado.

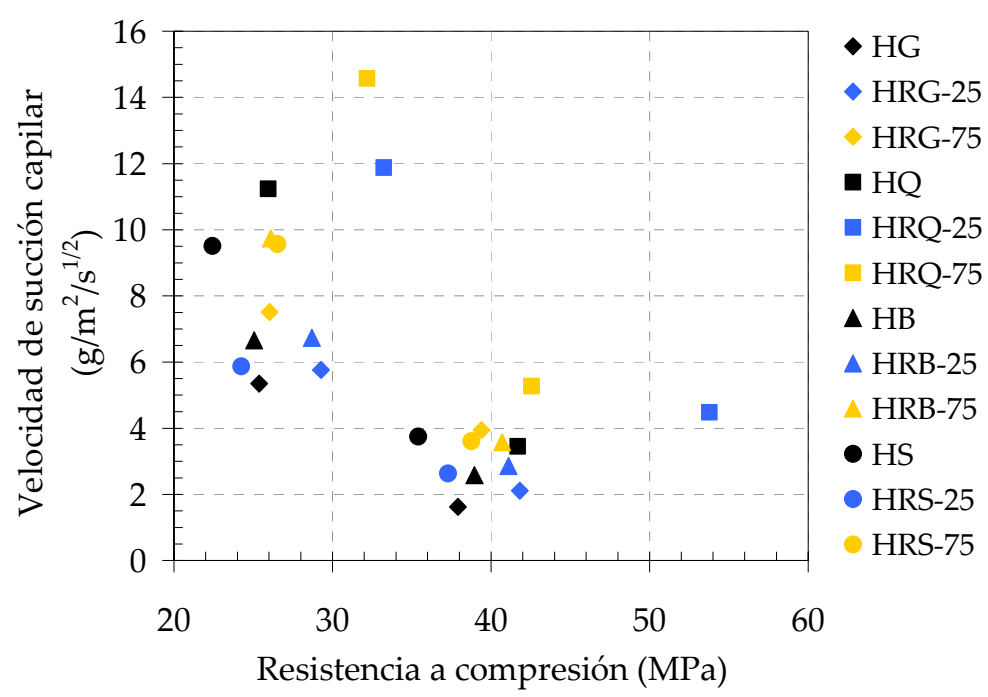

Figura 6.23. Relación entre la resistencia a compresión y la velocidad de succión capilar.

En los hormigones HG, a medida que se incrementa la resistencia a compresión, la velocidad de succión capilar decrece un $70 \%$, mientras que en los hormigones HRG dicha disminución alcanza valores del 63 y $48 \%$ en los elaborados con 25 y 75 \% de AGR, respectivamente. En los hormigones HQ la disminución de velocidad es del 69 \% mientras que en los HRQ es del 62 y $64 \%$. Los hormigones HB, HS, HRB y HRS presentan entre ellos un comportamiento similar, habiéndose determinado disminuciones de la velocidad de succión del orden del 60 \% a medida que se incrementa la resistencia a compresión.

De la Figura 6.23 surge también que el tipo AGN tiene mayor influencia que el porcentaje de AGR empleado sobre la velocidad de succión capilar. Considerando los 
hormigones con nivel resistente superior a $35 \mathrm{MPa}$, se puede observar que los elaborados con AGR de cuarcita presentan velocidades $V_{\text {sc }}$ superiores a $4 \mathrm{~g} / \mathrm{m}^{2} / \mathrm{s}^{1 / 2}$, las cuales superan además a las del resto de los hormigones, a pesar que su resistencia a compresión resulta también mayor. Para los hormigones con resistencias inferiores a $35 \mathrm{MPa}$ se verifica el mismo comportamiento, presentando los hormigones HQ y HRQ velocidades superiores a las del resto de los hormigones.

Si se relaciona la resistencia a compresión con el coeficiente de difusión ( $\mathrm{Dap}_{\text {a }}$ de cloruro soluble en agua de los hormigones originales y reciclados (Figura 6.24), se puede observar también que, para ambos tipos de hormigones, a medida que se incrementa el nivel resistente se produce un mejor comportamiento durable de los mismos.

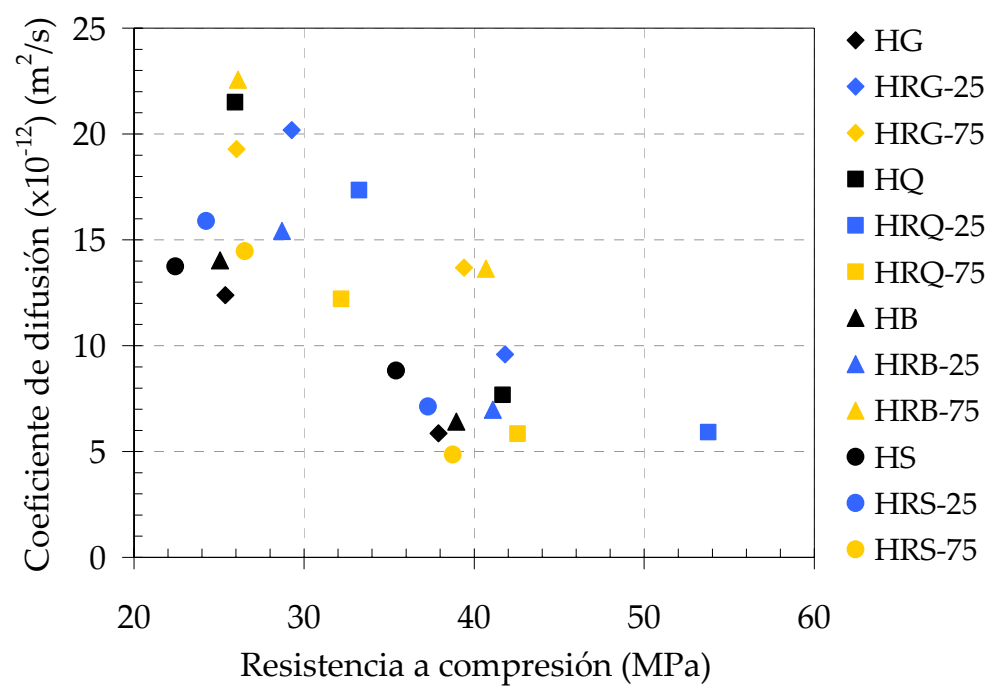

Figura 6.24. Relación entre la resistencia a compresión y el coeficiente de difusión de cloruro soluble en agua.

Al observar la variación del coeficiente de difusión con el aumento de resistencia, surge que los hormigones HG, HB, HRG-25 y HRB-25 presentan un comportamiento similar, produciéndose un descenso del orden del $54 \%$, mientras que en los HRG-75 y HRB-75 la disminución producida es del 29 y 40 \% respectivamente. Los hormigones HQ presentan un comportamiento semejante al mencionado anteriormente, produciéndose descensos del Dap del orden del $65 \%$ en los hormigones HQ y HRQ-25 y del 52 \% en los HRQ-75. En los hormigones con canto rodado (S) la disminución del Dap resulta más importante cuanto mayor es el porcentaje de AGR utilizado, siendo del $36 \%$ para los hormigones HS, del $55 \%$ para los HRS-25 y del $66 \%$ para los HRS-75. 
En el caso de relacionar la resistencia a compresión con la penetración media de agua a presión, en la Figura 6.25 puede observarse que, al igual que en los casos planteados anteriormente, también se verifica que el incremento en la resistencia produce una mejora en el desempeño durable de los hormigones, independientemente del contenido de AGR empleado.

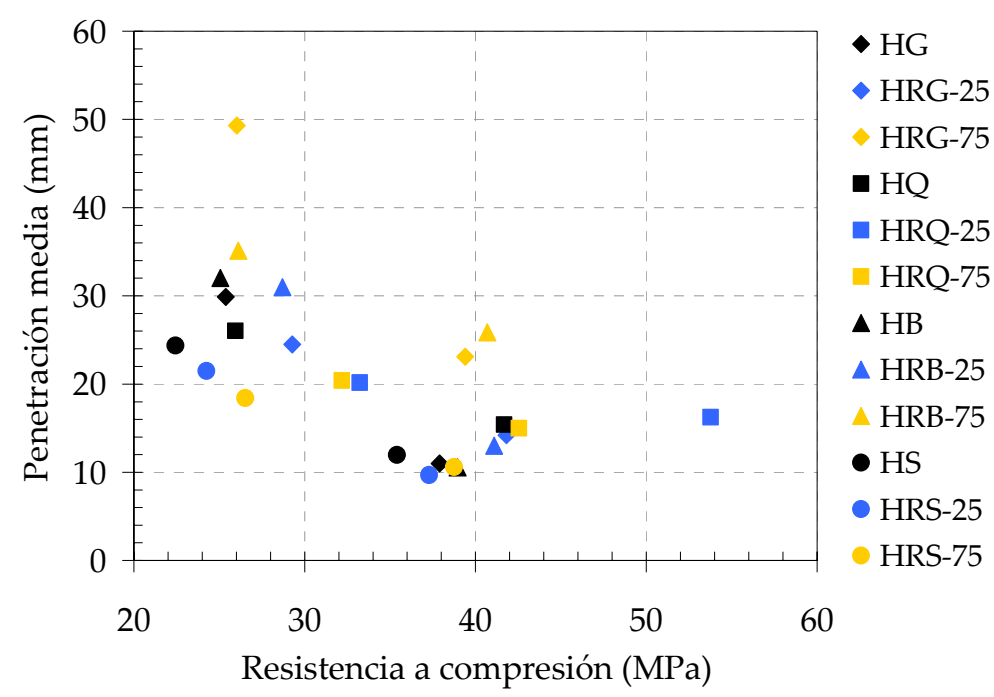

Figura 6.25. Relación entre la resistencia a compresión y la penetración media de agua a presión.

Realizando un análisis análogo al efectuado para la velocidad de succión capilar y el coeficiente de difusión de cloruro, en el caso de la penetración de agua a presión se observa que los hormigones HRG y HRB presentan, respecto a los HG y HB, un comportamiento similar al descripto para el coeficiente de difusión. Para los hormigones HS y HRS, las diferencias entre las penetraciones de agua con el aumento de resistencia resultan similares, con valores cercanos al $50 \%$.

Respecto a la influencia del nivel de resistencia con relación a las variables de durabilidad presentadas en este punto, se percibe que los hormigones con agregados reciclados de granito y basalto (HRG y HRB) fueron los que presentaron las mayores variaciones, principalmente para el coeficiente de difusión de cloruro y la penetración de agua.

En este sentido, los hormigones HRQ presentaron pocas variaciones en las mencionadas propiedades en relación al empleo del agregado natural. Entre los cuatro agregados naturales estudiados, en los hormigones HS y HRS se obtuvieron las menores diferencias con respecto a la sustitución del AGN por el AGR, principalmente para la velocidad de succión y la penetración de agua a presión. 


\subsection{Conclusiones sobre la durabilidad de los hormigones reciclados}

Del análisis de resultados presentados en este capítulo sobre diferentes propiedades de transporte de hormigones reciclados de dos niveles resistentes, elaborados con $25 \mathrm{y}$ $75 \%$ de AGR obtenidos de la trituración de hormigones conteniendo cuatro tipos de AGN, surge que:

- La razón a/c de la matriz constituye la variable de primer orden que modifica el comportamiento durable de los hormigones reciclados, no adquiriendo preponderancia el tipo de AGN y el porcentaje de AGR utilizado.

- Las velocidades de succión capilar $\left(\mathrm{V}_{\mathrm{sc}}\right)$ de los hormigones reciclados de razón a/c 0,45 cumplen con el requisito de durabilidad establecido en el Proyecto de Reglamento CIRSOC 201:2005 ( $\left.\mathrm{V}_{\mathrm{sc}}<4 \mathrm{~g} / \mathrm{m}^{2} / \mathrm{s}^{1 / 2}\right)$, a excepción de los que contienen los AGR de cuarcita. En tal sentido, para una misma razón a/c, el tipo de AGN empleado tiene mayor influencia que el contenido de AGR.

- Los hormigones reciclados de razón a/c 0,45, con ambos porcentajes de reemplazo, cumplen con el valor límite de penetración de agua a presión indicado en el Proyecto de Reglamento CIRSOC 201:2005 ( $\mathrm{P}_{\mathrm{med}}<30 \mathrm{~mm}$ ).

- Los hormigones reciclados presentan una mayor capacidad de retención de cloruro que los hormigones originales, hecho que es más notorio en los que contienen agregados de cuarcita y canto rodado. En el caso de los elaborados con cuarcita se debe a un mayor contenido de productos de hidratación del cemento, mientras que en los de canto rodado a un menor ingreso de cloruro debido a la mejor calidad de las interfaces AGR-mortero.

- Respecto a la influencia del nivel de resistencia sobre la durabilidad de los hormigones estudiados, debe indicarse que los elaborados con los agregados reciclados de granito y basalto presentan las mayores variaciones con relación a los hormigones con agregados naturales, mientras que cuando se empleó canto rodado silíceo como AGN, las diferencias entre los hormigones originales y reciclados fueron menores que en los restantes hormigones estudiados. 


\subsection{Experiencia de campo: exposición en suelo con sulfato}

Otro de los temas que está relacionado con la durabilidad de los hormigones, se refiere a la agresión física por precipitación de sales que puede ocurrir en ciclos alternados de humedecimiento y secado, situación que se produce cuando las estructuras se encuentran en contacto con agua o suelos que contienen sulfato. A continuación se presentan los resultados obtenidos en una experiencia de campo, realizada empleando un hormigón con AGN de granito y hormigones con 25 y $75 \%$ AGR expuestos en suelo con sulfato.

En la Figura 6.26 puede observarse la degradación superficial producida en los hormigones convencional y reciclados a través del tiempo. Si bien las fotografías muestran el aspecto que presentaban las probetas a partir de una edad de exposición avanzada (1300 días), igualmente puede observarse en cada caso el incremento del deterioro al transcurrir el tiempo de exposición. Además, para cada edad en que se realizó el relevamiento, se observa que tanto el hormigón convencional como los reciclados presentan un nivel de deterioro semejante, hecho que se vio reflejado en los resultados obtenidos de los parámetros evaluados, los cuales son presentados posteriormente.

De la observación visual realizada a cada edad de evaluación, se puede indicar que el deterioro más importante se produce sobre la mitad de la probeta que se encuentra al aire, debido a que dicha zona resulta mayormente afectada por los ciclos de humedecimiento y secado. El deterioro comienza con un descascaramiento del mortero de recubrimiento de las caras que se encuentran semi-enterradas, en mayor medida en la cara de moldeo, produciéndose generalmente una fisuración en dirección longitudinal a la probeta en las zonas próximas a los vértices de las caras, la cual termina por ocasionar el desprendimiento de dicho vértice. Este mayor ataque se debe a que los mismos presentan una mayor superficie de exposición, donde los sulfatos penetran por ambas caras adyacentes al vértice.

A medida que avanza el descascaramiento, los agregados gruesos quedan expuestos al ataque directo de los sulfatos, los cuales, en el caso del AGN, comienzan a desprenderse al deteriorarse el mortero que los rodea, mientras que en el caso de los AGR, dadas las características que presentan, para que se produzca el desprendimiento de las partículas del agregado natural tiene que deteriorarse también el mortero que forma parte de los mismos. Este hecho podría explicar el mejor comportamiento que presentan los hormigones reciclados respecto al hormigón elaborado en su totalidad con agregados naturales. 
1300 días

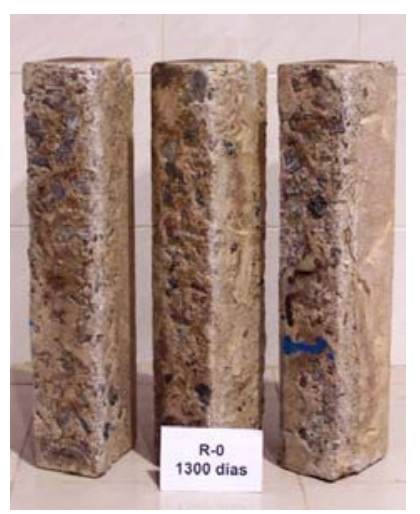

R-0

R-25
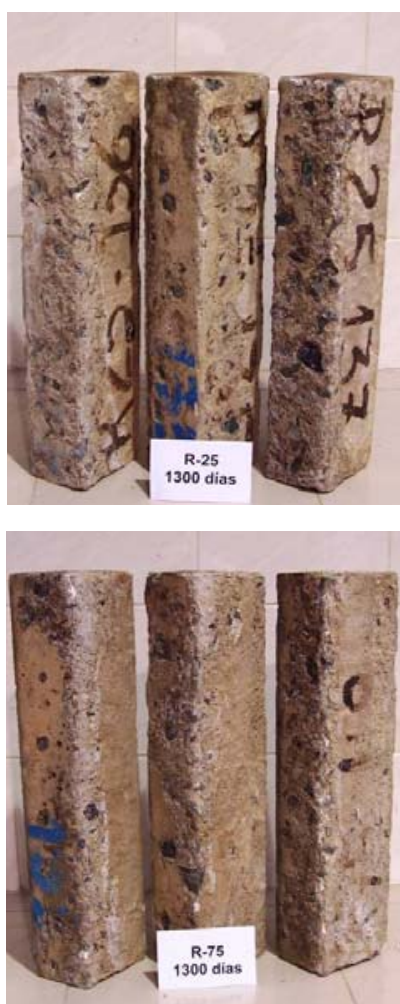

1480 días
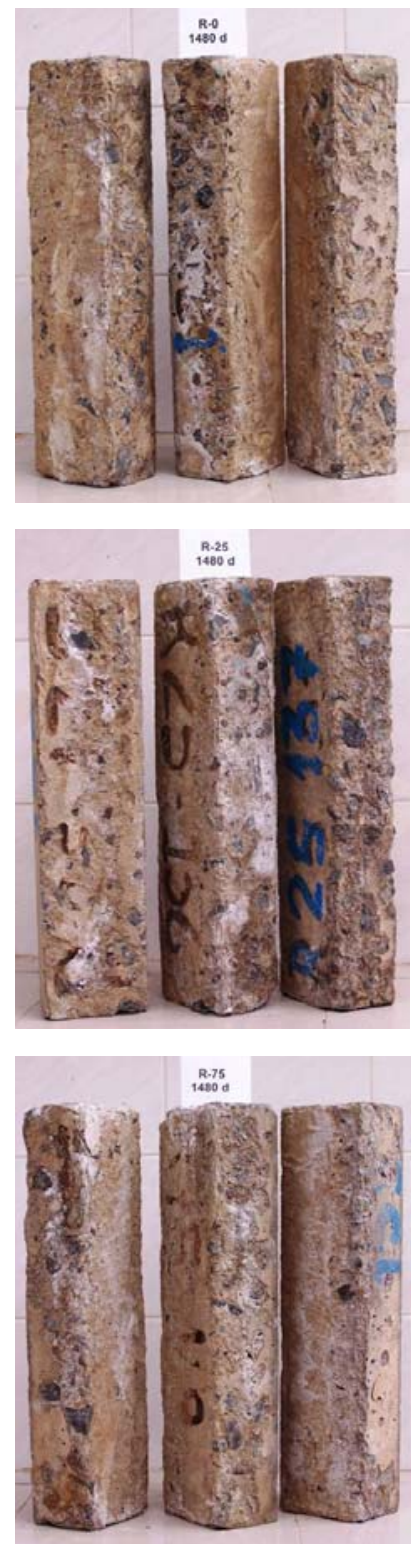

2400 días
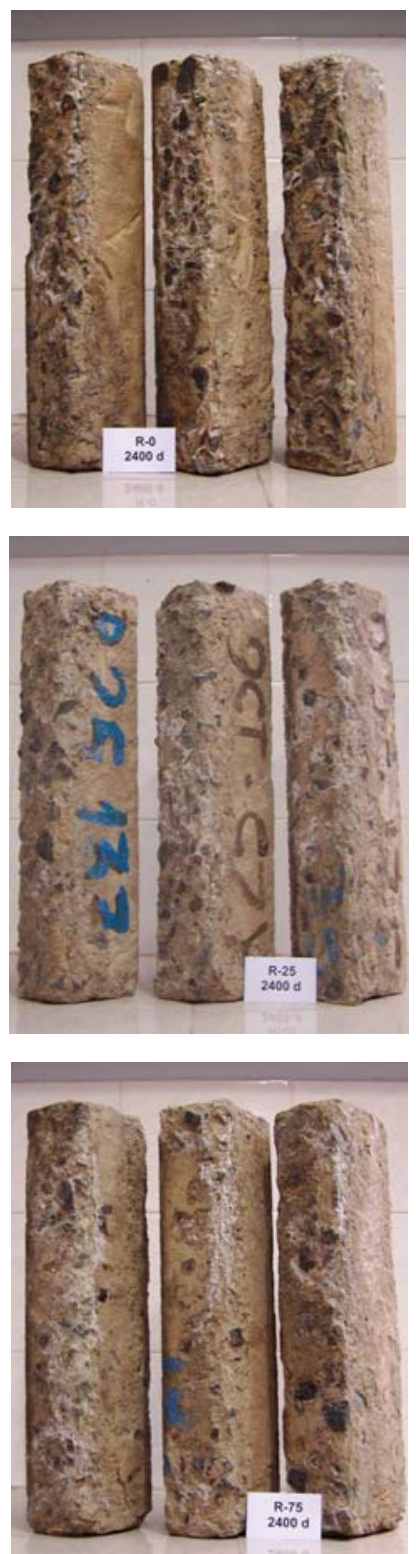

\section{R-75}

Figura 6.26. Aspecto visual de las probetas expuestas en suelo con sulfato.

En la Figura 6.27 se presenta la variación relativa del módulo de elasticidad dinámico en el tiempo para los hormigones convencional y reciclados, donde cada punto corresponde al promedio de tres determinaciones. Se observa que el módulo de elasticidad se mantienen constante en todos los hormigones hasta aproximadamente los 1000 días de exposición. A partir de dicha edad se produce un descenso paulatino del módulo, debido a la degradación que sufren las probetas, el cual resulta de menor importancia cuanto mayor es el porcentaje de AGR empleado. Para la última edad de evaluación (2400 días), los módulos de elasticidad adquieren valores relativos del 66, 69 y 73 \% para los hormigones R-0, R-25 y R-75, respectivamente. Este descenso es atribuido a la acción física del sulfato que precipita en los poros del hormigón generando tensiones de tracción, lo cual 
provoca una fisuración de las probetas, y a un menor peso de las mismas debido a la pérdida de material producida por la fisuración mencionada. Dicha disminución del módulo de elasticidad dinámico resulta más importante para el hormigón R-0, presentando a la edad de 1500 días similar valor que el hormigón R-25, mientras que a los 2400 días todos los hormigones presentan similares valores del módulo de elasticidad dinámico.

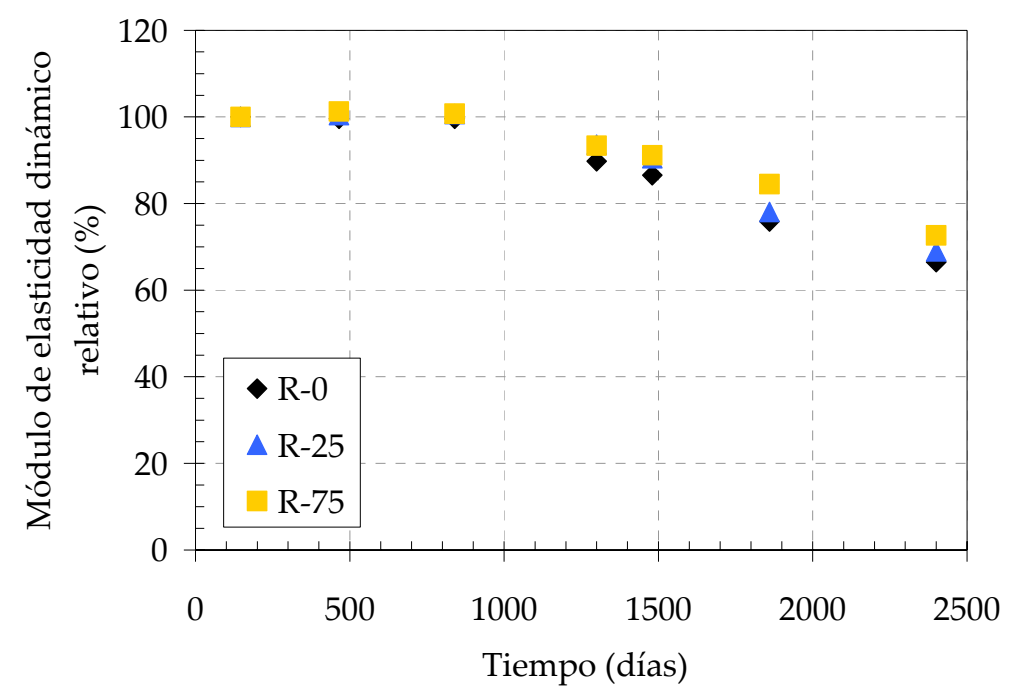

Figura 6.27. Variación relativa del módulo de elasticidad dinámico en el tiempo para hormigones expuestos en suelo con sulfato.

En la Figura 6.28 se presenta la variación relativa del peso de las probetas en el tiempo, representando cada punto el promedio de tres probetas. Se observa un descenso continuo en el peso de las probetas con el tiempo de exposición, debido a las tensiones producidas por la cristalización de las sales existentes en el interior de los poros permeables del hormigón, durante los ciclos de humedecimiento y secado. No se observan diferencias significativas entre la variación de peso de los hormigones R-0, R-25 y R-75.

La variación relativa de la velocidad del pulso ultrasónico en el tiempo de los hormigones en estudio se presenta en la Figura 6.29. Al igual que lo indicado para el módulo dinámico, en este caso se observa también que la velocidad ultrasónica se mantiene aproximadamente constante en todos los hormigones hasta los 100 días de exposición, produciéndose luego un descenso de la misma, obteniéndose en todos los hormigones a la edad de 1850 días, valores del orden del $97 \%$ de la velocidad inicial. 


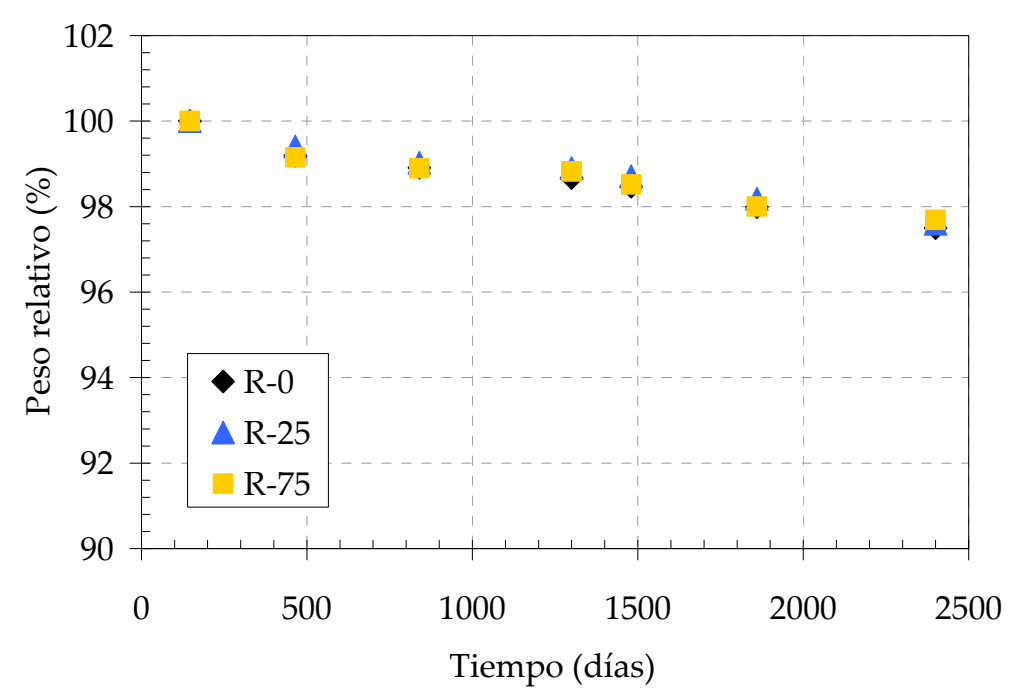

Figura 6.28. Variación relativa del peso de las probetas en el tiempo para hormigones expuestos en suelo con sulfato.

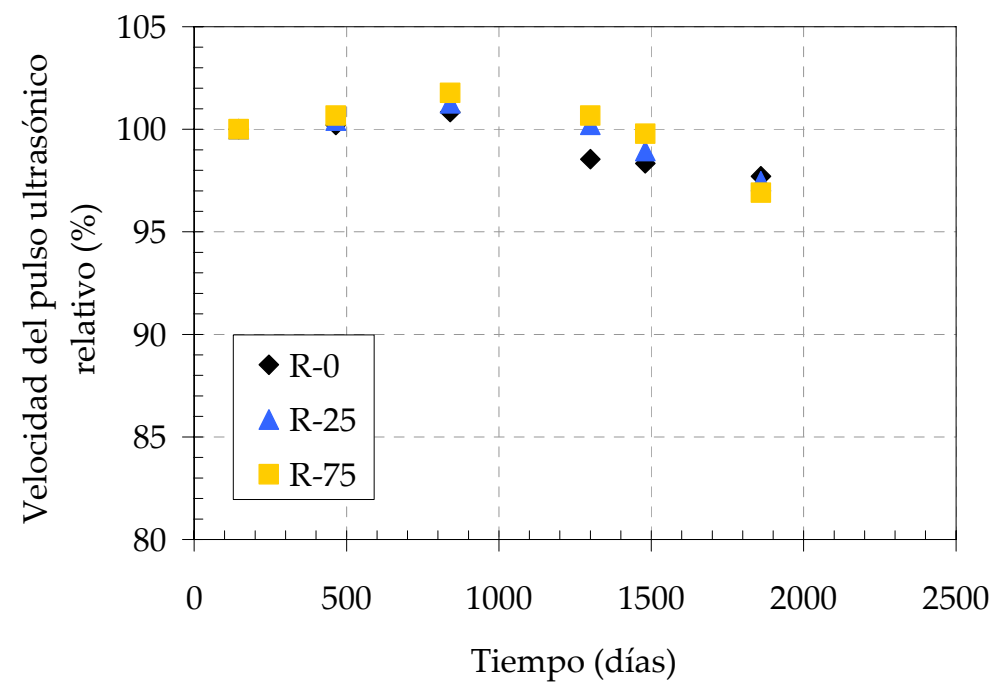

Figura 6.29. Variación relativa de la velocidad del pulso ultrasónico en el tiempo para hormigones expuestos en suelo con sulfato.

De los resultados obtenidos sobre el desempeño de los hormigones convencional y reciclados expuestos en suelo con sulfato, los cuales poseen una razón a/c 0,48 y piedra partida granítica como AGN, surge que los hormigones reciclados presentan un comportamiento semejante al del hormigón con agregados naturales, ya sea en cuanto a la variación en el tiempo de los parámetros evaluados (velocidad del pulso ultrasónico y módulo de elasticidad dinámico) como en lo que respecta al aspecto visual de los mismos. 


\section{Conclusiones}

Este trabajo de tesis contribuye al conocimiento de las propiedades de los agregados gruesos reciclados (AGR) obtenidos a partir de hormigones de desecho de diferentes características tecnológicas. Los estudios se realizaron sobre el material resultante de la trituración de hormigones de dos niveles de resistencia (a/c 0,45 y 0,65), y elaborados con cuatro tipos de agregados gruesos naturales (AGN) habitualmente utilizados en nuestro país (piedras partidas de granito, cuarcita y basalto, y canto rodado silíceo). Con los AGR se elaboraron hormigones de características similares a las de su procedencia, reemplazando los AGN por 25 y $75 \%$ de AGR. Los resultados obtenidos han permitido definir en qué medida el tipo de AGN de origen afecta las propiedades de los AGR, como así también el de los hormigones con ellos elaborados, considerando tanto el comportamiento mecánico como durable.

A continuación se enumeran las conclusiones generales y se sugieren posibles lineamientos para estudios futuros.

\section{Conclusiones generales}

\section{a) Propiedades de los agregados gruesos reciclados}

El análisis de AGR provenientes de la trituración de hormigones con niveles resistentes comprendidos en el rango 20-50 MPa, muestra que algunas de sus propiedades son similares a las de cualquier AGN (índices de lajosidad y elongación, pasa tamiz de $75 \mu \mathrm{m}$, porcentaje de vacíos), mientras que otras como la densidad, absorción de agua y pérdida por abrasión presentan diferencias considerables. Estas últimas propiedades se ven más afectadas por el tipo de AGN que contiene el hormigón de origen que por la razón a/c.

Así puede indicarse que la resistencia a la abrasión de los AGR resulta, en general, inferior a la del AGN que contienen, pudiéndose obtener pérdidas de hasta $200 \%$ superiores a las del AGN. Cuanto menor es la resistencia del AGN, la diferencia con el AGR se reduce, produciéndose en el caso de los agregados reciclados de cuarcita un $10 \%$ menos de pérdida por abrasión que en el correspondiente agregado natural. Además, para cada 
tipo de AGN empleado, se observó que hormigones de origen de inferior calidad conducen a una disminución en el contenido de mortero en los AGR.

La absorción de agua de los AGR puede llegar a ser hasta 14 veces superior a la de los AGN. Por tal motivo, esta propiedad deberá ser tenida especialmente en cuenta en la elaboración de los hormigones, debiéndose considerar el porcentaje de AGR a utilizar.

La densidad de los AGR es hasta un $12 \%$ inferior a la de los AGN que contienen, aunque la variación entre distintos AGR es menor a la que se obtiene entre diferentes tipos de AGN.

\section{b) Comportamiento mecánico de los hormigones reciclados}

En hormigones reciclados elaborados con un mismo contenido unitario de cemento y para una consistencia establecida, se obtuvieron resistencias a compresión entre 20 y $50 \mathrm{MPa}$ a pesar de emplear AGR de diferentes características. En general, las resistencias de los hormigones con $25 \%$ de AGR son entre 5 y $15 \%$ superiores a las de los hormigones originales, siendo más notorio en los elaborados con AGR de cuarcita, presentando incrementos superiores al $20 \%$. En el caso de los hormigones con $75 \%$ de AGR, las resistencias a compresión son similares a las de los hormigones originales.

En los hormigones con AGN de trituración, los elaborados con $25 \%$ de AGR presentan los mayores incrementos en el módulo de rotura, siendo superiores al $17 \%$, mientras que en los hormigones con canto rodado el mayor incremento se produce en los que contienen $75 \%$ de AGR, siendo el mismo del orden del $16 \%$. Los hormigones reciclados y originales presentan similares relaciones entre las resistencias a tracción y compresión, no observándose influencia del tipo de agregado empleado.

Un hecho a resaltar está relacionado con el módulo de elasticidad estático, ya que los hormigones reciclados pueden alcanzar disminuciones de hasta un $20 \%$ (para reemplazos del $75 \%$ ) en comparación con sus pares convencionales, debido a la menor rigidez de los AGR. En este caso también las diferencias entre hormigones con diferentes AGR es menor que la producida entre hormigones con distintos tipos de AGN. No obstante, si el módulo de elasticidad resulta de importancia para una determinada aplicación, habrá que realizar mediciones especialmente. 


\section{c) Durabilidad de los hormigones reciclados}

El comportamiento durable de los hormigones reciclados está regido por la razón a/c de la matriz, constituyéndose en el principal factor que gobierna los mecanismos de transporte en los hormigones, tanto para la succión capilar, permeabilidad al agua o difusión, independientemente del tipo de AGN y del origen y porcentaje de AGR que puedan contener. En general, los hormigones reciclados de razón a/c 0,45 satisfacen los requisitos de durabilidad indicados en el Proyecto de Reglamento CIRSOC 201:2005, relacionados con la penetración media de agua a presión $\left(\mathrm{P}_{\mathrm{med}}\right)$ y velocidad de succión capilar $\left(\mathrm{V}_{\mathrm{sc}}\right)$, presentando $P_{\text {med }}<30 \mathrm{~mm}$ y $V_{\mathrm{sc}}<4 \mathrm{~g} / \mathrm{m}^{2} / \mathrm{s}^{1 / 2}$, a excepción de la velocidad de succión de los hormigones reciclados de cuarcita. Además, puede indicarse que los hormigones reciclados de baja razón a/c presentan un buen comportamiento frente a la difusión de cloruro, a excepción de los elaborados con 75 \% de AGR de granito y basalto.

En segundo orden de importancia, el tipo de AGN del hormigón de origen tiene mayor influencia que el contenido de AGR sobre dichas propiedades de transporte, como así también sobre su capacidad de retención de cloruro, especialmente para agregados naturales de alta porosidad como es el caso de la cuarcita. Los hormigones reciclados presentan, para un mismo nivel resistente, mayor capacidad de retención de cloruro que los hormigones con agregados naturales, siendo este hecho más notorio en los elaborados con AGR de cuarcita y de canto rodado, debido, en el caso de la cuarcita a un mayor contenido de productos de hidratación del cemento, y en los de canto rodado a un menor ingreso de cloruro como consecuencia de la mejora en la calidad de las interfaces AGR-mortero.

A medida que se incrementa el nivel resistente, la mejora producida en el comportamiento durable de los hormigones reciclados de granito y basalto es menos significativa que la correspondiente a los hormigones originales. En los hormigones elaborados con canto rodado, las diferencias entre los reciclados y originales son menores que en el resto de los hormigones.

Por lo expuesto puede concluirse que hormigones de razón a/c 0,45 y con un $25 \%$ de AGR, provenientes de la trituración de hormigones convencionales elaborados con granito, cuarcita, basalto y canto rodado silíceo, pueden ser utilizados en la elaboración de una gran variedad de elementos estructurales, ya que su comportamiento resistente y durable cumple satisfactoriamente los requisitos estipulados en la reglamentación argentina vigente. El empleo de un mayor porcentaje de AGR (75\%) podrá también conducir a 
hormigones con adecuados comportamientos mecánico y durable, aunque ello dependerá de la calidad del AGR y de las exigencias de exposición de la estructura.

En tal sentido, un criterio a seguir para definir el porcentaje de uso de AGR en hormigones estructurales, es considerar la calidad del AGR y los requerimientos de la estructura a construir. Con relación al AGR, será importante cuantificar la absorción de agua y la pérdida por abrasión, mientras que respecto al hormigón reciclado se deberán tener en cuenta requisitos específicos como la resistencia a compresión, módulo de elasticidad estático y/o durabilidad. La consideración conjunta de los factores antes mencionados permitirá establecer el contenido óptimo de AGR a emplear.

\section{Estudios futuros}

A partir de los estudios realizados en este trabajo de tesis, surge que es posible emplear AGR obtenidos de hormigones de desecho para la producción de nuevos hormigones. Sin embargo, es necesario realizar nuevos estudios a fin de profundizar sobre distintos aspectos relacionados con la durabilidad de los hormigones. A continuación se indican algunos estudios a realizar:

- Evaluar el desempeño durable de hormigones reciclados de diferentes características tecnológicas cuando son expuestos a ambientes muy agresivos que puedan provocar la corrosión de las armaduras, tales como atmósferas marina natural o industrial, o con una elevada concentración de $\mathrm{CO}_{2}$. En algunos casos, en ensayos acelerados de laboratorio se ha determinado un mayor ingreso de cloruro y espesor de material carbonatado en el hormigón reciclado, aunque las diferencias respecto a los hormigones con AGN parecen disminuir al hacerlo el nivel de agresividad al que está expuesto.

- Otro ítem a estudiar vinculado con la durabilidad de los hormigones reciclados y sobre la cual existe muy poca información a nivel internacional, está relacionado con el empleo de AGR provenientes de la demolición de estructuras muy afectadas por RAS (reacción álcali-sílice). Es importante determinar si existe capacidad latente de reacción en los agregados reciclados y si la misma es suficiente como para producir la degradación de hormigones elaborados con dichos agregados reciclados. 
- Se sugiere también estudiar más detalladamente las diferencias de microestructura en hormigones con AGN y AGR, principalmente desde el punto de vista de la distribución de tamaño de poros, composición de la solución de poros, hidróxido de calcio remanente y otras variables microestructurales relacionadas con la durabilidad.

- Debido a la escasez, en muchas zonas de nuestro país, de arenas gruesas naturales de río aptas para la producción de hormigones, siendo cada vez más frecuente el empleo de las arenas naturales de trituración en dicho proceso, sumado a cuestiones medioambientales vinculadas con el uso integral de los residuos de construcción y demolición, resulta de importancia estudiar la factibilidad de uso del agregado fino reciclado (AFR), el cual queda remanente al emplear los AGR. Es de interés determinar las propiedades físico-químicas, mecánicas y durables de los AFR procedentes de la trituración de hormigones, temática sobre la cual existen pocos antecedentes y que está tomando gran importancia a nivel internacional. Se considera necesario evaluar las modificaciones que pueden producirse en las mezclas al emplear este material fino debido a su elevada absorción de agua, atendiendo también al comportamiento durable y a los cambios volumétricos que pueden presentar los hormigones como consecuencia del elevado contenido de polvo. 


\section{Referencias Bibliográficas}

ACI 213 R-87; Guide for structural lightweight aggregate concrete. American Concrete Institute, Farmington Hills, Michigan, 1987.

ACI 318M, 2002. Building Code Requirements for Structural Concrete. ACI Committee 318. American Concrete Institute, Farmington Hills, Michigan.

ACI Committee 555, 2002. Removal and reuse of hardened concrete. Materials Journal, ACI, № 99-M31, pp. 300-323.

Ajdukiewicz, A. y Kliszczewicz, A., 2002. Influence of recycled aggregates on mechanical properties of HS/HPC. Cement \& Concrete Composites, Vol. 24, № 2, pp. 269279 .

ASTM C 1150:1990. Standard Test Method for the Break-Off Number of Concrete. Annual Book of ASTM Standards, Vol. 04.02, ASTM International, West Conshonocken, PA.

ASTM C 469:2002. Standard Test Method for Static Modulus of Elasticity and Poisson's Ratio of Concrete in Compression. Annual Book of ASTM Standards, Vol. 04.02, ASTM International, West Conshonocken, PA.

ASTM C 642:1990. Standard Test Method for Specific Gravity, Absorption, and Voids in Hardened Concrete. Annual Book of ASTM Standards, Vol. 04.02, ASTM International, West Conshonocken, PA.

Balázs, G.L., Kausay, T., Simon, T.K., 2008. Technical Guideline for Recycled Aggregate Concrete in Hungary. Concrete Structures, Annual Technical Journal, Vol. 9, pp. 45-55.

Bouquety, M.N., Descantes, Y., Barcelo, L., de Larrard, F., Clavaud, B., 2007. Experimental study of crushed aggregate shape. Construction and Building Materials, Vol. 21, № 4, pp. 865-872.

Buttler, A.M., 2003. Concreto com agregados graúdos reciclados de concreto - Influência da idade de reciclagem nas propriedades dos agregados e concretos reciclados. Tesis de Magíster, Escola de Engenharia de São Carlos, Universidade de São Paulo, 199p.

Buyle-Bodin, F., Hadjieva-Zaharieva, R., 2002. Influence of industrially produced recycled aggregates on flow properties of concrete. Materials and Structures, Vol. 35, № 252, pp. 504-509.

Casuccio, M., Torrijos, M.C., Giaccio, G., Zerbino, R., 2008. Failure mechanism of recycled aggregate concrete. Construction and Building Materials, Vol. 22, № 7, pp. 1500 1506.

CIRSOC 201:1982. Proyecto, Cálculo y Ejecución de Estructuras de Hormigón Armado y Pretensado. Tomo I. Instituto Nacional de Tecnología Industrial. 
CIRSOC 201:2005. Proyecto de Reglamento Argentino de Estructuras de Hormigón. Instituto Nacional de Tecnología Industrial. (En trámite de aprobación)

Cúneo Simian, H.A., Durán, M.G., 1995. Propiedades mecánicas y físicas de hormigones con agregados reciclados. Memorias XII Reunión Técnica de la Asociación Argentina de Tecnología del Hormigón, AATH, La Plata, Argentina, pp. 291-304.

Czarnecka, E.T., Gillott, J.E., 1982. Effect of different types of crushers on shape and roughness of aggregates. Cement, Concrete and Aggregates, ASTM, Vol. 4, № 1, pp. 33-38.

De Schutter, G., Audenaert, K., 2004. Evaluation of water absorption of concrete as a measure for resistance against carbonation and chloride migration. Materials and Structures, Vol. 37, № 11, pp. 591-596.

Dhir, R.K., Jones, M.R., $\quad$ Ahmed, H.E.H., $\quad$ Seneviratne, A.M.G., $\quad$ 1990. Rapid estimation of chloride diffusion coefficient in concrete. Magazine of Concrete Research, Vol. 42, № 152, pp. 177-185.

Di Maio, A., Giaccio, G., Zerbino, R., 2002. Hormigones con agregados reciclados. Ciencia y Tecnología del Hormigón, LEMIT, № 9, pp. 5-10.

Di Maio, A.A., Gutiérrez, F., Traversa, L.P., 2001. Comportamiento físico mecánico de hormigones elaborados con agregados reciclados. Memorias $14^{\circ}$ Reunión Técnica de la Asociación Argentina de Tecnología del Hormigón, AATH, Olavarría, Argentina, pp. 3744 .

Di Maio, A.A., Traversa, L., Giovambattista, A., 1985. Non destructive combined methods applied to structural concrete members. Cement, Concrete and Aggregates, ASTM, Vol. 2, № 7, pp. 89-94.

Di Maio, A.A., Traversa, L.P., 2003. Evaluation of recycled concrete by means of non destructive tests. Revista Materiales de Construcción, IETCC, №s 271-272, Vol. 53, pp. 37-46.

Di Maio, A.A., Zega, C.J., Traversa, L.P., 2005. Estimation of Compressive Strength of Recycled Concretes with the Ultrasonic Method. Journal of ASTM International (JAI), ASTM, Vol. 2, № 5. (Disponible en www.astm.org)

EHE, 2008. Instrucción de Hormigón Estructural. Comisión Permanente del Hormigón, Ministerio de Fomento, España. Anejo 15, Recomendaciones para la utilización de hormigones reciclados. (Disponible en www.fomento.es)

Evangelista, L., de Brito, J., 2007. Mechanical behaviour of concrete made with fine recycled concrete aggregates. Cement \& Concrete Composites, Vol. 29, № 5, pp. 397-401.

Frederiksen, J.M., Sørensen, H.E., Andersen, A., Klinghoffer, O., 1997. HETEK, The effect of the $\mathrm{w} / \mathrm{c}$ ratio on chloride transport into concrete - Immersion, migration and resistivity tests. The Road Directorate, Copenhagen, Dinamarca, 35p.

Giaccio, G., Zerbino, R., 1997. Concrete as a composite material: Effect of the coarse aggregates and matrix strength level. L'Industria del cemento, Italia, № 6, pp. 486-493.

Giaccio, G., Zerbino, R., 1998. Failure mechanism of concrete: combined effects of coarse aggregates and strength level. Advanced Cement based Materials, USA, Vol. 7, № 1, pp. 41-48. 
Gokce, A., Nagataki, S., Saeki, T., Hisada, M., 2004. Freezing and thawing resistance of air-entrained concrete incorporating recycled coarse aggregate: The role of air content in demolish concrete. Cement and Concrete Research, Vol. 34, № 5, pp. 799-806.

Gómez, J.M., Agulló, L., Vázquez, E., 2001. Cualidades físicas y mecánicas de los agregados reciclados de concreto. Construcción y Tecnología, Vol. XIII, № 157, pp. 10-20.

Gómez-Soberón, J.M.V., 2002. Porosity of recycled concrete with substitution of recycled concrete aggregate: An experimental study. Cement and Concrete Research, Vol. 32, № 8, pp. 1301-1311.

Gonçalves, A., Esteves, A., Vieira, M., 2004. Influence of recycled concrete aggregates on concrete durability. International RILEM Conference "The use of recycled materials in building and structures", Barcelona, España. Ed. E. Vázquez, Ch.F. Hendriks y G.M.T. Janssen, RILEM, pp. 554-562.

Grübl, P., Rühl, M., 1998. German Committee for Reinforced Concrete (DafStb) Code: Concrete with Recycled Aggregates. Proc. Int. Symposium Sustainable Construction: Use of Recycled Concrete Aggregates. University of Dundee, London. (Disponible en www.b-i-m.de)

Hansen, T.C., 1986. Recycled aggregates and recycled aggregate concrete. Second State-of-the-art. Report developments 1945-1985. RILEM Technical Committee-37-DRC, Demolition and Recycling of Concrete. Materials and Structures, Vol. 19, № 111, pp. 201246.

Hansen, T.C., Narud, H., 1983. Strength of recycled concrete made from crushed concrete coarse aggregate. Concrete International, Vol. 5, № 1, pp. 79-83.

Hernández, C., Fornasier, G., 2005. Caracterización de hormigones elaborados con agregado grueso reciclado. Memorias Simposio Internacional fib "El Hormigón Estructural y el Transcurso del Tiempo", La Plata, Argentina. Ed. A. Di Maio y C. Zega, Vol. 2, pp. 833-840.

IRAM 1857:2000. Hormigón de cemento Pórtland. Determinación del contenido de ion cloruro en el hormigón. Instituto Argentino de Normalización y Certificación, Argentina.

IRAM 1871:2004. Hormigón. Método de ensayo para determinar la capacidad y la velocidad de succión capilar de agua del hormigón endurecido. Instituto Argentino de Normalización y Certificación, Argentina.

IRAM 1501-2:2002. Tamices de ensayo. Tela de tejido metálico, chapa metálica perforada y lámina electroformada. Tamaños nominales de abertura. Instituto Argentino de Normalización y Certificación, Argentina.

IRAM 1505:2005. Agregados. Análisis granulométrico. Instituto Argentino de Normalización y Certificación, Argentina.

IRAM 1519:1982. Rocas basálticas. Método de determinación de la estabilidad. Ensayo de inmersión en etanodiol (etilen glicol). Instituto Argentino de Normalización y Certificación, Argentina.

IRAM 1525:1985. Agregados. Método de ensayo de durabilidad por ataque con sulfato de sodio. Instituto Argentino de Normalización y Certificación, Argentina. 
IRAM 1532:2000. Agregados gruesos. Método de ensayo de resistencia al desgaste con la máquina "Los Ángeles". Instituto Argentino de Normalización y Certificación, Argentina.

IRAM 1531:2006. Agregado grueso para hormigón de cemento. Instituto Argentino de Normalización y Certificación, Argentina.

IRAM 1533:2002. Agregados Gruesos. Métodos de laboratorio para la determinación de la densidad relativa real, de la densidad relativa aparente y de la absorción de agua. Instituto Argentino de Normalización y Certificación, Argentina.

IRAM 1534:2004. Hormigón. Preparación y curado de probetas en laboratorio para ensayos de compresión y de tracción por compresión diametral. Instituto Argentino de Normalización y Certificación, Argentina.

IRAM 1536:1978. Hormigón fresco de cemento Pórtland. Método de ensayo de la consistencia utilizando el tronco de cono. Instituto Argentino de Normalización y Certificación, Argentina.

IRAM 1540:2004. Agregados. Método de ensayo del material fino que pasa por el tamiz IRAM $75 \mu \mathrm{m}$, por lavado. Instituto Argentino de Normalización y Certificación, Argentina.

IRAM 1546:1992. Hormigón de cemento Pórtland. Método de ensayo de compresión. Instituto Argentino de Normalización y Certificación, Argentina.

IRAM 1548:2003. Agregados. Determinación de la densidad a granel y de los espacios vacíos. Instituto Argentino de Normalización y Certificación, Argentina.

IRAM 1554:1983. Hormigón de cemento Pórtland. Método de determinación de la penetración de agua a presión en el hormigón endurecido. Instituto Argentino de Normalización y Certificación, Argentina.

IRAM 1562:1978. Hormigón fresco de cemento Pórtland. Método de determinación de la densidad, el rendimiento y el contenido de aire. Instituto Argentino de Normalización y Certificación, Argentina.

IRAM 1602-1:1988. Hormigón de cemento Pórtland. Método por presión para la determinación del contenido de aire en mezclas frescas de hormigones y morteros. Parte 1: Método A. Instituto Argentino de Normalización y Certificación, Argentina.

IRAM 1627:1997. Agregados. Granulometría de los agregados para hormigones. Instituto Argentino de Normalización y Certificación, Argentina.

IRAM 1658:1995. Hormigón. Determinación de la resistencia a la tracción simple por compresión diametral. Instituto Argentino de Normalización y Certificación, Argentina.

IRAM 1683:1990. Hormigón de cemento Pórtland. Método para la determinación de la velocidad de pulsos ultrasónicos. Instituto Argentino de Normalización y Certificación, Argentina.

IRAM 1687-1:1996. Agregados. Método de determinación del índice de lajosidad. Instituto Argentino de Normalización y Certificación, Argentina. 
IRAM 1687-2:1997. Agregados. Determinación del índice de elongación. Instituto Argentino de Normalización y Certificación, Argentina.

IRAM 1693:1969. Hormigones. Método de determinación de las frecuencias fundamentales de vibración de probetas de hormigón. Instituto Argentino de Normalización y Certificación, Argentina.

Janssen, G.M.T., Put, J.A.L., 2005. Overview regarding construction and demolition waste in The Netherlands. Use of Recycled Materials, RILEM TC 198-URM, Final Report, pp. 15-17.

Kasai, Y., 1994. Guidelines and the Present State of the Reuse of Demolished Concrete in Japan. Demolition and Reuse of Concrete and Masonry, Proceedings of the Third International RILEM Symposium. Ed. Lauritzen, E.K., E\&FN Spon, 2-6 Boundary Row, London SE1 8HN, pp. 93-104.

Kasai, Y., 2004. Recent trends in recycling of concrete waste and use of recycled aggregate concrete in Japan. En SP-219: "Recycling Concrete and Other Materials for Sustainable development". ACI International, Ed. Tony C. Liu and Christian Meyer. pp. 1134.

Katz, A., 2003. Properties of Concrete made with Recycled Aggregate from Partially Hydrated Old Concrete. Cement and Concrete Research, Vol. 33, № 5, pp. 703-711.

Katz, A., Baum, H., Nissim, I., 2005. Overview regarding construction and demolition waste in Israel. Use of Recycled Materials, RILEM TC 198-URM, Final Report, pp. 1314.

Khatib, J.M., 2005. Properties of concrete incorporating fine recycled aggregate. Cement and Concrete Research, Vol. 35, № 4, pp. 763-769.

Lauritzen, E.K., 2004. Recycling concrete - An overview of challenges and opportunities. En SP-219: "Recycling Concrete and Other Materials for Sustainable development". ACI International, Ed. Tony C. Liu and Christian Meyer. pp. 1-10.

Leite, M.B., Pedrozo, P.H. y Dal Molin, D.C.C., 2000. Agregado reciclado para concreto: proposta de desenvolvimento de um método para determinação da taxa de absorção do material. IBRACON 2000, 42ํㅡㄹ Congreso Brasilero del Hormigón, Fortaleza, Brasil.

Levy, S.M., Helene, P., 2004. Durability of recycled aggregates concrete: a safe way to sustainable development. Cement and Concrete Research, Vol. 34, № 11, pp. 1975-1980.

Limbachiya, M.C., Leelawat, T., Dhir, R.K., 2000. Use of Recycled Concrete Aggregate in High-Strength Concrete. Materials and Structures, Vol. 33, № 233, pp. 574-580.

Machado, E.F., Latterza, L.M., 1997. Concreto com agregado graúdo proveniente da reciclagem de residuos de construçâo e demoliçâo. Um novo material para fabricaçâo de painéis leves de vedaçâo. Primer Seminario de Tecnología del Hormigón en la Vivienda del Mercosur, Santa Fé, Argentina, pp. 207-218.

Malhotra, V.M., 2002. Introduction: Sustainable development and concrete technology. Concrete International, ACI, Vol. 24, № 7, p. 22.

Mehta, P.K., 2002. Greening of the concrete industry for sustainable development. Concrete International, ACI, Vol. 24, № 7, pp. 23-28. 
Mehta, P.K., Monteiro, P.J.M., 1998. Concreto. Estructura, propiedades y materiales. Instituto Mexicano del Cemento y del Concreto, A.C. México.

Mindess, S., Young, J.F., 1981. Concrete. Ed. N.M. Newmark y W,J, Hall. PrenticeHall, Inc. Englewood Cliffs, New Jersey 07632.

Müller, A., 2005. Overview regarding construction and demolition waste in Germany. Use of Recycled Materials, RILEM TC 198-URM, Final Report, pp. 3-5.

Neville, A.M., 1977. Tecnología del Concreto. Tomo I. Instituto Mexicano del Cemento y del Concreto, A.C. México.

Nilsson, L.O., Poulsen, E., Sandberg, P., Sorensen, H.E., Klinghoffer, O., 1996. HETEK, Chloride penetration into concrete, State-of-the-art, Transport processes, corrosion initiation, test methods and prediction models. Report № 53. Road Directorate. ISBN 8774917366 .

Nixon, P.J., 1978. Recycled concrete as an aggregate for concrete - a review. Matériaux et Constructions, Vol. 11, № 65, pp. 371-378.

Olorunsogo, F.T., Padayachee, N., 2002. Performance of recycled aggregate concrete monitored by durability indexes. Cement and Concrete Research, Vol. 32, № 2, pp. 179-185.

Otsuki, N., Miyazato, S., Yodsudjai, W., 2003. Influence of recycled aggregate on interfacial transition zone, strength, chloride penetration and carbonation of concrete. Journal of Materials in Civil Engineering, ASCE, Vol. 15, № 5, pp. 443-451.

Padmini, A.K., Ramamurthy, K., Mathews, M.S., 2009. Influence of parent concrete on the properties of recycled aggregate concrete. Construction and Building Materials, Vol. 23, № 2, pp. 829-836.

Poole, A., Sims, I., 2003. Geology, aggregates and classification. In: “Advanced Concrete Technology-Constituent Materials", Ed. John Newman y Ban Seng-Choo, Elsevier Ltd.

Poon, C.S., 2005. Overview regarding construction and demolition waste in Hong Kong. Use of Recycled Materials, RILEM TC 198-URM, Final Report, pp. 7-11.

Poon, C.S., Shui, Z.H., Lam, L., Fok, H., Kou, S.C., 2004a). Influence of moisture states of natural and recycled aggregates on the slump and compressive strength of concrete. Cement and Concrete Research, Vol. 34, № 1, pp. 31-36.

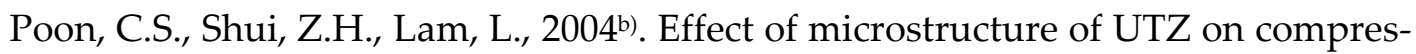
sive strength of concrete prepared with recycled aggregates. Construction and Building Materials, Vol. 18, № 6, pp. 461-468.

Rasheeduzzafar, Asfahanullah Khan, 1984. Recycled concrete - A source for new aggregate. Cement, Concrete and Aggregate, ASTM, Vol. 6, № 1, pp. 17-27.

RILEM Recommendation 121-DRG, 1994. Guidance for demolition and reuse of concrete and masonry. Specifications for concrete with recycled aggregates. Materials and Structures, Vol. 27, pp. 557-559. 
Sagoe-Crentsil, K., Brown, T., 1998. Guide for Specification of Recycled Concrete Aggregates (RCA) for Concrete Production - Final Report. CSIRO, Building, Construction and Engineering, PO Box 56, Highett Road, Victoria. 3190.

Sánchez de Juan, M., Alaejos Gutiérrez, P., 2003. Utilización de árido reciclado para la fabricación de hormigón estructural. II Congreso de ACHE de Puentes y Estructuras.

Sánchez de Juan, M., Alaejos Gutiérrez, P., 2009. Study on the influence of attached mortar content on the properties of recycled concrete aggregate. Construction and Building Materials, Vol. 23, № 2, pp. 872-877.

Skoog. D.A., West, D.M., Holler, F.J., Crouch, S.R., 2005. Fundamentos de Química Analítica. 8va. Edición, Thompson Learning, Inc., México D.F., México, 1065 p.

Sri Ravindrarajah, R., Loo, Y.H., Tam, C.T., 1987. Recycled concrete as fine and coarse aggregates in concrete. Magazine of Concrete Research, Vol. 39, № 141, pp. 214220.

Sri Ravindrarajah, R., Loo, Y.H., Tam, C.T., 1988. Strength evaluation of recycledaggregate concrete by in-situ tests. Materials and Structures, Vol. 21, № 124, pp. 289-295.

Sri Ravindrarajah, R., Tam, C.T., 1985. Properties of concrete made with crushed concrete as coarse aggregate. Magazine of Concrete Research, Vol. 37, № 130, pp. 29-38.

Tabsh, S.W., Abdelfatah, A.S., 2009. Influence of recycled concrete aggregates on strength properties of concrete. Construction and Building Materials, Vol. 23, № 2, pp. 1163-1167.

Tam, V.W.Y., Gao, X.F., Tam, C.M., Chan, C.H., 2008. New approach in measuring water absorption of recycled aggregates. Construction and Building Materials, Vol. 22, № 3, pp. 364-369.

Tanaka, K., Yada, K., Maruyama, I., Sato, R., Kawai, K., 2004. Study on corrosion of reinforcing bar in recycled concrete. International RILEM Conference on the Use of Recycled Materials in Buildings and Structures, Barcelona, España. Ed. E. Vázquez, Ch.F. Hendriks y G.M.T. Janssen, RILEM, pp. 643-650.

Taus, V.L., Di Maio, A.A., Traversa, L.P., 2005. Sorptivity: Parameter for the evaluation of cover concrete quality. Proc. Fourth International Conference "Quality of Concrete Structures and Recent Advances in Concrete Materials and Testing", Olinda, PE, Brasil. Ed. P. Helene, E. Pazini Figueiredo, T. Holland y R. Bittencourt. SP-229, ACI, pp. 121-133.

Tavakoli, M., Soroushian, P., 1996. Strengths of recycled aggregate concrete made using field-demolished concrete as aggregate. Materials Journal, ACI, pp. 182-190.

Topçu, I.B., Sengel, S., 2004. Properties of concretes produced with waste concrete aggregate. Cement and Concrete Research, Vol. 34, № 8, pp. 1307-1312.

Vázquez, E., 2005. Overview regarding construction and demolition waste in Spain. Use of Recycled Materials, RILEM TC 198-URM, Final Report, pp. 25-26.

Vázquez, E., Barra, M., 2002. Reciclaje y reutilización del hormigón. Monografía CIMNE: Desarrollo sostenible del cemento y del hormigón, № 67, pp. 43-65. 
Villagrán Z., Y.A., Taus, V.L., Zega, C.J., Di Maio, A.A., Traversa, L.P., 2005. Propiedades de transporte en hormigones convencionales y reciclados y su influencia en la corrosión de armaduras. Memorias Simposio Internacional fib "El Hormigón Estructural y el Transcurso del Tiempo", La Plata, Argentina. Ed. A. Di Maio y C. Zega, Vol. 1, pp. 9198.

Villagrán Z., Y.A., Zega, C.J., Di Maio, A.A., 2008. Chloride Penetration and Binding in Recycled Concrete. Journal of Materials in Civil Engineering, ASCE, Vol. 20, № 6, pp. 449-455.

Vyncke, J., Rousseau, E., 1994. Recycling of Construction and demolition Waste in Belgium : Actual Situation and Future Evolution. Demolition and Reuse of Concrete and Masonry, Proceedings of the Third International RILEM Symposium. Ed. Lauritzen, E.K., E\&FN Spon, 2-6 Boundary Row, London SE1 8HN, pp. 57-69.

Zaharieva, R., Buyle-Bodin, F., Skoczylas, F., Wirquin, E., 2003. Assesment of the surface permeation properties of recycled aggregate concrete. Cement \& Concrete Composites, Vol. 25, № 2, pp. 223-232.

Zaharieva, R., Buyle-Bodin, F., Wirquin, E., 2004. Frost resistance of recycled aggregate concrete. Cement and Concrete Research, Vol. 34, № 10, pp. 1927-1932.

Zega, C.J., Taus, V.L., Villagrán Z., Y.A., Di Maio, A.A., 2005a). Comportamiento físico-mecánico de hormigones sometidos a reciclados sucesivos. Memorias Simposio Internacional fib "El Hormigón Estructural y el Transcurso del Tiempo", La Plata, Argentina. Ed. A. Di Maio y C. Zega, Vol. 2, pp. 761-768.

Zega, C., Fornasier, G., Ponce, M., Di Maio, A.A., 2005ㅎ․ Hormigones reciclados expuestos a ciclos rápidos de congelación y deshielo. Hormigón № 41, AATH, pp. 53-61.

Zega, C.J., 2008. Hormigones reciclados: caracterización de los agregados gruesos reciclados. Tesis de Magíster, Facultad de Ingeniería, Universidad Nacional del Centro de la Provincia de Buenos Aires, 135p.

Zega, C.J., Di Maio, A.A., 2007. Efecto del Agregado Grueso Reciclado sobre las Propiedades del Hormigón. Boletín Técnico (IMME), Universidad Central de Venezuela, Vol. 45, № 2, pp. 1-11. (Disponible en www.revele.com.ve)

Zega, C.J., Taus, V.L., Di Maio, A.A., 2006. Comportamiento físico-mecánico de hormigones reciclados elaborados con canto rodado. Boletín Técnico (IMME), Universidad Central de Venezuela, Vol. 44, № 3, pp. 17-26. (Disponible en www.revele.com.ve)

Ziegeldorf, S., 1983. Phenomenological aspects of the fracture of concrete, en Fracture mechanics of concrete, Ed. F. Wittmann, Elsevier, Amsterdam, pp. 31-41. 